\title{
Baseline Surveys of Rocky Intertidal Ecological Resources at Point Loma, San Diego
}

By John M. Engle ${ }^{1}$ and Gary E. Davis ${ }^{2}$

\section{U.S. GEOLOGICAL SURVEY}

Open-File Report 00-61

Prepared for:

U.S. Navy

Naval Facilities Engineering Command

Department of Defense Legacy Program

Letter of Agreement \#N68711-94-LT-4032

${ }^{1} 7554$ Palos Verdes Drive

Goleta, California 93117

${ }^{2}$ National Biological Service

Channel Islands National Park

1901 Spinnaker Drive

Ventura, California 93001 


\title{
U.S. DEPARTMENT OF THE INTERIOR \\ BRUCE BABBITT, Secretary
}

\author{
U.S. GEOLOGICAL SURVEY
}

Charles G. Groat, Director

The use of firm, trade, and brand names in this report is for identification purposes only and does not constitute endorsement by the U.S. Geological Survey

For additional information write to:

Center Director

Western Ecological Research Center

U.S. Geological Survey

Placer Hall, Suite 2012

$6000 \mathrm{~J}$ Street

Sacramento, CA 95819-6129
Copies of this report can be purchased from:

U.S. Geological Survey

Information Services

Box 25286

Federal Center

Denver, CO 80225 


\section{Table of Contents}

List of Tables.

List of Figures

ABSTRACT.

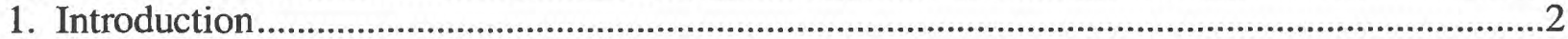

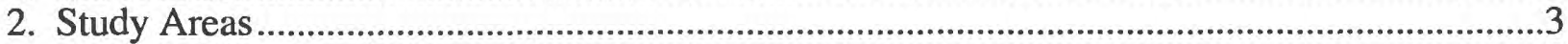

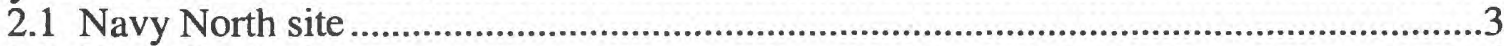

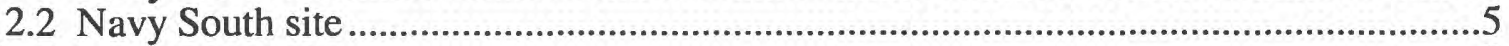

3. Methods

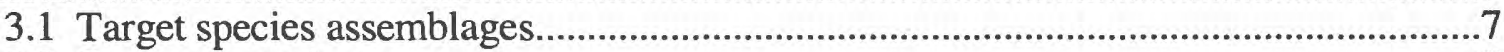

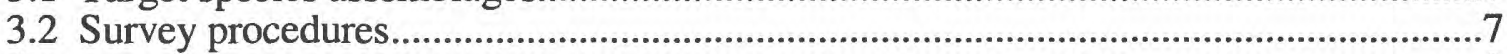

4. Results.

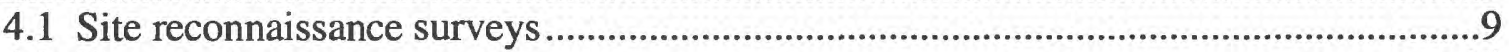

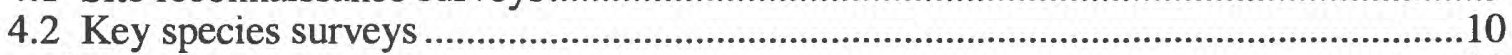

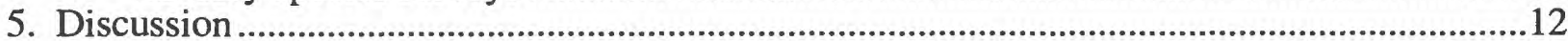

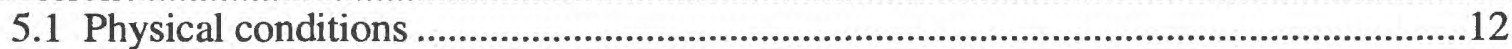

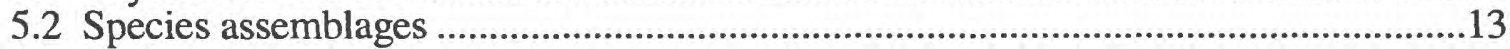

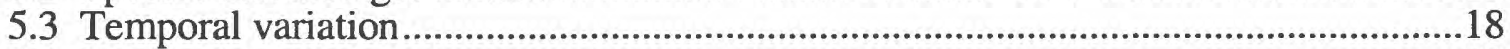

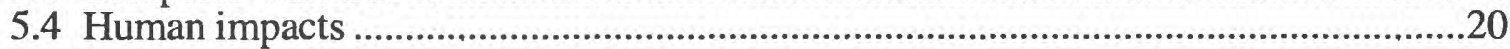

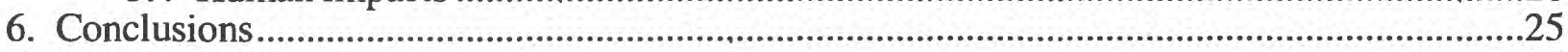

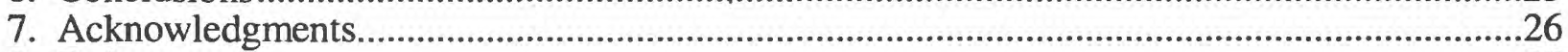

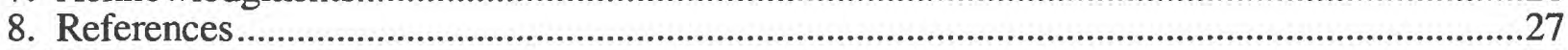

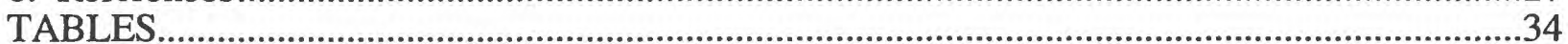

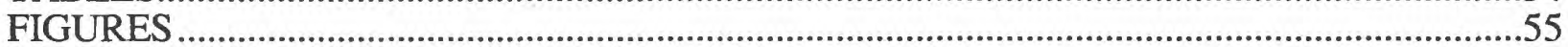

APPENDIX 1. Threatened, Endangered, or Proposed Species .................................................64

APPENDIX 2. Summary of Information for Listed Species Encountered.................................64

APPENDIX 3. Key Species Natural History ..........................................................................64

APPENDIX 4. Point Loma Rocky Intertidal Baseline Survey Handbook ................................71

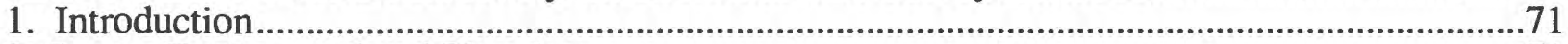

2. Survey Background and Planning ...................................................................................

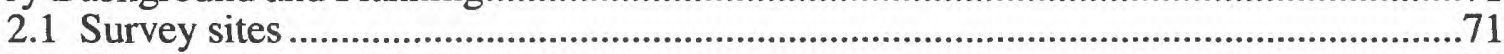

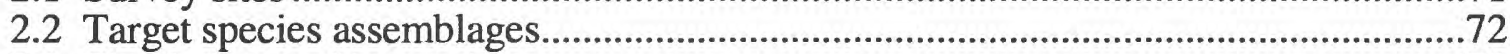

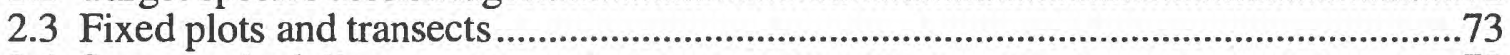

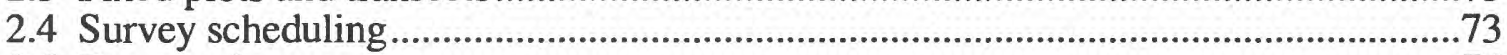

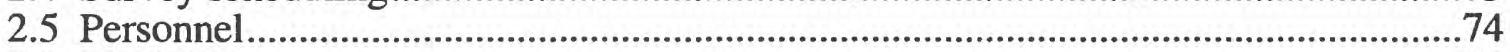

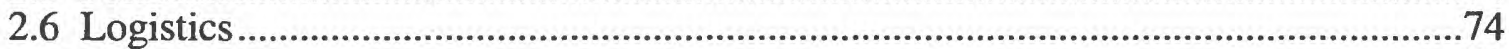

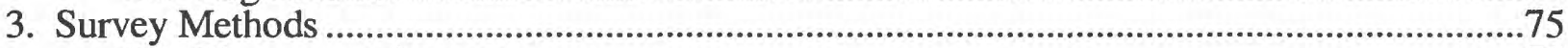

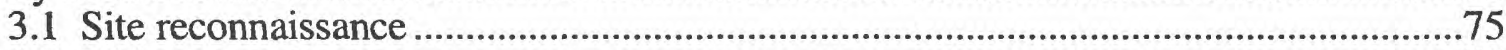

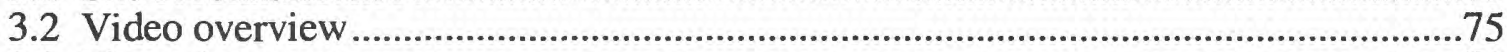

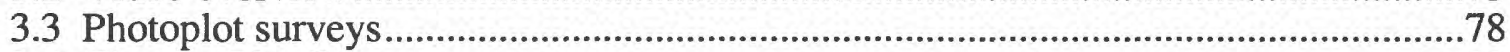

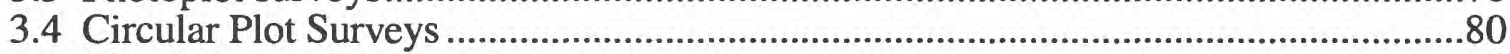

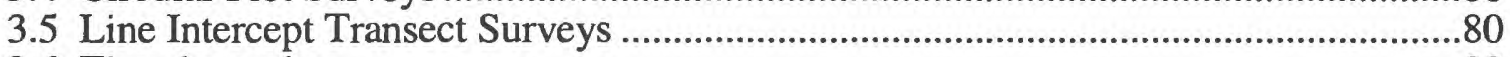

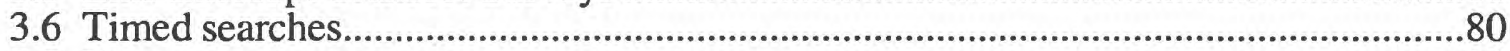

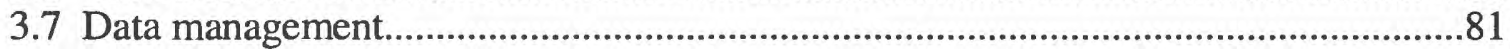




\section{List of Tables}

Table 1. Index Taxa and Monitoring Techniques at Navy North and South Sites...................34

Table 2. Rocky Intertidal Survey Plots and Plot Identification Codes ....................................35

Table 3. Navy North Rocky Intertidal Interplot Measurements ............................................36

Table 4. Navy South Rocky Intertidal Interplot Measurements ............................................37

Table 5. Field Activities for Point Loma Rocky Intertidal Baseline Surveys ...........................38

Table 6. Participants in the Point Loma Rocky Intertidal Baseline Surveys..............................38

Table 7. Point Loma Rocky Intertidal Species Relative Abundances .....................................39

Table 8. Intertidal Cover within Photoplots in Spring 1995 ................................................44

Table 9. Intertidal Cover within Photoplots in Fall 1995 .................................................45

Table 10. Photoplot Species Summary Data by Site ............................................................46

Table 11. Photoplot Primary Index Taxa Summary Data...........................................................46

Table 12. Density and Size Distribution of Owl Limpets in Circular Plots in Spring 1995 .........47

Table 13. Density and Size Distribution of Owl Limpets in Circular Plots in Fall 1995.............49

Table 14. Owl Limpet Density and Size Data by Plot................................................................51

Table 15. Owl Limpet Density and Size Summary Data by Site ..............................................51

Table 16. Intertidal Cover along Line Transects in Spring 1995 .............................................52

Table 17. Intertidal Cover along Line Transects in Fall 1995 .................................................53

Table 18. Line Transect Species Summary Data by Site...........................................................54

Table 19. Line Transect Primary Index Taxa Summary Data ...................................................54

\section{List of Figures}

Figure 1. Point Loma Rocky Intertidal Monitoring Sites ...................................................55

Figure 2. Point Loma Navy North Map: Overview, Area R1, Area R2 ..................................56

Figure 3. Point Loma Navy North Map: Area R3 ..............................................................57

Figure 4. Point Loma Navy South Map: Overview, Area R1, Area R2 .................................58

Figure 5. Point Loma Navy South Map: Area R3, Area R4 ..................................................59

Figure 6. Seawater Temperatures at the Scripps Pier from 1989 to 1995 ...............................60

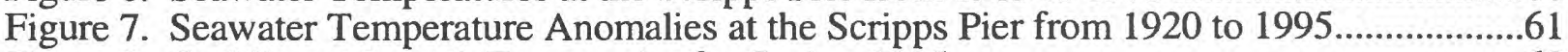

Figure 8. Owl limpet Length Frequencies for Spring 1995 ...............................................62

Figure 9. Owl Limpet Length Frequencies for Fall 1995 ................................................63 


\section{ABSTRACT}

This report provides the results of baseline surveys conducted during Spring and Fall 1995 at 2 rocky intertidal sites within the U.S. Navy Fort Rosecrans Military Reservation on the outer coast of Point Loma, San Diego, California. Habitat descriptions, species inventories, and seasonal monitoring of index species assemblages within fixed plots and transects were carried out using the same methods as surveys ongoing at the nearby Cabrillo National Monument in order to assess the current condition of rocky shore resources so that impacts from military and other activities can be minimized. The sites were characterized by productive, species-rich communities on gently-sloping sandstone reefs and talus rubble backed by high, erodable cliffs and bathed by relatively warm, surf-swept waters. Extensive, diverse flora and fauna were found on broad benches around irregular headlands, with varying wave exposures and numerous microhabitats. Prominent intertidal zonation consisted of an upper steeply-sloping zone characterized by ephemeral/crustose algae and small grazers, a mostly flat middle zone carpeted by turf algae with cryptic infauna, and a gradually-sloping low zone dominated by surf grass and understory biota. Ecologically-important species included rockweed, sargassum weed, red algal turf, coralline crusts, surf grass, barnacles, limpets, top snails, and chitons. Notably rare or absent were boa kelp, goose barnacles, black abalone, mussels, sea stars, and sea urchins. Seasonal variations in species abundances were minor in 1995, except for increased cover of opportunistic algae in Spring. Sources of natural disturbances in this system include fragmentation of the poorly-consolidated substrate, sand/gravel scour, storm swells, midday low tides combined with hot, dry winds, and continuation of a long-term seawater warming trend. Comparison of conditions at the Navy sites with 6-yr monitoring data at Cabrillo National Monument confirms that considerable changes in species abundances have occurred prior to 1995 , including increases in surf grass, declines in 5 other index species (boa kelp, pink-thatched and goose barnacles, owl limpets, and mussels), and continued absence of historically-resident black abalone and sea stars. Few confirmed human impacts were documented; however, suspected impacts include contamination from the nearby sewage outfall, ship discharges, outflows from the San Diego Harbor and Tijuana River, aerial fallout, shoreside runoff during rainstorms, and game collecting. Loss of pollution-sensitive resources, such as the extensive, highly productive, and species-rich surf grass beds would greatly reduce the structure, function, and value of Point Loma intertidal ecosystems. Once common mussel beds have been decimated; the reason is unclear, but trace metal contamination and game take are known impacts. Also, although the Navy sites are relatively inaccessible, collecting pressure apparently has removed larger, mostly female owl limpets from reproductive populations. Efforts to minimize human impacts should include identification and elimination of pollution sources as well as adoption of accidental spill prevention and rapid-response clean-up measures. Public use and resource management issues could best be addressed through the development of a peninsula-wide intertidal Resource Management Plan. One option is zonal management, in which some shores are open to public visitation, some partially restricted, and others left in an undisturbed "natural" state. Biological monitoring is essential for updated resource evaluation and management efforts. Experimental rocky intertidal studies and educational programs also should be encouraged so everyone can benefit from increased understanding of the ecological inter-relationships and value of this important land/water interface ecosystem. 


\section{Introduction}

Rocky intertidal communities along the ocean-facing side of Point Loma are the most extensive and diverse in San Diego County. With most of the peninsula owned by the U.S. Navy Fort Rosecrans Military Reservation, restrictions on public use have preserved the military coast as one of the few remote stretches of ocean shoreline in southern California. However, the rich communities of plants and animals found in these tidepools and rocky reef habitats are subject to influences from a multitude of human activities associated with the large metropolitan area of San Diego, including harbor commerce, nearshore shipping, the municipal sewage outfall, shoreside development, and direct disturbance and game collecting by beach explorers. Effective management of increasingly-valued intertidal resources requires dynamic baseline surveys to determine what is there and to understand how key components of this land/water interface ecosystem respond to natural environmental variations and human impacts.

Prior to the 1970's the extensive rocky intertidal resources of Point Loma remained largely unstudied, except for the occasional anecdotal account. The few systematic surveys carried out in San Diego County in earlier years (e.g., Dawson 1965) concentrated on La Jolla shores, close to Scripps Institution of Oceanography, where beach access was easy. Turner et al. (1968) conducted one-time surveys to assess impacts from operation of the municipal outfall at Point Loma, including single transects at 4 intertidal sites (Sunset Cliffs, Naval Electronics Lab, Sewage Disposal Plant, and Lighthouse). In the mid 1970's, the Bureau of Land Management initiated a 3-yr program of intertidal surveys at representative sites throughout the Southern California Bight, including one site at the north end of Point Loma at Ocean Beach (Seapy \& Littler 1977, 1978, 1979; Littler \& Seapy 1979). During the same period, a 2-yr intertidal resource inventory was undertaken at the south end of Point Loma for the Cabrillo National Monument (CABR) to evaluate public use effects and make management recommendations (Zedler 1976, 1978). From the time these surveys ended until 1990, few other intertidal studies took place at Point Loma, except for the excellent research on algal turf and surf grass communities by Stewart and Myers (1980) and Stewart $(1982,1983 ; 1989 a, b)$ that included several northern Point Loma sites and one at the CABR visitor area.

Since 1990 a long-term monitoring program has focused on 3 sites within CABR to establish a temporal baseline for evaluating visitor and other impacts (Davis \& Engle 1991; Engle \& Davis 1996a,b). These surveys proved valuable in assessing impacts from the massive sewage spill caused by rupture of the Point Loma Wastewater Treatment Plant undersea pipeline in 1992 (Engle 1992). Although some data are available from past studies at both ends of Point Loma, and biological monitoring is ongoing at the southern tip (CABR), intertidal resources of the 4-km central Point Loma coast, within the Fort Rosecrans Military Reservation, have not been surveyed. Here, despite extensive rocky shore features, limited access due to steep cliffs and military security regulations has resulted in poor understanding of what plants and animals are present and how the biological assemblages change through time. The purpose of this baseline survey is to initiate seasonal inventory and monitoring studies at 2 locations within the Military Reservation in order to begin to answer these questions. The results can then be used in conjunction with ongoing monitoring data from $\mathrm{CABR}$ to develop programs to minimize impacts from current or planned human activities and to assess accidental impacts should some catastrophic event such as an oil spill occur.

Assessing ecological conditions is a complex and often expensive undertaking. During the 1980's, Channel Islands National Park developed a cost-effective intertidal monitoring program that has become a model for rocky shore surveys throughout the Southern California 
Bight (Richards \& Davis 1988; Engle et al. 1994a,b), including those at CABR (Davis \& Engle 1991). Instead of detailed surveys of all species at many sites, ecological conditions at representative locations are evaluated by concentrating on selected key species assemblages that are monitored seasonally in fixed plots. Qualitative reconnaissance surveys yield inventory data and provide ecosystem perspective for the key species monitoring. The baseline surveys for this study utilized the same reconnaissance/key species monitoring approach, thus ensuring compatibility with ongoing studies at CABR and elsewhere in southern California. This report provides the results of surveys conducted during 1995 at 2 rocky intertidal sites within the Fort Rosecrans Military Reservation on the outer coast of Point Loma. Included is a Survey Handbook that describes the specific procedures for monitoring the target species assemblages. Since biological systems are dynamic, continued seasonal and annual biological data are needed for accurate baselines. Therefore, it would be valuable to continue low-level monitoring of these 2 sites beyond the present Navy contract. The Survey Handbook provides the detailed information necessary for biologists to continue low-cost monitoring in a practical and standardized manner.

\section{Study Areas}

Background information used to choose 2 survey sites within the Fort Rosecrans Military Reservation outer shore of Point Loma was obtained during scouting trips early in 1995. Access was a key consideration because there are only a few spots along this stretch of sheer palisades where one can scramble down to reach the beach. Rocky shore features were viewed from the cliffs above, access trails investigated, and nearly all shore habitats throughout the region explored by hiking trips along the intertidal zone at low tide. Conditions evaluated in choosing the 2 baseline survey sites included reasonable and safe access, regional representation of stable (bedrock or large boulder) habitats, sufficient abundances of the same key species monitored at $\mathrm{CABR}$, and adequate bedrock surfaces for establishing fixed plots. Other initial considerations that mostly did not apply to this shore region included areas previously surveyed, areas containing species of special concern with regard to human impacts, and areas uniquely diverse or pristine.

The two representative rocky intertidal sites chosen for these baseline surveys were designated Navy North (NN) and Navy South (NS), since no specific place names were available. Their general locations are shown in Figure 1. NS is located 0.2-0.3 km north of the northern boundary of the Point Loma Wastewater Treatment Facility. NN is $1.0-1.2 \mathrm{~km}$ upcoast of NS, just downcoast of a large white concrete Navy office building on the mesa high above the shore. Detailed maps of NN are provided in Figures 2 and 3; maps for NS are in Figures 4 and 5. The Survey Handbook provides directions for access to the sites. The physical and biological characteristics of each site are described below.

\subsection{Navy North site}

The NN location encompasses approximately $300 \mathrm{~m}$ of rocky shore along the base of sheer 25-30 m high cliffs in the central portion of the Fort Rosecrans Military Reservation (Fig. 1). A prominent landmark for this site is the centrally-located pinnacle rock $(10 \mathrm{~m} \mathrm{high;} 30 \mathrm{~m}$ in diameter) that represents the eroded tip of a high bluff promontory. This chimney rock is about $20 \mathrm{~m}$ offshore from the main promontory such that it is surrounded by water at high tide. The $\mathrm{NN}$ site extends from roughly $200 \mathrm{~m}$ upcoast of the chimney rock to $100 \mathrm{~m}$ downcoast (see Figs. 2 \& 3). The rocky intertidal zone at this site consists primarily of broad, gently-sloping wave-cut 
benches composed of many horizontal layers of poorly-consolidated sandstone. There are numerous crevices, channels, and pools on the mostly low-medium relief features. Large slabs of this relatively soft sedimentary rock may be tilted or broken off from the bedrock. The rock surface shows cracks where layers are breaking, smooth depressions eroded by wave action, and tiny slots where chitons have bored down a few centimeters. Mixtures of loose rocks and stable boulders occur at the base of the cliffs and less commonly scattered atop the bedrock flats. There is little sand on this headland shore. Unstable cobble occurs in surge channels.

The gradual beach slope at NN creates extensive intertidal reef area, extending 30-100 m offshore. The intertidal zone here is wider than most of the other shelves along this section of coast, except for the south end of CABR. The site is fully exposed to ocean swells, but the outer reef margin dissipates some of the wave energy, especially at low tide. Reef portions immediately upcoast and downcoast of the chimney rock received extra protection from the promontory point, depending on the prevailing swell direction. Chimney rock itself has a steeply-sloping, narrow intertidal zone that receives the direct force of waves.

The extensive reef system at NN, with a range of wave exposures and a variety of microhabitats, supports diverse assemblages of intertidal plants and animals. Of these, a few species or groups of species obviously dominated, forming conspicuous bands or patches of life from the highest to lowest intertidal height zones. In the broadest sense, the major zones at this site include 1) the upper intertidal dominated by ephemeral and crustose algae, 2) the middle intertidal dominated by turf algae, and 3 ) the low intertidal dominated by surf grass. The biological characteristics of $\mathrm{NN}$ will be described below within the context of these major zones.

The uppermost splash zone life at NN occurred as a relatively narrow band on vertical walls at the cliff base, primarily upcoast of the chimney rock. Downcoast, unstable mostly bare talus rocks predominated high on the shore. Even to the north, much of the rock surface was bare, but wetter, shadier locations here had extensive cover of slippery blue-green algal films. Bright green patches of Enteromorpha and other green algae were common on freshwater seeps in Spring 1995. The periwinkles, Littorina keenae and $L$. scutulata, were common, along with numerous small limpets (Collisella digitalis, C. scabra, and C. strigatella). Patches of thin hairlike green (Chaetomorpha linum) and brown (Scytosiphon dotyi) algae, were evident. Striped shore crabs, Pachygrapsus crassipes, were common in crevices from this zone on down to the algal turf flats.

Below the splash zone, the high intertidal zone occurred on the steeply-sloping upper shore or high on rocks projecting up from lower zones, hence it too was fairly narrow in extent. White acorn barnacles (Chthamalus fissus/dalli) were present, but not forming a dense band. Clumps of the predatory (on barnacles) snail, Acanthina lugubris, were fairly common. The rockweed, Pelvetia fastigiata, was rare upcoast of the chimney rock. It was common in patches in the downcoast lee of the promontory point. Slightly lower, pink thatched barnacles (Tetraclita rubescens) were present; not dense, but scattered. Patches of goose barnacles (Pollicipes polymerus) and mussels (Mytilus californianus) were rare overall at NN. They mostly occurred on a narrow, exposed shelf at the northern end of the site and did not extend to lower zones. Owl limpets (Lottia gigantea) were common in this zone, notably on the pitted walls and around the chimney rock. Next lower on soft bedrock at the cliff base were high densities of small chitons (Nuttalina fluxa), nestled in pits along with various other chitons (e.g., Lepidochitona hartwegii and Mopalia muscosa), limpets (e.g., Collisella spp. and Fissurella volcano) and littorines. Extending from the cliff base over boulders to the reef flats were areas dominated by ephemeral algae, including slimes, tiny sea lettuce (Ulva), and bubble kelp (Colpomenia sinuosa). Also 
abundant here, especially in damper shaded areas, were black crusts (Ralfsia) and pink coralline crusts. The limpet, Collisella limatula, was common on shaded rock sides. Clonal aggregations of the anemone, Anthopleura elegantissima, that can occur at this tide level, were absent at NN.

The broad flats of the middle intertidal zone throughout $\mathrm{NN}$ were dominated by dense cover of low (up to $10 \mathrm{~cm}$ ) red algal turf. This extensive turf mat was composed of a diverse mixture of small algae. Erect corallines (esp. Corallina spp.) were most abundant, but also present were Chondria sp, Colpomenia spp., Gastroclonium coulteri, Gelidium spp., Gigartina canaliculata, Laurencia pacifica, Plocamium spp., and others as described by Stewart (1982). Numerous tiny invertebrates such as polychaete worms, isopods, amphipods, and mollusks inhabit this low thicket. Thatched barnacles, thin brown blades of Endarachne binghamiae, and various crusts occurred on drier rocks in this zone. Higher pools typically had nearly solid cover of crustose coralline algae or black Ralfsia crusts. Lower pools were dominated by surf grass (Phyllospadix torreyi) and sargassum weed (Sargassum muticum). Hermit crabs (Pagurus spp.) and black turban snails (Tegula funebralis), were present in some pools and wet crevices. Tidepool sculpins (Clinocottus analis) and opaleye (Girella nigricans) occurred in pools here and lower down on the shore.

The flat benches into the lower intertidal, where red algal turf cover gave way to extensive meadows of surf grass. The meter-long green leaves of this flowering plant covered nearly $100 \%$ of most rock surfaces. Beneath the grass canopy was a diverse assemblage of crustose and erect coralline algae, other turf algae, and sessile invertebrates. Common understory algae included Corallina spp., Laurencia spp., Plocamium spp., and Pterocladia capillacea. Also present were Chondria sp, Codium fragile, Colpomenia sp., Dictyopteris undulata, Dictyota flabellata, Gastroclonium coulteri, Gigartina canaliculata, and Sargassum agardianum. Sargassum weed was common, especially in calmer pools and channels, along with various coralline algae. The brown alga, Halidrys dioica, and red alga, Prionitis lanceolata, were present around the 0.0 tide level, mixed in with the surf grass or in more exposed pools and channels. Boa kelp (Egregia menziezii) was remarkably rare in the low intertidal at NN. Invertebrates under the surf grass canopy included small sponges, hydroids, anemones, worms, snails, brittle stars, and ascidians. The relatively soft sandstone rock was pitted with small holes created by many generations of boring clams (Pholadidae). Live individuals were evident in the lowest areas. The turban snail, Tegula eiseni, was abundant. Individuals of the anemone, Anthopleura elegantissima, were present in pools and channels. The above invertebrates also were found under the relatively few turnable rocks down in the surge channels. Surprisingly, there were no purple or red urchins, even in pools or channels or under rocks. In addition, abalone and sea stars were absent, except for one giant-spined sea star (Pisaster giganteus).

\subsection{Navy South site}

The NS site encompasses approximately $250 \mathrm{~m}$ of rocky shore along the base of $25 \mathrm{~m}$ high cliffs at the southern end of the Fort Rosecrans Military Reservation, 0.2-0.3 km north of the northern boundary of the Point Loma Wastewater Treatment Facility (Fig. 1). A prominent landmark for this site is the narrow promontory (Ref. 3 area) separating the broad cove to the south (Ref. 4 area) from the narrow access inlet to the north (Ref. 2 area) (see Figs. 4 \& 5). This promontory has several crawl- or walk-through arches. The NS site extends from about $100 \mathrm{~m}$ upcoast of the promontory tip to about $150 \mathrm{~m}$ downcoast. Like NN about $1 \mathrm{~km}$ upcoast, NS intertidal shore consists primarily of wave-cut benches composed of many horizontal layers of poorly-consolidated sandstone. However, NS has a more irregular shoreline, resulting in greater 
diversity of physical habitats, and narrower intertidal reefs (5-20 m wide, except for the southern cove where few plots are located), resulting in greater wave shock for benches not protected by headlands.

There are 4 subareas of physical features within NS; from upcoast to downcoast, they include the following:

1) Reference 1 area, which is composed of wave-swept $20 \mathrm{~m}$ wide bedrock benches extending out from the steep-sloped high intertidal that forms the cliff base. The predominantly flat reefs have few channels, pools, crevices, or movable rocks.

2) Reference 2 area, which includes narrow (roughly $5 \mathrm{~m}$ wide), steep-sloped intertidal that drops into a narrow partly-sheltered inlet cove with boulder and talus rocks throughout the innermost beach and low intertidal. In the low intertidal only, there are deep pools crevices between rocks, some unstable cobble, and minor sand accumulation.

3) Reference 3 area at the promontory point, which is similar to Reference 1 area, except that the south side of the promontory is semi-protected, and a series of benches separated by channels continue downcoast (parallel to shore), across the mouth of the southern cove. The shaded arch cutting across the promontory tip is awash at high tide.

4) Reference 4 area inside the southern cove, partially protected by the outer reefs, is composed of bedrock slabs, boulders, and cobble talus from the cliffs above. The medium-relief rubble provides numerous crevices and pools. There is some sand and gravel on the inner beach.

Overall, the biological character of the reef system at NS is quite similar to that of NN. This is not surprising because, except as described above, both sites have similar types of substrate, range of habitats, and degrees of wave exposure. Therefore description of the biological resources of NS will be limited to characterization of those features that are different from NN. Emphasis will be placed on those portions of the site where most of the fixed plots and transects are located, thus areas of small rocks and cobble will not be described in detail. Like $\mathrm{NN}$, the major intertidal life zones can be divided into 3 conspicuous bands (or patches) of species (or species groups) separated by height on the shore. At NS these broad zones include the upper intertidal dominated by a mixture of crustose algae and small invertebrates, the middle intertidal dominated by turf algae, and the lower intertidal dominated by surf grass.

Like NN, the uppermost splash zone and upper intertidal zones at NS were relatively narrow bands located on the steeply-sloping base of the high cliffs. Abundances of barnacles, shore crabs, limpets, periwinkles, and chitons were similar; however, at NS there were fewer ephemeral algae types, such as Enteromorpha, Chaetomorpha, Ulva, Colpomenia, and Scytosiphon. Black Ralfsia crusts and pink coralline crusts were very common, especially on north-facing shaded walls and inside arches. These crusts plus small invertebrates such as Chthamalus, Tetraclita, Collisella spp., Fissurella, Lottia, and Nuttalina dominated this zone. Rockweed was only found in the semi-protected southern cove (Ref. 4 area), on boulder tops. Goose barnacles and mussels were uncommon, generally confined to a few narrow patch strips in the high intertidal where small individuals of the two species occurred together at lowdensities.

Red algal turf also dominated the gradual slope low-relief benches at NS, and species composition appeared similar. The main difference was that the benches at NS were much narrower and exposed to more direct surf than most of the same zone at NN. Some bare and worn patches were observed in the turf zone at NS that may have been due to storm disturbance. Except for the boulder areas in coves, there were fewer channels and pools on the turf flats at NS, but those present had comparable life to NN. A similar situation existed in the low intertidal 
at NS, where surf grass was the overwhelming dominant, but the width of this zone was relatively narrow compared to that at NN. The understory algae were typical. Sargassum weed was less common out on the more exposed grass flats, but quite common back in the semiprotected coves. Halidrys and Prionitis were present. Like NN, boa kelp was rare as well at NS, even though the habitat looked appropriate. Boring clams and turban snails were very common. Only a few red urchins and one giant-spined sea star was seen at NS; no abalone, purple urchins, or other sea stars, despite good amounts of under-rock habitats within the coves. Mounds of the colonial sand castle worm, Phragmatopoma californica, were more common at NS compared to $\mathrm{NN}$, primarily around boulders inside the coves and under the flow-through promontory arch. Under-rock life (sponges, worms, porcelain crabs, snails, brittle stars, and ascidians) was quite common in the more protected coves at NS, and much more diverse than at NN.

\section{Methods}

\subsection{Target species assemblages}

Ideally one would like to monitor the abundances of all species in an area; however, limited resources require that a subset of the resident species be targeted. Intertidal zonation is frequently characterized by distributions of dominant attached plants and sessile animals (Ricketts et al. 1985). Therefore, a representative group of important taxa (species or species groups), also referred to as "target" or "key" species assemblages, can provide an accurate index of ecological conditions (see Ambrose et al. 1995 for discussion). Thirteen index taxa are monitored at the 3 CABR sites (Davis \& Engle 1991; Engle \& Davis 1996a,b). The same species and species groups monitored at CABR were utilized in this study in order to maximize data compatibility. Criteria used for selecting these target species assemblages include the following:

- Species ecologically important in structuring intertidal communities

- Species characteristic of discrete intertidal heights

- Species that have been well-studied

- Species that are especially vulnerable to human impacts

- Species practical for long-term monitoring

The index taxa surveyed at the NN and NS intertidal sites are listed in Table 1. In addition to the key species, broad categories (other plants, other animals, other biota) are scored, as well as the amount of tar and bare substrate (rock or sand). The natural history and ecology for each of the key species are summarized in Appendix 3.

\subsection{Survey procedures}

The sampling techniques used to survey NN and NS sites were identical to those employed at CABR to ensure optimum compatibility between the 2 studies (Davis \& Engle 1991; Engle \& Davis 1996a,b.) These include qualitative species inventories combined with quantitative cover (for sessile species) or count (for mobile species) data for the index taxa within fixed plots or along fixed transects. Fixed sampling units reduce the variability that would result from random sampling, and thus give more statistical power to detect changes in cover or density over time (see Ambrose et al. 1995 for discussion of advantages and limitations of fixed plot sampling). Each site was sampled twice in 1995, in the Spring and Fall, to evaluate seasonal population changes during the periods when maximum differences were expected. Survey techniques are summarized below. Further details, guidelines, and examples of data forms are provided in the Survey Handbook (Appendix 4). 
Thirty-three fixed plots and transects were established within each of the 2 survey sites during February 1995 (see maps in Figs. 2-5). These permanent sample locations were marked with $3 / 8$ in stainless steel bolts fixed into the bedrock with epoxy. Specific bolts were marked with notches to identify the plot's number (Table 2). In addition, there are generally 3 or more large (1/2 in) reference bolts (also notched) located throughout the site. These strategicallyplaced bolts were used as standards for measurements to plots for mapping and efficient relocation, and also as video and photo reference markers. Distances and bearings were recorded from each notched plot and transect bolt to one or more reference bolts; other measurements were taken between nearby plots and transects (Tables 3,4). These measurements were used in conjunction with sketches of physical features at each location to produce scaled site maps (Figs. 2-5). Quadrats and transects were drawn onto each site map, with notched marker bolt positions indicated.

Reconnaissance surveys were conducted during the Spring and Fall surveys at both Navy sites. Physical conditions were described at each site, including weather conditions, sea conditions, substrate types, presence of tar, and other unusual occurrences such as debris or pollutants. Biological features were characterized, included habitat types and zonation, distribution and abundance of species, condition of individuals and populations (e.g., sizestructure, color pattern, epiphyte load), and animal behavior. The presence and activities of birds, marine mammals, and humans were recorded. Representative habitats and microhabitats (e.g., crevices, tidepools, under-rock, under-plant) throughout each site were explored and species composition noted. Relative abundances (rare, present, common, abundant) for plant, invertebrate, and fish species encountered were estimated wherever possible; these estimates were based on the maximum potential abundance for each species in southern California. Overview photos (Spring and Fall) and videos (Spring only) were taken to document site-wide physical and biological conditions.

Table 1 summarizes the sampling techniques and number of replicate fixed plots for each key species at the 2 monitoring sites. Rectangular $\left(50 \times 75 \mathrm{~cm} ; 0.375 \mathrm{~m}^{2}\right.$ ) photoquadrats were used to monitor the population dynamics of 5 relatively small, densely-spaced target species, acorn barnacles (Chthamalus spp.), pink-thatched barnacles (Tetraclita rubescens), rockweed (Pelvetia fastigiata), mussels (Mytilus californianus), and goose barnacles (Pollicipes polymerus). Bolts mark 3 of the 4 corners of each plot (upper left, lower left, upper right). The upper left bolt heads were marked with notches for plot identification. Still photos were taken during each seasonal survey using a quadrapod apparatus, which holds a camera and strobe in a fixed orientation over each quadrat. Five replicate photoquadrats were surveyed for each target species, except for goose barnacles; these have 6 replicates for consistency with the Cabrillo sites (at which 3 band transects were converted to photoplots, with 2 plots per transect). Species abundance was scored from the slides in the laboratory as percentage cover by the point contact method. The slide was projected onto a grid of 100 uniformly-distributed points. The number of points occupied by key species, higher taxa, tar, and bare substrate were recorded to determine percentage cover of each taxon.

The number and size distribution of owl limpets (Lottia gigantea) were monitored within permanent circular plots at NN and NS intertidal sites. There are 6 replicate plots at each site. Plots were marked with a center bolt, notched to indicate the plot number. All limpets $\geq 15 \mathrm{~mm}$ found within a $1 \mathrm{~m}$ radius circle $\left(3.14 \mathrm{~m}^{2}\right.$ area) around each bolt were counted and measured (maximum length in millimeters). 
Boa kelp (Egregia menziezii), sargassum weed (Sargassum muticum), red algal turf (Corallina spp. and other tufted algae), surf grass (Phyllospadix spp), and aggregating anemones (Anthopleura elegantissima) were sampled by line-intercepts along $10 \mathrm{~m}$ long permanent transects. Six replicate transects were used at each site. Two transects represented the middle intertidal zone dominated by red algal turf, 2 others the upper half of the low intertidal zone dominated by surf grass, and the last 2 represented the lower half of the low zone, also dominated by surf grass at present (at CABR this lowest zone was previously dominated by boa kelp). Each transect was marked at both ends and the center with stainless steel bolts. Bolts at the start (north end) of each transect were notched for identification. The abundance and distribution of the key species, other biota, tar, and bare substrate were recorded as distances (to the nearest centimeter) along the edge of a meter tape laid out between the bolts.

Historically, ochre sea stars (Pisaster ochraceus) and black abalone (Haliotis cracherodii) were important components of Point Loma's intertidal ecosystem (Zedler 1978). However, these key species have not been found here in recent years. Timed searches ( 30 person minutes) of likely habitats throughout each survey site were conducted during each sampling period in order to document possible occurrences of any species of abalone or sea stars.

\section{Results}

Table 5 lists the schedule of field activities for the intertidal baseline surveys at the Military Reservation along Point Loma's outer coast. For efficiency, we concentrated the work during periods in Spring and Fall 1995 when good low tides occurred during midday hours. A crew of 7-9 experienced biologists and assistants worked about $6 \mathrm{hr}$ each day (low tide $\pm 3 \mathrm{hr}$ ) in the field to complete the surveys successfully (Table 6). An additional $6 \mathrm{hr}$ each field day was spent preparing for the field work in the morning and organizing the data and field notes in the evening. The greatest amount of time was spent weeks ahead of the surveys organizing the people, equipment, and supplies; then after the surveys scoring photo slides, entering data into the computer in standard formats, and analyzing and writing up results.

The NN and NS sites were established and surveyed for Spring conditions during February 23-March 2, 1995. Fall surveys took place during October 21-25, 1995. The 3 CABR sites were sampled during the same time periods. Results from Spring and Fall reconnaissance and key species surveys at the 2 Navy sites are reported below. For ease of presentation, the 2 sampling seasons will be abbreviated as S95 for Spring 1995 and F95 for Fall 1995.

\subsection{Site reconnaissance surveys}

During each visit to the Navy sites, qualitative physical and biological observations were recorded on Field Log data sheets (see Appendix 5), videotape (S95 only), and photographs. No unusual weather conditions were encountered during the surveys in 1995. During both $\mathrm{S} 95$ and F95 it was noted that headland areas of NS received more wave exposure than those at NN (because the narrower shelf at NS is less effective in dissipating wave energy). Also, the inner coves at NS experienced calmer conditions than any areas at NN. Disturbance from moving sand (burial or scour) was not observed at either site; however, limited cobble scour was seen in some surge channels at both sites. Cracking, flaking, and breakage of the horizontal layers of soft sedimentary rock was obvious throughout the sites and likely is a major source of disturbance to intertidal assemblages during periods of strong swells. Drift algal debris (primarily pieces of giant kelp, Macrocystis pyrifera) was not that prevalent at the sites, except at the upcoast end of $\mathrm{NN}$ in F95 (when many of the mussel/goose barnacle plots were partly buried) and on the 
innermost beaches of the coves in NS during both seasons. The S95 surveys followed a period of heavy rains, and freshwater seeps were observed, especially at the upcoast end of NN, where blooms of Enteromorpha and other ephemeral algae were found. These blooms were not present in F95. Air and seawater temperatures were typical of the seasons. Minor bleaching of red algal turf and surf grass within the uppermost portions of their respective zones was noted, primarily in S95, after the months when the lowest tides occur during midday hours. Seawater temperature records from surface water at the Scripps pier (upcoast at La Jolla) recorded from 1920-1995 were plotted to document current temperature patterns and to compare them to historical conditions for this area (Figs. 6 \& 7). The data indicate that from Winter 1992 to Spring 1995 , water temperatures were consistently warmer than the $76 \mathrm{yr}$ mean, and that this warming trend has been occurring since 1976. The species assemblages documented at NN and NS sites in 1995 likely reflect the influence of this long-term warming pattern.

Little evidence of direct effects of human activities was observed during the limited field surveys at the Navy sites in 1995. Some litter, in the form of cans, bottles, styrofoam, wood, etc. was noted in cove areas, primarily at the upcoast end of NN and in the two coves at NS. A few spots of weathered tar were seen at the sites, but no major concentrations or fresh material. Balls of monofilament line were found entangling several of the mussel/goose barnacle plot bolts at the north end of $\mathrm{NN}$ in F95. These were the same plots partially covered with drift algal debris. No human activities were observed at these relatively inaccessible sites, except that one person walked through NN in S95, and one person with a dog hiked through NS in F95. Both visitors had walked along the shore downcoast from Sunset Cliffs.

The biological features of the Navy sites were described in Section 2 above. The results of the qualitative species reconnaissance surveys are presented in Table 7, and incorporated into the Section 2 site descriptions. A total of 158 species or higher taxa that could be identified in the field were recorded during these inventory surveys. These include 59 plants, 92 invertebrates, and 7 fishes. Many other species were present, but smaller, difficult to identify organisms need to be collected, preserved, and identified by taxonomic experts, a process beyond the scope of this study. No State or Federal listed species were encountered during these surveys.

\subsection{Key species surveys}

The abundances of acorn barnacles, thatched barnacles, rockweed, mussels, goose barnacles, other plants, other animals, and bare substrate in $50 \times 75 \mathrm{~cm}$ photoplots for NN and NS sites are presented in Table 8 (S95) and Table 9 (F95). F95 photodata for NS rockweed plots and 1 barnacle plot, and 1 mussel plot at $\mathrm{NN}$ were lost due to camera malfunction. Site-wide comparisons are reported as means of the 5 replicate plots for all taxa (Table 10). Seasonal comparisons of percentage cover for the 5 key species are shown in Table 11.

Acorn and thatched barnacles occurred mainly in the photoplots in which they were specifically targeted (barnacle plots). Even here, acorn barnacles averaged only $9 \%$ of plot cover at $\mathrm{NN}$ and $7 \%$ at NS in S95. Cover in both areas declined to trace levels (2\% at NN; $1 \%$ at NS) by F95. Thatched barnacle cover was higher ( $28 \%$ at NN and $15 \%$ at NS in S95) than that of acorn barnacles. Cover declined slightly (by $6 \%$ at NN and 3\% at NS) from Spring to Fall at both sites. Most of the cover in the barnacle plots at both sites (60-88\% of site-wide means) was made up of other plants and bare substrate. At both sites other plant cover increased from Spring to Fall; bare rock declined at NN, but stayed the same at NS. 
Rockweed occurred only in the plots where it was targeted, except for minor amounts in 2 NN barnacle plots. Cover was high (51-96\%) at NN plots in S95, but considerably less (30$59 \%$ ) at NS plots. Rockweed abundance remained unchanged at NN between Spring and Fall. F95 data were not available for NS; however observations indicated little or no change here as well. Other plants made up most of the secondary cover in the rockweed plots at both sites. They were more important at NS (40\% of S95 site-wide mean versus $10 \%$ at NN), where rockweed cover was lower. Other plant cover often is composed of algal crusts which typically are hidden beneath the rockweed canopy. Thus other plant cover tends to vary inversely with rockweed cover.

Mussels and goose barnacles overall were not common at the Navy sites, and where found they were intermingled. Because of this intermixing, the 2 key species were surveyed in 11 mussel/goose barnacle replicate plots instead of 5 emphasizing mussels and 6 emphasizing goose barnacles (as is the case at the CABR sites). S95 mussel cover in the 11 plots at both sites was mostly low, but variable (0-44\% at NN; $1-37 \%$ at NS), with mean site-wide cover of $10 \%$ at $\mathrm{NN}$ and $15 \%$ at NS. There was little change in cover at either site by F95. Overall, goose barnacle cover was higher than that for mussels in the 11 plots at both sites, with mean site-wide cover of $17 \%$ at NN and $19 \%$ at NS. There was no seasonal change in cover at either site. Most (63-74\% of site-wide means) of the cover in the mussel/goose barnacle plots was made up of other plants and bare substrate. Bare substrate was approximately twice as common as other plants.

Owl limpets were the only key species counted and measured in $1 \mathrm{~m}$ radius circular plots. The abundances and size distributions of owl limpets recorded in 6 plots each at NN and NS are shown in Table 12 and Figure 8 for S95 and Table 13 and Figure 9 for F95. Seasonal comparisons of counts and size statistics are given in Table 14. Site-wide comparisons are reported as total numbers for the 6 plots combined of all limpets, small limpets $(15-30 \mathrm{~mm})$, and large limpets ( $\geq 30 \mathrm{~mm}$ ) (Table 15$)$.

The number of owl limpets found in the $3.1 \mathrm{~m}^{2}$ plots ranged from 24-36 at NN and 27-62 at NS in S95. NS had more limpets overall (270 vs. 187). Minimum, maximum, and mean sizes were similar between the 2 sites. Size-frequency distributions were generally similar as well; however, NN had more frequency peaks (but also more variation in number per size category) for 35-45 mm lengths, while NN limpets were more uniformly distributed across size categories (Figure 8). Year class modes were not evident in the histograms. Limpet counts and population size structures did not change substantially between S95 and F95 for either site. The total number of limpets decreased by 7 at NN; those at NS increased by 20 . Mean sizes for both sites increased slightly from site-wide means of $36 \mathrm{~mm}$ in Spring to $39 \mathrm{~mm}$ in Fall as fewer small and more large limpets were recorded, primarily at NS. These relatively minor differences in population size-structure are evident in Figures 8 and 9.

The abundances of boa kelp, sargassum weed, red algal turf, surf grass, aggregating anemone, other biota, and bare substrate along 10-m long line-intercept transects at NN and NS are presented in Tables 16 and 17. Site-wide comparisons are reported as means of the 2 replicate transects for all taxa (Table 18 ). Seasonal comparisons of percentage cover for the 2 abundant key species are shown in Table 19. At CABR, boa kelp has been monitored on the offshore surf grass transects, sargassum weed on the inshore surf grass transects, and aggregating anemones on the red algal turf transects. However, along the transects at NN and NS, boa kelp and aggregating anemones were absent and sargassum weed rare. Site-wide reconnaissance at the Navy sites found boa kelp to be rare, sargassum weed common, and aggregating anemones 
present (Table 6); the latter key species were associated more with crevices and pools rather than reef flats where transects were placed.

Red algal turf was always abundant on the 2 middle intertidal transects at each Navy site along which this key species was targeted. Cover ranged from 93-97\% at NN and NS in S95, and from $95-100 \%$ in F95. Small amounts (1-10\%) of turf cover occurred on most of the surf grass transects as well. Surf grass also was consistently abundant at both sites and during both seasons, within the inshore and offshore pairs of low intertidal transects. There were no trends between sites or seasons. Cover for the total of 8 transects at both sites ranged from $85-100 \%$ in $\$ 95$ and from $95-100 \%$ in F95.

Timed searches (30 person-minutes) for abalone and sea stars were conducted both Spring and Fall at the Navy sites, but no black abalone (live or shells) or ochre sea stars were found. Also, there were no live green abalone, bat stars, or fragile rainbow stars. Two green abalone shells were found at NN in S95. One giant-spined star (Pisaster giganteus) was found at $\mathrm{NN}$ in F95. It measured $14 \mathrm{~cm}$ (mouth to longest ray tip). Another giant-spined star $(6 \mathrm{~cm})$ was recorded at NS.

\section{Discussion}

This section synthesizes information acquired during the Fort Rosecrans rocky intertidal surveys with respect to biotic community composition, temporal variability of populations, and effects of human activities. The ecological character of NN and NS sites are compared to other rocky habitats on Point Loma (especially the $3 \mathrm{CABR}$ locations that were sampled contemporaneously using the same techniques) and areas to the north (e.g., La Jolla) where relevant survey data are available. Previous studies are reviewed in the Introduction (Section 1.0). All concurrent CABR data are from Engle and Davis (1996b). Key species cover and density data from the fixed plots cannot be compared among sites because the level of randomized effort necessary to achieve accurate quantitative characterization was impractical (see Ambrose et al. 1995 for discussion). Instead, inter-site species abundances are compared qualitatively from site-wide reconnaissance surveys. The fixed plot data for index species are used to evaluate temporal variation within and between sites. The natural history and ecology of the 13 index species targeted in this study are summarized in Appendix 3.

\subsection{Physical conditions}

Physical features of the land/water interface environment determine to a large extent the distribution and abundance of rocky shore life. Major physical influences include substrate type and heterogeneity, slope and topographic relief, and amount of wave exposure. The western shoreline of Point Loma, including the Fort Rosecrans coast, is composed of high, sea-eroded cliffs fronted primarily by talus rubble and varying widths of gently-sloping, pavement-like sandstone reefs. A key factor in community stability here is the friable nature of the poorlyconsolidated substrate. Disturbance from gradual erosion and flaking as well as fragmentation of rock layers or whole sections is characteristic of this region. Vertical relief may result from various combinations of cliff walls, pinnacles, outcroppings, boulders, and erosion-formed channels and ledges. Pocket sand, gravel, and cobble beaches are interspersed among the predominant bedrock reefs. The region is exposed to open ocean swells, but where benches are broad, inshore intertidal zones are semi-protected. The NN and NS sites are representative of these conditions and generally are similar in physical make-up. Both sites have the same soft 
sedimentary substrate, experience relatively little sand influence, and encompass headlands and inlets which provide habitat diversity. $\mathrm{NN}$ has more extensive mid-low intertidal reefs separated by surge channels, but less extreme shoreline irregularity and fewer boulder/cobble habitats than NS. Both locations are fairly exposed to prevailing waves; however, NS experiences more extremes - the roughest conditions on the narrow benches (where most of the survey plots and transects are located) and the calmest conditions in the inlets protected by headlands and reefs extending across cove mouths.

The 3 CABR sites farther south on Point Loma (Fig. 1) have much in common with the Navy sites. CABR I and the northern part of CABR II are most similar to NS in having relatively narrow, exposed shelves with considerable boulder/cobble overlying the pavement reef. The southern part of CABR II and all of CABR III have much more extensive (60-100 m wide) and flatter reefs than any of the other locations. The back-beach bluffs are lower and, in CABR III, fronted with introduced granitic riprap to reduce erosion. From the north end of CABR II south, higher-relief outcrops, boulders, and surge channels become progressively less common on the broad mid/low zone reefs. Many of the fixed plots here were established on the few projecting rocks because target species were rare elsewhere. Overall, these southernmost Point Loma sites are the least heterogeneous, the most protected from wave disturbance, and have the greatest exposure to hot, dry air during midday low tides. None of the CABR sites experience major sand influence, but some sand can accumulate at cliff bases. The turf and grass habitats at the CABR sites have more embedded sand than equivalent habitats at Navy sites.

Rocky shores on northern Point Loma also contain sedimentary bedrock reefs and boulder habitats. A research site at Ladera Street, $0.8 \mathrm{~km}$ north of the Navy Reservation, is a relatively flat, unbroken platform (Stewart \& Meyers 1980; Stewart 1982, 1983, 1989a, 1989b). However, in general, the broader, gently-sloping reefs characteristic of southern and central Point Loma narrow and steepen toward Sunset Cliffs, and end near the Ocean Beach Pier. The smaller benches to the north typically have deep surge channels and high, sharp profiles along reef edges. They are subject to greater wave exposure and often have more sand influence in lower zones. The BLM site at Ocean Beach received the most wave shock of all 21 BLM survey locations in southern California (Littler \& Seapy 1979). Like northern Point Loma, rocky beaches in La Jolla tend to have narrow, steeply-sloping sedimentary platforms exposed to stronger wave action than the central and southern Point Loma coast. Some exceptional semiprotected locations with broader, flatter reefs (e.g., Pacific Beach Point, Point La Jolla) have been the focus of intertidal research (e.g., Gunnill 1980, 1985; Stewart \& Meyers 1980; Stewart 1982, 1983).

\subsection{Species assemblages}

Large-scale intertidal zonation patterns mostly were similar between the 2 Navy sites, and compared with sites studied further south (CABR) and north (e.g., Ladera Street) on Point Loma. This is not surprising in light of the physical habitat similarities described above. The upper intertidal zones typically occurred as relatively narrow bands on steeply-sloping walls at cliff bases or on projecting rocks or uplifted benches farther out on the shore. Slippery algal films and hard crusts predominated, along with sessile invertebrates (especially barnacles) and numerous motile grazers (i.e., periwinkles, limpets, chitons) that nestled in damp pits and crevices. Small chitons (Nuttallina fluxa), that often were abundant (to $500 / \mathrm{m}^{2}$; J. Barry, pers. comm.) in the lower portions of this zone, increased microhabitat (and thus species) diversity by rasping slit-like pits throughout the soft rock. Opportunistic algae (especially small greens) were 
locally abundant where fresh-water seeps occurred (notably at the north end of NN in S95) and where layers of rock had broken out, creating fresh bare surfaces. The Navy sites had greater numbers of periwinkles and more chitons compared to the CABR sites, probably because higher wave exposures at NN and NS provided more moisture to the upper intertidal zone during low tides that enhanced plant growth, decreased desiccation, and lowered temperatures. White acorn barnacles (Chthamalus spp.) were present at Navy and CABR locations, but not forming a dense band as they can, especially in areas with more water motion. The larger, longer-lived pink thatched barnacles (Tetraclita rubescens) were more common at the CABR sites, where they reached highest densities on harder rocks that were less subject to erosion.

Owl limpets (Lottia gigantea) are an ecologically important species in high intertidal areas because they maintain territories that they keep free of most invertebrates and plants, except for the rapidly-growing algal films upon which they graze (Stimpson 1970; Wright 1982). These "clearings" vary in appearance with Lottia size and structural features of the substrate, creating a patchwork of differing microhabitats. Owl limpets were common at all Navy and CABR sites, with highest densities in the most exposed subareas. However, the owl limpets at the Navy sites were obviously smaller than those at CABR. Mean sizes of the limpets monitored within fixed plots in 1995 (38 $\mathrm{mm}$ at NN, $38 \mathrm{~mm}$ at NS, $44 \mathrm{~mm}$ at CABR I, $49 \mathrm{~mm}$ at CABR II, $46 \mathrm{~mm}$ at CABR III) were indicative of the Navy versus CABR site differences. Owl limpets in Navy plots rarely exceeded $55 \mathrm{~mm}$ in length and none were more than $66 \mathrm{~mm}$. Those at CABR often measured $55-70 \mathrm{~mm}$ and ranged up to $85 \mathrm{~mm}$. Similar, but more extreme differences were reported 18 yr previous by Zedler (1978), who compared owl limpet size distributions between CABR and Sunset Cliffs. Limpet sizes at CABR ranged widely from $27-71 \mathrm{~mm}$ (50 mm mean) while those at Sunset Cliffs ranged narrowly from 24-38 (31 mm mean). A likely reason for these differences is that the CABR sites are protected from sport collecting, which would target larger individuals for food. Even occasional sport take by people hiking along the shore to reach the Navy sites could alter owl limpet size distributions because they grow slowly and are longlived (at least 10-15 yr; Morris et al. 1980). Selective loss of large individuals may impair reproductive capabilities within owl limpet populations, since Lottia are protandrous hermaphrodites in which the largest limpets are nearly always females (Wright \& Lindberg 1982).

Other ecologically important species occurring slightly lower in the high intertidal zone at Point Loma include rockweed (Pelvetia fastigiata), California mussels (Mytilus californianus), and goose barnacles (Pollicipes polymerus). Rockweed is a dominant perennial brown alga whose thick clumps provide shelter and protection from desiccation for many animals that otherwise could not exist so high up on the shore (Hill 1980; Gunnill 1983; Ricketts et al. 1985). A related rockweed species, Hesperophycus harveyanus, was not found anywhere on Point Loma. Overall Pelvetia was not common at the Navy and CABR sites; instead it was present in patches on the sides of harder projecting rocks, or in partially protected habitats, such as the downcoast lees of headlands. The combination of wave shock plus friable rock surfaces may make it difficult for rockweed to reach greater abundances at Point Loma. Gunnill (1980a, 1985) monitored populations of rockweed at La Jolla from 1973-77 and 1981-83, and found that mortality of juveniles was high, especially those settling on unstable substrates, but established patches on stable rock persisted for many years.

Beds of densely-packed California mussels are a prominent feature of surf-swept rocky shores along the entire Pacific Coast, where they can range widely from high to low tide zones. Thick beds trap water, sediment, and detritus that provide food and shelter for an incredible 
diversity of plants and animals, including cryptic forms inhabiting spaces between mussels as well as biota attached to mussel shells (Paine 1966; MacGinitie \& MacGinitie 1968; Suchanek 1979; Kanter 1980). One would expect mussel communities to be common at Point Loma; however, the mussels were found to be rare throughout the peninsula, including at the Navy and $\mathrm{CABR}$ sites where the few present were targeted for fixed plot monitoring. Only scattered small patches occurred along cliff bases or on the sides of higher rock outcrops in areas with direct wave exposure. Where mussels occurred, they were limited to narrow bands along lower portions of the high tide level, just above the red algal turf zone. Individuals varied in size from about 5-15 cm, with larger individuals more common at the CABR sites, but all mussels appeared to be relatively old (size is not necessarily a good indicator of age in mussels). There was little evidence of recent recruitment in these sparse mussel populations.

Surveys conducted 17-30 yr ago indicate that mussels previously were much more common at Point Loma. Turner et al. (1968) surveyed a transect in CABR III and recorded "sea mussels (Mytilus californianus) and stalked barnacles (Pollicipes polymerus) formed large dense beds on the upper surfaces of the rocky outcrops...". Zedler (1976) inventoried CABR I and II and observed that mussels were "very common in large colonies, attached to large mid-tide rocks; smaller colonies found at base of cliff face". At Ocean Beach on northern Point Loma, Seapy and Littler $(1977,1978,1979)$ reported that mussels "blanket the horizontal areas and extend onto vertical surfaces". Kanter (1980), working at the same site, found 23 plant and 120 animal species associated with these beds. We visited the Ocean Beach site in Spring 1995 and found sparse mussel beds, more than at the Navy or CABR sites, but nowhere near covering the available shelf area. Clearly, the mussel beds and their associated flora and fauna present today on Point Loma are remnants of what were once extensive, diverse communities. The reason for this decline is unknown, but several sources of disturbance are possible factors. First, mussels are collected for food and bait. Second, tissues from mussels on Point Loma analyzed by federal and state Mussel Watch Program have shown some of the highest levels of silver found in mussels anywhere in the country (NOAA 1989; SWRCB 1989, 1995). Finally, mussel populations may have been adversely affected by the long-term seawater warming trend (since 1976; see Fig. 7). Roemmich and McGowan (1995) reported an 80\% decline in macrozooplankton biomass in southern California waters from 1951 to 1993; during the same time period, surface waters warmed by at least $1.5^{\circ} \mathrm{C}$. Filter-feeding mussels could be suffering from insufficient planktonic food, thermal stress, or some other condition related to warmer temperatures. Whatever the cause, the outcome appears to be impairment of reproduction or recruitment, since there is an obvious paucity of juveniles in the remaining mussel populations on Point Loma.

Stalked goose barnacles (Pollicipes polymerus) are conspicuous on upper intertidal waveswept shores where they form tight clusters on exposed outcrops, ridges, and walls, just above or intermixed with mussels. Like the mussels, goose barnacles were much less common than expected at Point Loma. Overall, they were rare at the Navy sites where they were mingled with the few mussels. They were present in slightly greater numbers at the CABR locations. Here they were not only found with mussels (mostly in CABR I), but also as a spotty narrow band higher up along the cliff base or on riprap (CABR III). All sizes were found at both Navy and CABR sites, including juveniles. Researchers who reported mussels to be common in the past at Point Loma also noted large numbers of goose barnacles (Turner et al. 1968; Zedler 1976; Seapy \& Littler 1977, 1978, 1979).

The middle intertidal zones at Point Loma are relatively flat benches covered by lowgrowing red algal turf. Previous work (Stewart 1982) has shown that a few low-growing plants, 
primarily the coralline algae Corallina vancouveriensis and $C$. pinnatifolia, dominate, but many other algal species (at least 67) occur as epiphytes on the anchor taxa, and numerous small invertebrates (more than 45 species, not counting sponges, worms, burrowing mollusks, ascidians, and minute forms $<5 \mathrm{~mm}$ ) inhabit the carpet-like thicket. Stewart (1982) also reported that the turf assemblage at the Cabrillo Tide Pools (CABR I) contained more weedy, short-lived species (e.g., the green leafy Ulva, the erect coralline Lithothrix), that at Ladera Street contained more Corallina species, and in La Jolla the gelatinous red alga Pterocladia capillacea becomes more prominent. In the current survey, turf assemblages were abundant at all Navy and CABR areas, but were most extensive in CABR II and III where the broadest mid-tidal reef flats occurred. The turf at NN and NS trapped less sand than that at CABR, and appeared to be slightly taller and healthier (less bleached). The stubbier, more stunted turf at CABR probably was influenced by a combination of sand scour, partial burial, and trampling by the many intertidal visitors. Stewart (1989b) found that the red algal turf at Point Loma was highly resistant to disturbance from sand movements and from desiccation; this likely applies to trampling as well.

Two key species, aggregating anemones (Anthopleura elegantissima) and sargassum weed (Sargassum muticum) occurred in low depressions within the algal turf zone and in tidepools and surge channels at Point Loma. Anemones were more common at the CABR sites where the larger flats drained more slowly, and more sand in the turf matrix appeared to retain more moisture. In addition to the larger solitary Anthopleura inhabiting wetter microhabitats, smaller clonal forms were present just above the turf zone, usually on the inshore sides of outcrops near sand pockets. These shelly-sand covered aggregations also were more common at CABR, where sand influence was slightly higher. The differences in appearance and microhabitat, combined with evidence of reproductive isolation led Francis (1979) to suggest that the 2 forms of A. elegantissima are not a single species, but instead represent a sibling species pair. The non-native sargassum weed was common at both the Navy and CABR sites. Some dense patches occurred in sheltered pools and on wet surfaces where breakout of rock slabs or overturned rocks had exposed bare substrate. Although Sargassum is an opportunistic "weedy" species that can quickly colonize bare spaces and unstable substrates, it is a poor competitor for space, thus in time native plants usually take over (Deysher \& Norton 1982).

Extensive meadows of surf grass (Phyllospadix torreyi) draped over much of the low intertidal zones at the Navy and CABR sites on Point Loma. The surf grass assemblage looked quite healthy at all sites, with dark green plants, typical epiphytes, and a rich variety of understory and infaunal organisms. Phyllospadix was particularly dense (often reaching $100 \%$ cover) on the flat offshore benches at the Navy sites, where waves splashed over the grass habitat even at low tide. At the CABR sites, the grass beds were generally less dense, more broken up by cobble and boulders overlying the outer reefs, and contained greater amounts of sand than those at NN and NS. The inshoremost grass patches at all areas were confined to tidepools, where the plants were shorter and often partially bleached. Surf grass beds are known to be highly productive ecosystems, providing structurally complex microhabitats for a rich variety of epiphytes, epibenthos, and infauna. Stewart and Myers (1980) identified 71 species of algae and 90 species of invertebrates associated with surf grass habitats in San Diego. Also, Phyllospadix beds provide nursery habitat for various fishes and invertebrates, including the California spiny lobster Panulirus interruptus (Engle 1979). Surf grass beds are persistent (Turner 1985) and can preempt space from other plants, including boa kelp (Black 1974) and sargassum weed (Deysher \& Norton 1982). Surf grass cannot tolerate much heat or drying; thus the shoreward extension of beds into the mid intertidal algal turf habitat is limited by physical factors (Stewart 1989a). 
The brown, strap-like boa kelp (Egregia menziezii) often intermingles with surf grass in low intertidal and shallow subtidal zones, where densely draping fronds provide protection from desiccation for understory plants and animals, as well as food for grazers such as isopods, kelp crabs, snails, and limpets (Humphrey 1965). However, boa kelp was uncommon at Point Loma during the 1995 baseline surveys. Egregia was quite rare at the Navy sites, where only the occasional weathered adult or fresh juvenile was encountered. It was found more often at the CABR sites, but far below the abundances recorded in prior year's monitoring. Transects set up in boa kelp habitats in 1980 now are dominated by surf grass in all 3 areas. Boa kelp is sensitive to desiccation and heat stress, as evidenced by catastrophic mortalities in La Jolla populations during the 1982-83 El Niño (Gunnill 1985). Similar observations of deterioration at CABR during the recent years of above normal sea temperature conditions (see Fig. 6) make it appear likely that the plants succumbed to heat stress. The presence of some juveniles indicates that recruitment is continuing, probably as a result of reproducing subtidal plants. If temperatures return to normal, recovery of decimated populations of boa kelp could occur in 1-2 yr due to relatively rapid growth rates (Murray \& Littler 1979; Vesco \& Gillard 1980).

Black abalone (Haliotis cracherodii) are ecologically important herbivores that cluster in wet crevices, under boulders, or on the walls of surge channels in mid-low intertidal habitats, where they feed primarily on drift kelp. These large mollusks are slow-growing and long-lived (>30 yr), with recruitment apparently low and variable (Morris et al. 1980; Van Blaricom 1993). Black abalone once were abundant in southern California, reaching densities $>100 / \mathrm{m}^{2}$ (Douros 1987; Richards \& Davis 1993); however, since the mid-80's populations have suffered catastrophic declines (associated with a mysterious "withering " syndrome) that have resulted in their nearly complete disappearance along mainland shores south of Point Conception (Davis \& Engle 1991; Miller \& Lawrenze-Miller 1993; Ambrose et al. 1995), as well as at the many of the Channel Islands (Lafferty \& Kuris 1993; Richards \& Davis 1993). No black abalone (live or shells) were found during the 1995 surveys at the Navy or CABR sites, nor at CABR from 199094. Historically, black abalone occurred at Point Loma; apparently they were common in some crevice habitats (R. Gladden, pers. comm.), but quantitative data are lacking. Turner et al. (1968) did not record black abalone along their 4 narrow transects. Zedler (1976) found individuals attached to bases and undersides of mid-tide rocks in CABR I and II. Seapy and Littler (1977, 1978, 1979) reported black abalone as present at Ocean Beach. Thus, despite suitable habitat, availability of drift kelp from offshore giant kelp beds, and evidence of prior occurrence, black abalone today appear to be extinct throughout this mainland region. Prospects for recovery are long-term at best, and may require transplants or other assistance programs.

Like black abalone, ochre sea stars (Pisaster ochraceus) are large, long-lived, ecologically important inhabitants of mid-low tide zones, whose populations in southern California have been decimated. Widespread mortality has resulted from a "wasting" disease, apparently caused by a warm-water bacterium of the genus Vibrio (Schroeter \& Dixon pers. comm.). Although a couple of specimens of a related sea star (the giant-spined Pisaster giganteus) were found at the Navy sites, no ochre sea stars have been found anywhere at the Navy or CABR sites in 1995, or at CABR sites from 1990-1994. P. ochraceus was not reported by Turner et al. (1968) along their 4 Point Loma transects, nor by Seapy and Littler (1977, 1978, 1979) at Ocean Beach. Zedler (1976) recorded a few individuals from the base of large musselcovered rocks in CABR I and II. Despite the paucity of past records, it is likely that ochre sea stars were present all along the rocky shores of Point Loma, in association with mussels, their chief food. Interestingly, the mussel beds at Point Loma are in drastic decline even though a major predator, the ochre sea star, is absent from the system. 


\subsection{Temporal variation}

The condition of intertidal resources at any one time reflects the result of complex biological responses to the physical environment as well as interactions among the diverse plants and animals in the ecosystem. Because physical and biological influences are ever changing, adequate baseline surveys must monitor the system at appropriate time intervals and evaluate resource dynamics with respect to our increasing knowledge of the effects of environmental variations on rocky intertidal species distribution and abundance. Temporal environmental variations may be short-term or long-term, natural or human-influenced, cyclical or unpredictable, or minor perturbations versus catastrophic disturbances. This $1 \mathrm{yr}$ study can only begin to evaluate temporal variations in rocky intertidal life at the Fort Rosecrans Military Reservation, based on 2 seasonal surveys and information gained from related intertidal work, especially the $6 \mathrm{yr}$ of semi-annual monitoring of index taxa at CABR.

Short-term environmental changes include fairly predictable as well as unforseen variations in tidal exposure, water and air temperature, light level, wave height, sand movement, and other conditions. Important seasonal changes include the occurrence of midday low tides, colder water, more storms, and less sand influence in Winter compared to Summer. If the lowest low tides that occur during midday hours from November to March coincide with warm air temperatures and low humidity conditions (as is likely this time of year in San Diego), then heat and desiccation stress can injure or kill sensitive species (Littler 1980; Gunnill 1980a; Stewart 1989a). Major die-offs are possible during Santa Anas, when extremely hot, dry winds blow offshore from the desert. Colder water may stress species adapted to warm conditions, while higher nutrient levels associated with cooler temperatures can enhance productivity and growth throughout the food web. Storm swells may tear plants and animals loose from the soft sandstone substrate (or break out entire rock layers), causing patchy or extensive mortality. Loss of cover may free up space that will be colonized temporarily at least by opportunistic species (Littler \& Seapy 1979). Heavy surf, usually from W/NW swells in Winter, also removes sand from the intertidal, which is returned gradually during calmer periods, most often in the Summer months (Stewart 1983, 1989a).

Less is known about ecosystem responses to environmental variability over time scales of years to decades or more, because relatively few long-term intertidal databases exist. Daily surface water temperatures taken at the Scripps Institution of Oceanography pier (La Jolla) since 1920 reveal remarkable long-term trends (see Fig. 7). Notably, the 32-yr period from 1944-1975 was characterized by cooler than average temperatures, except for the 1957-1959 El Niño years. In contrast, the 20 -yr period from 1976 to the present has been warmer than the 75 -yr mean, except for a few normal or cool years. This 20 -yr warming trend includes several El Niño episodes, such as the major 1982-83 event, in which a combination of severe storms, high temperatures, and low nutrients caused dramatic changes in marine ecosystems (Gunnill 1985; Tegner \& Dayton 1987; Seymour et al. 1989; Engle 1994). Long-term warming has been associated with northward shifts in the ranges of southern species (Barry et al. 1995) and with dramatic declines in the abundance of zooplankton in southern California (Roemmich \& McGowan 1995). The insight gained from these long-term perspectives of oceanographic conditions is that the species assemblages found in rocky intertidal habitats at Point Loma in 1995 likely reflect the cumulative effects of two decades of warm-water conditions.

Comparison of S95 versus F95 abundance data for the index taxa surveyed at NN and NS revealed only relatively minor changes in cover or density, which for the most part probably 
reflect variability inherent in the sampling techniques. This lack of change is not surprising because the sites were only surveyed twice, and most of the index taxa are long-lived dominants that would not be expected to show dramatic short-term fluctuations in abundance under normal circumstances. The most pronounced seasonality was noted in the upper intertidal zone, especially at NN, where opportunistic algae (e.g., blue greens, Ulva, Enteromorpha, Scytosiphon) were common or abundant in S95, but only present or rare in F95. This "blooming" of the upper intertidal, creating slippery surfaces, was noted regularly during Spring surveys at CABR in 1990-1995, and in past surveys at Ocean Beach (Seapy \& Littler 1977, 1978, 1979). The quickly-growing, ephemeral algae probably are able to survive at this high tide level in Winter/Spring because the rocks are dampened by greater surf splash and nutrient-rich freshwater seeps.

Other seasonal changes were noted at the Navy sites during the qualitative reconnaissance surveys. The red "worm" alga, Nemalion helminthoides, was present only in S95. Sargassum weed was shorter in F95 $(10-20 \mathrm{~cm})$ versus S95 $(30-100 \mathrm{~cm})$, because it dies back in Summer after reproduction (Gunnill 1980a; Deysher \& Norton 1982). On the other hand, the brown alga Halidrys dioica was larger in the Fall than in Spring; it dies back later in the year than Sargassum. Bleaching of red algal turf and surf grass plants within the uppermost portions of their respective zones was relatively minor overall, but more prevalent in S95. Bleaching in marine plants is a common sign of stress, in this case, due to desiccation or excessive heat from aerial exposure during warm, dry midday hours. This phenomenon most often occurs during November-March (Gunnill 1980a, 1985; Stewart 1989a). Plant bleaching often was noted during the Spring monitoring surveys at CABR, but the extent of it varied each year. Exposed boa kelp there was sensitive to bleaching, which varied more with current weather conditions than with season of the year.

The 6-yr monitoring program at CABR provides additional information on seasonality not evident at the Navy sites in 1995. Surf grass, in particular, showed a cyclical pattern of Spring declines and Fall increases in cover. Others also have reported this seasonality (e.g., Stewart 1989a for Ladera Street; Ambrose et al. 1995 for sites in Santa Barbara County), which can result not only from aerial exposure stress, but also from storm wave losses (Stewart 1989a). Vegetative regrowth via rhizome mats can replace lost plants relatively rapidly if the disturbance was not too extensive. Rockweed sometimes appeared sparser and more tattered in Spring periods at CABR, but the seasonality was not consistent. In Santa Barbara County, rockweed cover typically was lower in Spring, most likely due to winter storms tearing out some plants (Ambrose et al. 1995). Gunnill (1983) described seasonal variations in the invertebrate assemblage under rockweed cover. Species composition changed coincidentally with changes in water temperature, tidal exposure, and wave height. The surf grass and algal turf habitats can experience seasonal fluctuations in the amount of sand covering the plant bases. Sand levels varied some in these habitats at CABR, but not in a particular Spring/Fall pattern. The pattern may be more like Summer/Winter, as sand levels increase during calm periods (usually Summer) and decrease during stormy weather (usually Winter) (Stewart 1983, 1989a). Despite sand level variations, Stewart \& Meyers (1980) found no consistent seasonal fluctuations in occurrences or abundances of the flora and fauna within the surf grass community, and Stewart (1982) reported no change in the number of epiphyte species with season in turf habitats.

The 1990-1995 monitoring program at CABR also gives insight into long-term trends in index taxa abundances that should be applicable to the rocky intertidal communities at Fort Rosecrans. Over the 6-yr period, 2 key species populations (rockweed and red algal turf) 
remained fairly stabile, 1 (surf grass) increased, 3 declined moderately (pink thatched barnacles, goose barnacles, and owl limpets), and 2 declined drastically (boa kelp and mussels). In addition, 2 key species once present at CABR (black abalone and ochre sea stars) disappeared completely and mussels declined dramatically some time before the CABR monitoring began in 1990 . The dynamic trends in most of these index species populations demonstrate the value of long-term monitoring in assessing the changing "baseline" condition of intertidal resources. However, the fact that 7 of these 10 key species have either declined significantly (presumably along with their associated flora and fauna) or remain absent from the CABR ecosystem is cause for concern. The reasons for these changes are not easily discerned. For example, black abalone and ochre sea star losses may be associated with disease agents (see above for discussion); if so, why have these diseases been so catastrophic in recent years? Causative factors for any of the above index species changes may be due to natural phenomena or human impacts (e.g., pollution, collecting activities) or some combination of both. It is possible that at least some of the key species trends are linked directly or indirectly to the remarkable 20-yr trend of warmer than normal seawater temperatures (see Fig. 7), a condition especially evident during the past 6 years (see Fig. 6), and one that may have changed the species composition of intertidal communities in Monterey (Barry et al. 1995) and decimated zooplankton populations in southern California (Roemmich \& McGowan 1995). Is this warm-water pattern part of some long-term natural cycle or evidence of global warming? Clearly, directed research is needed to address these critical issues. Continued monitoring of rocky intertidal index taxa at CABR and Navy sites on Point Loma, as well as elsewhere at representative locations throughout southern California, is vital to assessing future trends in rocky intertidal ecosystems in order to provide the quantitative temporal data necessary for designing appropriate research programs and implementing practical resource management plans.

\subsection{Human impacts}

Impacts from human activities on rocky intertidal ecosystems may be caused by various types of pollution from point sources (e.g., outfalls, vessel spills) and non-point sources (e.g., storm runoff, aerial fallout), drift debris washing ashore, and visitor activities including collecting, trampling, or disturbing marine life (see Ghazanshahi et al. 1983; Foster et al. 1988; Anderson et al. 1993 for reviews). Little obvious evidence of human impacts was noted during the limited baseline surveys at the Navy sites in 1995 (mainly upper beach debris including balls of fishing line, a few tar spots, and several visitors). This should not lead one to conclude that impacts are not occurring; it simply means that this study was not extensive enough to address the complex task of distinguishing human effects from natural variation. In fact, the location of Point Loma within a large metropolitan area next to a major harbor, and with shoreside development, offshore shipping, and a municipal outfall nearby, guarantees that human activities are impacting intertidal communities, but the level of impact is difficult to determine. Impacts may range from single events affecting one location (e.g., a shipwreck on the beach) to chronic (but often low level), widespread conditions (e.g., trace metal contamination) that may-show little short-term effect, but cause significant cumulative effects over many years or decades. For example, Widdowson (1971) resurveyed intertidal transects in the Los Angeles area that had been originally sampled by Dawson (1965) in 1956-1959, and found widespread declines in algal diversity that were attributed to human usage, air pollution, and water contamination. Thom and Widdowson (1978) expanded these resurveys throughout southern California $15 \mathrm{yr}$ after Dawson's initial characterizations, and discovered general shifts in the flora away from massive 
species and toward turf and crustose species. These intertidal community changes were most evident at stations located in heavily-populated metropolitan areas or in public parks with heavy recreational use. With these concepts in mind, the discussion below will briefly consider ecological issues relating to likely impacts affecting Point Loma intertidal communities and the measures that might be taken to minimize these impacts.

When considering intertidal impacts, catastrophic point-source events, especially massive oil spills, have received much attention. Oil spills can greatly impact intertidal habitats because floating components wash ashore and coat intertidal life with greasy films and tar that can result in widespread mortality. Oil and other chemical spills are a major concern at Point Loma due to the heavy ship traffic associated with the harbor. The literature on biological effects of oil spills is extensive (see Foster et al. 1988 for review) and complex because variables such as volume and type of oil, duration of exposure, hydrographic conditions, weather, season, etc. all influence spill impact. Overall, the greatest impacts may result when the oil contacts sensitive species that are long-lived community dominants. For example, the extensive beds of surf grass at Point Loma are known to be sensitive to oiling (Foster et al 1971), support a diverse species assemblage (Stewart \& Meyers 1980), and provide critical nursery habitat for spiny lobsters (Engle 1979). Loss of these grass beds from an oil spill or other impact would greatly alter the rocky intertidal ecosystem, with recovery probably slow at best. There is no way to fully protect open-coast resources from oil spills; however, the best approach is to adopt procedures to minimize their occurrence, and develop rapid-response capabilities for containing the spill and cleaning it up without compounding the ecological impacts.

Another source of pollution at Point Loma is the San Diego Wastewater Treatment Plant outfall, located $7.2 \mathrm{~km}$ (4 km prior to Nov 1994) offshore from the southern end of NS, that has been in operation since 1963. Municipal discharges are the principal source of most marine pollutants in California (Anderson et al. 1993). Each day, many hundred-million liters of partially treated commercial and residential sewage are discharged from the Point Loma outfall, including such materials as human fecal wastes, oils and greases, chemicals such as trace metals and synthetic organic compounds, and particulates that increase turbidity and siltation. Though released far offshore, currents may distribute dissolved/suspended materials widely, and accidental spills can occur. In February 1992, a catastrophic rupture occurred in the undersea pipeline $1 \mathrm{~km}$ offshore in $11 \mathrm{~m}$ water depth, releasing approximately 680 million liters of sewage effluent per day for 2 mo. Bacteriological monitoring indicated that contaminated water was reaching Point Loma's intertidal shores. Post-spill surveys at the CABR sites revealed no catastrophic impacts among the index species; however, there was increased cover of opportunistic algae and diatoms, more silt in turf habitats, and a light brown scum that floated ashore. Apparently the main impact of this spill was the addition of dissolved organics to the intertidal zone, which produced a temporary bloom of ephemeral plants on the upper shore. Possible low-level impacts were not assessed. Littler and Murray (1975) monitored the effects of a small outfall at San Clemente Island that discharged untreated sewage directly onto the intertidal zone. Ecological changes in the local ecosystem included reduced species diversity and community complexity. The reduced complexity was due primarily to the absence of surf grass, boa kelp, and two other brown algae (Halidrys dioica and Sargassum agardhianum). These species were replaced by rapidly-growing, opportunistic colonizers ("weed" species). Impacted habitats compared to unaffected areas had less plant cover and more invertebrates in the lower intertidal, but more plants and fewer invertebrates in the upper intertidal. 
Various small outfall pipes along the Fort Rosecrans and CABR shore project out from the bluffs and open directly onto the intertidal zone. Apparently some originate from onshore facilities and some are storm drains. There was no evidence of flow through these pipes during the field surveys. Any contaminated discharge through these pipes could seriously impact intertidal life. This includes stormwater runoff that may contain pollutants as well as sediment and debris that could smother, scour, or smash organisms on the rocks below. These possible outfalls should be investigated to determine whether they are functioning at any time. If discharges do occur, then effluent samples should be analyzed periodically for water quality conditions. If effluent water quality exceeds acceptable standards, then measures should be taken to eliminate or minimize such discharges.

Compared to conspicuous point source spills, less attention has been focused on nonpoint source impacts, such as wide-ranging seawater contaminants, that often are invisible and at sublethal levels, but chronic in nature and cumulative in effect. If point source pollutants are dispersed, they become non-point sources; therefore, along Point Loma shores, the San Diego Harbor, various wastewater discharges (from shore or ships), storm/river runoff, and aerial fallout all contribute to this generally less conspicuous pollution. Dissolved and floating substances may be carried great distances by ocean currents, as evidenced by periodic contamination of San Diego beaches from Tijuana River outflows. Some chemical contaminants (e.g., inorganic trace metals, synthetic organic compounds) are especially persistent and toxic. The Southern California Coastal Water Research Project has monitored seasonal storm water runoff in the Los Angeles area and found high levels of contaminants such as oil and grease, zinc, lead, and copper (Anderson et al. 1993).

Both the State (SWRCB 1995) and Federal Government (NOAA 1989) run Mussel Watch Programs in which tissue samples from mussels in representative locations are analyzed periodically for various chemical contaminants which they bioaccumulate. The State program includes two sites on Point Loma (Sunset Cliffs and CABR II), and the Federal program monitors one site at the Point Loma Lighthouse (CABR III). Since 1988, mussels at both State sites consistently have contained unusually high concentrations of copper and silver and occasionally high levels of zinc. A status report (SWRCB 1989) stated "the Point Loma shore has silver levels in mussels among the highest levels measured in the State. A gradient of silver stretching from Point Loma has been measured up to $100 \mathrm{~km}$ into northern Baja California. Silver is extremely toxic and hazardous to marine life, raising concerns about the long-term effects of this municipal waster discharge on near-coastal waters". A similar report for the years 1986-1988 of the Federal program found that concentrations of silver in Point Loma mussels were the second highest levels of any site in the country. The source of this silver has not been determined. The San Diego Wastewater Treatment Plant outfall discharges silver, but the mass emissions are not unusually high for a major outfall. Since silver is known to be toxic and mussel populations at Point Loma have declined drastically (the remnant populations are composed primarily of older mussels, presumably carrying heavy silver loads), it should be a high priority to determine the source of the contamination and take measures to minimize or eliminate it.

Another non-point pollution source is runoff from the land during the rainy season, which can carry with it various chemicals (oil and grease, pesticides, herbicides, organic matter, etc.) as well as suspended sediments. Point Loma intertidal habitats located below canyons, drainage channels, or storm drain pipes will be affected by the runoff. Freshwater can stress or kill many marine species (Littler \& Littler 1987) and chemicals have various, perhaps more subtle impacts depending on their nature and concentration. Erosion and landslides from the poorly- 
consolidated bluffs can cause major siltation of reefs, which could smother or scour the biota and clog the filtering mechanisms of suspension-feeding invertebrates. These types of disturbances generally lead to less diverse intertidal communities in which relatively few stress-tolerant and opportunistic species dominate (Seapy \& Littler 1982; Littler et al. 1983). To minimize impacts from storm runoff and erosion, efforts should be made to remove landside sources of contaminants and to institute erosion control where practical, keeping in mind that erosion also is a natural (and inevitable) process along the Point Loma bluffs. Future development activities should be planned to minimize runoff of pollutants or sediments onto intertidal habitats.

Beach debris is evident along Point Loma shores. Driftwood, lobster traps, shipwreck junk, ropes, bottles, cans, styrofoam, fishing line, etc. were all observed frequently during the Navy or various CABR surveys. Hard materials washed ashore by wave action can abrade, smash, or dislodge intertidal plants and animals. These physical disturbances can be repeated periodically as high tides or storm swells refloat and rearrange the debris. Also, birds and mammals may ingest or become entangled in certain types of litter. The beach debris impacts at Point Loma could be minimized by education and enforcement programs to reduce sources of litter, and by sponsoring beach clean-up events to remove anthropogenic debris from the shore.

Recreational use of rocky shores creates primarily physical impacts on intertidal life. Visitor activities can include littering, trampling, disturbing (e.g., turning over rocks, poking at anemones, moving animals, frightening birds), and specimen collecting (see Ghazanshahi et al. 1983 for review). These activities vary depending on such factors as ease of shore access, time of low tide, and weather conditions. Recreational use impacts often are difficult to quantify, but even low levels of public use, continued for years or decades, can result in major changes in intertidal communities (see Widdowson 1971; Thom \& Widdowson 1978). Chan (1970) reported lower abundances of mussels, anemones, snails, and sea stars at Duxbury Reef (just north of San Francisco), where visitation levels were high. Zedler (1976) compared areas varying in degree of human use at CABR and found lower abundances of coralline algae, sand castle worms, and limpets in more heavily-visited habitats. In experiments with turning over rocks at CABR, species diversity of exposed invertebrates declined rapidly after 2 weeks, and opportunistic green algae invaded by 4 weeks (Zedler 1978). In trampled algal turf mats, the more brittle species of erect coralline algae were most impacted, with recovery estimated to take 1-2 yr (Zedler 1978). Beachamp and Gowing (1982) found lower densities and species diversity on more trampled reefs in Santa Cruz. A rockweed (Pelvetiopsis) was absent on the most trampled reef. Engle (unpublished data) experimentally trampled barnacle, rockweed, turfweed, and mussel plots at Santa Catalina Island. All species were greatly diminished by heavy trampling, but turfweed and barnacles recovered fairly rapidly $(0.5-2 \mathrm{yr})$, rockweed more slowly (6-8 yr), and mussels still had not fully recovered after $12 \mathrm{yr}$.

Compared to CABR, where visitors are encouraged, the Fort Rosecrans rocky shores are relatively inaccessible to the public due to military restrictions and difficult access. Only 2 people were seen at NN and NS during the 1995 surveys, whereas hundreds were present at the CABR sites each low-tide day. However, recreational use impacts likely occur along the Fort Rosecrans coast despite low visitation levels because it takes only a few avid collectors (operating legally or illegally) to affect populations of highly desired species. Mussels, limpets, turban snails, goose barnacles, and some algae are targeted for food. Mussels and shore crabs are popular as fish bait. Sea stars and shells (often containing hermit crabs) are collected for souvenirs. Though little studied, continued (even low-level) removal of these ecologically important (and often long-lived) species extended over years or decades may result in critical 
changes in intertidal communities. The CABR reefs are protected from collecting, but even there the rangers occasionally caught people carrying burlap bags filled with hundreds of owl limpets. Comparison of owl limpet size-frequencies in the protected area of CABR versus unprotected areas at Sunset Cliffs (Zedler 1978) and at NN/NS (this 1995 study) found that large limpets are missing in the locations where collecting can occur. The most probable conclusion is that over the years, collectors have preferentially removed the largest limpets from the Point Loma shores, except for CABR. Since the largest owl limpets are females (Wright \& Lindberg 1982), reproduction in the non-protected populations may be impaired. The fact that these two studies carried out $18 \mathrm{yr}$ apart produced the same results indicates the long-term nature of continuous collecting impacts.

Based on the above discussion, it is clear that many more people visit the CABR rocky intertidal shore compared to the poorly accessible Fort Rosecrans shore. It is logical then that most visitor impacts occur at CABR, except that collecting is prohibited at CABR, while game taking (both legal and illegal) occurs to some unknown extent along the rest of the Point Loma coast. In order to minimize public use impacts at Point Loma, educational programs for both public visitors and military personnel should be promoted, existing California Department of Fish and Game regulation enforcement increased, further research on ecological conditions encouraged, and development of a resource management plan for the entire Point Loma coastal system considered. One option for this plan would be to develop a zonal management scheme in which some intertidal areas are open to public visitation, some partially restricted, and others left in an undisturbed "natural" state. Educational programs could be emphasized and rules to minimize impacts implemented in the easily-accessible public use areas, such as at CABR. No game-taking would be allowed. Public visitation of light use areas could be on a "discover" basis, and some game taking allowed, consistent with Fish and Game regulations. Finally, visitation in the natural areas would be discouraged and no game take allowed. These non-use areas could serve as scientific "control" locations for evaluating natural ecosystem dynamics and would provide a source of recruits for the other more disturbed areas. Monitoring of key resources in all three types of management areas would be essential for evaluating the dynamics of natural and human use ecosystems. Experimental ecology studies would be needed as well. Intertidal ecologists often have avoided working at Point Loma due to security restrictions, access problems, and limitations on experimental manipulations. Renewed emphasis should be placed on making it easier for intertidal research to be conducted at Point Loma so everyone can benefit from increased understanding of the ecological inter-relationships and value of this important land/water interface ecosystem. 


\section{Conclusions}

Based on the results of Spring and Fall 1996 baseline surveys at 2 rocky intertidal sites within the Fort Rosecrans Military Reservation, comparisons with related shore surveys, and review of relevant ecological literature, we present the following conclusions regarding factors important to the structure and function of these rocky coast ecosystems at Point Loma, and management recommendations for protecting, enhancing, and minimizing future impacts to these valuable resources:

1) Rocky intertidal habitats at Point Loma support highly productive, species-rich communities that are among the most extensive in San Diego County. The diversity and abundance of intertidal life is determined primarily by the physical environment, which includes gently-sloping sandstone reefs and talus rubble backed by high, erodable cliffs and bathed by relatively warm, nutrient-rich waters. The most extensive resources are found on the broadest benches on irregular shorelines; these provide a variety of wave exposure conditions and numerous microhabitats supporting diverse plants and animals.

2) The major intertidal zones include an upper steeply-sloping zone characterized by ephemeral and crustose algae and small grazers, a middle mostly flat zone carpeted by turf algae with cryptic infauna, and a low gradually-sloping zone draped with surf grass with associated flora and fauna. Key dominant species structuring intertidal assemblages included rockweed, sargassum weed, red turf, coralline crusts, surf grass, barnacles, limpets, top snails, and chitons. Ecologically-important species that were notably rare or absent included boa kelp, goose barnacles, black abalone, mussels, sea stars, and sea urchins.

3) Important sources of natural disturbance to Point Loma intertidal life include waveinduced flaking or fragmentation of the poorly-consolidated substrate, winter storm swells, chance combinations of midday low tides with hot, dry winds, and changing oceanographic conditions associated with continuation of a long-term warming trend in southern California waters.

4) Comparison of current conditions at the Navy sites with 1990-1995 monitoring data from 3 generally similar CABR sites confirms that considerable changes in key species abundances have occurred prior to 1995. Declines in 5 of the index species (boa kelp, pinkthatched barnacles, goose barnacles, owl limpets, and mussels) at CABR and continued absence of historically-resident black abalone and sea stars raises important questions about causality and the role of natural environmental change versus human impacts on the Point Loma intertidal ecosystem.

5) Few obvious human impacts were documented at either Navy or CABR sites during these limited 1995 surveys; however, the likelihood is great that their location within a large metropolitan area next to a harbor, shipping lanes, municipal outfall, and shoreside development has lead to various acute or chronic impacts. Known impacts include effects from a 1992 sewage spill, chemical contamination of mussels, presence of beach debris, and public use activities, including trampling, disturbing, and specimen collecting. Suspected impacts include chemical contamination from the sewage outfall, ship discharges, outflows from the San Diego Harbor and Tijuana River, and shoreside runoff during rainstorms. Concerns exist for potential impacts from major oil or chemical spills, increased erosion and siltation from shoreside development, and increased public use. Loss of pollution-sensitive intertidal resources, such as the extensive, highly productive, and species-rich surf grass beds would greatly reduce the fundamental structure, function, and value of Point Loma intertidal ecosystems. 
6) Compared to CABR, where visitors are encouraged, the Navy rocky shores are relatively inaccessible to the public due to military restrictions and difficult access. However, the Navy coast is not protected from collecting activities, and continued, even low-level take is known to affect populations of highly-desired species. Collecting pressure apparently has removed the larger, mostly female owl limpets from Point Loma, except for protected habitats at CABR.

7) Measures to minimize the threat to Point Loma shores from external pollutants require cooperative efforts among various agencies. Goals should include identification of pollution sources (e.g., the source of silver contaminating mussels), adoption of procedures to reduce ongoing or accidental chemical releases, and development of rapid-response capabilities for containing spills and removing or detoxifying contaminants without compounding shore impacts. Actual and potential sources of contaminants on Navy property (e.g., outfall pipes, trash dumps, storage facilities) should be identified and investigated. Storm runoff patterns should be evaluated, with emphasis on reducing sediment runoff (especially during construction activities) and bluff erosion wherever possible. Beach debris impacts at Point Loma could be minimized by controlling sources and sponsoring beach clean-up events.

8) Public use and resource management issues at Point Loma could best be addressed through the development of a peninsula-wide intertidal Resource Management Plan. One option is a zonal management approach in which some beaches are open to public visitation, some partially restricted, and others left in an undisturbed "natural" state. Low-impact observation and education could be emphasized in the easily-accessible visitation areas, such as at CABR. Exploration of less-accessible light-use areas (limited game take allowed) could be on a "discover" basis. Finally, visitation in natural areas would be discouraged and no game take allowed. These "control" areas would permit evaluation of relatively undisturbed resource dynamics and could provide recruits for the other more disturbed areas.

9) Periodic monitoring of key resources is essential for updated resource evaluation and management efforts. It is strongly recommended that semi-annual surveys of changing baseline conditions in index species populations be continued at the Navy and CABR sites. The benefits of this low-cost approach to assessing short- and long-term ecological variations can be seen clearly in the results of the $6 \mathrm{yr}$ monitoring program at CABR, where 7 of 10 key species either declined or remained absent.

10) Experimental rocky intertidal studies also should be encouraged. Ecologists often have avoided working at Point Loma due to security restrictions and difficult access. Emphasis should be placed on making it easier for intertidal research to be conducted at Point Loma so everyone can benefit from increased understanding of the ecological inter-relationships and value of this important land/water interface ecosystem.

\section{Acknowledgments}

Special thanks to the U.S. Navy, especially William Fisher, for assistance in initiating this project, and to the Cabrillo National Monument for providing field equipment and logistical support. Valuable help in the field was provided by Mark Conlin, Robert Duran, Robert Gladden, Constance Gramlich, Daniel Heilprin, David Hubbard, Robin Lewis, Daniel Martin, Cynthia Taylor, Valorie Vucich, and Samatha Weber. David Farrar, David Hubbard, Daniel Martin, and Melissa Wilson assisted in the data analysis and report preparation. This research was funded by the Naval Facilities Engineering Command, Department of Defense Legacy Program. 


\section{References}

Abbott, I.A. and G.J. Hollenberg. 1976. Marine algae of California. Stanford University Press, Stanford, California. 827 p.

Ambrose, R.F., J.M. Engle, P.T. Raimondi, M. Wilson and J. Altstatt. 1995. Rocky intertidal and subtidal resources: Santa Barbara County mainland. Final Report, OCS Study MMS 950067, U.S. Minerals Management Service, Pacific OCS Region. 172 p.

Anderson, J.W., D.J. Reish, R.B. Spies, M.E.Brady and E.W. Segelhorst. 1993. Human impacts. Chapter 12, pp. 682-766 in Dailey, M.D., D.J. Reish and J.W. Anderson (eds). Ecology of the Southern California Bight, University of California Press, Los Angeles, California.

Barry, J.P., C.H. Baxter, R.D. Sagarin and S.E. Gilman. 1995. Climate-related, long-term faunal changes in a California rocky intertidal community. Science 267:672-675.

Beauchamp, K.A. and M.M. Gowing. 1982. A quantitative assessment of human trampling effects on a rocky intertidal community. Mar. Environ. Res. 7:279-93.

Black, R. 1974. Some biological interactions affecting intertidal populations of the kelp Egregia laevigata. Mar. Biol. 28:189-98.

Black, R. 1976. The effects of grazing by the limpet, Acmaea incessa, on the kelp, Egregia laevigata, in the intertidal zone. Ecology 57: 265-77.

Chan, G.L. 1973. A study of the effects of the San Francisco oil spill on marine organisms. Pp 741-782 in Proceedings of joint conference on prevention and control of oil spills. American Petroleum Institute, Washington, D.C.

Davis, G.E. and J.M. Engle. 1991. Ecological condition and public use of the Cabrillo National Monument, San Diego, California. National Park Service Tech. Rep. NPS/WRUC/NRTR 92/45. 33 p.

Dawson, E.Y. 1965. Intertidal algae. In An oceanographic and biological survey of the southern California mainland shelf. Publs. Calif. St. Wat. Qual. Contr. Bd. 27:220-31, 351-438.

Dawson, E.Y. and M.S. Foster. 1982. Seashore plants of California. University of California Press, Los Angeles, California. 226 p.

Dayton, P.K. 1971. Competition, disturbance and community organization: the provision and subsequent utilization of space in a rocky intertidal community. Ecol. Monogr. 41:35189.

Deysher, L. and T.A. Norton. 1982. Dispersal and colonization in Sargassum muticum (Yendo) Fensholt. J. Exp. Mar. Biol. Ecol. 56: 179-95.

Douros, W.J. 1987. Stacking behavior of an intertidal abalone: an adaptive response or a consequence of space limitation? J. Exp. Mar. Biol. Ecol. 108:1-14. 
Engle, J.M. 1979. Ecology and growth of juvenile California spiny lobster, Panulirus interruptus (Randall). Ph.D. Dissertation, University of Southern California. 298 p.

Engle, J.M. 1992. Rocky intertidal resource monitoring at the Cabrillo National Monument, San Diego, two months after cessation of the Point Loma Wastewater Plant undersea pipeline sewage spill. Report to the San Diego Water Utilities Department, San Diego, CA. 59 p.

Engle, J.M. 1994. Perspectives on the structure and dynamics of nearshore marine assemblages of the California Channel Islands. In: Fourth California Islands Symposium: Update on the Status of Resources (W.L. Halvorson, ed.), Santa Barbara Museum of Natural History. pp. 13-26.

Engle, J.M and G.E. Davis. 1996a. A handbook for monitoring ecological conditions and public use in the intertidal zone of Cabrillo National Monument, San Diego, California. National Biological Service, Ventura CA.

Engle, J.M and G.E. Davis. 1996b. Rocky intertidal ecological monitoring at Cabrillo National Monument, San Diego, California: 1990-1995. National Biological Service, Ventura CA.

Engle, J.M., J.M. Altstatt, P.T. Raimondi and R.F. Ambrose. 1994a. Rocky intertidal monitoring handbook for inventory of intertidal resources in Santa Barbara County. Report to the U.S. Minerals Management Service, Pacific OCS Region. 92 p.

Engle, J.M., L. Gorodezky, K.D. Lafferty, R.F. Ambrose and P.T. Raimondi,. 1994b. First year study plan for inventory of coastal ecological resources of the northern Channel Islands and Ventura/Los Angeles Counties. Report to the California Coastal Commission. 31 p.

Foster, M., M. Neushul and R. Zingmark. 1971. The Santa Barbara oil spill. Part 2. Initial effects on intertidal and kelp bed organisms. Environ. Pollut. 2:115-34.

Foster, M.S., A.P. DeVogelaere, C. Harrold. J.S. Pearse and A.B. Thum. 1988. Causes of spatial and temporal patterns in rocky intertidal communities of Central and Northern California. Memoirs of the California Academy of Sciences \#9, San Francisco, California. 45 p.

Ghazanshahi, J., T.D. Huchel and J. S. Devinny. 1983. Alteration of southern California rocky shore ecosystems by public recreational use. J. Environ. Manag. 16:379-94.

Glynn, P.W. 1965. Community composition, structure, and interrelationships in the marine intertidal Endocladia muricata - Balanus glandula association in Monterey Bay, California. Beaufortia 12:1-198.

Gunnill, F.C. 1980a. Recruitment and standing stocks in populations of one green alga and five brown algae in the intertidal zone near La Jolla, California during 1973-1977. Mar. Ecol. Prog. Ser. 3:231-43.

Gunnill, F.C. 1980b. Demography of the intertidal brown alga Pelvetia fastigiata in southern California, USA. Mar. Biol. 59:169-79. 
Gunnill, F.C. 1983. Seasonal variations in the invertebrate faunas of Pelvetia fastigiata (Fucaceae): effects of plant size and distribution. Mar. Biol. 73:115-130.

Gunnill. F.C. 1985. Population fluctuations of seven macroalgae in southern California during 1981-1983 including effects of severe storms and an El Niño. J. Exp. Mar. Biol. Ecol. 85: 149-64.

Hill, M.L. 1980. Structure, organization and persistence of the Pelvetia fastigiata (Phaeophyceae: Fucales) community on a rocky intertidal shoreline at Dana Point, Orange County, California. Master's Thesis, California State University, Fullerton, California. $116 \mathrm{p}$.

Hines, A.H. 1978. Reproduction in three species of intertidal barnacles from central California. Biol. Bull. 154:262-81.

Humphrey, A.E. 1965. The fauna of the seaweed Egregia laevigata at Santa Barbara, California. M.A. Thesis, University of California, Santa Barbara. 30 p.

Kanter, R.G. 1980. Biogeographic patterns in mussel community distribution from the southern California Bight. Pp. 341-355 in The California Islands: proceedings of a multidisciplinary symposium. D.M. Power, ed. Santa Barbara Museum of Natural History, Santa Barbara, California.

Kinnetics Laboratories, Inc. 1992. Study of the rocky intertidal communities of Central and Northern California. Report to the Minerals Management Service. OCS Study MMS 910089.

Kozloff, E.N. 1993. Seashore life of the northern Pacific coast. University of Washington Press, Seattle. 370 p.

Lafferty, K.D. and A.M. Kuris. 1993. Mass mortality of abalone Haliotis cracherodii on the California Channel Islands: tests of epidemiological hypotheses. Mar. Ecol. Prog. Ser. 96:239-48.

Leet, W.S., C.M. Dewees and C.W. Haugen., eds. 1992. California's living marine resources and their utilization. California Sea Grant Extension Publication UCSGEP-92-12. 257 p.

Littler, M.M. 1980. Overview of the rocky intertidal systems of southern California. In: The California Islands: Proceedings of a Multidisciplinary Symposium (edited by D.M. Power), Santa Barbara Museum of Natural History, Santa Barbara. pp. 265-306.

Littler, M.M. and D.S. Littler. 1987. Effects of stochastic processes on rocky intertidal biotas: An unusual flash flood near Corona del Mar, California. Bull. South. Calif. Acad. Sci. 86:95106.

Littler, M.M., D.R. Martz and D.S. Littler. 1983. Effects of recurrent sand deposition on rocky intertidal organisms: importance of substrate heterogeneity in a fluctuating environment. Mar. Ecol. Prog. Ser. 11:129-39. 
Littler, M.M. and S.N. Murray. 1975. Impact of sewage on the distribution, abundance, and community structure of rocky intertidal macro-organisms. Mar. Biol. 30: 277-91.

Littler, M.M and R.R. Seapy. 1979. The impact of exceptionally high surf activity on the rocky intertidal biota at Ocean Beach, San Diego County during November 1977 and April 1978. Tech. Reps. 3.1 and 3.2 in Littler, M.M. (ed.). The distribution, abundance and community structure of rocky intertidal and tidepool biotas in the Southern California Bight. U.S. Bureau of Land Management Year III.

MacGinitie, G.E. and N. MacGinitie. 1968. Natural history of marine animals. 2nd ed. McGraw Hill, New York. 523 p.

Miller, A.C. and S.E. Lawrence-Miller. 1993. Long-term trends in black abalone, Haliotis cracherodii Leach, 1814, populations along the Palos Verdes Peninsula, California. J. Shellfish Res. 12(2):195-200.

Morris, R.H., D.P. Abbott and E.C. Haderlie, eds. 1980. Intertidal invertebrates of California. Stanford University Press, Stanford, California. 690 p.

Murray, S.N. and M.M. Littler. 1979. Experimental studies of the recovery of populations of rocky intertidal macro-organisms following mechanical disturbance. Science Applications, Inc., Tech. Rept. II-2.0 to the Bureau of Land Management.

NOAA. 1989. A summary od data on tissue contamination from the first three years (1986-1988) of the mussel watch project. NOAA Technical Memorandum NOS OMA 49. U.S. Department of Commerce, National Oceanic and Atmospheric Administration, National Ocean Service, Rockville, Maryland.

North, W.J., M. Neushul and K.A. Clendenning. 1965. Successive biological changes observed in a marine cover exposed to a large spillage of mineral oil. Pp. 335-354 in Proceedings of the Comm. Int. Explor. Scient. Mer. Merit. Symposium on marine pollution caused by micro-organisms and mineral oils, Monaco.

PG\&E 1993. Thermal effects monitoring program. Diablo Canyon Power Plant 1992 Annual Report. Pacific Gas and Electric Co., San Francisco, California.

Paine, R.T. 1966. Food web complexity and species diversity. Am. Nat. 100:65-75.

Paine, R.T. 1974. Intertidal community structure: experimental studies on the relationship between a dominant competitor and its principal predator. Oecologia 15:93-120.

Richards, D.V. and G.E. Davis. 1988. Rocky intertidal communities monitoring handbook, Channel Islands National Park, California. National Park Service, Ventura, CA. 15 p.

Richards, D.V. and G.E. Davis. 1993. Early warnings of modern population collapse in black abalone Haliotis cracherodii, Leach, 1814 at the California Channel Islands. J. Shellfish Res. 12(2):189-94. 
Ricketts, E.G., J. Calvin, J. Hedgepeth and D.W. Phillips. 1985. Between Pacific tides, 5th ed., revised by J. Hedgpeth. Stanford University Press, Palo Alto, California. 652 p.

Roemmich, D. and J. McGowan. 1995. Climatic warming and the decline of zooplankton in the California Current. Science 267:1324-1326.

Scagel, R.F. 1956. Introduction of a Japanese alga, Sargassum muticum, into the Northeast Pacific. Wash. Dep. Fish. Fish. Res. Pap. 1:1-10.

Seapy, R.R. and M.M. Littler. 1977. Biological features of rocky intertidal communities near Ocean Beach, San Diego, California. Tech. Rep 2.1.6 in Littler, M.M. (ed.). Spatial and temporal variations in the distribution and abundance of rocky intertidal and tidepool biotas in the Southern California Bight. U.S. Bureau of Land Management. Year I.

Seapy, R.R. and M.M. Littler. 1978. Variations in the rocky intertidal biota near Ocean Beach, San Diego, California. Tech. Rep. 1.1.6 in Littler, M.M. (ed.). The annual and seasonal ecology of southern California subtidal, rocky intertidal and tidepool biotas. U.S. Bureau of Land Management. Year II.

Seapy, R.R. and M.M. Littler. 1979. Assessments of the distribution, abundance, and community structure of rocky intertidal organisms at Ocean Beach, San Diego County. Tech. Rep 1.7 in Littler, M.M. (ed.). The distribution, abundance and community structure of rocky intertidal and tidepool biotas in the Southern California Bight. U.S. Bureau of Land Management Year III.

Seapy, R.R. and M.M. Littler. 1982. Population and species diversity fluctuations in a rocky intertidal community relative to severe aerial exposure and sediment burial. Mar. Biol. 71:87-96.

Seapy, R.R. and M.M. Littler. 1993. Rocky intertidal macroinvertebrates of the Southern California Bight: an overview and checklist. In: Third California Islands Symposium: Recent Advances in Research on the California Islands (F.G. Hochberg, ed.). Santa Barbara Museum of Natural History, Santa Barbara. 293-322.

Sebens, K.P. 1980. The regulation of asexual reproduction and indeterminate body size in the sea anemone Anthopleura elegantissima (Brandt). Biol. Bull. 158:370-82.

Sebens, K.P. 1982. Asexual reproduction in Anthopleura elegantissima (Anthozoa: Actiniaria): seasonality and spatial extent of clones. Ecology 63:434-44.

Seymour, R.J., M.J. Tegner, P.K. Dayton and P.E. Parnell. 1989. Storm wave induced mortality of giant kelp, Macrocystis pyrifera, in southern California. Estuarine, Coastal and Shelf Science 28:277-292.

SWRCB. 1989. State mussel watch program status report, February 27, 1989. Environmental Services Division, California Department of Fish and Game and State Water Resources Control Board, Cailfornia Environmental Protection Agency, Sacramento, CA. 
SWRCB. 1995. State mussel watch program 1987-93 data report No. 94-1WQ. State Water Resources Control Board, Cailfornia Environmental Protection Agency, Sacramento, CA.

Stewart, J.G. and B. Myers. 1980. Assemblages of algae and invertebrates in Southern California Phyllospadix-dominated intertidal habitats. Aquatic Botany 9:73-94.

Stewart, J.G. 1982. Anchor species and epiphytes in intertidal algal turf. Pacific Sci. 36(1): 4559.

Stewart, J.G. 1983. Fluctuations in the quantity of sediments trapped among algal thalli on intertidal rock platforms in southern California. J. Exp. Mar. Biol. Ecol. 73:205-11.

Stewart, J.G. 1989a. Maintenance of a balanced, shifting boundary between the seagrass Phyllospadix and algal turf. Aquatic Botany 33: 223-41.

Stewart, J.G. 1989b. Establishment, persistence and dominance of Corallina (Rhodophyta) in algal turf. J. Phycol. 25: 436-46.

Stimpson, J. 1970. Territorial behavior of the owl limpet Lottia gigantea. Ecology 51:113-18.

Stimsen, 1973. The role of territory in the ecology of the intertidal limpet Lottia gigantea (Gray). Ecology 54: 1020-30.

Suchanek, T.H. 1979. The Mytilus californianus community: studies on composition, structure, organization, and dynamics of a mussel bed. Ph.D. Thesis, University of Washington, Seattle, Washington.

Taylor, P.R. and M.M. Littler 1979. The effects of Anthopleura elegantissima and Haliotis cracherodii on rocky intertidal community structure. Tech. Rep. 4.0 in Littler, M.M. (ed.). The distribution, abundance and community structure of rocky intertidal and tidepool biotas in the Southern California Bight. U.S. Bureau of Land Management Year III.

Taylor, P.R. and M.M. Littler 1982. The roles of compensatory mortality, physical disturbance, and retention substrate in the development and organization of a sand-influenced rockyintertidal community. Ecology 63:135-46.

Tegner, M.J. and P.K. Dayton. 1987. El Niño effects on southern California kelp forest communities. Adv. Ecol. Res. 17:243-79.

Thom, R.M. and T.B. Widdowson. 1978. A re-survey of E. Yale Dawson's 42 intertidal algae transects on the southern California mainland after 15 years. Bull. South. Calif. Acad. Sci. 77:1-13.

Turner, C.H., E.E. Ebert and R.R. Given 1968. The marine environment offshore from Point Loma, San Diego County. Calif. Dept. Fish and Game Fish Bulletin 140. 85 p.

Turner, T. 1983. Complexity of early and middle successional stages in a rocky intertidal surf grass community. Oecologia 60:56-65. 
Turner, T. 1985. Stability of rocky intertidal surf grass beds: persistence, preemption, and recovery. Ecology 66:83-92.

VanBlaricom, G.R. 1993. Dynamics and distribution of black abalone populations at San Nicolas Island, California. In: Third California Islands Symposium: recent advances in research on the California Islands (F.G. Hochberg, ed.), Santa Barbara Museum of Natural History, Santa Barbara. 323-34.

Vesco, L.L. and R. Gillard. 1980. Recovery of benthic marine populations along the Pacific Coast of the United States following man-made and natural disturbances including pertinent life history information. U.S. Department of the Interior, Bureau of Land Management Service, POCS Reference Paper No. 53-4. 48 p.

Widdowson, T. 1971. Changes in the intertidal algal flora of the Los Angeles area since the survey of E. Yale Dawson in 1956-1959. Bull. South. Cal. Acad. Sci. 70:2-16.

Wright, W.G. 1982. Ritualized behavior in a territorial limpet. J. Exp. Mar. Biol. Ecol. 60: 24551.

Wright, W.G. and D.R. Lindberg. 1982. Direct observation of sex change in the patellacean limpet Lottia gigantea. J. Mar. Biol. Assoc. U.K. 62:737-38.

Zedler, J.B. 1976. Ecological resource inventory of the Cabrillo National Monument intertidal zone. Biol. Dept. San Diego State Univ. Proj. Rpt. USDI, National Park Service. 69 p.

Zedler, J.B. 1978. Public use effects in the Cabrillo National Monument Intertidal Zone. Biol. Dept. San Diego State University proj. rep. for U. S. Dept. Interior, National Park Service. $52 \mathrm{p}$. 


\section{TABLES}

Table 1. Index Taxa and Monitoring Techniques at Navy North and South Sites. Values in parentheses indicate the number of replicate plots emphasizing those particular species.

\begin{tabular}{|c|c|c|c|}
\hline Technique/Taxa & Dimensions & $\begin{array}{l}\text { Number } \\
\text { Per Area }\end{array}$ & $\begin{array}{l}\text { Total } \\
\text { Sample }\end{array}$ \\
\hline Photoplot & $50 \times 75 \mathrm{~cm}$ & 21 & 42 \\
\hline \multicolumn{4}{|l|}{ Acorn Barnacle } \\
\hline \multicolumn{4}{|l|}{ Chthamalus spp. } \\
\hline Pink Thatched Barnacle & & (5) & \\
\hline \multicolumn{4}{|l|}{ Tetraclita rubescens } \\
\hline Rockweed & & (5) & \\
\hline \multicolumn{4}{|l|}{ Pelvetia fastigiata } \\
\hline California Mussel & & (5) & \\
\hline \multicolumn{4}{|l|}{ Mytilus californianus } \\
\hline Goose Barnacle & & (6) & \\
\hline \multicolumn{4}{|l|}{ Pollicipes polymerus } \\
\hline \multicolumn{4}{|l|}{ Other Plants } \\
\hline \multicolumn{4}{|l|}{ Other Animals } \\
\hline \multirow{2}{*}{\multicolumn{4}{|c|}{$\begin{array}{l}\text { Tar } \\
\text { Bare Substrate }\end{array}$}} \\
\hline & & & \\
\hline \multirow{3}{*}{\multicolumn{4}{|c|}{$\begin{array}{l}\text { Circular Plot } \\
\text { Owl Limpet } \\
\qquad \text { Lottia gigantea }\end{array}$}} \\
\hline & & & \\
\hline & & & \\
\hline \multirow{2}{*}{\multicolumn{4}{|c|}{$\begin{array}{l}\text { Line Transect } \\
\text { Boa Kelp }\end{array}$}} \\
\hline & & & \\
\hline \multicolumn{4}{|l|}{ Egregia menziesii } \\
\hline \multicolumn{4}{|l|}{ Sargassum Weed } \\
\hline \multicolumn{4}{|l|}{ Sargassum muticum } \\
\hline Red Algal Turf & & (2) & \\
\hline \multicolumn{4}{|l|}{ Corallina spp. et al. } \\
\hline Surf grass & & (4) & \\
\hline \multicolumn{4}{|l|}{ Phyllospadix spp. } \\
\hline \multicolumn{4}{|c|}{ Aggregating Anemone } \\
\hline \multicolumn{4}{|c|}{ Anthopleura elegantissima } \\
\hline \multicolumn{4}{|c|}{ Other Biota } \\
\hline \multirow{2}{*}{\multicolumn{4}{|c|}{$\begin{array}{l}\text { Tar } \\
\text { Bare Substrate }\end{array}$}} \\
\hline & & & \\
\hline Timed Search & 30 person-minutes & 1 & 2 \\
\hline Black Abalone & & & \\
\hline Haliotis cracherodii & & & \\
\hline Ochre Sea star & & & \\
\hline Pisaster ochraceus & & & \\
\hline
\end{tabular}


Table 4. Navy South Rocky Intertidal Interplot Measurements.

B= Barnacle $G=$ Grass $L=$ Limpet $\quad P o=$ Pollicepes $M=$ Mussel $T=$ Turf $C=$ Center $N=$ North $R=$ Reference $S=$ South $P e=P$

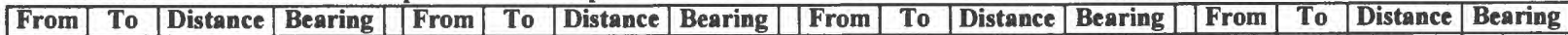

\begin{tabular}{|c|c|c|c|c|c|c|c|c|c|c|c|c|c|c|c|}
\hline & & & & & & & & & & & & & & & \\
\hline B1 & M7 & 27.00 & 330 & G5S & B5 & 9.66 & 25 & M4 & L6 & 1.17 & 285 & R2 & $\mathrm{B} 2$ & 2.64 & 210 \\
\hline B1 & M8 & 2.55 & 110 & G5S & G5N & 9.96 & 335 & M4 & M5 & 0.92 & 55 & R2 & B3 & 2.44 & 165 \\
\hline B1 & R1 & 10.26 & 340 & G5S & G6C & 16.17 & 110 & M4 & R3 & 3.38 & 295 & $\mathrm{R} 2$ & L1 & 3.83 & 245 \\
\hline B1 & T1S & 18.30 & 315 & G5S & G6N & 13.18 & 90 & & & & & $\mathrm{R} 2$ & L2 & 2.08 & 235 \\
\hline & & & & G5S & G6S & 19.97 & 120 & M5 & L6 & 1.85 & 255 & $\overline{R 2}$ & L3 & 2.05 & 40 \\
\hline $\mathrm{B} 2$ & $\mathrm{B3}$ & 1.96 & 85 & G5S & R3 & 18.01 & 355 & M5 & M4 & 0.92 & 235 & $\mathrm{R} 2$ & $\mathrm{~L} 4$ & 31.79 & 180 \\
\hline B2 & L2 & 1.16 & 340 & G5S & T2C & 9.48 & 45 & M5 & R3 & 3.91 & 280 & $\bar{R} 2$ & M2 & 2.94 & 40 \\
\hline B2 & $\mathrm{R} 2$ & 2.64 & 30 & G5S & $\mathrm{T} 2 \mathrm{~N}$ & 11.88 & 20 & M5 & T2N & 6.38 & 155 & & & & \\
\hline & & & & G5S & T2S & 9.39 & 75 & & & & & R3 & B5 & 11.63 & 145 \\
\hline B3 & $\overline{B 2}$ & 1.96 & 265 & & & & & M6 & M7 & 1.65 & 180 & $\mathrm{R} 3$ & G5C & 13.50 & 180 \\
\hline B3 & M2 & 4.69 & 360 & G6C & G5S & 16.17 & 290 & M6 & Pol & 6.49 & 330 & R3 & G5N & 9.38 & 195 \\
\hline B3 & $\mathrm{R} 2$ & 2.44 & 345 & G6C & G6N & 4.99 & 340 & M6 & R1 & 18.27 & 160 & $\mathrm{R} 3$ & G5S & 18.01 & 175 \\
\hline & & & & G6C & \begin{tabular}{|l|} 
R3 \\
\end{tabular} & 29.32 & 325 & & & & & $\overline{\mathrm{R} 3}$ & G6C & 29.32 & 145 \\
\hline B4 & G5N & 7.31 & 135 & G6C & $\mathrm{T} 2 \mathrm{~S}$ & 10.34 & 325 & M7 & B1 & 27.00 & 150 & $\mathrm{R} 3$ & G6N & 24.17 & 140 \\
\hline B4 & L4 & 3.94 & 320 & & & & & M7 & M6 & 1.65 & 360 & $\mathrm{R} 3$ & G6N & 24.52 & 140 \\
\hline$\overline{\mathrm{B} 4}$ & L5 & 5.45 & 25 & G6N & G5S & 13.18 & 270 & M7 & R1 & 16.79 & 155 & $\overline{\mathrm{R} 3}$ & G6S & 34.20 & 145 \\
\hline B4 & L6 & 9.35 & 80 & G6N & G6C & 4.99 & 160 & M7 & T1N & 5.78 & 250 & R3 & L6 & 2.21 & 130 \\
\hline B4 & M3 & 2.47 & 330 & $\mathrm{G} 6 \mathrm{~N}$ & G6S & 9.98 & 160 & M7 & TIS & 11.03 & 180 & R3 & M4 & 3.38 & 115 \\
\hline & & & & G6N & R3 & 24.17 & 320 & & & & & $\mathrm{R} 3$ & M5 & 3.91 & 100 \\
\hline B5 & G5S & 9.66 & 205 & G6N & R3 & 24.52 & 320 & M8 & B1 & 2.55 & 290 & R3 & T2C & 14.08 & 140 \\
\hline$\overline{\mathrm{B} 5}$ & R3 & 11.63 & 325 & G6N & R4 & 81.00 & 110 & M8 & M9 & 1.01 & 145 & R3 & T2N & 9.30 & 135 \\
\hline B5 & $\mathrm{T} 2 \mathrm{C}$ & 2.54 & 135 & G6N & T2S & 5.59 & 315 & M8 & R1 & $? 12.23$ & 325 & R3 & $\mathrm{T} 2 \mathrm{~S}$ & 19.02 & 145 \\
\hline B5 & T2N & 2.77 & 350 & & & & & & & & & & & & \\
\hline$\overline{B 5}$ & T2S & 7.44 & 140 & G6S & G5S & 19.97 & 300 & M9 & G4C & 12.54 & 235 & R4 & $\mathrm{G} 6 \mathrm{~N}$ & 81.00 & 290 \\
\hline & & & & G6S & G6N & 9.98 & 340 & M9 & G4N & 13.10 & 260 & R4 & PeI & $? 0.39$ & 80 \\
\hline G3C & G3N & 5.00 & 335 & G6S & $\mathrm{R3}$ & 34.20 & 325 & M9 & G4S & 13.69 & 220 & R4 & Pe2 & 3.43 & 170 \\
\hline G3C & R1 & 17.29 & 105 & G6S & T2S & 15.25 & 335 & M9 & M10 & 4.03 & 160 & R4 & $\mathrm{Pe} 3$ & 6.78 & 110 \\
\hline G3C & T1N & 8.34 & 20 & & & & & M9 & M8 & 1.01 & 325 & R4 & Pe4 & 7.67 & 110 \\
\hline G3C & TIS & 7.56 & 100 & $\mathrm{Ll}$ & L2 & 1.96 & 80 & M9 & R1 & 13.23 & 330 & R4 & Pe5 & 7.76 & 110 \\
\hline & & & & L1 & M1 & 13.17 & 290 & & & & & & & & \\
\hline G3N & G3C & 5.00 & 155 & L1 & $\overline{R 2}$ & 3.83 & 65 & M10 & G4S & 11.97 & 225 & T1C & R1 & 13.95 & 120 \\
\hline G3N & G3S & 10.00 & 155 & & & & & M10 & L4 & 38.45 & 140 & TIC & T1N & 5.00 & 330 \\
\hline G3N & R1 & 21.14 & 115 & $\overline{L 2}$ & B2 & 1.16 & 160 & M10 & M9 & 4.03 & 340 & & & & \\
\hline G3N & TIN & 6.45 & 60 & $\mathrm{~L} 2$ & L1 & 1.96 & 260 & & & & & T1N & G3C & 8.34 & 200 \\
\hline G3N & T1S & 11.35 & 120 & L2 & $\bar{R} 2$ & 2.08 & 55 & Pel & $\mathrm{Pe} 2$ & 3.37 & 175 & T1N & G3N & 6.45 & 240 \\
\hline & & & & & & & & Pel & R4 & $? 0.39$ & 260 & TIN & G3S & 12.15 & 180 \\
\hline G3S & G3N & 10.00 & 335 & $\mathrm{~L} 3$ & M2 & 1.10 & 40 & & & & & TIN & MO & 9.79 & 15 \\
\hline G3S & G4N & 16.24 & 160 & L3 & $\mathrm{R} 2$ & 2.05 & 220 & $\overline{\mathrm{Pe}} 2$ & Pe1 & 3.37 & 355 & TIN & M7 & 5.78 & 70 \\
\hline G3S & \begin{tabular}{|l|}
$\mathbf{R} 1$ \\
\end{tabular} & 14.19 & 90 & & & & & $\mathrm{Pe} 2$ & Pe3 & 5.78 & 80 & TIN & R1 & 18.51 & 165 \\
\hline G3S & T1N & 12.15 & 360 & L4 & B4 & 3.94 & 140 & $\mathrm{Pe} 2$ & R4 & 3.43 & 350 & TIN & TIC & 5.00 & 150 \\
\hline G3S & T1S & 5.95 & 60 & L4 & G4S & 38.71 & 315 & & & & & T1N & T1S & 9.99 & 150 \\
\hline & & & & L4 & M1 & 38.15 & 325 & $\mathrm{Pe} 3$ & $\mathrm{Pe} 2$ & 5.78 & 260 & & & & \\
\hline $\bar{G} 4 \mathrm{C}$ & G4N & 5.01 & 330 & $\overline{L 4}$ & $\mathrm{M} 10$ & 38.45 & 320 & Pe3 & Pe4 & 1.22 & 65 & T1S & $\mathrm{B} 1$ & 18.30 & 135 \\
\hline G4C & \begin{tabular}{|l|} 
M99 \\
\end{tabular} & 12.54 & 55 & L4 & M3 & 1.52 & 130 & $\mathrm{Pe} 3$ & R4 & 6.78 & 290 & T1S & G3C & 7.56 & 280 \\
\hline G4C & RI & 19.01 & 15 & $\overline{L 4}$ & R2 & 31.79 & 360 & & & & & T1S & G3N & 11.35 & 300 \\
\hline & & & & & & & & $\mathrm{Pe} 4$ & $\mathrm{Pe} 3$ & 1.22 & 245 & T1S & G3S & 5.95 & 240 \\
\hline $\mathrm{G} 4 \mathrm{~N}$ & G3S & 16.24 & 340 & L5 & B4 & 5.45 & 205 & Pe4 & Pe5 & 1.41 & 200 & T1S & M7 & 11.03 & 360 \\
\hline $\mathrm{G} 4 \mathrm{~N}$ & $\mathrm{G} 4 \mathrm{C}$ & 5.01 & 150 & L5 & $\overline{G 5 N}$ & 10.60 & 165 & $\mathrm{Pe} 4$ & R4 & 7.67 & 290 & T1S & R1 & 9.87 & 110 \\
\hline $\mathrm{G} 4 \mathrm{~N}$ & G4S & 10.08 & 150 & L5 & M3 & 4.46 & 225 & & & & & T1S & TIN & 9.99 & 330 \\
\hline G4N & M9 & 13.10 & 80 & & & & & Pe5 & Pe4 & 1.41 & 20 & & & & \\
\hline G4N & R1 & 15.63 & 30 & L6 & B4 & 9.35 & 260 & Pe5 & R4 & 7.76 & 290 & T2C & $\overline{B 5}$ & 2.54 & 315 \\
\hline & & & & L6 & G5N & 8.61 & 205 & & & & & $\mathrm{~T} 2 \mathrm{C}$ & G5S & 9.48 & 225 \\
\hline G4S & G4N & 10.08 & 330 & L6 & M4 & 1.17 & 105 & R1 & B1 & 10.26 & 160 & $\mathrm{~T} 2 \mathrm{C}$ & \begin{tabular}{|l|} 
R33 \\
\end{tabular} & 14.08 & 320 \\
\hline G4S & L4 & 38.71 & 135 & L6 & M5 & 1.85 & 75 & R1 & G3C & 17.29 & 285 & $\mathrm{~T} 2 \mathrm{C}$ & $\mathrm{T} 2 \mathrm{~N}$ & 5.00 & 325 \\
\hline G4S & M10 & 11.97 & 45 & L6 & R3 & 2.21 & 310 & R1 & G3N & 21.14 & 295 & & & & \\
\hline G4S & M9 & 13.69 & 40 & L6 & T2N & 7.28 & 135 & R1 & G3S & 14.19 & 270 & $\mathrm{~T} 2 \mathrm{~N}$ & $\bar{B} 5$ & 2.77 & 170 \\
\hline G4S & R1 & 22.90 & 10 & & & & & R1 & $\mathrm{G} 4 \mathrm{C}$ & 19.01 & 195 & T2N & G5N & 8.79 & 260 \\
\hline & & & & M0 & M6 & 6.49 & 150 & RI & G4N & 15.63 & 210 & $\mathrm{~T} 2 \mathrm{~N}$ & G5S & 11.88 & 200 \\
\hline G5C & G5N & 4.99 & 335 & MO & R1 & 24.69 & 155 & RI & G4S & 22.90 & 190 & $\mathrm{~T} 2 \mathrm{~N}$ & L6 & 7.28 & 315 \\
\hline G5C & R3 & 13.50 & 360 & $\mathrm{M0}$ & TIN & 9.79 & 195 & R1 & M0 & 24.69 & 335 & $\mathrm{~T} 2 \mathrm{~N}$ & M5 & 6.38 & 335 \\
\hline & & & & & & & & R1 & M6 & 18.27 & 340 & $\mathrm{~T} 2 \mathrm{~N}$ & R3 & 9.30 & 315 \\
\hline G5N & B4 & 7.31 & 315 & M1 & L1 & 13.17 & 110 & R1 & M7 & 16.79 & 335 & $\mathrm{~T} 2 \mathrm{~N}$ & $\mathrm{~T} 2 \mathrm{C}$ & 5.00 & 145 \\
\hline G5N & G5C & 4.99 & 155 & M1 & L4 & 38.15 & 145 & R1 & M8 & $? 12.23$ & 145 & $\mathrm{~T} 2 \mathrm{~N}$ & T2S & 10.00 & 145 \\
\hline G5N & G5S & 9.96 & 155 & & & & & RI & M9 & 13.23 & 150 & & & & \\
\hline G5N & L5 & 10.60 & 345 & M2 & B3 & 4.69 & 180 & R1 & T1C & 13.95 & 300 & $\mathrm{~T} 2 \mathrm{~S}$ & B5 & 7.44 & 320 \\
\hline G5N & L6 & 8.61 & 25 & M2 & $\mathrm{L3}$ & 1.10 & 220 & R1 & TIN & 18.51 & 345 & T2S & G5S & 9.39 & 255 \\
\hline G5N & $\mathrm{R} 3$ & 9.38 & 15 & M2 & $\mathrm{R} 2$ & 2.94 & 220 & R1 & T1S & 9.87 & 290 & $\mathrm{~T} 2 \mathrm{~S}$ & G6C & 10.34 & 145 \\
\hline G5N & $\mathrm{T} 2 \mathrm{~N}$ & 8.79 & 80 & & & & & & & & & $\mathrm{~T} 2 \mathrm{~S}$ & G6N & 5.59 & 135 \\
\hline & & & & M3 & B4 & 2.47 & 150 & & & & & T2S & G6S & 15.25 & 155 \\
\hline & & & & M3 & L4 & 1.52 & 310 & & & & & $\mathrm{~T} 2 \mathrm{~S}$ & R3 & 19.02 & 325 \\
\hline & & & & M3 & L5 & 4.46 & 45 & & & & & $\mathrm{~T} 2 \mathrm{~S}$ & $\mathrm{~T} 2 \mathrm{~N}$ & 10.00 & 325 \\
\hline
\end{tabular}


Table 5. Field Activities for Point Loma Rocky Intertidal Baseline Surveys.

\begin{tabular}{|l|l|l|l|}
\hline \multicolumn{1}{|c|}{ Season } & \multicolumn{1}{|c|}{ Date } & \multicolumn{1}{c|}{ Hours } & \multicolumn{1}{c|}{ Field Activity } \\
\hline Spring 1995 & February 15 & $1330-1700$ & Site Scouting Survey \\
\hline & February 16 & $1400-1730$ & Site Scouting Survey \\
\hline & February 17 & $1500-1800$ & Site Scouting Survey \\
\hline & February 23 & $0900-1530$ & Site Scouting Surveys \\
\hline & February 24 & $0930-1500$ & Establish Navy South Site \\
\hline & February 25 & $1000-1600$ & Survey Cabrillo Sites I \& II \\
\hline & February 26 & $1030-1600$ & Survey Cabrillo Sites I, II, \& III \\
\hline & February 27 & $1045-1700$ & Establish Navy North Site \\
\hline & February 28 & $1115-1700$ & Survey Navy North Site \\
\hline & March 1 & $1215-1730$ & Survey Navy South Site \\
\hline & March 2 & $1300-1700$ & Upgrade Cabrillo Sites I, II, \& III \\
\hline & March 14 & $1100-1700$ & Photograph Navy Sites \\
\hline & October 21 & $1130-1630$ & Survey Cabrillo Sites I \& II \\
\hline & October 22 & $1200-1700$ & Survey Cabrillo Sites I, II, \& III \\
\hline & October 23 & $1100-1700$ & Survey Navy North Site \\
\hline & October 24 & $1100-1800$ & Survey Navy South Site \\
\hline & October 25 & $1330-1800$ & Upgrade Cabrillo Sites I, II, \& III \\
\hline
\end{tabular}

Table 6. Participants in the Point Loma Rocky Intertidal Baseline Surveys.

\begin{tabular}{|l|l|c|c|}
\hline \multicolumn{1}{|c|}{ Participants } & \multicolumn{1}{c|}{ Affiliation } & Spring & Fall \\
\hline Mark Conlin & Mark Conlin Photography & X & X \\
\hline Gary Davis & National Biological Service & X & X \\
\hline Robert Duran & Univ. Calif., Santa Barbara & X & \\
\hline John Engle & Univ. Calif., Santa Barbara & X & X \\
\hline Robert Gladden & San Diego State University & X & \\
\hline Constance Gramlich & San Diego State University & X & X \\
\hline Daniel Heilprin & Science Applications, Inc. & X & \\
\hline David Hubbard & Univ. Calif., Santa Barbara & & X \\
\hline Robin Lewis & California Fish and Game, OSPR & & X \\
\hline Daniel Martin & Univ. Calif., Santa Barbara & $\mathrm{X}$ & $\mathrm{X}$ \\
\hline Cynthia Taylor & San Diego State University & $\mathrm{X}$ & $\mathrm{X}$ \\
\hline Valorie Vucich & San Diego State University & $\mathrm{X}$ & \\
\hline Samantha Weber & Cabrillo National Monument & & $\mathrm{X}$ \\
\hline
\end{tabular}


Table 2. Rocky Intertidal Survey Plots and Plot Identification Codes.

\begin{tabular}{|c|c|c|c|}
\hline Plot Type & Key Species & Plot Code & Photo Code \\
\hline \multirow[t]{21}{*}{ Photoplot } & \multirow[t]{5}{*}{ Barnacles } & B1 & 101 \\
\hline & & B2 & 102 \\
\hline & & B3 & 102 \\
\hline & & B4 & 104 \\
\hline & & B5 & 105 \\
\hline & \multirow[t]{5}{*}{ Rockweed } & $\mathrm{Pe} 1$ & 001 \\
\hline & & $\mathrm{Pe} 2$ & 002 \\
\hline & & $\mathrm{Pe} 3$ & 003 \\
\hline & & Pe4 & 004 \\
\hline & & Pe5 & 005 \\
\hline & \multirow{10}{*}{$\begin{array}{c}\text { Mussel/ } \\
\text { Goose barnacle }\end{array}$} & MO & 200 \\
\hline & & M1 & 201 \\
\hline & & M2 & 202 \\
\hline & & M3 & 203 \\
\hline & & M4 & 204 \\
\hline & & M5 & 205 \\
\hline & & M6 & 206 \\
\hline & & M7 & 207 \\
\hline & & M8 & 208 \\
\hline & & M9 & 209 \\
\hline & \multirow{6}{*}{ Owl limpet } & M10 & 210 \\
\hline \multirow{5}{*}{ Circular Plot } & & $\begin{array}{l}\text { L1 } \\
\text { L2 }\end{array}$ & \\
\hline & & L3 & \\
\hline & & L4 & \\
\hline & & L5 & \\
\hline & & L6 & \\
\hline \multirow[t]{6}{*}{ Line Transect } & \multirow{6}{*}{$\begin{array}{l}\text { Red algal turf } \\
\text { Surfgrass }\end{array}$} & T1 & \\
\hline & & T2 & \\
\hline & & G3 & \\
\hline & & G4 & \\
\hline & & G5 & \\
\hline & & G6 & \\
\hline
\end{tabular}

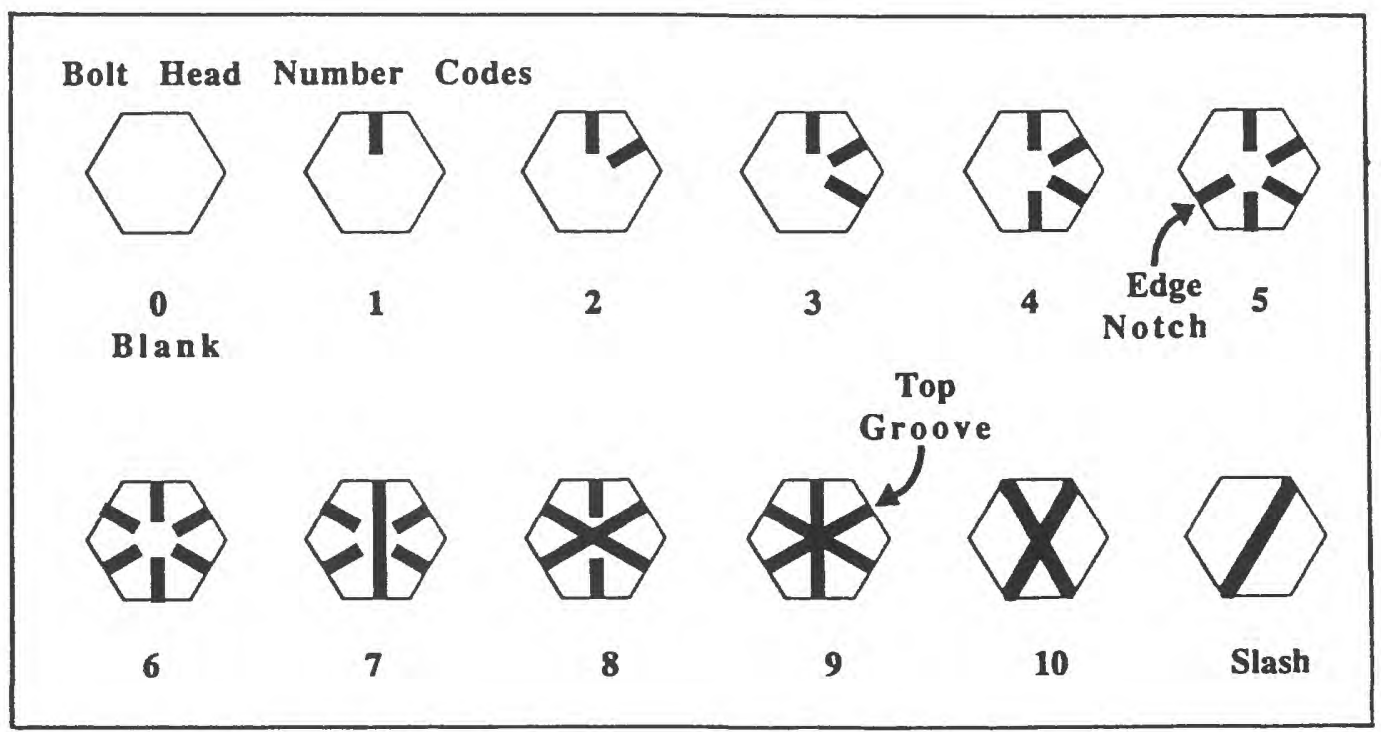


Table 3. Navy North Rocky Intertidal Interplot Measurements.

B = Barnacle $G=$ Grass $L=$ Limpet Po=Pollicepes $M=$ Mussel $T=$ Turf $C=$ Center $\quad N=$ North $R=$ Reference $S=$ South

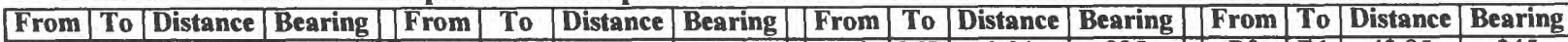

\begin{tabular}{|c|c|c|c|c|c|c|c|c|c|c|c|c|c|c|c|}
\hline & & & & & & & & & & & & & & & \\
\hline B1 & B2 & 3.33 & 160 & G5S & G5N & 10.01 & $310^{\circ}$ & M6 & M5 & 1.04 & 325 & $\mathrm{R} 2$ & $\overline{B 1}$ & 43.95 & 345 \\
\hline B1 & G3 & 13.38 & 220 & G5S & G6N & 36.45 & 110 & M6 & M7 & 1.32 & 85 & $\mathrm{R} 2$ & $\overline{\mathrm{B} 2}$ & 40.64 & 345 \\
\hline B1 & $\mathrm{R} 2$ & 43.95 & 165 & G5S & $\mathrm{R} 3$ & 31.74 & 45 & M6 & RI & 3.70 & 55 & $\mathrm{R} 2$ & B3 & 5.16 & 355 \\
\hline B1 & $\mathrm{T1}$ & 17.21 & 135 & & & & & & & & & $\mathrm{R} 2$ & B4 & 6.27 & 170 \\
\hline & & & & G6C & G6N & 5.41 & 320 & M7 & M6 & 1.32 & 265 & $\mathrm{R} 2$ & B5 & 8.24 & 165 \\
\hline B2 & Bi & 3.33 & 340 & G6C & R3 & 40.29 & 340 & M7 & M8 & 3.00 & 145 & $\mathrm{R} 2$ & G3 & 32.62 & 320 \\
\hline B2 & G3 & 11.75 & 230 & G6C & T2S & 29.62 & 5 & M7 & RI & 2.88 & 60 & $\bar{R} 2$ & G3 & 37.53 & 325 \\
\hline B2 & $\mathrm{G} 3$ & 17.39 & 195 & & & & & & & & & R2 & G3 & 27.72 & 320 \\
\hline B2 & $\mathrm{R} 2$ & 40.64 & 165 & G6N & G5S & 36.45 & 290 & M8 & $\mathrm{LI}$ & 4.40 & 165 & $\overline{\mathrm{R} 2}$ & G4 & 23.00 & 245 \\
\hline B2 & T1 & 14.21 & 130 & G6N & G6C & 5.41 & 140 & M8 & M7 & 3.00 & 325 & $\mathrm{R} 2$ & G4 & 20.77 & 255 \\
\hline & & & & G6N & G6S & 9.97 & 135 & M8 & RI & 4.07 & 350 & $\mathrm{R} 2$ & G4 & 25.82 & 235 \\
\hline $\mathrm{B} 3$ & B4 & 11.44 & 175 & G6N & $\mathrm{R} 3$ & 35.19 & 345 & & & & & $\overline{\mathrm{R} 2}$ & L4 & 43.88 & 165 \\
\hline $\bar{B} 3$ & R2 & 5.16 & 175 & G6N & T2S & 26.21 & 15 & M9 & $\overline{\mathrm{LI}}$ & 5.10 & 5 & $\mathrm{R} 2$ & RI & 111.94 & 5 \\
\hline B3 & TI & 18.95 & 360 & & & & & M9 & L2 & 1.95 & 165 & $\mathrm{R} 2$ & $\mathrm{R} 3$ & 95.95 & $\sim 140$ \\
\hline B3 & T1 & 23.84 & 355 & G6S & G6N & 9.97 & 315 & M9 & RI & 13.21 & 350 & $\mathrm{R} 2$ & $\mathrm{TI}$ & 24.08 & 360 \\
\hline B3 & T1S & 14.15 & 10 & G6S & R3 & 43.86 & 335 & & & & & $\mathrm{R} 2$ & T1 & 28.97 & 355 \\
\hline & & & & G6S & $\mathrm{T} 2 \mathrm{~S}$ & 31.45 & 360 & M10 & $\mathrm{L3}$ & 1.64 & 360 & $\mathrm{R} 2$ & TIS & 19.24 & 5 \\
\hline B4 & B3 & 11.44 & 355 & & & & & M10 & R1 & 18.51 & 345 & & & & \\
\hline B4 & $\bar{B} 5$ & 2.27 & 140 & $\overline{\mathrm{LI}}$ & M8 & 4.40 & 345 & & & & & $\mathrm{R3}$ & G5 & 32.33 & 240 \\
\hline B4 & R2 & 6.27 & 350 & L1 & M9 & 5.10 & 185 & Pel & $\mathrm{Pe} 2$ & 8.07 & 145 & R3 & G5 & 33.83 & 245 \\
\hline & & & & $\mathbf{L I}$ & $\mathrm{R} 1$ & 8.23 & 350 & $\overline{\text { Pel }}$ & Pe5 & 15.73 & 165 & R3 & G5 & 31.74 & 225 \\
\hline B5 & B4 & 2.27 & 320 & & & & & Pel & $\mathrm{R} 3$ & 28.27 & 170 & $\mathrm{R3}$ & G6 & 40.29 & 160 \\
\hline B5 & G4 & 23.34 & 265 & $\overline{\mathrm{L} 2}$ & $\overline{\mathrm{L} 3}$ & 2.11 & 145 & & & & & R3 & G6 & 35.19 & 165 \\
\hline B5 & G4 & 22.82 & 280 & $\overline{\mathrm{L} 2}$ & M9 & 1.95 & 345 & $\mathrm{Pe} 2$ & Pel & 8.07 & 325 & $\mathrm{R} 3$ & G6 & 43.86 & 155 \\
\hline B5 & G4 & 24.57 & 250 & $\overline{\mathrm{L} 2}$ & R1 & 15.08 & 350 & $\mathrm{Pe} 2$ & $\mathrm{Pe} 3$ & 3.02 & 135 & R3 & L6 & 56.03 & 300 \\
\hline B5 & $\mathrm{R} 2$ & 8.24 & 345 & & & & & $\mathrm{Pe} 2$ & Pe4 & 7.21 & 160 & $\mathrm{R3}$ & $\mathrm{Pel}$ & 28.27 & 350 \\
\hline & & & & $\mathrm{L} 3$ & $\mathrm{~L} 2$ & 2.11 & 325 & $\mathrm{Pe} 2$ & Pe5 & 8.42 & 180 & R3 & $\mathrm{Pe} 2$ & 20.94 & 355 \\
\hline G3C & G3 & 4.94 & 335 & L3 & M10 & 1.64 & 180 & $\mathrm{Pe} 2$ & R3 & 20.94 & 175 & R3 & $\mathrm{Pe} 3$ & 18.82 & 360 \\
\hline $\mathrm{G} 3 \mathrm{C}$ & $\mathrm{R} 2$ & 32.62 & 140 & L3 & RI & 17.04 & 345 & & & & & $\overline{\mathrm{R} 3}$ & $\mathrm{Pe} 4$ & 14.21 & 5 \\
\hline & & & & & & & & $\mathrm{Pe} 3$ & $\mathrm{Pe} 2$ & 3.02 & 315 & $\overline{\mathrm{R} 3}$ & Pe5 & 12.60 & 355 \\
\hline G3N & B1 & 13.38 & 40 & $\mathrm{~L} 4$ & G4S & 42.70 & 315 & Pe3 & Pe4 & 4.67 & 175 & $\overline{\mathrm{R} 3}$ & $\mathrm{R} 2$ & 95.95 & 180 \\
\hline G3N & B2 & 11.75 & 50 & $\mathbf{L 4}$ & L5 & 2.34 & 205 & $\mathrm{Pe} 3$ & Pe5 & 6.79 & 205 & $\overline{\mathrm{R} 3}$ & $\mathrm{~T} 2$ & 16.39 & 105 \\
\hline G3N & G3 & 4.94 & 155 & L4 & L6 & 8.05 & 190 & $\mathrm{Pe} 3$ & R3 & 18.82 & 180 & $\mathrm{R} 3$ & T2 & 13.43 & 90 \\
\hline G3N & G3 & 9.94 & 155 & $\mathrm{~L} 4$ & R2 & 43.88 & 345 & & & & & $\mathrm{R3}$ & T2S & 20.12 & 120 \\
\hline G3N & $\mathrm{R2}$ & 37.53 & 145 & & & & & Pe4 & $\overline{\mathrm{Pe} 2}$ & 7.21 & 340 & & & & \\
\hline G3N & T1 & 19.18 & 100 & $\overline{\mathrm{L} 5}$ & L4 & 2.34 & 25 & $\mathrm{Pe} 4$ & $\mathrm{Pe} 3$ & 4.67 & 355 & TIC & B3 & 18.95 & 180 \\
\hline G3N & T1S & 24.67 & 125 & L5 & L6 & 5.92 & 175 & $\mathrm{Pe} 4$ & Pe5 & 3.34 & 235 & TIC & $\mathrm{R} 2$ & 24.08 & 180 \\
\hline & & & & & & & & $\mathrm{Pe} 4$ & R3 & 14.21 & 185 & & & & \\
\hline G3S & B2 & 17.39 & 15 & L6 & G5N & 41.65 & 150 & $\mathrm{Pe} 4$ & T2N & 18.89 & 135 & TIN & $\overline{B 1}$ & 17.21 & 315 \\
\hline G3S & G3 & 9.94 & 335 & L6 & $\mathrm{L} 4$ & 8.05 & 10 & Pe4 & T2S & 28.71 & 140 & T1N & $\overline{\mathrm{B} 2}$ & 14.21 & 310 \\
\hline G3S & G4 & 27.19 & 190 & L6 & L5 & 5.92 & 355 & & & & & T1N & $\overline{\mathrm{B} 3}$ & 23.84 & 175 \\
\hline G3S & $\mathrm{R2}$ & 27.72 & 140 & L6 & $\overline{\mathrm{R}} 3$ & 56.03 & 120 & Pe5 & Pel & 15.73 & 345 & TIN & G3 & 19.18 & 280 \\
\hline G3S & TI & 16.35 & 70 & & & & & Pe5 & $\mathrm{Pe} 2$ & 8.42 & 360 & T1N & G3 & 16.35 & 250 \\
\hline G3S & T1S & 17.66 & 105 & M0 & M1 & 1.71 & 195 & Pe5 & Pe3 & 6.79 & 25 & T1N & R2 & 28.97 & 175 \\
\hline & & & & M0 & RI & 9.29 & 160 & Pe5 & \begin{tabular}{|l|}
$\mathrm{Pe} 4$ \\
\end{tabular} & 3.34 & 55 & & & & \\
\hline G4C & B5 & 23.34 & 85 & & & & & Pe5 & R3 & 12.60 & 175 & TIS & B33 & 14.15 & 190 \\
\hline$\overline{\mathrm{G} 4 \mathrm{C}}$ & G4 & 5.00 & 5 & M1 & M0 & 1.71 & 15 & & & & & TIS & G3 & 24.67 & 305 \\
\hline G4C & R2 & 23.00 & 65 & M1 & M2 & 0.96 & 230 & R1 & $\mathrm{Ll}$ & 8.23 & 170 & T1S & G3 & 17.66 & 285 \\
\hline & & & & M1 & RI & 7.95 & 155 & R1 & L2 & 15.08 & 170 & & & & \\
\hline G4N & B5 & 22.82 & 100 & & & & & RI & \begin{tabular}{|l|} 
L3 \\
\end{tabular} & 17.04 & 165 & $\mathrm{~T} 2 \mathrm{C}$ & $\overline{R 3}$ & 16.39 & 285 \\
\hline G4N & G3 & 27.19 & 10 & M2 & M1 & 0.96 & 50 & R1 & M0 & 9.29 & 340 & T2C & T2 & 5.04 & 330 \\
\hline $\mathrm{G} 4 \mathrm{~N}$ & G4 & 5.00 & 185 & M2 & $\mathrm{M} 3$ & 1.75 & 150 & R1 & MI & 7.95 & 335 & & & & \\
\hline $\mathrm{G} 4 \mathrm{~N}$ & G4 & 9.99 & 185 & M2 & $\mathrm{RI}$ & 7.71 & 150 & RI & M2 & 7.71 & 330 & $\mathrm{~T} 2 \mathrm{~N}$ & Pe4 & 18.89 & 315 \\
\hline G4N & $\mathrm{R} 2$ & 20.77 & 75 & & & & & R1 & M3 & 6.05 & 325 & $\mathrm{~T} 2 \mathrm{~N}$ & R3 & 13.43 & 270 \\
\hline & & & & $\mathrm{M} 3$ & $\mathrm{M} 2$ & 1.75 & 330 & R1 & M4 & 4.76 & 310 & $\mathrm{~T} 2 \mathrm{~N}$ & $\mathrm{~T} 2$ & 5.04 & 150 \\
\hline$\overline{\mathrm{G}} 4 \mathrm{~S}$ & B5 & 24.57 & 70 & M3 & M4 & 2.22 & 190 & R1 & M5 & $3 . \overline{94}$ & 260 & $\mathrm{~T} 2 \mathrm{~N}$ & T2S & 10.03 & 150 \\
\hline G4S & G4 & 9.99 & 5 & M3 & $\mathrm{R} 1$ & 6.05 & 145 & R1 & M6 & 3.70 & 235 & & & & \\
\hline G4S & L4 & 42.70 & 135 & & & & & RI & M7 & 2.88 & 240 & T2S & G6 & 29.62 & 185 \\
\hline G4S & $\bar{R} 2$ & 25.82 & 55 & & & & & R1 & M8 & 4.07 & 170 & $\mathrm{~T} 2 \mathrm{~S}$ & G6 & 26.21 & 195 \\
\hline & & & & M4 & M3 & 2.22 & 10 & RI & M9 & {$[13.1$} & 170 & T2S & G6 & 31.45 & 180 \\
\hline G5C & G5 & 4.97 & 310 & M4 & M5 & 3.51 & 185 & R1 & M10 & 18.51 & 165 & $\mathrm{~T} 2 \mathrm{~S}$ & Pe4 & 28.71 & 320 \\
\hline G5C & R3 & 32.33 & 60 & M4 & RI & 4.76 & 130 & RI & \begin{tabular}{|l|}
$\mathrm{R} 2$ \\
\end{tabular} & 111.94 & 185 & $\mathrm{~T} 2 \mathrm{~S}$ & R3 & 20.12 & 300 \\
\hline & & & & & & & & & & & & $\mathrm{T} 2 \mathrm{~S}$ & $\mathrm{~T} 2$ & 10.03 & 330 \\
\hline G5N & G5 & 4.97 & 130 & M5 & M4 & 3.51 & 5 & & & & & & & & \\
\hline G5N & G5 & 10.01 & 130 & M5 & M6 & 1.04 & 145 & & & & & & & & \\
\hline G5N & L6 & 41.65 & 330 & M5 & R1 & 3.94 & 80 & & & & & & & & \\
\hline G5N & $\mathrm{R3}$ & 33.83 & 65 & & & & & & & & & & & & \\
\hline
\end{tabular}


Table 7. Point Loma Rocky Intertidal Species Relative Abundance.

Relative abundance codes: $1=$ rare; $2=$ present; $3=$ common; $4=$ abundant

$\mathrm{X}=$ found, but abundance not determined; $\mathrm{J}=$ juvenile

\begin{tabular}{|c|c|}
\hline \multicolumn{2}{|c|}{ NAVY NORTH } \\
\hline SPR 95 & FALL 95 \\
\hline 2 & 2 \\
\hline 1 & \\
\hline 2 & 2 \\
\hline 3 & 1 \\
\hline 3 & 2 \\
\hline
\end{tabular}

\begin{tabular}{|l|l|}
\hline \multicolumn{2}{|c|}{ NAVY SOUTH } \\
\hline SPR 95 & FALL 95 \\
\hline
\end{tabular}

CABRILLO I, II, III \begin{tabular}{|l|l|}
\hline SPR 95 & FALL 95 \\
\hline
\end{tabular}

PHYLUM CHLOROPHYTA

\begin{tabular}{|l|l|l|}
\hline CHAETOMORPHA LINUM & 2 & 2 \\
\hline CHAETOMORPHA SPIRALIS & 1 & \\
\hline CODIUM FRAGILE & 2 & 2 \\
\hline ENTEROMORPHA SP. & 3 & 1 \\
\hline ULVA SP. & 3 & 2 \\
\hline
\end{tabular}

\begin{tabular}{|l|l|}
\hline $\mathrm{X}$ & 1 \\
\hline & \\
\hline 2 & 2 \\
\hline 2 & 1 \\
\hline 2 & 2 \\
\hline
\end{tabular}

\begin{tabular}{|c|c|}
\hline$X$ & $X$ \\
\hline & \\
\hline 2 & 2 \\
\hline 2 & $X$ \\
\hline 2 & $X$ \\
\hline
\end{tabular}

PHYLUM PHAEOPHYTA

COLPOMENIA SINUOSA

COLPOMENIA TUBERCULATA

CYLINDROCARPUS RUGOSUS

DICTYOPTERIS UNDULATA

DICTYOTA FLABELLATA

ECTOCARPOID FUZZ

EGREGIA MENZIESII

EISENIA ARBOREA

ENDARACHNE BINGHAMIAE

HALIDRYS DIOICA

MACROCYSTIS PYRIFERA

PACHYDICTYON CORIACEUM

PELVETIA FASTIGIATA

PSEUDOLITHODERMA NIGRA

RALFSIA SP.

SARGASSUM AGARDHIANUM

SARGASSUM MUTICUM

SCYTOSIPHON DOTYI

SCYTOSIPHON LOMENTARIA

SPHACELARIA CALIFORNICA

\begin{tabular}{|c|c|}
\hline 3 & 2 \\
\hline 2 & \\
\hline 2 & 2 \\
\hline 1 & 1 \\
\hline 1 & 1 \\
\hline 2 & 2 \\
\hline 1 & 1 \\
\hline $1 J$ & $1 J$ \\
\hline 2 & 2 \\
\hline 2 & 2 \\
\hline & \\
\hline 1 & 1 \\
\hline 2 & 2 \\
\hline$X$ & $X$ \\
\hline 3 & 3 \\
\hline 2 & 2 \\
\hline 3 & 3 \\
\hline 4 & 3 \\
\hline 2 & \\
\hline 3 & 3 \\
\hline
\end{tabular}

\begin{tabular}{|c|c|}
\hline 1 & 2 \\
\hline & \\
\hline$X$ & 2 \\
\hline 1 & 1 \\
\hline 1 & 1 \\
\hline 2 & 2 \\
\hline 1 & 2 \\
\hline $1 J$ & $1 J$ \\
\hline 1 & 1 \\
\hline 2 & 2 \\
\hline & $1 J$ \\
\hline 1 & 1 \\
\hline 2 & 2 \\
\hline$X$ & $X$ \\
\hline 3 & 3 \\
\hline 1 & 1 \\
\hline 3 & 3 \\
\hline 3 & 2 \\
\hline & \\
\hline 3 & 3 \\
\hline
\end{tabular}

\begin{tabular}{|c|c|}
\hline 1 & $X$ \\
\hline & \\
\hline$X$ & $X$ \\
\hline$X$ & $X$ \\
\hline$X$ & $X$ \\
\hline 2 & 2 \\
\hline & \\
\hline 1 & 1 \\
\hline 3 & 3 \\
\hline & \\
\hline$X$ & $X$ \\
\hline 2 & 2 \\
\hline$X$ & $X$ \\
\hline 3 & 3 \\
\hline$X$ & $X$ \\
\hline 3 & 3 \\
\hline 2 & $X$ \\
\hline & \\
\hline$X$ & $X$ \\
\hline
\end{tabular}

PHYLUM RHODOPHYTA

ACROSORIUM UNCINATUM

BOSSIELLA / CALLIARTHRON

CENTROCERAS CLAVULATUM

CERAMIACEAE

CERAMIUM CODICOLA

CHONDRIA SP.

COELOSEIRA COMPRESSA

CORALLINA OFFICINALIS

CORALLINA VANCOUVERIENSIS

CORALLINES - ENCRUSTING

CORALLINES - ERECT

ERYTHROCYSTIS SACCATA

GASTROCLONIUM COULTERI

GELIDIUM COULTERI

GIGARTINA CANALICULATA

GIGARTINA LEPTORHYNCHOS

GIGARTINA SPINOSA

HALIPTYLON GRACILE

JANIA SP.

LAURENCIA PACIFICA

LAURENCIA SPECTABILIS

LITHOTHRIX ASPERGILLUM

MELOBESIA MEDIOCRIS

NEMALION HELMINTHOIDES

NIENBURGIA ANDERSONIANA

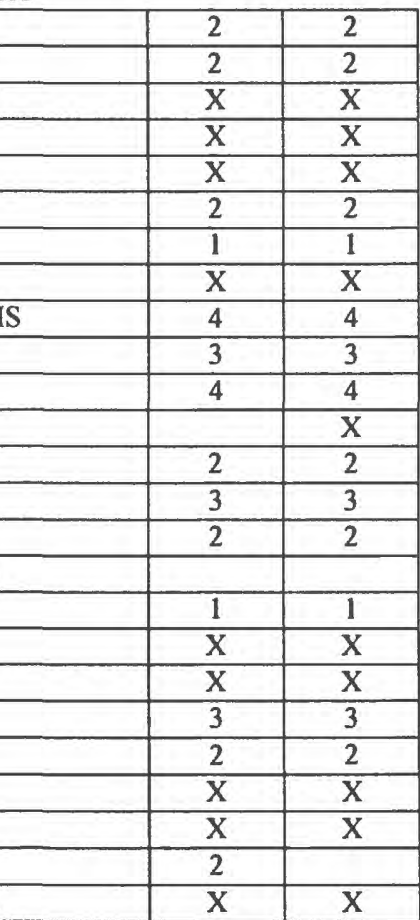

\begin{tabular}{|c|c|}
\hline 2 & 2 \\
\hline $\bar{X}$ & $\bar{X}$ \\
\hline $\mathrm{X}$ & $\mathrm{X}$ \\
\hline $\mathbf{X}$ & $\mathrm{X}$ \\
\hline $\bar{X}$ & $\mathrm{X}$ \\
\hline 2 & 2 \\
\hline$\overline{\mathbf{X}}$ & $\mathrm{X}$ \\
\hline 4 & 4 \\
\hline 3 & 3 \\
\hline \multirow[t]{2}{*}{4} & 4 \\
\hline & $\bar{X}$ \\
\hline 2 & 2 \\
\hline 3 & 3 \\
\hline \multirow[t]{2}{*}{2} & 2 \\
\hline & 1 \\
\hline $\bar{X}$ & $\mathrm{X}$ \\
\hline $\mathrm{X}$ & $\mathrm{X}$ \\
\hline 2 & 2 \\
\hline 2 & 2 \\
\hline$\overline{\mathrm{X}}$ & $\bar{X}$ \\
\hline $\bar{X}$ & $\bar{X}$ \\
\hline 1 & \\
\hline $\bar{X}$ & $\mathrm{X}$ \\
\hline
\end{tabular}

\begin{tabular}{|c|c|}
\hline$X$ & $X$ \\
\hline$X$ & $X$ \\
\hline$X$ & $X$ \\
\hline$X$ & $X$ \\
\hline$X$ & $X$ \\
\hline$X$ & $X$ \\
\hline$X$ & $X$ \\
\hline 4 & 4 \\
\hline 3 & 3 \\
\hline 4 & 4 \\
\hline$X$ & \\
\hline 3 & 3 \\
\hline 2 & 2 \\
\hline & \\
\hline & \\
\hline$X$ & $X$ \\
\hline$X$ & $X$ \\
\hline$X$ & $X$ \\
\hline$X$ & $X$ \\
\hline 1 & \\
\hline & \\
\hline
\end{tabular}


Table 7. Point Loma Rocky Intertidal Species Relative Abundance.

Relative abundance codes: $1=$ rare; $2=$ present; $3=$ common; $4=$ abundant

$\mathrm{X}=$ found, but abundance not determined; $\mathrm{J}=$ juvenile

\begin{tabular}{|l|l|}
\hline \multicolumn{2}{|c|}{ NAVY NORTH } \\
\hline SPR 95 & FALL 95 \\
\hline
\end{tabular}

\begin{tabular}{|l|l|}
\hline \multicolumn{2}{|c|}{ NAVY SOUTH } \\
\hline SPR 95 & FALL 95 \\
\hline
\end{tabular}

CABRILLO I, II, III

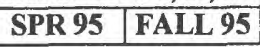

\begin{tabular}{|l|c|c|}
\hline PLOCAMIUM CARTILAGINEUM & 3 & 3 \\
\hline PLOCAMIUM VIOLACEUM & 2 & 2 \\
\hline PRIONITIS LANCEOLATA & 2 & 2 \\
\hline PTEROCLADIA CAPILLACEA & 3 & 3 \\
\hline RHODOCHORTON PURPUREUM & $\mathrm{X}$ & \\
\hline RHODYMENIA CALIFORNICA & 1 & 1 \\
\hline
\end{tabular}

\begin{tabular}{|l|l|}
\hline 3 & 3 \\
\hline 2 & 2 \\
\hline 2 & 2 \\
\hline 3 & 3 \\
\hline & \\
\hline & \\
\hline
\end{tabular}

\begin{tabular}{|c|c|}
\hline$X$ & $X$ \\
\hline$X$ & $X$ \\
\hline 2 & 2 \\
\hline$X$ & $X$ \\
\hline & \\
\hline & \\
\hline
\end{tabular}

PHYLUM TRACHEOPHYTA PHYLLOSPADIX TORREYI

\begin{tabular}{|l|l|}
\hline 4 & 4 \\
\hline
\end{tabular}

\begin{tabular}{|l|l|}
\hline 4 & 4 \\
\hline
\end{tabular}

\begin{tabular}{|l|l|}
\hline 4 & 4 \\
\hline
\end{tabular}

MISCELLANEOUS PLANT TYPES

CYANOBACTERIAL FILM

DIATOM FILM

\begin{tabular}{|l|l|l|}
\hline & $X$ & $X$ \\
\hline & $X$ & $X$ \\
\hline
\end{tabular}

\begin{tabular}{|l|l|}
\hline$X$ & $X$ \\
\hline$X$ & $X$ \\
\hline
\end{tabular}

\begin{tabular}{|l|l|}
\hline $\mathrm{X}$ & $\mathrm{X}$ \\
\hline $\mathrm{X}$ & $\mathrm{X}$ \\
\hline
\end{tabular}

PHYLUM PROTOZOA

GROMIA OVIFORMIS

PHYLUM PORIFERA

CLASS CALCAREA

CLATHRINA BLANCA

\begin{tabular}{|l|l|}
\hline 3 & 3 \\
\hline
\end{tabular}

\begin{tabular}{|l|l|}
\hline $\mathrm{X}$ & $\mathrm{X}$ \\
\hline
\end{tabular}

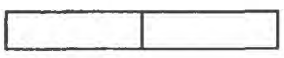

CLASS DEMOSPONGIAE

\begin{tabular}{|l|l|l|}
\hline APLYSINA FISTULARIS & 3 & 3 \\
\hline ENCRUSTING SPONGES & 3 & 3 \\
\hline -PINK & 2 & 2 \\
\hline -ORANGE & 2 & 2 \\
\hline -RED & $\mathrm{X}$ & $\mathrm{X}$ \\
\hline HALICLONA SP.
\end{tabular}

\begin{tabular}{|c|c|}
\hline 2 & 2 \\
\hline $\mathrm{X}$ & $\mathrm{X}$ \\
\hline $\bar{X}$ & $\mathrm{X}$ \\
\hline $\mathrm{X}$ & $\bar{X}$ \\
\hline & $\mathrm{X}$ \\
\hline
\end{tabular}

\begin{tabular}{|c|c|}
\hline $\mathrm{X}$ & $\mathrm{X}$ \\
\hline $\mathrm{X}$ & $\mathrm{X}$ \\
\hline $\mathrm{X}$ & $\mathrm{X}$ \\
\hline $\mathrm{X}$ & $\mathrm{X}$ \\
\hline & \\
\hline
\end{tabular}

PHYLUM CNIDARIA

CLASS HYDROZOA

OBELIA SP.

ORDER ACTINARIA

ANTHOPLEURA ELEGANTISSIMA EPIACTIS PROLIFERA

$\mathrm{X}$
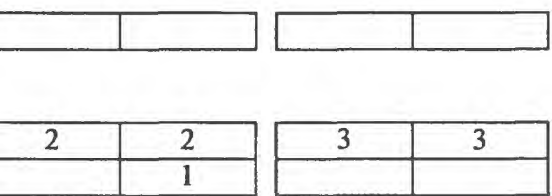

PHYLUM PLATYHELMINTHES NOTOPLANA

\begin{tabular}{|l|l|}
\hline $\mathrm{X}$ & $\mathrm{X}$ \\
\hline
\end{tabular}

\begin{tabular}{|l|l|}
\hline $\mathrm{X}$ & $\mathrm{X}$ \\
\hline
\end{tabular}

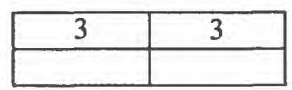

PHYLUM SIPUNCULA

PHASCOLOSOMA AGASSIZII

PHYLUM ANNELIDA

CLASS POLYCHAETA

\begin{tabular}{|l|c|c|}
\hline NEREID & & \\
\hline PHRAGMATOPOMA CALIFORNICA & $\mathrm{I}$ & $\mathrm{I}$ \\
\hline POLYNOID & $\mathrm{X}$ & \\
\hline SERPULID & $\mathrm{X}$ & $\mathrm{X}$ \\
\hline SPIROBRANCHUS SPINOSUS & $\mathrm{X}$ & $\mathrm{X}$ \\
\hline SPIRORBID & $\mathrm{X}$ & $\mathrm{X}$ \\
\hline
\end{tabular}

\begin{tabular}{|c|c|}
\hline & $X$ \\
\hline 2 & 2 \\
\hline & \\
\hline$X$ & $X$ \\
\hline$X$ & $X$ \\
\hline$X$ & $X$ \\
\hline
\end{tabular}

\begin{tabular}{|c|c|}
\hline & \\
\hline 2 & 2 \\
\hline & \\
\hline$X$ & $X$ \\
\hline$X$ & $X$ \\
\hline$X$ & $X$ \\
\hline
\end{tabular}

PHYLUM ARTHROPODA

CLASS CRUSTACEA

SUBCLASS CIRRIPEDIA 
Table 7. Point Loma Rocky Intertidal Species Relative Abundance.

Relative abundance codes: $1=$ rare; $2=$ present; $3=$ common; $4=$ abundant

$\mathrm{X}=$ found, but abundance not determined; $\mathrm{J}=$ juvenile

\begin{tabular}{|l|l|}
\hline \multicolumn{2}{|c|}{ NAVY NORTH } \\
\hline SPR 95 & FALL 95 \\
\hline
\end{tabular}

\begin{tabular}{|l|l|}
\hline \multicolumn{2}{|c|}{ NAVY SOUTH } \\
\hline SPR 95 & FALL 95 \\
\hline
\end{tabular}

CABRILLO I, II, III \begin{tabular}{|l|l|}
\hline SPR 95 & FALL 95 \\
\hline
\end{tabular}

\begin{tabular}{|l|l|l|}
\hline CHTHAMALUS DALLI / FISSUS & 2 & 2 \\
\hline POLLICIPES POLYMERUS & 1 & 1 \\
\hline TETRACLITA RUBESCENS & 2 & 2 \\
\hline
\end{tabular}

\begin{tabular}{|l|l|}
\hline 2 & 2 \\
\hline 2 & 2 \\
\hline 2 & 2 \\
\hline
\end{tabular}

\begin{tabular}{|l|l|}
\hline 2 & 2 \\
\hline 2 & 2 \\
\hline 3 & 3 \\
\hline
\end{tabular}

\section{SUBCLASS MALACOSTRACA} ORDER MYSIDA

\begin{tabular}{|c|c|c|}
\hline MYSIDS & & \\
\hline \multicolumn{3}{|c|}{ ORDER ISOPODA } \\
\hline IDOTEA SP. & $\mathrm{X}$ & $\bar{X}$ \\
\hline LIGIA OCCIDENTALIS & $\mathrm{X}$ & $\mathrm{X}$ \\
\hline
\end{tabular}

\section{E-}

\begin{tabular}{|l|l|}
\hline & $\mathbf{X}$ \\
\hline
\end{tabular}

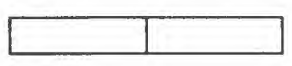

\section{ORDER AMPHIPODA}

GAMMARID

ORDER DECAPODA

SUBORDER NATANTIA

BETAEUS LONGIDACTYLUS

HEPTACARPUS SP.

LYSMATA CALIFORNICA

\begin{tabular}{|l|l|l|} 
& $\mathrm{X}$ & $\mathrm{X}$ \\
\hline & $\mathrm{X}$ & $\mathrm{X}$ \\
\hline & & $\mathrm{X}$ \\
\hline
\end{tabular}

\begin{tabular}{|l|l|}
\hline $\mathrm{X}$ & $\mathrm{X}$ \\
\hline $\mathrm{X}$ & $\mathrm{X}$ \\
\hline & \\
\hline
\end{tabular}

\begin{tabular}{|l|l|}
\hline$X$ & $X$ \\
\hline$X$ & $X$ \\
\hline & \\
\hline
\end{tabular}

\section{SUBORDER REPTANTIA}

SECTION PALINURA

PANULIRUS INTERRUPTUS

\begin{tabular}{|l|l|}
\hline & \\
\hline
\end{tabular}

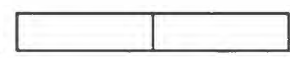

\begin{tabular}{|l|l|}
\hline $\mathrm{X}$ & \\
\hline
\end{tabular}

SECTION ANOMURA

PAGURUS HIRSUTIUSCULUS

PAGURUS SAMUELIS

PETROLISTHES SP.

\begin{tabular}{|c|c|}
\hline$X$ & $X$ \\
\hline$X$ & $X$ \\
\hline 2 & 2 \\
\hline
\end{tabular}

\begin{tabular}{|c|c|}
\hline$X$ & $X$ \\
\hline$X$ & $X$ \\
\hline 2 & 2 \\
\hline
\end{tabular}

\begin{tabular}{|l|l|}
\hline$X$ & $X$ \\
\hline$X$ & $X$ \\
\hline$X$ & $X$ \\
\hline
\end{tabular}

SECTION BRACHYURA

\begin{tabular}{|l|c|c|}
\hline CANCER ANTENNARIUS & & $\mathrm{X}$ \\
\hline CANCER SP. & & \\
\hline PACHYGRAPSUS CRASSIPES & 3 & 3 \\
\hline PARAXANTHIAS TAYLORI & $\mathrm{X}$ & $\mathrm{X}$ \\
\hline TALIEPUS NUTTALLI & $\mathrm{X}$ & $\mathrm{X}$ \\
\hline
\end{tabular}

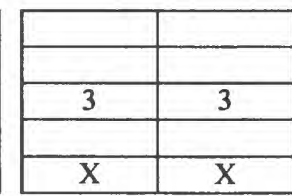

\begin{tabular}{|c|c|}
\hline $\mathrm{X}$ & \\
\hline & $\mathrm{XJ}$ \\
\hline 3 & 3 \\
\hline & \\
\hline & \\
\hline
\end{tabular}

PHYLUM MOLLUSCA

CLASS GASTROPODA

SUBCLASS PROSOBRANCHIA

ACANTHINA LUGUBRIS

ALIA CARINATA

ASTRAEA UNDOSA

CERATOSTOMA NUTTALLI

COLLISELLA DIGITALIS

COLLISELLA LIMATULA

COLLISELLA OCHRACEA

COLLISELLA PELTA

COLLISELLA SCABRA

COLLISELLA STRIGATELLA

CONUS CALIFORNICUS

CYPRAEA SPADICEA

FISSURELLA VOLCANO

HALIOTIS FULGENS

KELLETIA KELLETII

\begin{tabular}{|l|c|c|}
\hline & 3 & 3 \\
\hline & $\mathrm{X}$ & $\mathrm{X}$ \\
\hline LI & 1 & 2 \\
\hline & 2 & 2 \\
\hline & 4 & 4 \\
\hline & 3 & 3 \\
\hline & 1 & 1 \\
\hline & 4 & 1 \\
\hline & 4 & 4 \\
\hline & 1 & $X$ \\
\hline & & \\
\hline & & 3 \\
\hline
\end{tabular}

\begin{tabular}{|c|c|}
\hline 3 & 3 \\
\hline$X$ & $X$ \\
\hline$X$ & $X$ \\
\hline & 1 \\
\hline 4 & 4 \\
\hline 3 & 3 \\
\hline 1 & 1 \\
\hline 1 & 1 \\
\hline 4 & 4 \\
\hline 4 & 4 \\
\hline & \\
\hline & \\
\hline 3 & 3 \\
\hline & \\
\hline & \\
\hline
\end{tabular}

\begin{tabular}{|c|c|}
\hline 3 & 3 \\
\hline$X$ & $X$ \\
\hline$X$ & 2 \\
\hline$X$ & $X$ \\
\hline 3 & 3 \\
\hline 2 & 2 \\
\hline 1 & 1 \\
\hline 1 & 1 \\
\hline 3 & 3 \\
\hline 3 & 3 \\
\hline$X$ & $X$ \\
\hline$X$ & \\
\hline$X$ & $X$ \\
\hline 1 & \\
\hline 2 & 2 \\
\hline
\end{tabular}


Table 7. Point Loma Rocky Intertidal Species Relative Abundance.

Relative abundance codes: $1=$ rare; $2=$ present; $3=$ common; $4=$ abundant

$\mathrm{X}=$ found, but abundance not determined; $\mathrm{J}=$ juvenile

\begin{tabular}{|l|l|}
\hline \multicolumn{2}{|c|}{ NAVY NORTH } \\
\hline SPR 95 & FALL 95 \\
\hline
\end{tabular}

\begin{tabular}{|l|l|}
\hline \multicolumn{2}{|c|}{ NAVY SOUTH } \\
\hline SPR 95 & FALL 95 \\
\hline
\end{tabular}

CABRILLO I, II, III

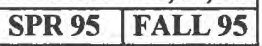

\begin{tabular}{|l|c|c|}
\hline LITTORINA KEENAE & 4 & 4 \\
\hline LITTORINA SCUTULATA & 3 & 3 \\
\hline LOTTIA GIGANTEA & 3 & 3 \\
\hline MACRON LIVIDUS & & $\mathrm{X}$ \\
\hline MEGATHURA CRENULATA & & \\
\hline PSEUDOMELATOMA SP. & & 1 \\
\hline PTEROPURPURA FESTIVA & 1 & \\
\hline ROPERIA POULSONI & & \\
\hline SERPULORBIS SQUAMIGERUS & 2 & 2 \\
\hline SIMNIA VIDLERI & & \\
\hline TEGULA AUREOTINCTA & 2 & 2 \\
\hline TEGULA EISENI & 4 & 4 \\
\hline TEGULA FUNEBRALIS & 2 & 2 \\
\hline VOLVARINA TAENIOLATA & $\mathrm{X}$ & $\mathrm{X}$ \\
\hline
\end{tabular}

\begin{tabular}{|l|l|}
\hline 4 & 4 \\
\hline 3 & 3 \\
\hline 3 & 3 \\
\hline & $X$ \\
\hline & \\
\hline & 1 \\
\hline & \\
\hline & 1 \\
\hline 2 & 2 \\
\hline & \\
\hline 2 & 1 \\
\hline 4 & 4 \\
\hline 2 & 2 \\
\hline$X$ & $X$ \\
\hline
\end{tabular}

\begin{tabular}{|c|c|}
\hline 3 & 3 \\
\hline 2 & 2 \\
\hline 3 & 3 \\
\hline & \\
\hline 1 & 1 \\
\hline & \\
\hline & \\
\hline & \\
\hline 2 & 2 \\
\hline & \\
\hline 4 & 4 \\
\hline$X$ & $X$ \\
\hline & \\
\hline
\end{tabular}

SUBCLASS OPISTHOBRANCHIA

APLYSIA CALIFORNICA

TYLODINA FUNGINA

\begin{tabular}{|l|l|l|}
\hline 1 & 1 \\
\hline
\end{tabular}
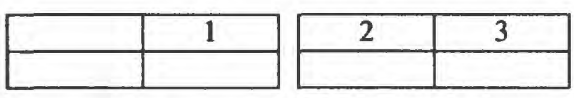

ORDER NUDIBRANCHIA

DIAULULA SANDIEGENSIS

DORIOPSILLA ALBOPUNCTATA (?)

\begin{tabular}{|l|l|}
\hline $\mathrm{X}$ & $\mathrm{X}$ \\
\hline & $\mathrm{X}$ \\
\hline
\end{tabular}
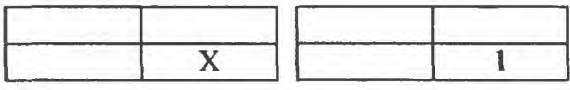

CLASS POLYPLACOPHORA

LEPIDOCHITONA HARTWEGII LEPIDOZONA PECTINULATA

MOPALIA MUSCOSA

NUTTALINA FLUXA

STENOPLAX CONSPICUA

\begin{tabular}{|c|c|}
\hline 3 & 3 \\
\hline$X$ & 1 \\
\hline 2 & 2 \\
\hline 4 & 4 \\
\hline$X$ & 2 \\
\hline
\end{tabular}

\begin{tabular}{|c|c|}
\hline 2 & 2 \\
\hline$X$ & 1 \\
\hline 2 & 2 \\
\hline 4 & 4 \\
\hline$X$ & 2 \\
\hline
\end{tabular}

\begin{tabular}{|c|c|}
\hline 2 & 2 \\
\hline$X$ & $X$ \\
\hline 2 & 2 \\
\hline 4 & 4 \\
\hline$X$ & $X$ \\
\hline
\end{tabular}

CLASS BIVALVIA

MYTILUS CALIFORNIANUS

PSEUDOCHAMA EXOGYRA

SEPTIFER BIFURCATUS

\begin{tabular}{|c|c|}
\hline 1 & 1 \\
\hline$X$ & $X$ \\
\hline 2 & 2 \\
\hline
\end{tabular}

\begin{tabular}{|c|c|}
\hline 1 & 1 \\
\hline$X$ & $X$ \\
\hline 2 & 2 \\
\hline
\end{tabular}

\begin{tabular}{|c|c|}
\hline 1 & 1 \\
\hline$X$ & $X$ \\
\hline 1 & 1 \\
\hline
\end{tabular}

\section{CLASS CEPHALOPODA}

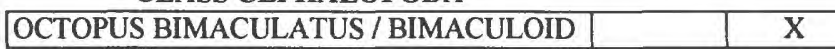
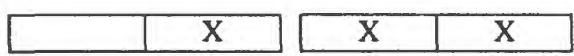

PHYLUM ECHINODERMATA

CLASS ASTEROIDEA

ASTERINA MINIATA

PISASTER GIGANTEUS

CLASS ECHINOIDEA

STRONGYLOCENTROTUS FRANCISCANU

CLASS OPHIUROIDEA

OPHIONEREIS ANNULATA

OPHIOPLOCUS ESMARKI

OPHIOTHRIX RUDIS

\begin{tabular}{|l|l|l|} 
& 2 & 2 \\
\hline & & \\
\hline
\end{tabular}

\begin{tabular}{|c|c|}
\hline 2 & 2 \\
\hline$X$ & $X$ \\
\hline 3 & 3 \\
\hline
\end{tabular}

\begin{tabular}{|l|l|}
\hline & \\
\hline $\mathrm{X}$ & \\
\hline $\mathrm{X}$ & $\mathrm{X}$ \\
\hline
\end{tabular}

CLASS HOLOTHUROIDEA

LISSOTHURIA NUTRIENS

PARASTICHOPUS PARVIMENSIS

\begin{tabular}{|l|l|l|}
\hline & 1 & \\
\hline
\end{tabular}
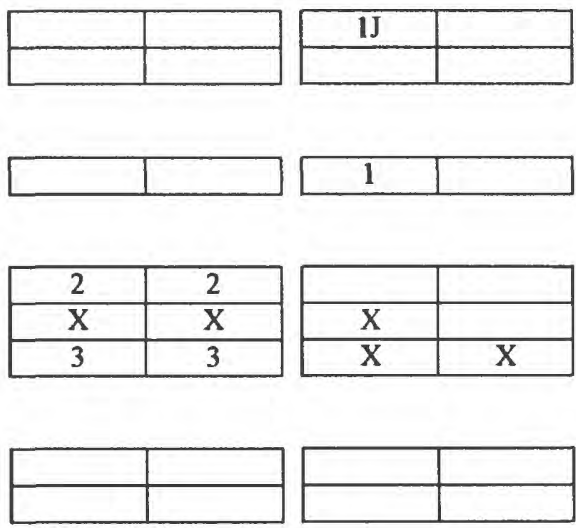

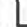

\begin{tabular}{|l|l|}
\hline 1 & \\
\hline
\end{tabular}

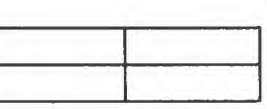


Table 7. Point Loma Rocky Intertidal Species Relative Abundance.

Relative abundance codes: $1=$ rare; $2=$ present; $3=$ common; $4=$ abundant

$\mathrm{X}=$ found, but abundance not determined; $\mathrm{J}=$ juvenile

NAVY NORTH SPR 95 1 FALL 95
NAVY SOUTH SPR 95 $\mid$ FALL 95
CABRILLO I, II, III \begin{tabular}{|l|l|}
\hline SPR 95 & FALL 95 \\
\hline
\end{tabular}

PHYLUM CHORDATA SUBPHYLUM UROCHORDATA

\begin{tabular}{|l|c|c|}
\hline BOTRYLLUS TUBERATUS & $\mathrm{X}$ & \\
\hline EUHERDMANIA CLAVIFORMIS & 2 & 2 \\
\hline METANDROCARPA TAYLORI & 2 & 2 \\
\hline TRIDIDEMNUM OPACUM & $\mathrm{X}$ & $\mathrm{X}$ \\
\hline
\end{tabular}

\begin{tabular}{|l|l|}
\hline & \\
\hline 2 & 2 \\
\hline 2 & 2 \\
\hline & \\
\hline
\end{tabular}

\begin{tabular}{|l|l|}
\hline & \\
\hline$X$ & $X$ \\
\hline$X$ & $X$ \\
\hline & \\
\hline
\end{tabular}

SUBPHYLUM VERTEBRATA

CLASS OSTEICHTHYES

ORDER GOBIESOCIFORMES

GOBIESOX RHESSODON

ORDER ATHERINIFORMES

\begin{tabular}{|l|l|l|}
\hline ATHERINIDS / LEURESTHES & & \\
\hline
\end{tabular}
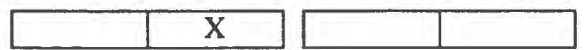

ORDER GASTEROSTEIFORMES BLENIIDAE

HYPSOBLENNIUS SP.
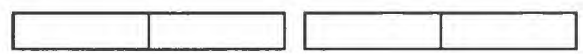

CLINIDAE
\begin{tabular}{|l|l|l|}
\hline GIBBONSIA SP. & & $\mathrm{X}$ \\
\hline \multicolumn{1}{|c|}{ COTTIDAE } & \\
\hline CLINOCOTTUS ANALIS & 3 & 3 \\
\hline
\end{tabular}
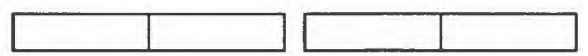

KYPHOSIDAE

GIRELLA NIGRICANS

HERMOSILLA AZUREA

\begin{tabular}{|l|l|}
\hline 3 & 3 \\
\hline \multicolumn{2}{|l}{} \\
\hline $2 J$ & $2 J$ \\
\hline & \\
\hline
\end{tabular}

\begin{tabular}{|l|l|}
\hline 3 & 3 \\
\hline
\end{tabular}

\begin{tabular}{|c|c|}
\hline $2 J$ & $2 J$ \\
\hline & \\
\hline
\end{tabular}




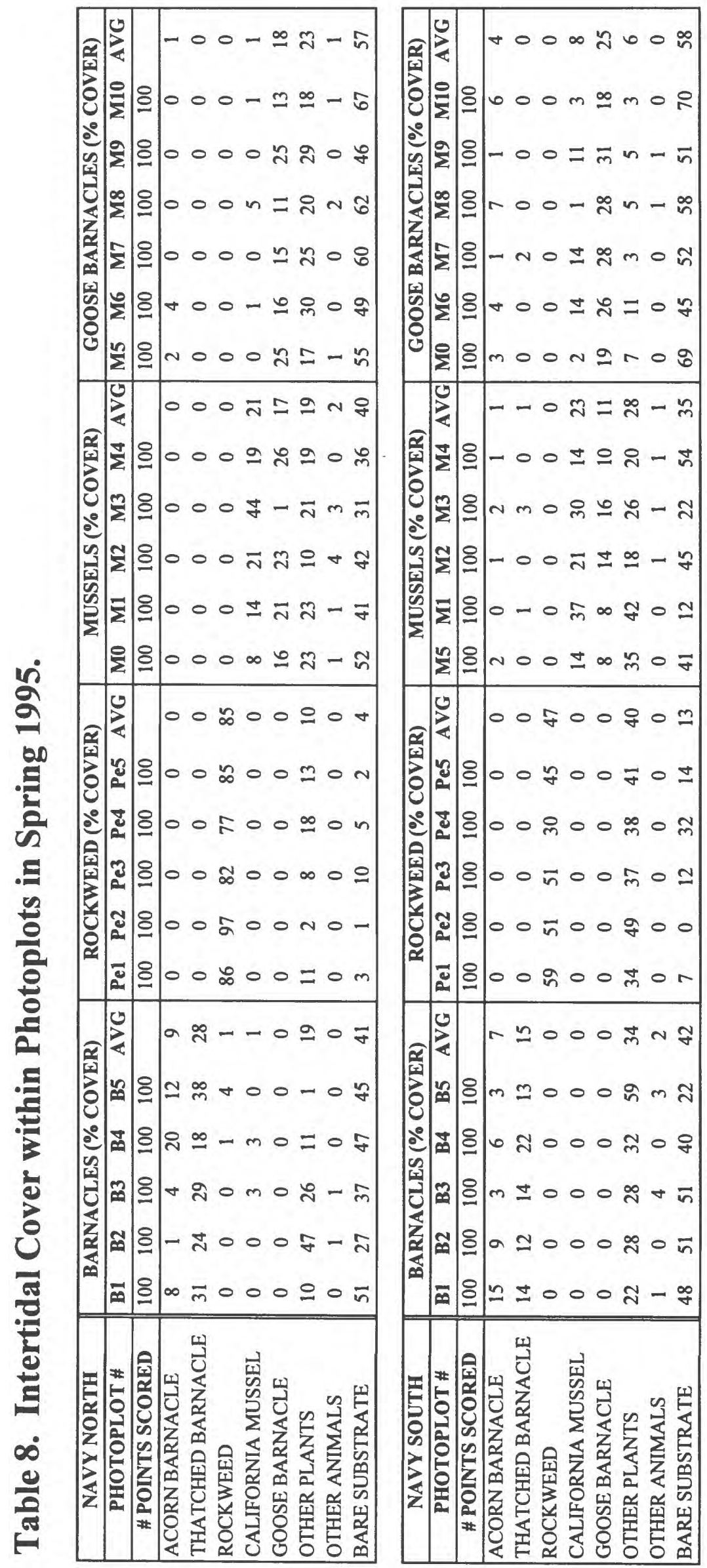




\begin{tabular}{|c|c|c|c|c|c|}
\hline 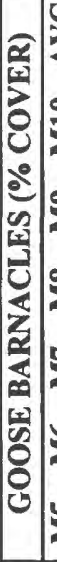 & 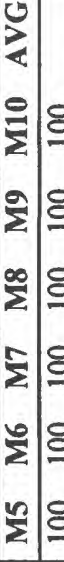 & 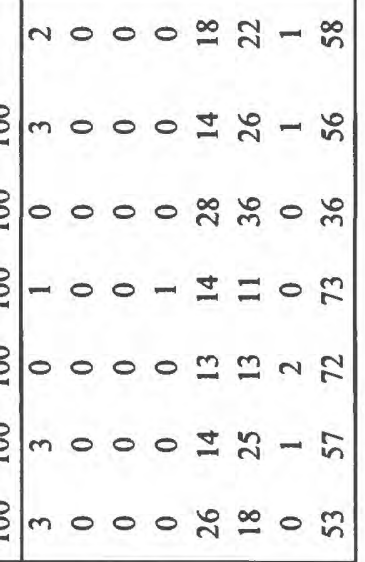 & 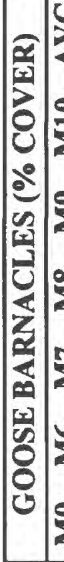 & 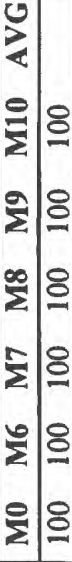 & 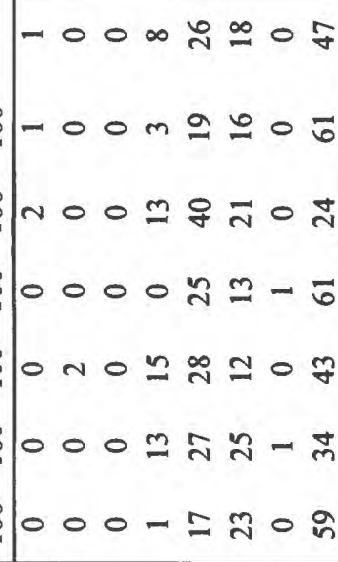 \\
\hline 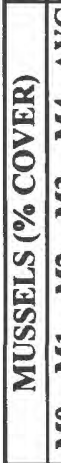 & 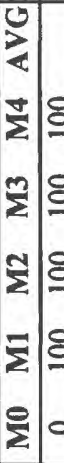 & 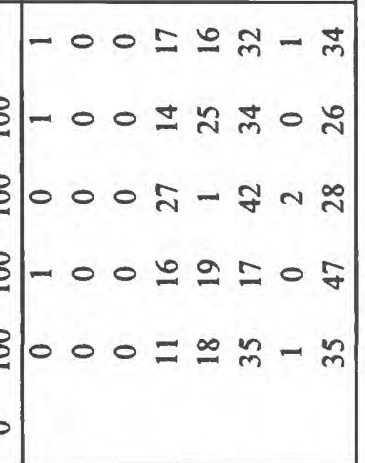 & 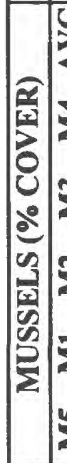 & 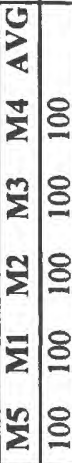 & 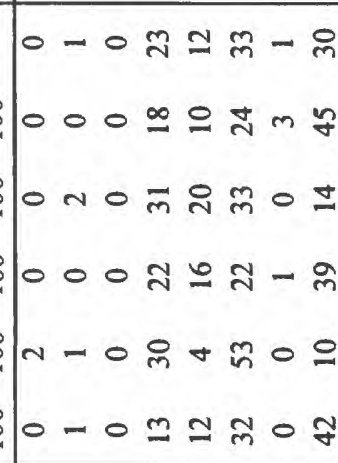 \\
\hline 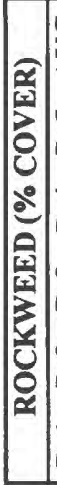 & 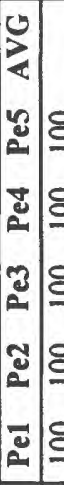 & 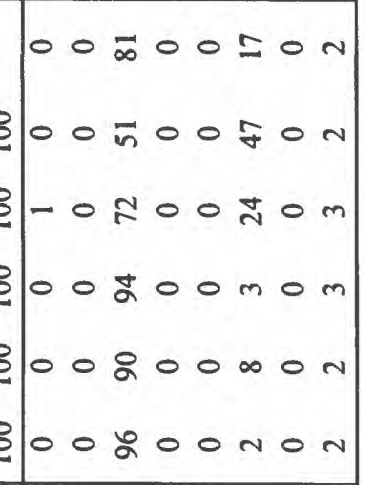 & $\mid$ & 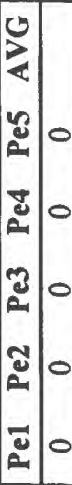 & \\
\hline 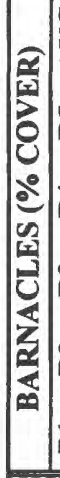 & 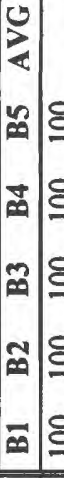 & 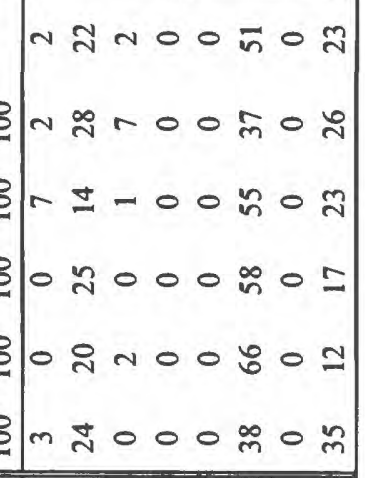 & 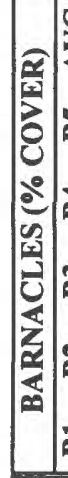 & 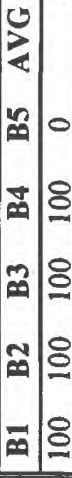 & 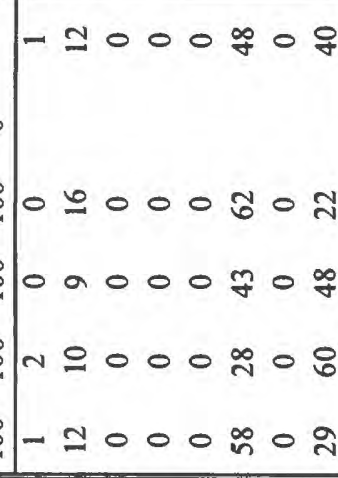 \\
\hline 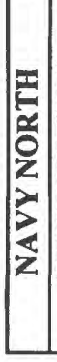 & 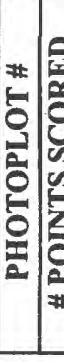 & 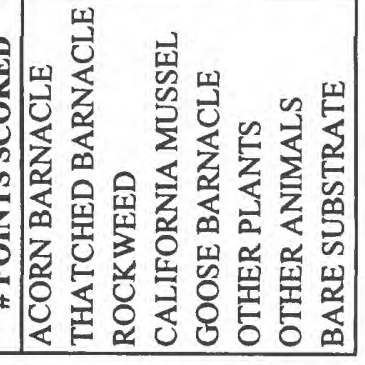 & $\mid \begin{array}{l}\mathbf{x} \\
5 \\
0 \\
0 \\
0 \\
2 \\
z \\
z \\
z\end{array}$ & 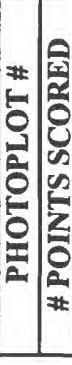 & 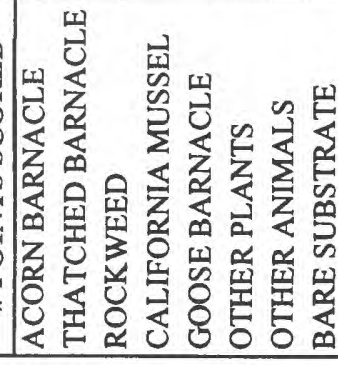 \\
\hline
\end{tabular}



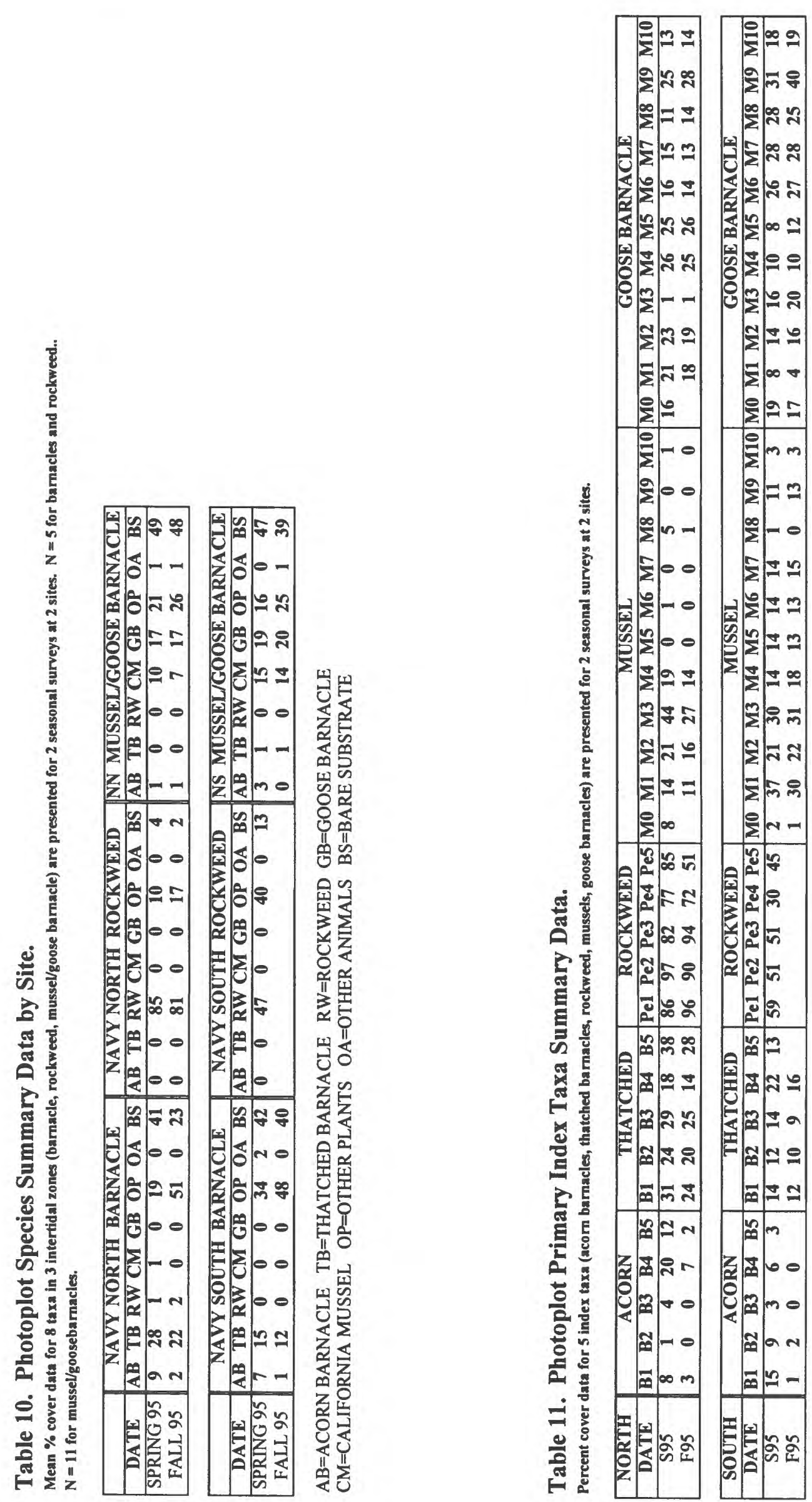
Table 12. Density and Size Distribution of Owl limpets within Circular Plots in Spring 1995

\begin{tabular}{|c|c|c|c|c|c|c|c|c|c|c|c|c|c|c|c|c|}
\hline \multirow{2}{*}{$\begin{array}{c}\text { LENGTH } \\
\text { (mm) }\end{array}$} & \multicolumn{8}{|c|}{ NAVY NORTH (\# OF LIMPETS) } & \multicolumn{8}{|c|}{ NAVY SOUTH (\# OF LIMPETS) } \\
\hline & 1 & 2 & 3 & 4 & 5 & 6 & ALL & $\%$ & 1 & 2 & 3 & 4 & 5 & 6 & ALL & $\%$ \\
\hline 15 & $\overline{0}$ & 0 & 1 & 0 & 1 & 0 & 2 & 1 & $\begin{array}{ll}0 & \\
\end{array}$ & $\overline{0}$ & 0 & 0 & 0 & 0 & 0 & 0 \\
\hline 16 & 0 & 0 & 0 & 0 & 0 & 0 & 0 & 0 & 0 & 0 & 1 & 1 & 0 & 0 & 2 & 1 \\
\hline 17 & 0 & 0 & 0 & 0 & 0 & 0 & 0 & 0 & 0 & 0 & 0 & 0 & 0 & 0 & 0 & 0 \\
\hline 18 & 0 & 1 & 0 & 0 & 0 & 1 & 2 & 1 & 1 & 0 & 1 & 1 & 0 & 1 & 4 & 1 \\
\hline 19 & 0 & 1 & 0 & 0 & 0 & 0 & 1 & 1 & 0 & 1 & 0 & 0 & 0 & 0 & 1 & 0 \\
\hline 20 & 1 & 0 & 0 & 0 & 1 & 2 & 4 & 2 & 1 & 0 & 1 & 0 & 1 & 1 & 4 & 1 \\
\hline 21 & 1 & 1 & 0 & 0 & 1 & 0 & 3 & 2 & 0 & 0 & 0 & 2 & 1 & 1 & 4 & 1 \\
\hline 22 & 1 & 1 & 0 & 0 & 2 & 0 & 4 & 2 & 1 & 0 & 1 & 1 & 0 & 0 & 3 & 1 \\
\hline 23 & 1 & 0 & 2 & 1 & 0 & 0 & 4 & 2 & 1 & 1 & 1 & 1 & 1 & 0 & 5 & 2 \\
\hline 24 & 0 & 0 & 0 & 0 & 0 & 0 & 0 & 0 & 1 & 1 & 0 & 0 & 0 & 1 & 3 & 1 \\
\hline 25 & 1 & 1 & 0 & 0 & 0 & 1 & 3 & 2 & 4 & 0 & 0 & 2 & 1 & 2 & 9 & 3 \\
\hline 26 & 1 & 1 & 0 & 0 & 2 & 1 & 5 & 3 & 0 & 0 & 2 & 2 & 2 & 2 & 8 & 3 \\
\hline 27 & 0 & 0 & 2 & 4 & 0 & 1 & 7 & 4 & 3 & 0 & 0 & 4 & 3 & 2 & 12 & 4 \\
\hline 28 & 0 & 1 & 0 & 2 & 0 & 0 & 3 & 2 & 1 & 0 & 2 & 1 & 1 & 1 & 6 & 2 \\
\hline 29 & 2 & 0 & 0 & 1 & 0 & 0 & 3 & 2 & 1 & 0 & 0 & 3 & 2 & 3 & 9 & 3 \\
\hline 30 & 1 & 2 & 1 & 1 & 1 & 0 & 6 & 3 & 0 & 1 & 1 & 2 & 0 & 1 & 5 & 2 \\
\hline 31 & 1 & 1 & 0 & 2 & 0 & 0 & 4 & 2 & 3 & 2 & 2 & 2 & 2 & 4 & 15 & 6 \\
\hline 32 & 1 & 1 & 0 & 1 & 1 & 2 & 6 & 3 & 2 & 0 & 2 & 3 & 1 & 3 & 11 & 4 \\
\hline 33 & 1 & 1 & 0 & 1 & 0 & 0 & 3 & 2 & 1 & 1 & 0 & 2 & 2 & 2 & 8 & 3 \\
\hline 34 & 1 & 1 & 2 & 0 & 2 & 2 & 8 & 4 & 0 & 2 & 0 & 2 & 2 & 2 & 8 & 3 \\
\hline 35 & 1 & 1 & 1 & 1 & 3 & 2 & 9 & 5 & 2 & 2 & 1 & 1 & 0 & 1 & 7 & 3 \\
\hline 36 & 0 & 2 & 1 & 1 & 0 & 0 & 4 & 2 & 2 & 2 & 2 & 2 & 2 & 0 & 10 & 4 \\
\hline 37 & 2 & 5 & 3 & 0 & 2 & 1 & 13 & 7 & 4 & 0 & 2 & 3 & 2 & 3 & 14 & 5 \\
\hline 38 & 3 & 4 & 3 & 2 & 2 & 1 & 15 & 8 & 1 & 0 & 2 & 1 & 2 & 4 & 10 & 4 \\
\hline 39 & 0 & 1 & 0 & 1 & 3 & 3 & 8 & 4 & 2 & 3 & 0 & 2 & 2 & 1 & 10 & 4 \\
\hline 40 & 6 & 0 & 0 & 1 & 4 & 7 & 18 & 10 & 1 & 2 & 1 & 0 & 0 & 2 & 6 & 2 \\
\hline 41 & 2 & 1 & 1 & 1 & 1 & 1 & 7 & 4 & 2 & 1 & 0 & 2 & 1 & 5 & 11 & 4 \\
\hline 42 & 1 & 0 & 1 & 1 & 1 & 3 & 7 & 4 & 0 & 0 & 3 & 1 & 1 & 4 & 9 & 3 \\
\hline 43 & 1 & 4 & 2 & 1 & 3 & 3 & 14 & 7 & 2 & 0 & 2 & 2 & 2 & 1 & 9 & 3 \\
\hline 44 & 0 & 0 & 1 & 0 & 2 & 0 & 3 & 2 & 3 & 1 & 2 & 4 & 3 & 2 & 15 & 6 \\
\hline 45 & 3 & 1 & 0 & 1 & 1 & 1 & 7 & 4 & 2 & 1 & 1 & 0 & 1 & 3 & 8 & 3 \\
\hline 46 & 0 & 1 & 0 & 0 & 0 & 0 & 1 & 1 & 1 & 2 & 1 & 1 & 1 & 4 & 10 & 4 \\
\hline 47 & 1 & 0 & 1 & 0 & 1 & 1 & 4 & 2 & 3 & 0 & 0 & 0 & 1 & 1 & 5 & 2 \\
\hline 48 & 0 & 1 & 2 & 0 & 0 & 0 & 3 & 2 & 0 & 1 & 0 & 1 & 1 & 0 & 3 & 1 \\
\hline 49 & 0 & 0 & 1 & 0 & 1 & 0 & 2 & 1 & 1 & 1 & 1 & 0 & 0 & 0 & 3 & 1 \\
\hline 50 & 2 & 0 & 0 & 0 & 1 & 0 & 3 & 2 & 1 & 0 & 1 & 3 & 0 & 1 & 6 & 2 \\
\hline 51 & 0 & 0 & 0 & 0 & 0 & 0 & 0 & 0 & 1 & 1 & 0 & 0 & 0 & 0 & 2 & 1 \\
\hline 52 & 0 & 0 & 0 & 0 & 0 & 0 & 0 & 0 & 1 & 1 & 0 & 2 & 1 & 1 & 6 & 2 \\
\hline 53 & 0 & 0 & 0 & 0 & 0 & 0 & 0 & 0 & 0 & 0 & 0 & 0 & 0 & 1 & 1 & 0 \\
\hline 54 & 0 & 0 & 0 & 1 & 0 & 0 & 1 & 1 & 1 & 0 & 1 & 0 & 1 & 0 & 3 & 1 \\
\hline 55 & 0 & 0 & 0 & 0 & 0 & 0 & 0 & 0 & 0 & 0 & 0 & 0 & 0 & 0 & 0 & 0 \\
\hline 56 & 0 & 0 & 0 & 0 & 0 & 0 & 0 & 0 & 0 & 0 & 0 & 0 & 1 & 1 & 2 & 1 \\
\hline 57 & 0 & 0 & 0 & 0 & 0 & 0 & 0 & 0 & 0 & 0 & 0 & 0 & 0 & 0 & 0 & 0 \\
\hline 58 & 0 & 0 & 0 & 0 & 0 & 0 & 0 & 0 & 0 & 0 & 0 & 0 & 0 & 0 & 0 & 0 \\
\hline 59 & 0 & 0 & 0 & 0 & 0 & 0 & 0 & 0 & 0 & 0 & 0 & 0 & 0 & 0 & 0 & 0 \\
\hline 60 & 0 & 0 & 0 & 0 & 0 & 0 & 0 & 0 & 1 & 0 & 0 & 0 & 0 & 1 & 2 & 1 \\
\hline 61 & 0 & 0 & 0 & 0 & 0 & 0 & 0 & 0 & 0 & 0 & 0 & 0 & 0 & 0 & 0 & 0 \\
\hline 62 & 0 & 0 & 0 & 0 & 0 & 0 & 0 & 0 & 0 & 0 & 0 & 0 & 0 & 0 & 0 & 0 \\
\hline 63 & 0 & 0 & 0 & 0 & 0 & 0 & 0 & 0 & 0 & 0 & 0 & 0 & 1 & 0 & 1 & 0 \\
\hline 64 & 0 & 0 & 0 & 0 & 0 & 0 & 0 & 0 & 0 & 0 & 0 & 0 & 0 & 0 & 0 & 0 \\
\hline 65 & 0 & 0 & 0 & 0 & 0 & 0 & 0 & 0 & 0 & 0 & 0 & 0 & 0 & 0 & 0 & 0 \\
\hline 66 & 0 & 0 & 0 & 0 & 0 & 0 & 0 & 0 & 0 & 0 & 0 & 0 & 0 & 0 & 0 & 0 \\
\hline 67 & 0 & 0 & 0 & 0 & 0 & 0 & 0 & 0 & 0 & 0 & 0 & 0 & 0 & 0 & 0 & 0 \\
\hline 68 & 0 & 0 & 0 & 0 & 0 & 0 & 0 & 0 & 0 & 0 & 0 & 0 & 0 & 0 & 0 & 0 \\
\hline
\end{tabular}


Table 12. Density and Size Distribution of Owl limpets within Circular Plots in Spring 1995

\begin{tabular}{|c|c|c|c|c|c|c|c|c|c|c|c|c|c|c|c|c|}
\hline \multirow{2}{*}{$\begin{array}{c}\text { LENGTH } \\
(\mathrm{mm})\end{array}$} & \multicolumn{8}{|c|}{ NAVY NORTH (\# OF LIMPETS) } & \multicolumn{8}{|c|}{ NAVY SOUTH (\# OF LIMPETS) } \\
\hline & 1 & 2 & 3 & 4 & 5 & 6 & ALL & $\%$ & 1 & 2 & 3 & 4 & 5 & 6 & ALL & $\%$ \\
\hline 69 & 0 & 0 & $\overline{0}$ & 0 & 0 & 0 & 0 & 0 & 0 & 0 & 0 & 0 & 0 & 0 & 0 & 0 \\
\hline 70 & 0 & 0 & 0 & 0 & 0 & 0 & 0 & 0 & 0 & 0 & 0 & 0 & 0 & 0 & 0 & 0 \\
\hline 71 & 0 & 0 & 0 & 0 & 0 & 0 & 0 & 0 & 0 & 0 & 0 & 0 & 0 & 0 & 0 & 0 \\
\hline 72 & 0 & 0 & 0 & 0 & 0 & 0 & 0 & 0 & 0 & 0 & 0 & 0 & 0 & 0 & 0 & 0 \\
\hline 73 & 0 & 0 & 0 & 0 & 0 & 0 & 0 & 0 & 0 & 0 & 0 & 0 & 0 & 0 & 0 & 0 \\
\hline 74 & 0 & 0 & 0 & 0 & 0 & 0 & 0 & 0 & 0 & 0 & 0 & 0 & 0 & 0 & 0 & 0 \\
\hline 75 & 0 & 0 & 0 & 0 & 0 & 0 & 0 & 0 & 0 & 0 & 0 & 0 & 0 & 0 & 0 & 0 \\
\hline 76 & 0 & 0 & 0 & 0 & 0 & 0 & 0 & 0 & 0 & 0 & 0 & 0 & 0 & 0 & 0 & 0 \\
\hline 77 & 0 & 0 & 0 & 0 & 0 & 0 & 0 & 0 & 0 & 0 & 0 & 0 & 0 & 0 & 0 & 0 \\
\hline 78 & 0 & 0 & 0 & 0 & 0 & 0 & 0 & 0 & 0 & 0 & 0 & 0 & 0 & 0 & 0 & 0 \\
\hline 79 & 0 & 0 & 0 & 0 & 0 & 0 & 0 & 0 & 0 & 0 & 0 & 0 & 0 & 0 & 0 & 0 \\
\hline 80 & 0 & 0 & 0 & 0 & 0 & 0 & 0 & 0 & 0 & 0 & 0 & 0 & 0 & 0 & 0 & 0 \\
\hline 81 & 0 & 0 & 0 & 0 & 0 & 0 & 0 & 0 & 0 & 0 & 0 & 0 & 0 & 0 & 0 & 0 \\
\hline 82 & 0 & 0 & 0 & 0 & 0 & 0 & 0 & 0 & 0 & 0 & 0 & 0 & 0 & 0 & 0 & 0 \\
\hline 83 & 0 & 0 & 0 & 0 & 0 & 0 & 0 & 0 & 0 & 0 & 0 & 0 & 0 & 0 & 0 & 0 \\
\hline 84 & 0 & 0 & 0 & 0 & 0 & 0 & 0 & 0 & 0 & 0 & 0 & 0 & 0 & 0 & 0 & 0 \\
\hline 85 & 0 & 0 & 0 & 0 & 0 & 0 & 0 & 0 & 0 & 0 & 0 & 0 & 0 & 0 & 0 & 0 \\
\hline 86 & 0 & 0 & 0 & 0 & 0 & 0 & 0 & 0 & 0 & 0 & 0 & 0 & 0 & 0 & 0 & 0 \\
\hline 87 & 0 & 0 & 0 & 0 & 0 & 0 & 0 & 0 & 0 & 0 & 0 & 0 & 0 & 0 & 0 & 0 \\
\hline 88 & 0 & 0 & 0 & 0 & 0 & 0 & 0 & 0 & 0 & 0 & 0 & 0 & 0 & 0 & 0 & 0 \\
\hline 89 & 0 & 0 & 0 & 0 & 0 & 0 & 0 & 0 & 0 & 0 & 0 & 0 & 0 & 0 & 0 & 0 \\
\hline 90 & 0 & 0 & 0 & 0 & 0 & 0 & 0 & 0 & 0 & 0 & 0 & 0 & 0 & 0 & 0 & 0 \\
\hline TOTAL \# & 35 & 34 & 25 & 24 & 36 & 33 & 187 & 100 & 51 & 27 & 34 & 54 & 42 & 62 & 270 & 100 \\
\hline MIN SIZE & 20 & 18 & 15 & 23 & 15 & 18 & 15 & & 18 & 19 & 16 & 16 & 20 & 18 & 16 & \\
\hline MAX SIZE & 50 & 48 & 49 & 54 & 50 & 47 & 54 & & 60 & 52 & 54 & 52 & 63 & 60 & 63 & \\
\hline AVG SIZE & 36 & 35 & 37 & 34 & 36 & 36 & 36 & & 37 & 38 & 35 & 35 & 37 & 37 & 36 & \\
\hline ST DEV & 8 & 8 & 9 & 7 & 9 & 8 & 8 & & 10 & 8 & 10 & 9 & 10 & 9 & 9 & \\
\hline
\end{tabular}


Table 13. Density and Size Distribution of Owl limpets within Circular Plots in Fall 1995.

\begin{tabular}{|c|c|c|c|c|c|c|c|c|c|c|c|c|c|c|c|c|}
\hline \multirow{2}{*}{$\begin{array}{c}\text { LENGTH } \\
\text { (MM) }\end{array}$} & \multicolumn{8}{|c|}{ NAVY NORTH (\# OF LIMPETS) } & \multicolumn{8}{|c|}{ NAVY SOUTH (\# OF LIMPETS) } \\
\hline & 1 & 2 & 3 & 4 & 5 & 6 & ALL & $\%$ & 1 & 2 & 3 & 4 & 5 & 6 & ALL & $\%$ \\
\hline 15 & 0 & 0 & 0 & 0 & 0 & 0 & 0 & 0 & 0 & 0 & 2 & 1 & 0 & 1 & 4 & 1 \\
\hline 16 & 0 & 1 & 1 & 0 & 0 & 0 & 2 & 1 & 0 & 0 & 2 & 2 & 0 & 0 & 4 & 1 \\
\hline 17 & 1 & 0 & 0 & 0 & 1 & 0 & 2 & 1 & 1 & 0 & 1 & 2 & 0 & 0 & 4 & 1 \\
\hline 18 & 0 & 0 & 0 & 0 & 1 & 0 & 1 & 1 & 0 & 0 & 0 & 1 & 0 & 0 & 1 & 0 \\
\hline 19 & 0 & 0 & 0 & 0 & 0 & 0 & 0 & 0 & 0 & 0 & 0 & 3 & 0 & 1 & 4 & 1 \\
\hline 20 & 2 & 0 & 0 & 0 & 0 & 0 & 2 & 1 & 0 & 0 & 1 & 1 & 1 & 0 & 3 & 1 \\
\hline 21 & 1 & 0 & 0 & 2 & 0 & 0 & 3 & 2 & 0 & 0 & 0 & 0 & 0 & 1 & 1 & 0 \\
\hline 22 & 0 & 0 & 1 & 0 & 1 & 0 & 2 & 1 & 0 & 0 & 1 & 0 & 0 & 0 & 1 & 0 \\
\hline 23 & 0 & 0 & 0 & 0 & 1 & 0 & 1 & 1 & 0 & 0 & 1 & 3 & 1 & 0 & 5 & 2 \\
\hline 24 & 0 & 0 & 1 & 0 & 0 & 0 & 1 & 1 & 0 & 0 & 0 & 0 & 0 & 0 & 0 & 0 \\
\hline 25 & 1 & 1 & 0 & 0 & 2 & 0 & 4 & 2 & 0 & 0 & 0 & 0 & 0 & 1 & 1 & 0 \\
\hline 26 & 0 & 0 & 0 & 1 & 1 & 1 & 3 & 2 & 0 & 0 & 0 & 2 & 0 & 1 & 3 & 1 \\
\hline 27 & 0 & 0 & 1 & 0 & 2 & 0 & 3 & 2 & 1 & 1 & 2 & 1 & 1 & 0 & 6 & 2 \\
\hline 28 & 0 & 0 & 2 & 2 & 0 & 0 & 4 & 2 & 1 & 1 & 0 & 1 & 2 & 0 & 5 & 2 \\
\hline 29 & 1 & 0 & 0 & 2 & 1 & 0 & 4 & 2 & 1 & 2 & 1 & 1 & 0 & 1 & 6 & 2 \\
\hline 30 & 2 & 1 & 0 & 2 & 0 & 0 & 5 & 3 & 3 & 0 & 4 & 2 & 0 & 1 & 10 & 3 \\
\hline 31 & 1 & 1 & 0 & 2 & 0 & 1 & 5 & 3 & 1 & 1 & 1 & 5 & 1 & 0 & 9 & 3 \\
\hline 32 & 1 & 1 & 1 & 1 & 2 & 1 & 7 & 4 & 1 & 1 & 0 & 2 & 0 & 1 & 5 & 2 \\
\hline 33 & 0 & 2 & 0 & 4 & 0 & 1 & 7 & 4 & 1 & 0 & 0 & 4 & 1 & 2 & 8 & 3 \\
\hline 34 & 2 & 0 & 1 & 2 & 0 & 1 & 6 & 3 & 2 & 2 & 1 & 3 & 1 & 1 & 10 & 3 \\
\hline 35 & 2 & 0 & 0 & 2 & 0 & 0 & 4 & 2 & 3 & 0 & 2 & 1 & 2 & 2 & 10 & 3 \\
\hline 36 & 1 & 0 & 0 & 0 & 1 & 3 & 5 & 3 & 4 & 2 & 0 & 2 & 0 & 0 & 8 & 3 \\
\hline 37 & 0 & 2 & 0 & 1 & 1 & 0 & 4 & 2 & 1 & 0 & 1 & 1 & 3 & 1 & 7 & 2 \\
\hline 38 & 1 & 1 & 0 & 1 & 2 & 1 & 6 & 3 & 4 & 1 & 0 & 0 & 3 & 1 & 9 & 3 \\
\hline 39 & 2 & 1 & 1 & 0 & 3 & 1 & 8 & 4 & 2 & 0 & 3 & 4 & 0 & 3 & 12 & 4 \\
\hline 40 & 1 & 4 & 0 & 1 & 0 & 2 & 8 & 4 & 1 & 1 & 0 & 2 & 2 & 3 & 9 & 3 \\
\hline 41 & 0 & 0 & 2 & 0 & 4 & 0 & 6 & 3 & 1 & 4 & 1 & 1 & 0 & 4 & 11 & 4 \\
\hline 42 & 0 & 3 & 1 & 0 & 2 & 1 & 7 & 4 & 1 & 1 & 3 & 3 & 4 & 4 & 16 & 6 \\
\hline 43 & 3 & 0 & 1 & 2 & 2 & 0 & 8 & 4 & 0 & 3 & 3 & 2 & 3 & 1 & 12 & 4 \\
\hline 44 & 0 & 3 & 0 & 1 & 2 & 0 & 6 & 3 & 0 & 1 & 0 & 2 & 1 & 3 & 7 & 2 \\
\hline 45 & 1 & 0 & 3 & 1 & 1 & 1 & 7 & 4 & 5 & 2 & 1 & 3 & 0 & 3 & 14 & 5 \\
\hline 46 & 2 & 0 & 1 & 0 & 0 & 2 & 5 & 3 & 1 & 3 & 3 & 0 & 1 & 0 & 8 & 3 \\
\hline 47 & 3 & 2 & 2 & 1 & 2 & 0 & 10 & 6 & 3 & 4 & 0 & 5 & 1 & 2 & 15 & 5 \\
\hline 48 & 2 & 0 & 2 & 1 & 1 & 2 & 8 & 4 & 1 & 2 & 2 & 2 & 0 & 2 & 9 & 3 \\
\hline 49 & 0 & 3 & 2 & 1 & 0 & 1 & 7 & 4 & 1 & 0 & 0 & 1 & 0 & 1 & 3 & 1 \\
\hline 50 & 1 & 1 & 0 & 1 & 0 & 1 & 4 & 2 & 1 & 0 & 2 & 0 & 1 & 4 & 8 & 3 \\
\hline 51 & 1 & 0 & 1 & 0 & 1 & 0 & 3 & 2 & 1 & 2 & 1 & 3 & 1 & 1 & 9 & 3 \\
\hline 52 & 2 & 0 & 0 & 0 & 2 & 1 & 5 & 3 & 1 & 0 & 0 & 1 & 2 & 1 & 5 & 2 \\
\hline 53 & 0 & 0 & 2 & 1 & 0 & 1 & 4 & 2 & 0 & 1 & 0 & 1 & 0 & 3 & 5 & 2 \\
\hline 54 & 0 & 0 & 0 & 0 & 0 & 0 & 0 & 0 & 0 & 0 & 0 & 1 & 0 & 0 & 1 & 0 \\
\hline 55 & 1 & 0 & 2 & 0 & 0 & 1 & 4 & 2 & 2 & 0 & 0 & 0 & 1 & 3 & 6 & 2 \\
\hline 56 & 0 & 0 & 0 & 0 & 0 & 0 & 0 & 0 & 1 & 0 & 0 & 0 & 1 & 2 & 4 & 1 \\
\hline 57 & 0 & 0 & 0 & 0 & 0 & 0 & 0 & 0 & 0 & 1 & 1 & 0 & 1 & 0 & 3 & 1 \\
\hline 58 & 0 & 0 & 0 & 0 & 0 & 0 & 0 & 0 & 0 & 0 & 0 & 0 & 1 & 1 & 2 & 1 \\
\hline 59 & 0 & 0 & 0 & 0 & 0 & 0 & 0 & 0 & 0 & 0 & 0 & 0 & 0 & 1 & 1 & 0 \\
\hline 60 & 0 & 0 & 0 & 0 & 0 & 0 & 0 & 0 & 0 & 0 & 0 & 1 & 0 & 0 & 1 & 0 \\
\hline 61 & 0 & 0 & 0 & 0 & 0 & 0 & 0 & 0 & 0 & 0 & 0 & 0 & 1 & 1 & 2 & 1 \\
\hline 62 & 0 & 0 & 0 & 0 & 0 & 0 & 0 & 0 & 0 & 0 & 1 & 0 & 0 & 0 & 1 & 0 \\
\hline 63 & 0 & 0 & 0 & 0 & 0 & 0 & 0 & 0 & 0 & 0 & 0 & 0 & 0 & 1 & 1 & 0 \\
\hline 64 & 0 & 0 & 0 & 0 & 0 & 0 & 0 & 0 & 0 & 0 & 0 & 0 & 0 & 0 & 0 & 0 \\
\hline 65 & 0 & 0 & 0 & 0 & 0 & 0 & 0 & 0 & 0 & 0 & 0 & 0 & 0 & 0 & 0 & 0 \\
\hline 66 & 0 & 0 & 0 & 0 & 0 & 0 & 0 & 0 & 0 & 0 & 0 & 0 & 1 & 0 & 1 & 0 \\
\hline 67 & 0 & 0 & 0 & 0 & 0 & 0 & 0 & 0 & 0 & 0 & 0 & 0 & 0 & 0 & 0 & 0 \\
\hline 68 & 0 & 0 & 0 & 0 & 0 & 0 & 0 & 0 & 0 & 0 & 0 & 0 & 0 & 0 & 0 & 0 \\
\hline
\end{tabular}


Table 13. Density and Size Distribution of Owl limpets within Circular Plots in Fall 1995.

\begin{tabular}{|c||cccccc|cc|cccccc|cc|}
\hline \multicolumn{1}{|c|}{ LENGTH } \\
(MM)
\end{tabular}



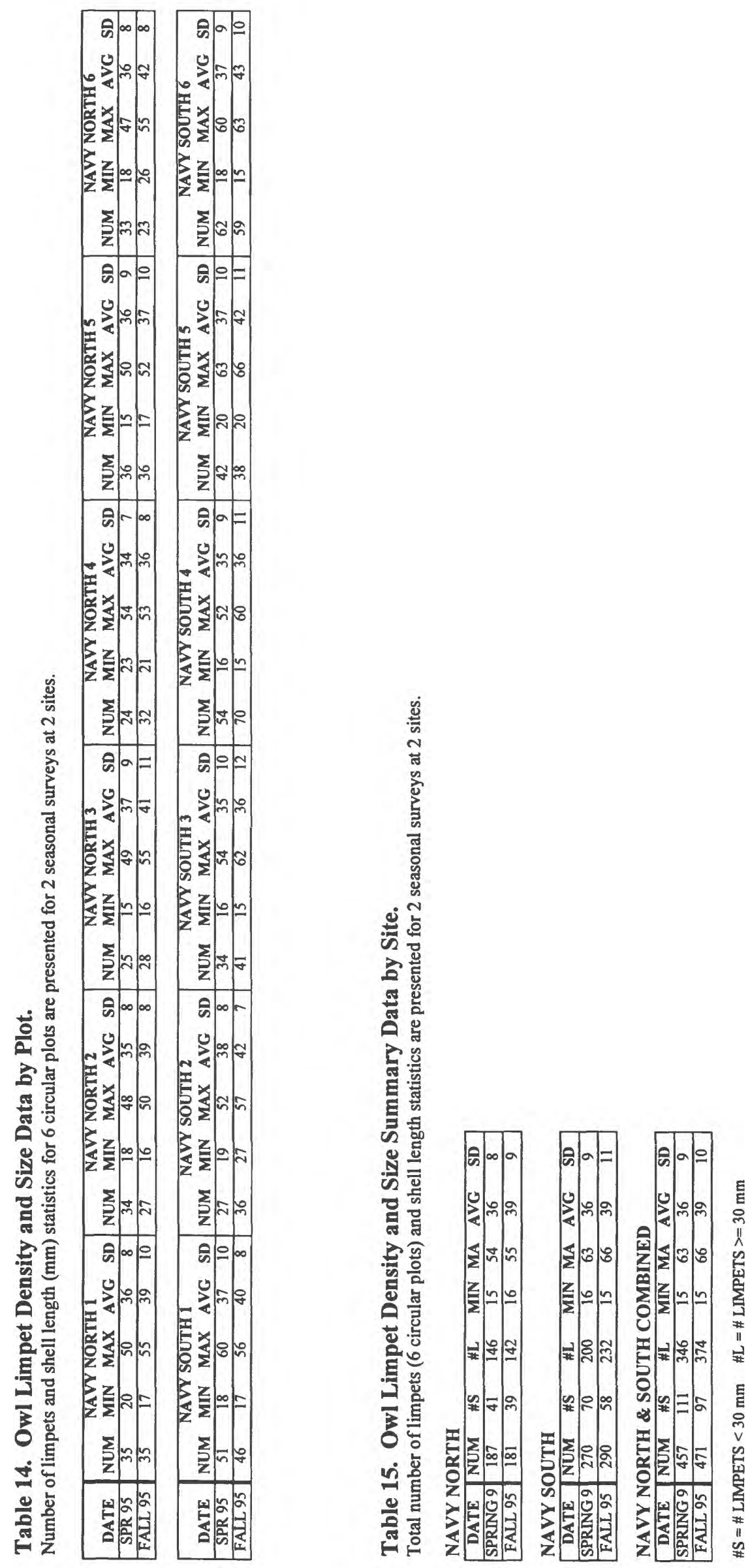
Table 16. Intertidal Cover Along Line Transects in Spring 1995.

\begin{tabular}{|l||ccc|ccc|ccc|}
\hline \multicolumn{1}{|c||}{} & \multicolumn{1}{c||}{ LINE TRANSECTS (\% COVER) } \\
\cline { 2 - 11 } \multicolumn{1}{c|}{ NAVY NORTH } & \multicolumn{3}{c|}{ TURF } & \multicolumn{3}{c|}{ INSHORE } & \multicolumn{3}{c|}{ OFFSHORE } \\
\multicolumn{1}{c|}{ TAXA } & $\mathbf{1}$ & $\mathbf{2}$ & AVG & $\mathbf{3}$ & $\mathbf{6}$ & $\mathbf{A V G}$ & $\mathbf{4}$ & $\mathbf{5}$ & AVG \\
\hline FEATHER BOA KELP & 0 & 0 & 0 & 0 & 0 & 0 & 0 & 0 & 0 \\
SARGASSUM WEED & 0 & 0 & 0 & 0 & 0 & 0 & 0 & 0 & 0 \\
RED ALGAL TURF & 96 & 97 & 97 & 0 & 7 & 3 & 6 & 12 & 9 \\
SURF GRASS & 0 & 0 & 0 & 100 & 91 & 95 & 94 & 87 & 90 \\
AGGREGATING ANEMONE & 0 & 0 & 0 & 0 & 0 & 0 & 0 & 0 & 0 \\
OTHER BIOTA & 0 & 0 & 0 & 0 & 0 & 0 & 0 & 0 & 0 \\
BARE SUBSTRATE & 4 & 3 & 3 & 0 & 3 & 1 & 0 & 1 & 1 \\
\hline
\end{tabular}

\begin{tabular}{|c|c|c|c|c|c|c|c|c|c|}
\hline \multirow{3}{*}{$\begin{array}{c}\text { NAVY SOUTH } \\
\text { TAXA }\end{array}$} & \multicolumn{9}{|c|}{ LINE TRANSECTS (\% COVER) } \\
\hline & \multicolumn{3}{|c|}{$\begin{array}{l}\text { TURF } \\
\text { ZONE }\end{array}$} & \multicolumn{3}{|c|}{$\begin{array}{c}\text { INSHORE } \\
\text { GRASS ZONE }\end{array}$} & \multicolumn{3}{|c|}{$\begin{array}{l}\text { OFFSHORE } \\
\text { GRASS ZONE }\end{array}$} \\
\hline & $\mathbf{1}$ & 2 & AVG & 5 & 6 & AVG & 3 & 4 & AVG \\
\hline FEATHER BOA KELP & 0 & 0 & 0 & 0 & 0 & 0 & 0 & 0 & 0 \\
\hline SARGASSUM WEED & 0 & 0 & 0 & 0 & 0 & 0 & 0 & 0 & 0 \\
\hline RED ALGAL TURF & 93 & 97 & 95 & 3 & 2 & 3 & 10 & 0 & 5 \\
\hline SURF GRASS & 1 & 0 & 0 & 96 & 95 & 95 & 85 & 99 & 92 \\
\hline AGGREGATING ANEMONE & 0 & 0 & 0 & 0 & 0 & 0 & 0 & 0 & 0 \\
\hline OTHER BIOTA & 0 & 0 & 0 & 0 & 0 & 0 & 0 & 0 & 0 \\
\hline BARE SUBSTRATE & 6 & 3 & 5 & 1 & 3 & 2 & 5 & 1 & 3 \\
\hline
\end{tabular}


Table 17. Intertidal Cover Along Line Transects in Fall 1995.

\begin{tabular}{|c|c|c|c|c|c|c|c|c|c|}
\hline \multirow{3}{*}{$\begin{array}{c}\text { NAVY NORTH } \\
\text { TAXA }\end{array}$} & \multicolumn{9}{|c|}{ LINE TRANSECTS (\% COVER) } \\
\hline & \multicolumn{3}{|c|}{$\begin{array}{l}\text { TURF } \\
\text { ZONE }\end{array}$} & \multicolumn{3}{|c|}{$\begin{array}{c}\text { INSHORE } \\
\text { GRASS ZONE }\end{array}$} & \multicolumn{3}{|c|}{$\begin{array}{l}\text { OFFSHORE } \\
\text { GRASS ZONE }\end{array}$} \\
\hline & 1 & 2 & AVG & 3 & 6 & AVG & 4 & 5 & AVG \\
\hline FEATHER BOA KELP & 0 & 0 & 0 & 0 & 0 & 0 & 0 & 0 & 0 \\
\hline SARGASSUM WEED & 1 & 0 & 0 & 0 & 0 & 0 & 0 & 0 & 0 \\
\hline RED ALGAL TURF & 95 & 99 & 97 & 0 & 1 & 0 & 4 & 5 & 4 \\
\hline SURF GRASS & 0 & 0 & 0 & 100 & 99 & 100 & 96 & 95 & 96 \\
\hline AGGREGATING ANEMONE & 0 & 0 & 0 & 0 & 0 & 0 & 0 & 0 & 0 \\
\hline OTHER BIOTA & 0 & 0 & 0 & 0 & 0 & 0 & 0 & 0 & 0 \\
\hline BARE SUBSTRATE & 5 & 1 & 3 & 0 & 0 & 0 & 0 & 0 & 0 \\
\hline
\end{tabular}

\begin{tabular}{|c|c|c|c|c|c|c|c|c|c|}
\hline \multirow{3}{*}{$\begin{array}{c}\text { NAVY SOUTH } \\
\text { TAXA }\end{array}$} & \multicolumn{9}{|c|}{ LINE TRANSECTS (\% COVER) } \\
\hline & \multicolumn{3}{|c|}{$\begin{array}{l}\text { TURF } \\
\text { ZONE }\end{array}$} & \multicolumn{3}{|c|}{$\begin{array}{c}\text { INSHORE } \\
\text { GRASS ZONE }\end{array}$} & \multicolumn{3}{|c|}{$\begin{array}{l}\text { OFFSHORE } \\
\text { GRASS ZONE }\end{array}$} \\
\hline & 1 & 2 & AVG & 5 & 6 & AVG & 3 & 4 & AVG \\
\hline FEATHER BOA KELP & 0 & 0 & 0 & 0 & 0 & 0 & 0 & 0 & 0 \\
\hline SARGASSUM W] & 0 & 0 & 0 & 0 & 0 & 0 & 0 & 0 & 0 \\
\hline RED ALGAL TURF & 95 & 100 & 98 & 3 & 2 & 2 & 0 & 0 & 0 \\
\hline SURF GRASS & 4 & 0 & 2 & 97 & 98 & 98 & 100 & 100 & 100 \\
\hline AGGREGATING ANEMONE & 0 & 0 & 0 & 0 & 0 & 0 & 0 & 0 & 0 \\
\hline OTHER BIOTA & 0 & 0 & 0 & 0 & 0 & 0 & 0 & 0 & 0 \\
\hline BARE SUBSTRATE & 1 & 0 & 1 & 0 & 0 & 0 & 0 & 0 & 0 \\
\hline
\end{tabular}



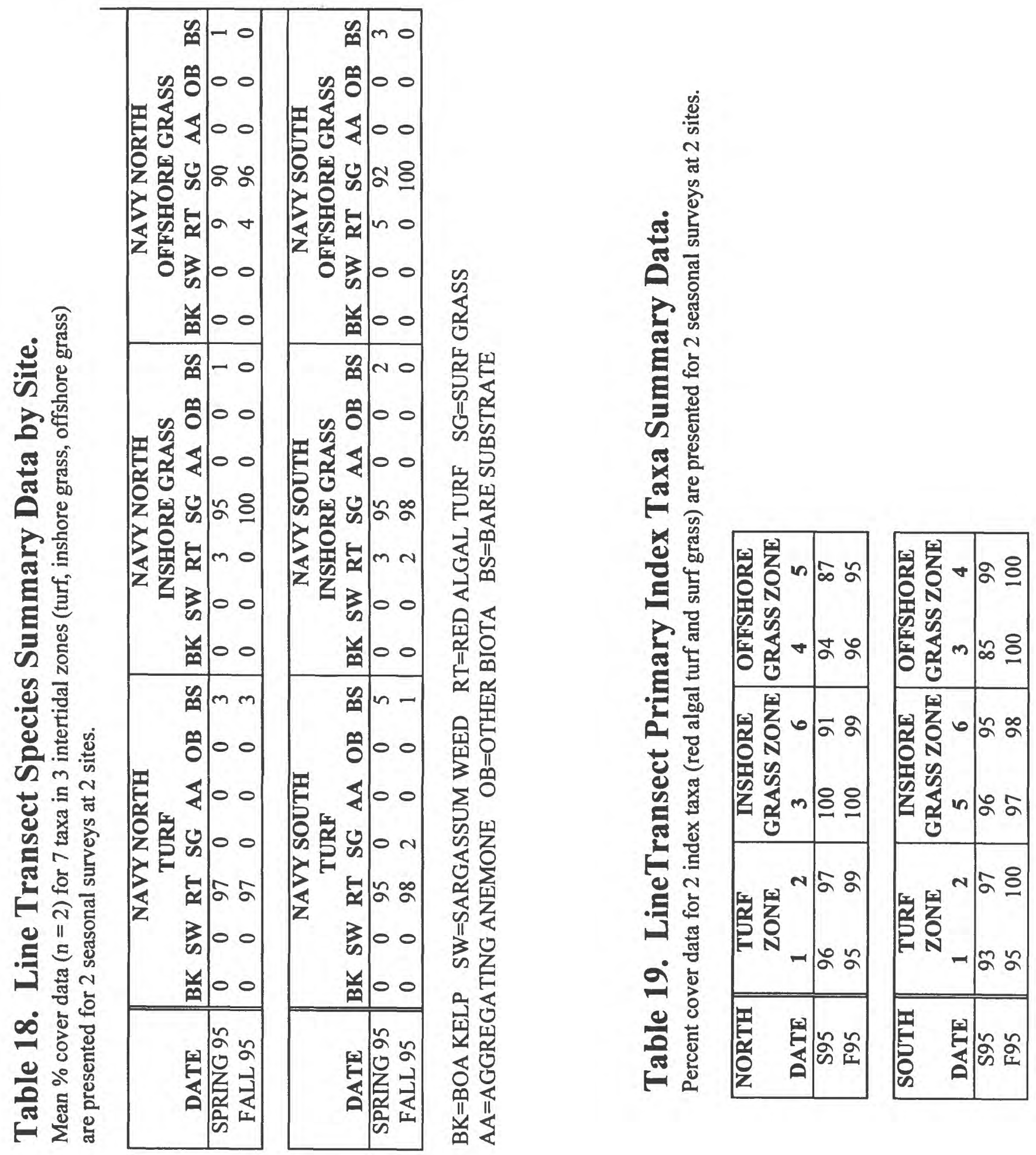
Fig. 1. Point Loma Rocky Intertidal Monitoring Sites.

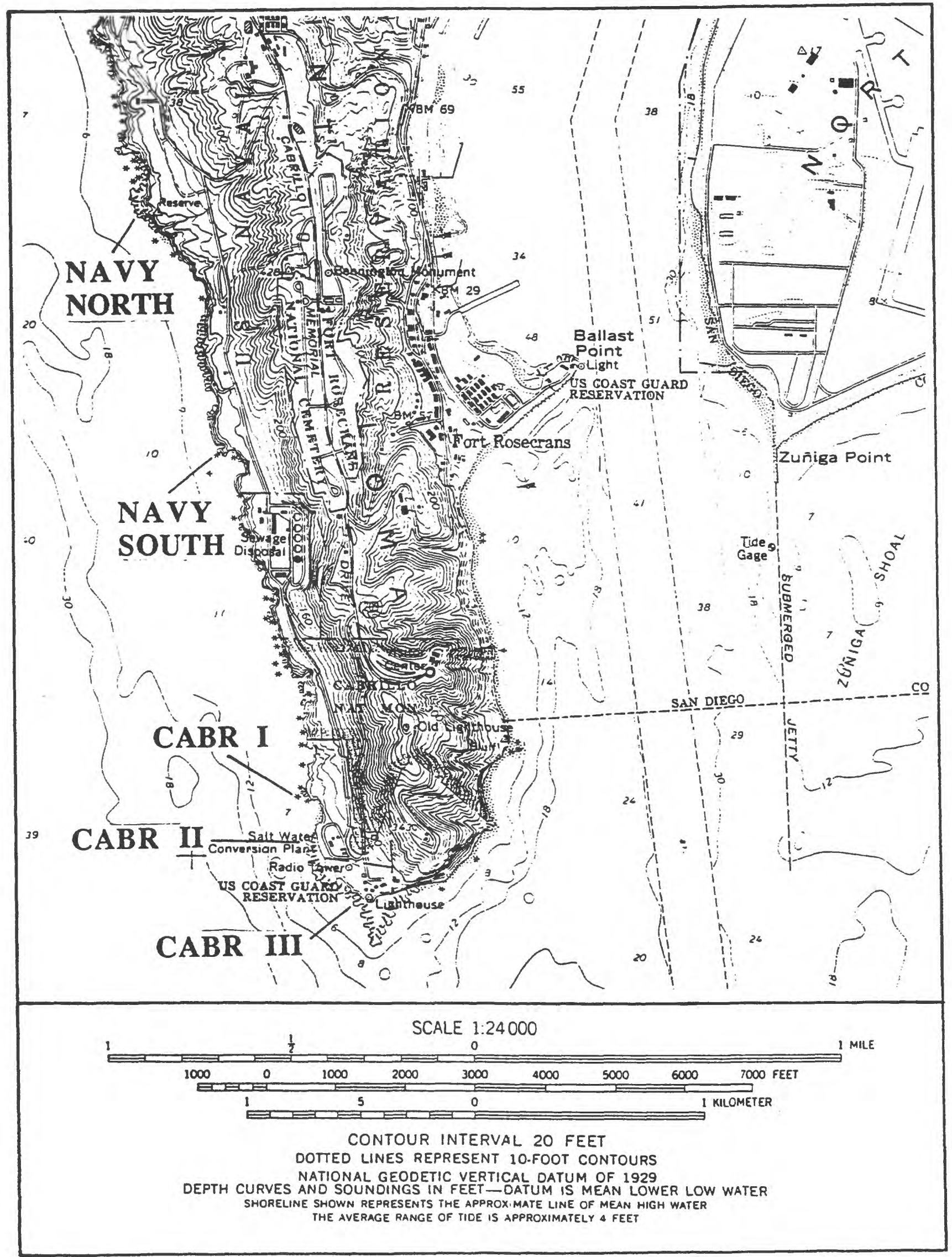


Figure 2. Point Loma Navy North Map: Overview, Area R1, Area R2

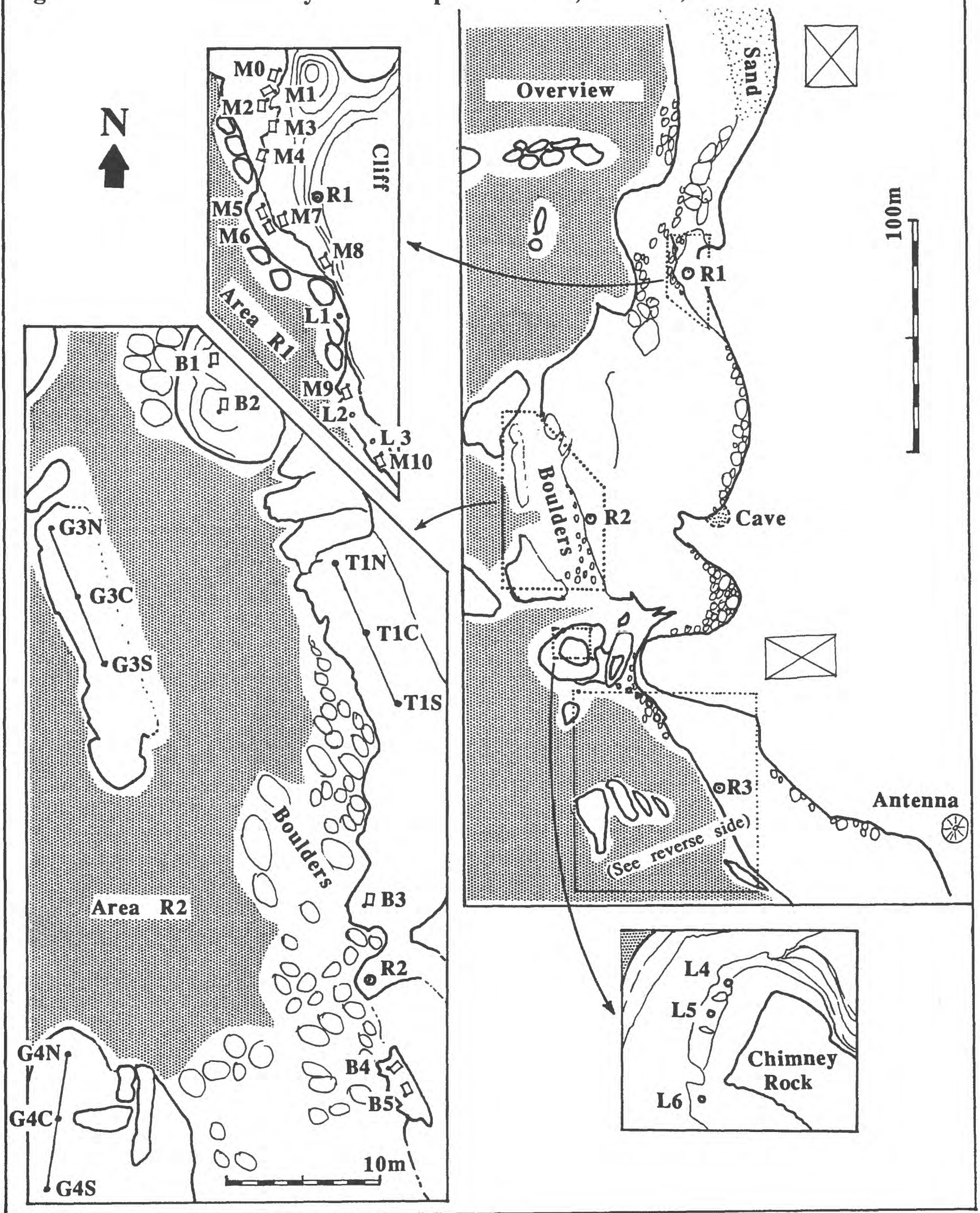




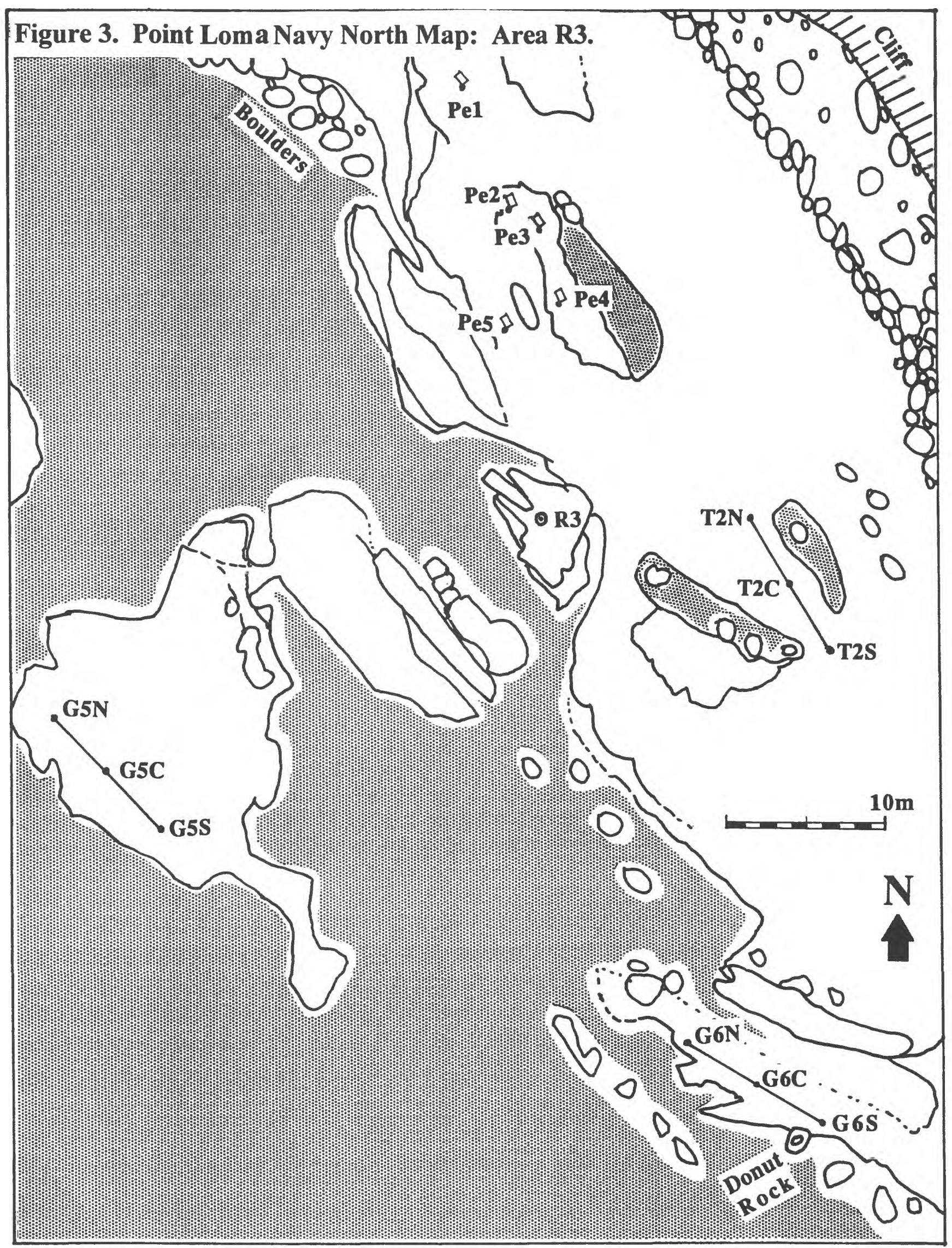


Figure 4. Point Loma Navy South Map: Overview, Area R1, Area R2

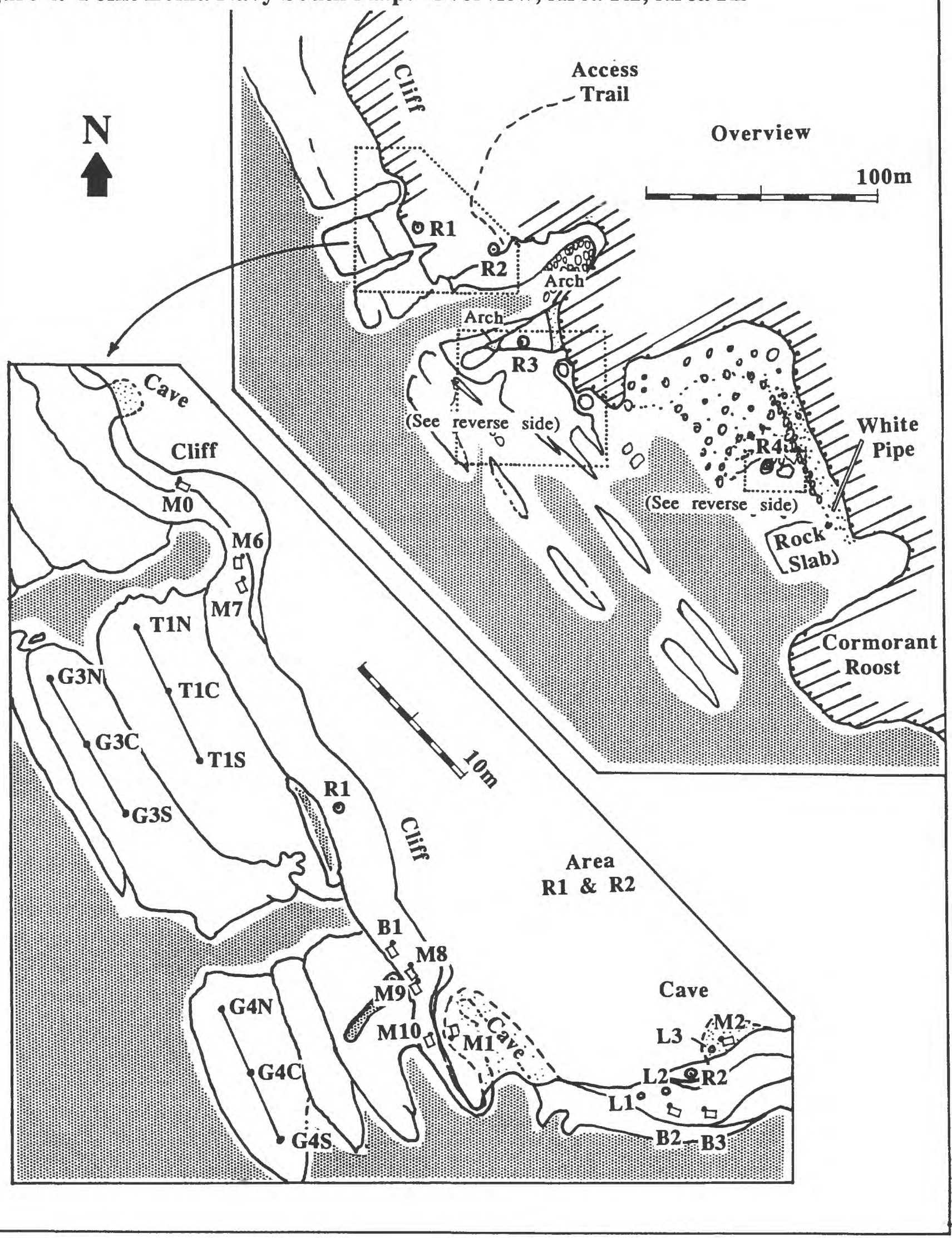


Figure 5. Point Loma Navy South Map: Area R3, Area R4

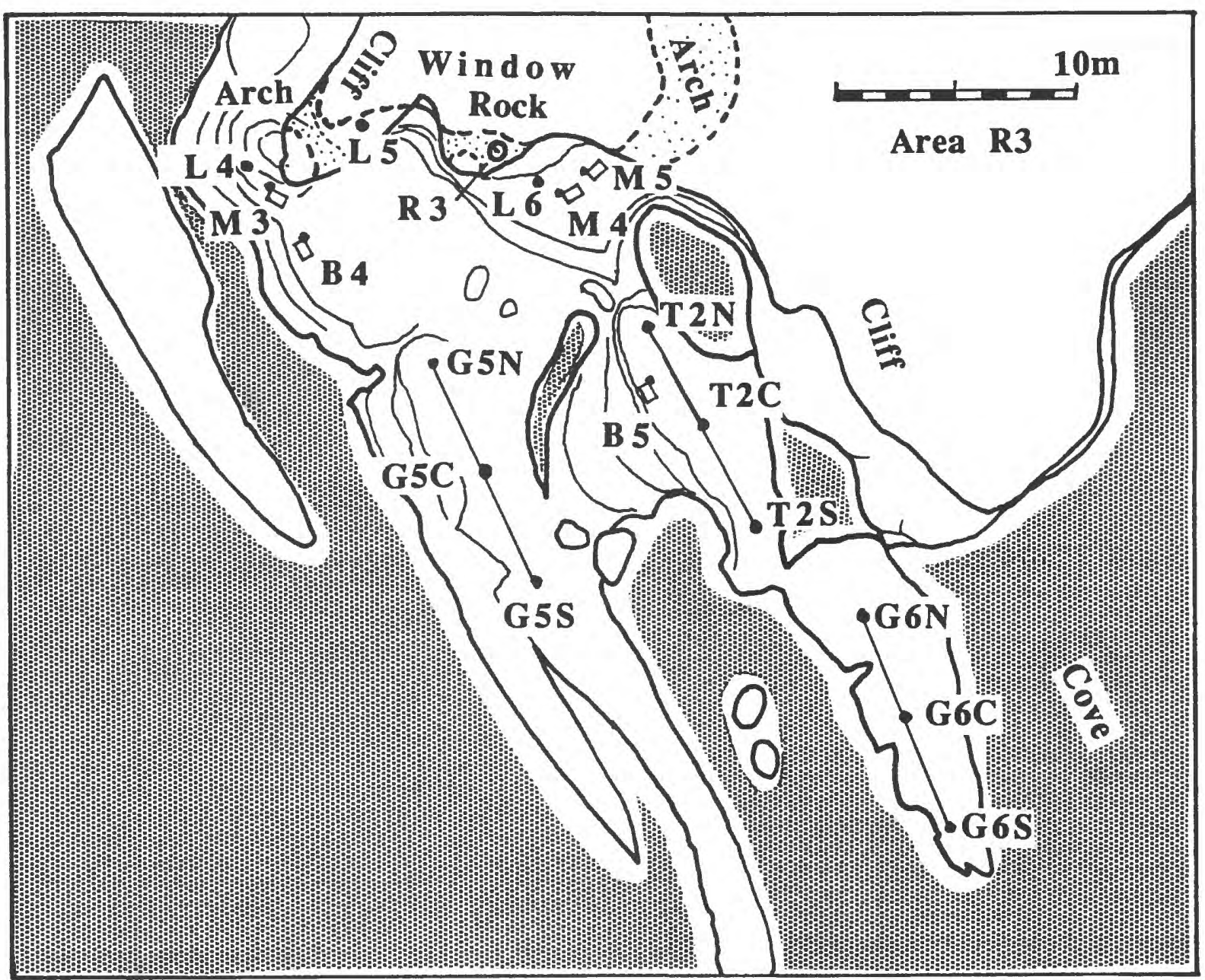

Area R4

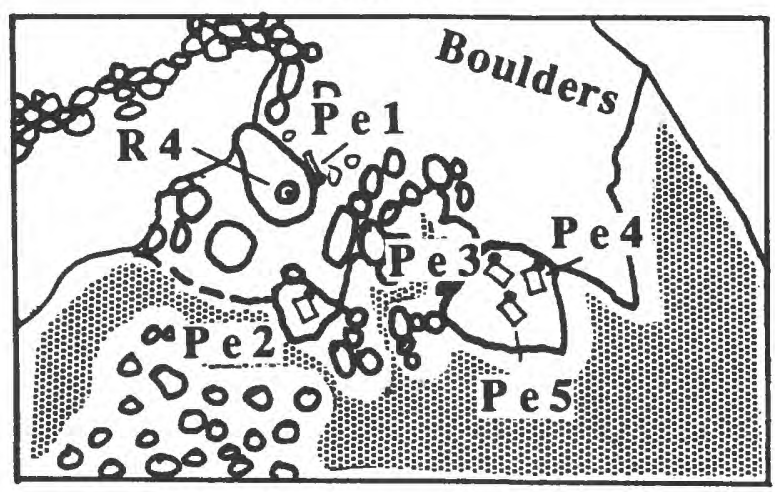

N 
눙

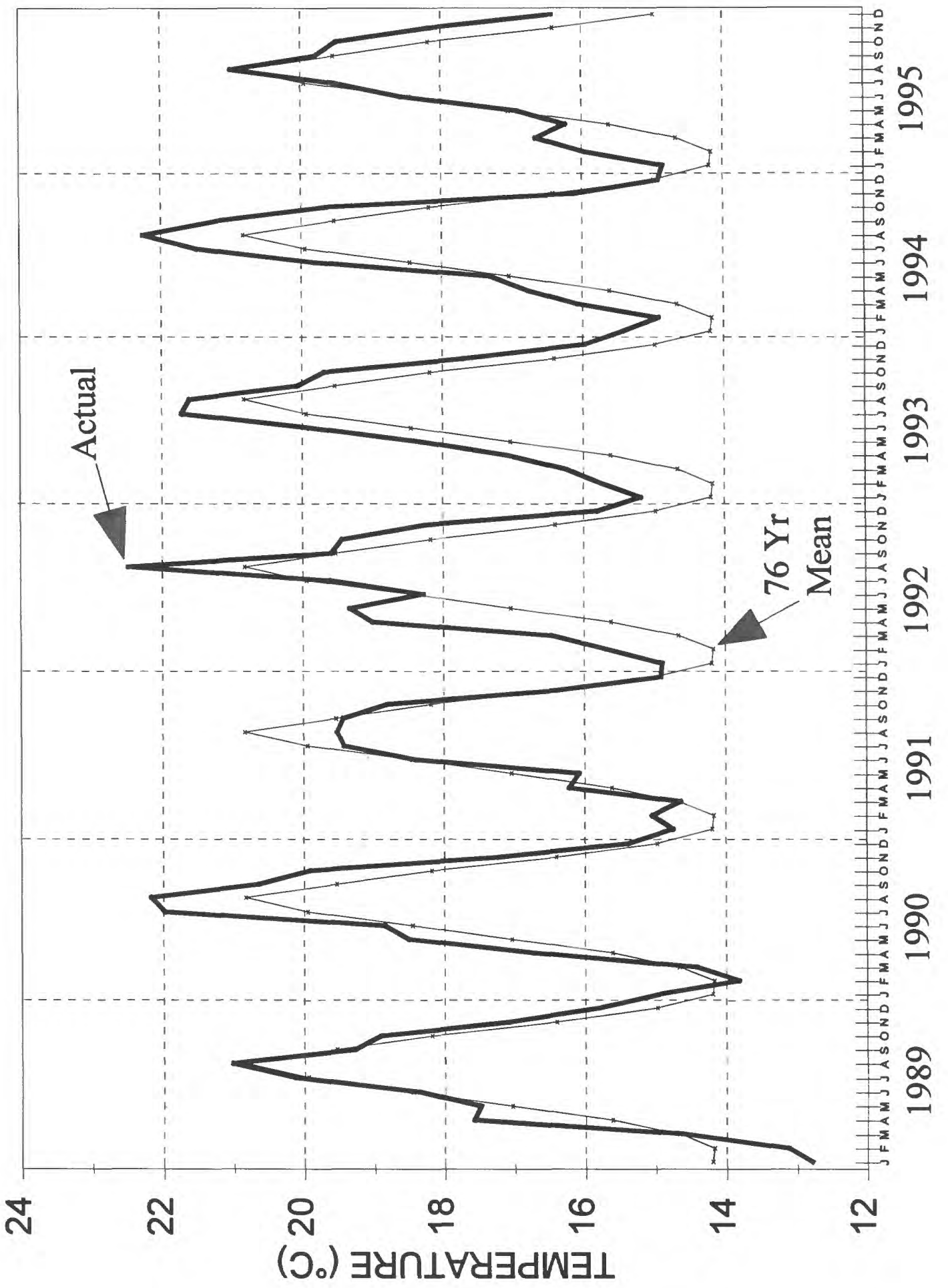




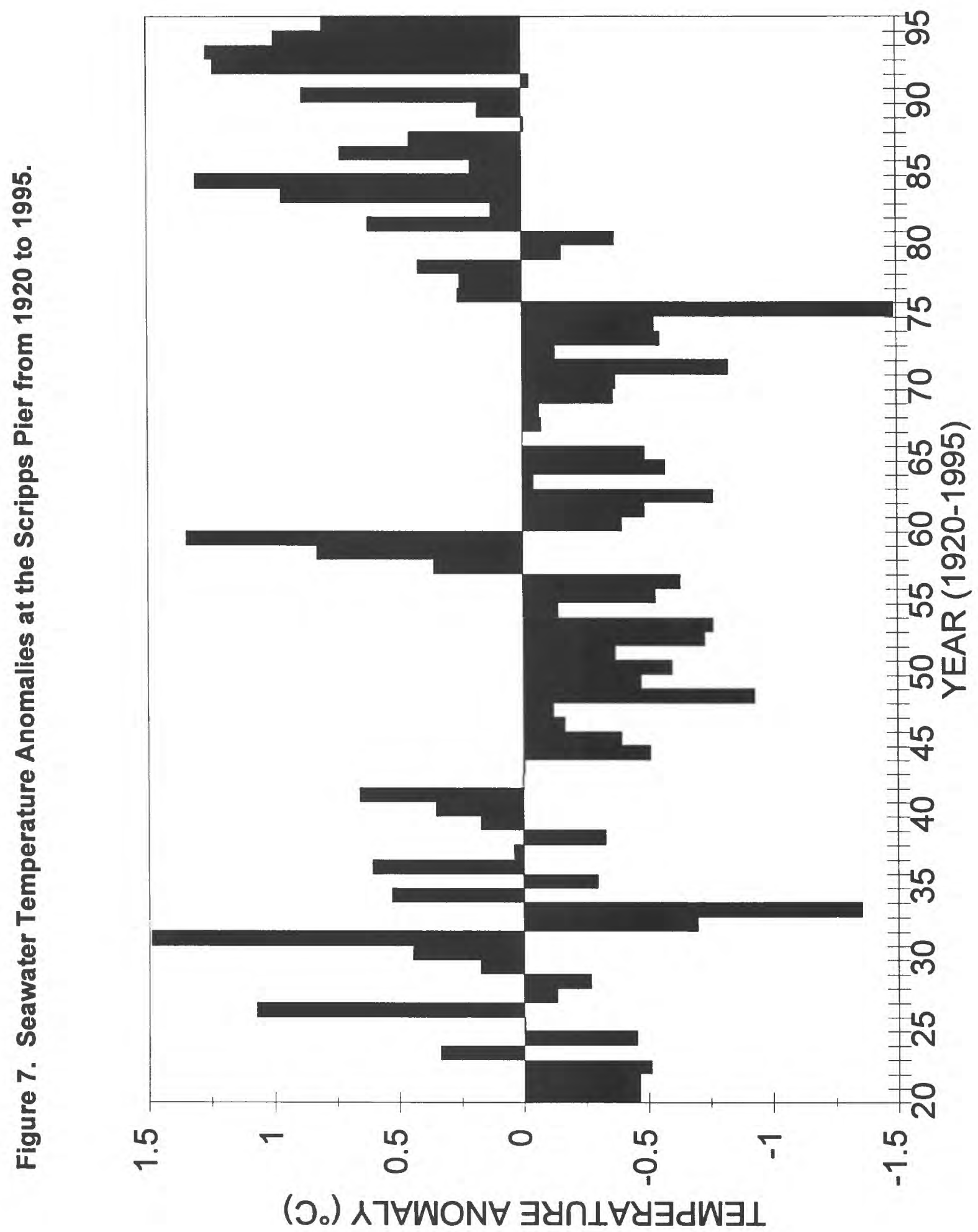



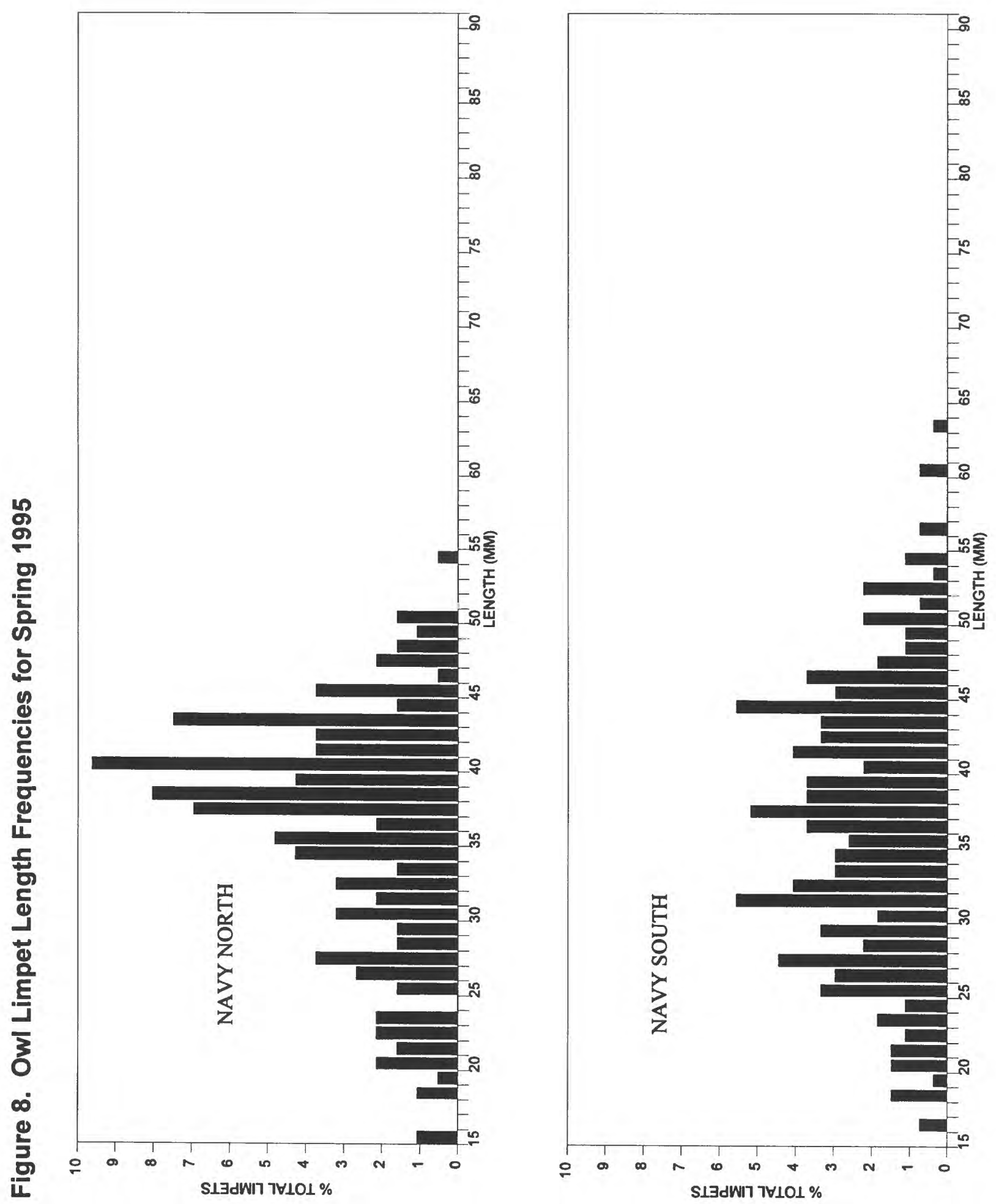

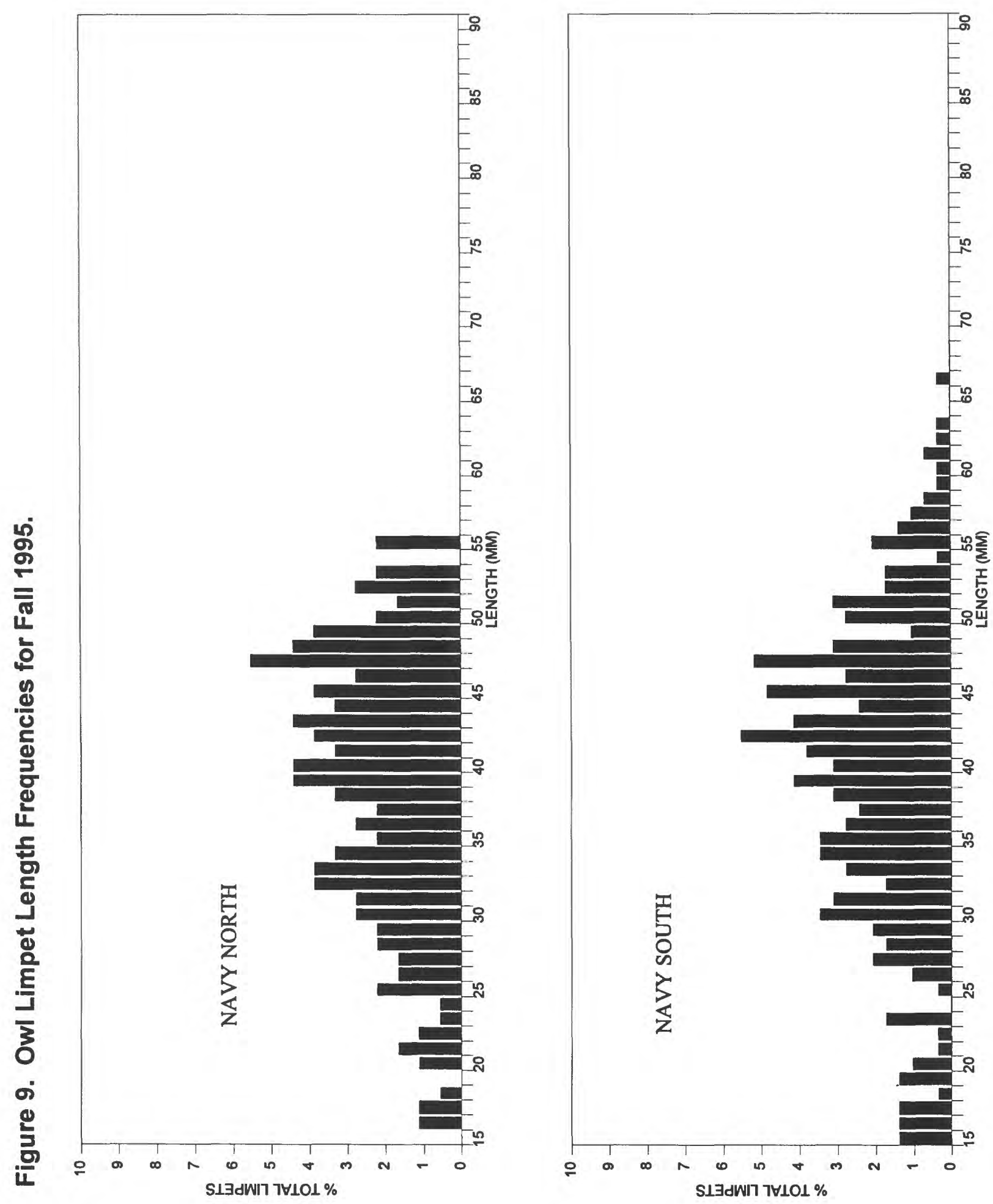


\section{APPENDIX 1. Threatened, Endangered, or Proposed Species}

No federal or state listed species were encountered during the rocky intertidal surveys conducted for this project.

\section{APPENDIX 2. Summary of Information for Listed Species Encountered.}

No federal or state listed species were encountered during the rocky intertidal surveys conducted for this project.

\section{APPENDIX 3. Key Species Natural History}

The following are summary descriptions of the natural history and ecology of the 13 key rocky intertidal species or species groups emphasized in this study:

\section{Rockweed (Pelvetia fastigiata)}

This conspicuous fucoid alga can be locally abundant in dense patches in upper mid-tidal regions of southern California rocky shores that are partially protected from open surf. The typical mainland form is an olive green or yellowish brown plant about $30 \mathrm{~cm}$ long, composed of thick, narrow, dichotomous branches. A finer-branched, lighter-colored form ( $P$. fastigiata gracilis) is more typical of the Channel Islands (Abbott and Hollenberg 1976). Pelvetia is a dominant perennial whose thick clumps provide shelter and protection from desiccation for many animals that otherwise could not exist so high up on the shore (Hill 1980; Gunnill 1983; Ricketts et al. 1985). Pelvetia plants are tough, resilient, and long-lived; however, recruitment is irregular, survivorship low, and individuals slow-growing (Gunnill 1980b; 1985). Rockweeds are vulnerable to oil spills because of their location fairly high on the shore. Specific sensitivity of Pelvetia to oiling is unclear, but other fucoids are known to be adversely affected (Foster et al. 1988). Recovery from impacts could take several years or more (Hill 1980; Vesco \& Gillard 1980; Engle unpub.).

\section{Sargassum Weed (Sargassum muticum)}

Sargassum muticum is a non-native species of brown fucoid algae that was introduced to the West Coast in the 1930's or 40's, apparently on the shells of young oysters released in Puget Sound (Scagel 1956). It spread southward from Washington State, established itself in southern California in the 1960's and 70's, and currently ranges to central Baja California. S. muticum can be distinguished from the two native species of Sargassum in California (S. agardhianum and $S$. palmeri) by its larger size (to $10 \mathrm{~m}$, but generally $<3 \mathrm{~m}$ intertidally) and undivided leaflike blades that occur singly along the main branches (Abbott \& Hollenberg 1976). Sargassum weed is widely distributed in sheltered and semi-exposed rocky habitats subtidally (to $10 \mathrm{~m}$ depth), along wet low tide zones, and in tidepools at higher zones. Its habitat requirements are generally similar to surf grass. They frequently occur intermixed; however, surf grass is more common in lower surf-swept areas, while sargassum weed dominates the warmer middle intertidal pools. $S$. muticum is an opportunistic "weedy" species that can quickly colonize bare spaces and unstable substrates, but it is a poor competitor for space, thus in time native plants usually take over (Deysher \& Norton 1982). Sargassum is perennial, but the coarse elongate fronds die back annually (after reproduction in Spring/Summer) to stubby bases (in Summer/Fall) (Gunnill 1980a). Sargassum weed grows rapidly in warm water, but can survive cold conditions, as evidenced by its northern range limit. It is susceptible to desiccation damage and can be dislodged by high surf, but is capable of rapid recovery from disturbance (Gunnill 1985). 


\section{Boa Kelp (Egregia menziesii)}

Boa kelp is one of the largest intertidal plants in California. It is a brown laminarian alga that forms conspicuous bands or patches in lower intertidal and shallow subtidal rocky habitats on exposed shores from central California to central Baja California (though some specimens range as far north as Alaska). Appearing like the feather boa wraps once worn by fashionable women, this rapidly-growing kelp produces $2-15 \mathrm{~m}$ long straplike stipes fringed with gas-filled bladders and numerous small, elongate blades in young plants or hair-like blades in old plants. The largest forms are subtidal. Boa kelp is perennial, but many plants die annually (Black 1974; Gunnill 1980a). Dense, draping fronds of Egregia provide protection from desiccation for understory plants and animals, as well as food for grazers such as isopods, kelp crabs, snails, and limpets (Humphrey 1965). One limpet, Notoacmaea incessa, is found only on Egregia. These short-lived limpets excavate pits or furrows in the kelp stipe which weaken the plant, increasing the likelihood of frond loss (Black 1976). Though tough, boa kelp can be abraded or torn out by wave action. It also is sensitive to desiccation and heat stress. During sunny midday low tides, plants uppermost on the shore may deteriorate, as evidenced first by color changes from brown to green, and later by sloughing of fronds. The 1982-83 El Niño caused catastrophic mortalities, but recruitment continued to occur (Gunnill 1985). Egregia was conspicuously absent from rocky habitat at the terminus of a small sewage outfall at San Clemente Island (Littler \& Murray 1975). If recruitment is successful, recovery from disturbance can be relatively rapid (0.5-2 yr) due to fast growth rates (Murray \& Littler 1979; Vesco \& Gillard 1980).

\section{Red Algal Turf (mostly Corallina spp.)}

Large portions of the middle intertidal zones of rocky shores in southern California are covered by a mixed assemblage of low-growing $(<7 \mathrm{~cm}$ high) green, brown, and red algal species, of which the reds predominate. This turf is best developed on relatively flat reefs where the algal mat forms a meshwork that traps sand and shell particles. Species composition within the turf assemblage varies geographically. In the San Diego area, as many as 67 species of attached and epiphytic plants are found within a relatively homogeneous and persistent assemblage (Stewart 1982). Two species of red erect coralline algae (Corallina vancouveriensis and $C$. pinnatifolia) dominate, together covering $>60 \%$ of the substrate. By cementing firmly to the rock, these perennial calcareous algae form a low, but highly structured thicket that supports diverse epiphytic plants and infaunal animals. Common epiphytes include Ceramium eatonianum, C. floccideum, Centroceras clavulatum, Hypnea valentiae, Lithothrix aspergillum, and Laurencia pacifica. The sea anemone, Anthopleura elegantissima, is the most conspicuous invertebrate within the turf assemblage. The turf may also enhance recruitment of mussels by providing attachment surfaces and a relatively sheltered micro-environment. Typically, the algal turf zone is located just above the surf grass zone, because algal turf is better able to withstand desiccation (Stewart 1989a). The Corallina species dominating the turf can bleach and die-back during daytime exposures to dry air (especially during the October-February low tides), or filaments may be broken off by storm waves, but erect portions easily grow back from the crusts that persist after such disturbances (Stewart 1989b). They also are highly resistant to the sand abrasion and burial which commonly occurs on low-sloping reefs. Corallina crusts can survive more than a year under sand; once re-exposed, they regain pink color and start growing erect portions within two weeks (Stewart 1989b). Turf algae species my bleach or die in response to oil, municipal wastes, or other pollutants (Foster et al. 1988). Recovery of Corallina-dominated turf after complete clearings can take about 2 yr (Stewart 1898b). 


\section{Surf Grass (Phyllospadix spp.)}

Surf grass is one of only two types of marine flowering plants on the West Coast. Unlike the eelgrass Zostera (often confused with surf grass) that grows in quiet-water mud or sand habitats, surf grass attaches by short roots to rock on surf-swept shores from the low intertidal down to 10-15 m depths. The 0.5-2 $\mathrm{m}$ tall, emerald green grass commonly occurs in dense perennial beds formed primarily by vegetative growth from spreading rhizomes. Two species ( $P$. torreyi \& P. scouleri) overlap in geographical distribution and morphological characteristics ( Dawson \& Foster 1982). P. torreyi generally has longer (1-2 m), narrower (1-2 mm) leaves, longer flower stems with several spadices, and occurs more in semi-protected habitats as well as at deeper depths. $P$. scouleri tends to have shorter $(<50 \mathrm{~cm})$, broader $(2-4 \mathrm{~mm})$ leaves, shorter flower stems with 1-2 spadices, and is found more often in wave-swept intertidal areas. Surf grass meadows are highly productive ecosystems, providing structurally complex microhabitats for a rich variety of epiphytes, epibenthos, and infauna. Stewart and Myers (1980) identified 71 species of algae and 90 species of invertebrates associated with surf grass habitats in San Diego. Some organisms, such as the red algae Smithora naiadum and Melobesia mediocris, are exclusive epiphytes on surf grass (or eelgrass) (Abbott \& Hollenberg 1976). Also, Phyllospadix beds provide nursery habitat for various fishes and invertebrates, including the California spiny lobster Panulirus interruptus (Engle 1979). Green lobster juveniles shelter in the thicket of leaves and forage on a variety of tiny gastropods and bivalves. Surf grass beds are persistent (Turner 1985) and can preempt space from other plants, including boa kelp (Black 1974) and sargassum weed (Deysher \& Norton 1982). Surf grass cannot tolerate much heat or drying; the leaves will bleach quickly when midday low tides occur during hot, calm-water periods. Surf grass can be particularly sensitive to sewage discharge (Littler \& Murray 1975) and oil pollution (Foster et al. 1988). Recovery can be relatively rapid if the rhizome systems remain functional, but might take many years if entire beds are lost, because recruitment is irregular and must be facilitated by the presence of perennial turf algae to which surf grass seeds attach (Turner 1983, 1985). Transplant projects undertaken to speed recovery of Phyllospadix beds destroyed by shoreline construction have been largely unsuccessful.

\section{Aggregating Anemone (Anthopleura elegantissima)}

Anthopleura elegantissima is abundant throughout semi-protected rocky shores of the Pacific Coast. This greenish anemone can exist as large (to $25 \mathrm{~cm}$ ) solitary individuals in tidepools and subtidally, or as small (to $8 \mathrm{~cm}$ ) densely aggregated clones in middle intertidal zones, especially sand-influenced habitats (Morris et al. 1980). Solitary A. elegantissima often are confused with $A$. xanthogrammica, a larger relative uncommon south of Point Conception. The green color of all of these Anthopleura comes from symbiotic unicellular plants. $A$. elegantissima are able to persist practically indefinitely under normal conditions because genetically-identical individuals are periodically produced by longitudinal fission (Sebens 1982). Extensive carpets of these clones may occur, but often go unrecognized under low tide conditions because the anemones contract to small sand or shell-covered blobs which provide protection from desiccation. Anemone mats create a moist microenvironment that allows the development of some other species, such as coralline algae and sand tube worms (Phragmatopoma californica) at higher intertidal levels than they would normally occur (Taylor \& Littler 1982). Adjacent anemone clones are separated by a narrow bare corridor caused by the withdrawal of non-clonemates following aggressive stinging encounters. A. elegantissima are quite resistant to disturbances from shifting sands. They not only withstand moderate sand abrasion, but can resist shallow sand burial by extending their columns to re-expose the tentacles 
and oral disk. If buried deeper, they can survive for at least 3 months by metabolizing body tissue (Sebens 1980). Aggregating anemones are not known to be unusually sensitive to oiling. Recovery from major disturbances may take 1-2 years or more (Vesco \& Gillard 1980).

\section{White Acorn Barnacles (Chthamalus fissus/dalli)}

White acorn barnacles typically dominate high intertidal zones along the West Coast. $C$. dalli and Balanus are most common in the colder waters north of Point Conception, but all three species overlap in southern California. Acorn barnacle species can be difficult to distinguish, especially in photographic monitoring. Tiny (to $8 \mathrm{~mm}$ ) C. fissus and $C$. dalli require dissection and microscopic examination of scutal plates. Balanus glandula can be field identified in most cases by its larger size (to $22 \mathrm{~mm}$ ), whiter color, and differing shell plate arrangements. It is rare at Point Loma. Acorn barnacles spawn often, at variable times throughout the year (Hines 1978), and settle in incredible densities (to $70,000 / \mathrm{m}^{2}$ ), forming distinct white bands along the upper intertidal that contain few other invertebrates except littorines and the hardiest limpets. Balanus can out compete Chthamalus by crowding or smothering, but Chthamalus can occupy higher tide levels than Balanus, because it is more resistant to desiccation. Slightly lower down, acorn barnacles mix in with the Endocladia assemblage, and are common on mussel shells.

Chthamalus species grow rapidly, but only survive a few months to a few years. Balanus can live longer (to 10 years), but its larger size and lower tidal position subject it to higher levels of mortality from predatory gastropods and ochre sea stars. White acorn barnacles are highly vulnerable to smothering from oil spills because floating oil often sticks along the uppermost tidal levels. Significant, widespread barnacle impacts were reported after the 1969 Santa Barbara oil platform blow-out (Foster et al. (1971) and the 1971 collision of two tankers off San Francisco (Chan 1973)). However, high recruitment rates may promote relatively rapid recovery of acorn barnacles; disturbance recovery times ranging from several months to several years have been reported ( Vesco \& Gillard 1980).

\section{Pink Thatched Barnacle (Tetraclita rubescens)}

The pink thatched barnacle is the largest (to $50 \mathrm{~mm}$ ) acorn barnacle commonly occurring in middle to low rocky intertidal habitats in southern California. This prominent, volcano-shaped barnacle ranges from Oregon to the southern tip of Baja California (Kozloff 1993). Unlike the aggregated white barnacles, Tetraclita tend to occur as solitary individuals scattered on rock surfaces and mussel shells. Pink thatched barnacles are effective competitors for space and likely influence the local distribution of mussels and other associated species (Foster et al. 1988). Adult Tetraclita are distinctive light pink to brick red in color, with tests composed of four plates whose outer surface is uniformly roughened by vertical grooves and ridges. Juveniles are white. Sexual maturity is reached in about $2 \mathrm{yr}$ (18 $\mathrm{mm}$ dia), and individuals may live as long as 10-15 yr (Hines 1978). A related form, Tetraclita rubescens var. elegans, is a smaller white variety more common in lower intertidal and subtidal water. Pink barnacles may be sensitive to sewage pollution; they were less common in the vicinity of a small sewage outfall at San Clemente Island than in nearby unpolluted areas (Littler \& Murray 1975). Recovery from major disturbance may take more than 2 yr (Murray \& Littler 1979).

\section{Goose Barnacles (Pollicipes polymerus)}

Goose barnacles are conspicuous in high to middle intertidal zones on surf-swept rocky shores all along the US Pacific Coast. Young goose barnacles settle preferentially among other Pollicipes, forming tight clusters on exposed outcrops, ridges, and walls, just above or intermixed with mussel beds. This distinctive black and white barnacle is firmly attached to the 
rock by a muscular (edible) stalk that holds the cirral net up to $8 \mathrm{~cm}$ high to filter-feed, primarily from wave backwash. Unlike white acorn barnacles, goose barnacles are relatively slow-growing and long-lived. Sexual maturity is reached in approximately 5 years, and large adults may be 20 years old (Morris et al. 1980). Pollicipes is very resistant to desiccation and can tolerate all but the highest wave exposures. Mortality has been reported from oil spills (Foster et al. 1971; Chan 1973), and recovery could be slow. Populations have been reduced in accessible areas where goose barnacles are collected for food.

\section{Owl Limpet (Lottia gigantea)}

Owl limpets are common in high and middle tide zones of exposed rocky shores from Washington south to Baja California. Adult Lottia are relatively easy to identify because of their large size $(5-10 \mathrm{~cm})$, oval shape with low rounded profile, and color patterns of brown, white, and black on the often eroded shell. Accessory gills on the mantle increase surface area for aerial respiration during low tide periods. Owl limpet habitats extend from the barnacle and Endocladia zones down to the mussel beds. Here they maintain feeding territories on relatively smooth rock surfaces which they keep free (by rasping and bulldozing) of most macroalgae and invertebrates, including turfweed, sea anemones, barnacles, mussels, and other limpets (Stimpson 1970; Wright 1982). By removing most competitors for space and grazers, they promote the growth of algal films upon which they systematically graze. These "clearings" vary in appearance with Lottia size and structural features of the substrate, creating a patchwork of differing microhabitats. Lottia tend to occupy one or more characteristic "home scars" within their territories. Here the shell margin conforms to the rock surface, making a tight seal to hold moisture during low tides. The limpets also may tuck into crevices and under mussels for protection from heat, desiccation, and high surf. Lottia grow slowly, taking up to 10-15 years to reach maximum size (Morris et al. 1980). As an ecological dominant, any change in Lottia populations greatly affects abundances of other species. The limpets and their feeding territories are vulnerable to oiling, but oil impacts are unclear. For example, they were not obviously affected by the 1971 San Francisco oil spill (Chan 1973). Recovery from any major disturbance likely would be lengthy. Larger owl limpets are collected for food, tasting much like abalone. Since the largest individuals are nearly always females (because Lottia are protandrous hermaphrodites) (Wright \& Lindberg 1982), collecting may impair reproductive capabilities within owl limpet populations.

\section{Black Abalone (Haliotis cracherodii)}

Black abalone inhabit mid-low intertidal levels down to shallow subtidal depths (to $6 \mathrm{~m}$ ) from Oregon to southern Baja California (Morris et al. 1980). They are readily identified by dark, bluish-black coloration, a smooth shell with 5-7 open respiratory holes, and relatively small size (5-20 cm as adults). Black abalone are relatively sedentary, and are typically found clustered in wet crevices, under boulders, or on the walls of surge channels along exposed shores. Juveniles graze on diatom films and coralline algae, while adults primarily eat drift algae, especially brown kelps. $H$. cracherodii compete with sea urchins and other crevice-dwellers for space and food (Taylor \& Littler 1979; Miller \& Lawrence-Miller 1993). Where abundant, abalone may be stacked on top of each other, reaching densities of more than $100 / \mathrm{m}^{2}$ (Douros 1987; Richards \& Davis 1993). Black abalone are slow-growing and long-lived, with recruitment apparently being low and variable (Morris et al. 1980; VanBla1.com 1993). Growth rates depend on animal size, location, food availability, reproductive condition, and other factors. Absolute longevity has not been determined, but ages greater than 30 years appear likely based on tagging and other population studies (e.g., VanBlaricom 1993). A large fishery exists, of which the black abalone has become increasingly harvested as stocks of other abalone declined (Leet et al. 1992). 
$H$. cracherodii populations in southern California suffered catastrophic declines since the mid1980 's that have resulted in nearly complete disappearance of black abalone along mainland shores south of Point Conception (Miller \& Lawrence-Miller 1993), as well as at many of the Channel Islands (Lafferty \& Kuris 1993; Richards \& Davis 1993). Mortality is associated with "withering syndrome", in which the foot shrinks and weakened individuals lose their grip on rock surfaces. Abalone also may be subject to smothering by sand burial, dislodgment by storm waves, and predation by octopus, sea stars, fishes, and sea otters (Morris et al. 1980; VanBlaricom 1993). Impacts from oil are little known, but North et al. (1965) reported black abalone mortality following a spill in Baja California. Because of low recruitment, slow growth, and already decimated reproductive populations, additional mortality from oil spills would be devastating, and recovery prospects long-term at best.

\section{California Mussel (Mytilus californianus)}

California mussels are abundant at middle to low levels of exposed rocky shores along the entire Pacific Coast. These $10-20 \mathrm{~cm}$ black/blue/gray mussels firmly attach to rocks or other mussels by tough byssal threads, forming dense patches or beds. The literature on Mytilus californianus is extensive, including key ecological studies on the effects of predation, grazing, and disturbance on succession and community structure (see for discussion Morris et al. 1980; Ricketts et al. 1985; Kinnetics 1992). The bay mussel, $M$. edulis, can co-occur with $M$. californianus, but is most common in sheltered habitats. Thick $(\geq 20 \mathrm{~cm})$ beds of California mussels trap water, sediment, and detritus that provide food and shelter for an incredible diversity of plants and animals, including cryptic forms inhabiting spaces between mussels as well as biota attached to mussel shells (Paine 1966; MacGinitie \& MacGinitie 1968; Suchanek 1979; Kanter 1980). For example, MacGinitie \& MacGinitie (1968) counted 625 mussels and 4,096 other invertebrates in a single $25 \mathrm{~cm}^{2}$ clump, and Kanter (1980) identified 610 species of animals and 141 species of algae from mussel beds at the Channel Islands. Kinnetics (1992) documented locational differences in the composition and abundance of mussel bed species. Northern sites had densely-packed, multi-layered beds, but the more open southern sites had higher species diversity. Mussels feed on suspended detritus and plankton. Young mussels settle preferentially into existing beds at irregular intervals, grow at variable rates depending on environmental conditions, and eventually reach ages of 8 years or more (Morris et al. 1980, Ricketts et al. 1985). Mussels can tolerate typical rigors of intertidal life quite successfully. However, desiccation likely limits the upper extent of mussel beds, storms tear out various-sized mussel patches, and sea stars prey especially on lower zone mussels. Mytilus are adversely affected by oil spills (Chan 1973; Foster et al. 1971). Recovery from disturbance varies from fairly rapid (if clearings are small and surrounded by mussels that can move in) to periods greater than 10 years (if clearings are large and recruitment is necessary for recolonization)( Vesco \& Gillard 1980; Kinnetics 1992).

\section{Ochre Sea Star (Pisaster ochraceus)}

Ochre sea stars are found on middle and low tide levels of wave-swept rocky coasts from Alaska to Baja California, but are much less common south of Point Conception. Their relatively large size (to $45 \mathrm{~cm}$ diameter), variety of colors (yellow, orange, purple, brown), and ability to withstand air exposure (at least 8 hours) attract considerable attention from visitors exploring the shore at low tide. The ochre sea star typically is associated with mussels, which constitute its chief food, but barnacles, limpets, snails, and chitons also may be taken (Morris et al. 1980). Predator-prey interactions involving ochre sea stars have been intensely studied, especially the role of $P$. ochraceus in determining the lower limit of northern mussel beds (Paine 1966, 1974: 
Dayton 1971). Like black abalone, ochre sea stars are relatively slow-growing, long-lived, and apparently variable in recruitment success. They are tolerant of high surf, using their numerous tube feet to remain firmly in place, often in cracks and crevices. They have few predators, except for curious tidepool visitors. However, in southern California, $P$. ochraceus populations have been decimated by a widespread wasting disease caused by a warm-water bacterium of the genus Vibrio (Schroeter \& Dixon pers. comm.). Sensitivity to oil spills is not well known; Chan (1973) saw no obvious effects from a San Francisco oil spill. Recovery time from any major population loss likely would be very long. 


\section{APPENDIX 4. Point Loma Rocky Intertidal Baseline Survey Handbook}

\section{Introduction}

The baseline surveys of rocky intertidal resources on the outer shore of Point Loma include 2 sites, Navy North (NN) and Navy South (NS), that were sampled in Spring and Fall 1995. These surveys provide qualitative inventory data for all field identifiable species and quantitative seasonal data for key species in fixed plots or transects. In order to better understand the temporal dynamics of key species at these sites, longer-term monitoring is necessary. Further monitoring would not only provide current information about natural variations in intertidal communities at these 2 sites that would be invaluable in the event of some impact, but also would enhance comparability with the 3 long-term monitoring sites downcoast at the Cabrillo National Monument (CABR). The CABR sites have been monitored semi-annually since 1990 and continued monitoring in future years is anticipated.

This handbook provides guidelines and specifies procedures for monitoring target species assemblages at the NN and NS rocky intertidal sites at Point Loma, San Diego. The handbook will help survey teams locate the permanent study plots and standardize sampling procedures for future surveys at these sites, either for continued seasonal monitoring or for impact prevention or assessment studies should the need arise.

\section{Survey Background and Planning}

This section provides background information about the survey sites, target species, and fixed plots. Survey planning activities are discussed, including scheduling, personnel, and logistical considerations. The guidelines are based on practical experience with monitoring surveys and the field conditions encountered at the 2 Navy sites in 1995 . The guidelines should not be applied rigidly because each survey has its particular circumstances (e.g., weather conditions, number and experience of samplers). Individual judgments will always be necessary in conducting the field surveys. It is important to maintain flexibility because unforseen situations may require last-minute modifications to sampling plans.

\subsection{Survey sites}

The 2 survey sites are designated Navy North (NN) and Navy South (NS). Their general locations are shown in Figure 1. NS is located 0.2-0.3 km north of the northern boundary of the Point Loma Wastewater Treatment Facility. NN is 1.0-1.2 km upcoast of NS, just seaward of a Navy building on the mesa high above the shore. Detailed maps of $\mathrm{NN}$ are provided in Figures 2 and 3; maps for NS are in Figures 4 and 5. Directions for getting to the sites and brief descriptions of physical features at the survey locations are as follows:

\section{Navy South}

From the entrance to the Point Loma Navy Facility (NRAD) at Electron Drive, drive 0.8 mi south on Route 209 to Woodward Road. Turn right, stop at the security kiosk, then proceed downhill $0.4 \mathrm{mi}$ to Exercise Street. Turn left and drive $0.7 \mathrm{mi}$ south to end of road. Turn right onto short dirt road and park on bluff top. Hike down any of several erosion gullies, then scramble down to the shore along the north side of a narrow inlet. This is the R2 area of NS.

The site encompasses approximately $250 \mathrm{~m}$ of rocky shore along the base of $25 \mathrm{~m}$ high cliffs at the southern end of the Fort Rosecrans Military Reservation, 0.2-0.3 km north of the 
northern boundary of the Point Loma Wastewater Treatment Facility (Fig. 1). A prominent landmark for this site is the narrow promontory (Ref. 3 area) separating the broad cove to the south (Ref. 4 area) from the narrow access inlet to the north (Ref. 2 area) (see Figs. 4 \& 5). This promontory has several crawl- or walk-through arches. The NS site extends from about $100 \mathrm{~m}$ upcoast of the promontory tip to about $150 \mathrm{~m}$ downcoast. NS intertidal shore consists primarily of wave-cut benches composed of many horizontal layers of poorly-consolidated sandstone.

There are 4 subareas of physical features within NS; from upcoast to downcoast, they include the following:

1) Reference 1 area, which is composed of wave-swept 20 m wide bedrock benches extending out from the steep-sloped high intertidal that forms the cliff base. The predominantly flat reefs have few channels, pools, crevices, or movable rocks.

2) Reference 2 area, which includes narrow (roughly $5 \mathrm{~m}$ wide), steep-sloped intertidal that drops into a narrow partly-sheltered inlet cove with boulder and talus rocks throughout the innermost beach and low intertidal. In the low intertidal only, there are deep pools crevices between rocks, some unstable cobble, and minor sand accumulation.

3) Reference 3 area at the promontory point, which is similar to Reference 1 area, except that the south side of the promontory is semi-protected, and a series of benches separated by channels continue downcoast (parallel to shore), across the mouth of the southern cove. The shaded arch cutting across the promontory tip is awash at high tide.

4) Reference 4 area inside the southern cove, partially protected by the outer reefs, is composed of bedrock slabs, boulders, and cobble talus from the cliffs above. The medium-relief rubble provides numerous crevices and pools. There is some sand and gravel on the inner beach.

\section{Navy North}

Follow the same directions given above to reach NS, then hike north along the shore approximately $1.1 \mathrm{~km}$ to the southern edge of $\mathrm{NN}$. The hike to $\mathrm{NN}$ takes about $20 \mathrm{~min}$. It is best done when the tide level is $<3 \mathrm{ft}$. The $\mathrm{NN}$ location encompasses approximately $300 \mathrm{~m}$ of rocky shore along the base of sheer 25-30 m high cliffs in the central portion of the Fort Rosecrans Military Reservation (Fig. 1). A prominent landmark for this site is the centrally-located pinnacle rock ( $10 \mathrm{~m}$ high; $30 \mathrm{~m}$ in diameter) that represents the eroded tip of a high bluff promontory. This chimney rock is about $20 \mathrm{~m}$ offshore from the main promontory such that it is surrounded by water at high tide. The NN site extends from roughly $200 \mathrm{~m}$ upcoast of the chimney rock to $100 \mathrm{~m}$ downcoast (see Figs. 2 \& 3). The rocky intertidal zone at this site consists primarily of broad, gently-sloping wave-cut benches composed of many horizontal layers of poorlyconsolidated sandstone. There are numerous crevices, channels, and pools on the mostly lowmedium relief features. Large slabs of this relatively soft sedimentary rock may be tilted or broken off from the bedrock. The rock surface shows cracks where layers are breaking, smooth depressions eroded by wave action, and tiny slots where chitons have bored down a few centimeters. Mixtures of loose rocks and stable boulders occur at the base of the cliffs and less commonly scattered atop the bedrock flats. There is little sand on this headland shore. Unstable cobble occurs in surge channels.

\subsection{Target species assemblages}

Key species and broader taxonomic categories surveyed at the NN and NS rocky intertidal sites are listed in Table 1 . The same 13 target species are monitored at each location. Grouped according to survey method, they are as follows:

- Photoplots: acorn, thatched, and goose barnacles, rockweed, and mussels 
- Circular plots: owl limpets

- Line transects: boa kelp, sargassum weed, algal turf, surf grass, and anemones

- Timed search: black abalone and ochre sea stars

\subsection{Fixed plots and transects}

Table 1 summarizes the sampling techniques and number of plots and transects for each key species at the 2 monitoring sites. The plots and transects were set up to have the same sampling scheme as the 3 survey sites at the Cabrillo National Monument (CABR) that have been monitored since 1990. There are 5 replicate photoplots emphasized, except for goose barnacles; these have 6 replicates because goose barnacle monitoring at CABR was changed from 3 band transects to 6 photoplots ( 2 per transect) in 1995. At all 3 CABR sites, boa kelp, red algal turf, and surf grass were targeted by 2 replicate line transects each. Boa kelp has since declined and been largely replaced by surf grass in the lowest intertidal zone. Since boa kelp also was rare at the Navy sites, at each area, we established 2 surf grass transects along the inshore portion of the low intertidal and 2 others in the offshore portion. The latter transects, though dominated by surf grass, are in the zone where boa kelp is likely to occur should conditions change.

The fixed plots and transects were established at NN and NS in Spring 1995. These relatively permanent sample plots/transects are marked with $3 / 8$ in stainless steel bolts fixed into the bedrock with epoxy. The bolts mark 3 corners of each rectangular photoplot (the plots at NN also have a blob of epoxy on the fourth corner), the center of each circular plot, and the start, middle, and end of each line-intercept transect. Some of the hexagonal bolt heads are marked (using a band saw or hack saw) with notches on the bolt head edge or with grooves across the bolt head top to identify the plot or transect number. Bolt head number codes based on notch and groove combinations are illustrated in Table 2. The number bolt is located in the upper left corners of each photoplot (with a blank bolt on each adjacent corner, on the center bolt of each circular plot, and at the start point (north end) of each transect. Transect center bolts are blank; end bolts are marked " $\mathrm{X}$ ". In addition, there are several ( 3 at NN, 4 at NS) larger (1/2 in) reference bolts (also notched) located throughout each site. Measurements (distance and bearing) taken from the number bolt of each plot/transect to one or more of the reference bolts are used for mapping the site (see Tables $3 \& 4$; Form 1), locating hard to find plots/transects, and as standard photo or video reference viewpoints.

\subsection{Survey scheduling}

The sites should be sampled semi-annually, in the Spring and Fall. Allow 1 day per site, working during the lowest tide $\pm 2-3 \mathrm{hr}$ (4-5 hr total time/sample). The sampling period can be scheduled tentatively months in advance by checking the appropriate San Diego tide table booklet, calendar, or computer program. If possible, survey the sites during the lowest ("Spring tide") daylight tide conditions in the months of March/April and October/November. At these times, the best low tides will occur in the afternoons. Generally, there are 5 to 7 workable days within each optimum tidal series. When planning the sampling schedule, remember to take into account factors such as:

- advance arrangements for security clearance for all participants

- the sites might not be accessible during weekends or holidays

- the time of low tide with respect to sunset (to allow time to complete the site)

- the time needed on first sample day to obtain security badges and vehicle pass 
- the extra time (at low water) needed to hike to NN (20 min each way)

- some days may not be workable due to rain, wind, or heavy swells.

- 1-2 days at the end of each tidal series should be reserved as "fall-back" days, in case a site survey must be rescheduled.

\subsection{Personnel}

The number of people needed to sample a site depends on level of experience. Four experienced people can sample a site adequately during 1 good low tide period of 4-5 hr; however 6 people, with at least 3 experienced, is recommended. Then it is possible to have 3 teams of 2. Each team should consist of at least 1 sampler who is familiar with that task's techniques and a recorder, who may or may not be experienced. In general there should be separate teams for the plot photographs, owl limpet measurements, and transect scoring. Other tasks to split among the teams include plot/transect location, cleaning/repair of all markers, site reconnaissance, timed search for abalone and sea stars, and video overview (optional).

\subsection{Logistics}

Equipment and materials needed for the monitoring should be stored in one location so that it can be assembled efficiently prior to each survey trip. Usually each person carries a backpack or bucket loaded with sampling and personal gear. Five or more rectangular quadrat frames can be carried in bundles held together with bungee cords or Velcro straps. It is important to use the Equipment Checklist (Form 2) to be sure nothing is forgotten. Expendable items such as film, batteries, and videotape need to be purchased. Spares should be taken to the site in case something does not work or gets dropped into a tidepool. Film and batteries can be purchased in bulk and stored in the refrigerator. Rechargeable batteries should be freshly charged. Load and test camera, strobe, and camcorder to be sure they are working properly. Required data forms include Field Logs (Form 3), Photo Logs (Form 4), Owl Limpet Measurements (Form 5), and Line-Transect Scores (Form 6). Bring a supply of sharpened \#2 pencils. Remind the data recorders to print legibly and darkly so that the completed data sheets can be photocopied.

Samplers should be prepared for all possible weather conditions (especially sun and wind) and should dress accordingly. Listen to the marine weather and surf reports for current sea conditions. Rubber boots may be worn; however, rugged neopreme booties or old sports shoes work quite well and are easier to walk in when filled with sea water. A spare change of clothing can be useful. Foam gardening pads provide comfort for kneeling during owl limpet measurements. Food, water, a hat, sunglasses, and sunscreen are all recommended.

Transportation time should be planned to arrive at the site anywhere from 2-3 hr before low tide. This includes driving, gear organizing, and hiking time. Allow extra time for security clearances on the first day. It is most efficient if everyone can travel in 1 vehicle, then only 1 vehicle pass is needed.

Much of the work should be done as the tide is going out. Generally the tide will be in the mid to late-afternoon, thus approaching darkness will limit work during the rising tide. The target species are best sampled during an out-going tide in this order:

1) High intertidal: goose barnacles, owl limpets, rockweed

2) Mid intertidal: acorn and thatched barnacles, mussels, turf, anemones

3) Low intertidal: sargassum weed, surf grass, boa kelp, abalone, sea stars 


\section{Survey Methods}

\subsection{Site reconnaissance}

During each survey it is important to observe and record the general physical and biological conditions at the site. These observations, along with any photo and video overviews, provide valuable perspective on site dynamics which assist in the interpretation of data from the fixed plots and transects. Often it is most practical to do at least part of the site reconnaissance upon first arrival (assuming a descending tide) because many of these observations can be done before the tide is low enough for performing other tasks. Additional notes can be added later during the monitoring, or even afterwards, when more time is available to organize thoughts.

Site reconnaissance notes are recorded on the Field Log form (Form 3). Physical conditions to be noted include weather conditions (cloud cover, wind speed and direction, air temperature), sea conditions (wave height and direction, surge, water temperature), substrate changes (sand/gravel burial or scouring, overturned boulders, landslides, etc.), presence and distribution of oil/tar, and other unusual occurrences such as floating debris or pollutants. Biological features that should be recorded include obvious changes (or lack thereof) in target and other species distribution, abundance, recruitment, and appearance (size, color, behavior, epiphytes, etc.). The presence of predators (e.g., birds), marine mammals, or humans (sport collectors?) is of interest. Signs of disturbance may be evident.

\subsection{Video overview}

Videotape overviews, along with still photographs, document the general physical and biological characteristics of a survey site. They also record plot and transect locations within the context of the entire site. If desired, they can be used to monitor large-scale temporal changes in biological assemblages. Audio tracks on the videotape allow site reconnaissance observations to be recorded along with the video images.

A videotape record of each survey site should be made during the initial survey. If time and personnel permit, video overviews can also be done during subsequent surveys. The video operator uses a portable camcorder protected by a splashproof housing to document the nature of conditions at each site through visual recordings on $8 \mathrm{~mm}$ tape accompanied by observational narration. Video views range from distant overviews of general habitat features to close-ups of individual species. Important conditions to document on video include the following: all survey plots and transects, sand influence (beach level, scour or smothering effects), health of organisms (bleached plants, dead barnacles, etc.), interesting concentrations of species, recruitment events, extent of ephemeral algae, oil/tar presence and extent, evidence of people use and/or pollution, and any unusual phenomena.

\subsubsection{Video procedures}

Video procedures for each site consist of the following:

- a broad overview of the entire site if possible from a high cliff vantage point

- a beach level overview of all plots and surrounding habitats from fixed points

- beach level closer views of interesting phenomena

The video documentation can be accomplished by a single experienced person (who knows how to use the equipment, the layout of the study site, and what to document visually and through narration). However, the process becomes most efficient if an assistant is available, because that person can carry supplies (batteries, tapes, maps, etc.), keep track of the sequence of video 
views, and look out for waves that may splash the video operator and camcorder. The time it takes to do a video survey depends on the spatial extent and complexity of the study site, and the thoroughness of the site documentation. Preliminary reconnaissance prior to actual videotaping is needed to evaluate conditions at the site and organize points to emphasize visually and verbally. This may take 30-60 min and can be done as the tide recedes. The video survey typically takes 1$2 \mathrm{hr}$ around the time of low tide. This includes about 30-60 min of actual videotaping and 30-60 min of other activities, including set-up at each view point, movement between view points, and changing batteries or tapes. Thus the entire video survey operation at one site takes approximately 1.5 to 3 hrs to complete.

Prior to each video survey, the equipment should be assembled and tested. Video camcorders can be finicky (especially Hi-8). Charge all batteries, clean the video head (if necessary), and make a test recording. Review the camcorder operation, the site-specific video plan, and the results of any previous video surveys (so you know what conditions and possible resource changes to look for). At the site, as the tide recedes, locate and mark all plots and reference bolts with bright materials (orange traffic cones for reference bolts, PVC frames for photoplots, flagging for owl limpet plots, and meter tapes for irregular plots and transects). Conduct an observational reconnaissance of the entire study site -- plots, species, etc. Plan the order (and sometimes modified locations) of video views based on sea conditions, tide levels, and sun position. Organize thoughts for narration during videotaping. Set up camcorder and record a title sequence listing study site and survey date. Also at this time, or at the start of the first overview sequence, verbally record the study site, date, video operator, current time, time and height of low tide, weather conditions, and other pertinent information.

Generally the cliff overview (if present) will be the first video sequence recorded. It puts the entire study site in perspective and documents large-scale changes (e.g., variations in sand levels). Best results are obtained when the tide is fairly low and the plots and reference bolts have been marked conspicuously. Establish a fixed view point, which may be marked or simply described. Use standardized operating procedures and verbal descriptions (see guidelines below). If possible, always start facing upcoast, then use wide-angle view to pan downcoast along the most offshore exposed portion of intertidal first. Reverse the pan for the next closer inshore view. Continue this procedure until the entire shore has been documented. During these video pans, zoom in on key reef areas or survey plots where appropriate, but do not overuse the zoom. All pan and zoom movements should be made slowly.

Beach level overviews are used to put the individual permanent plots or transects into perspective with surrounding assemblages. Record a video sequence from each designated vantage point (i.e., the reference bolts marked with orange cones). At most reference points, plan to do a circular pan $\left(360^{\circ}\right)$ beginning with the most upcoast view. Start with wide angle of more distant habitats on the first pan. If necessary, do a second circular pan of the closest habitats. At any time you can zoom in and describe particular marked plots or other interesting phenomena. It is not necessary to show great detail for each photoplot because the still photos cover that. If particular plots are not covered by video sequences from the marked vantage points, then each plot or group of plots should be videotaped from a standard unmarked view point, usually from about $3 \mathrm{~m}$ away with the sun at your back. For each transect not covered by sequences from the marked vantage points, stand about $3 \mathrm{~m}$ away from the center bolt (with sun at back), then pan slowly along the meter tape from the start bolt to the end bolt. For irregular plots, choose a central vantage point about $3 \mathrm{~m}$ off the plot (with sun at back if possible), then pan along farthest 
view of plot (starting upcoast and inshore if possible). Reverse the pan for next closer view and continue until the whole plot has been covered.

Close view video sequences of interesting intertidal phenomena not necessarily associated with the survey plots may be recorded if time permits. These need not be done from fixed vantage points, nor do they have to be taped during each succeeding survey at a particular site. If they are important enough to be repeatedly documented, then vantage points should be marked or described for standardization.

\subsubsection{Guidelines for best video results}

\section{Camcorder guidelines}

These guidelines are for Sony, Nikon, or Ricoh Hi-8 camcorders. Read the manual and know how to operate the camera properly to obtain the best quality video and sound recordings. Camcorders can be sensitive to jarring. Carry in a padded case whenever possible.

Hi- 8 tape cassettes provide the highest resolution; however, they are more expensive than regular $8 \mathrm{~mm}$ tapes, cannot be played back on standard $8 \mathrm{~mm}$ camcorders, and require a special monitor to take advantage of the increased resolution. If the drawbacks of Hi-8 tapes present a problem, regular $8 \mathrm{~mm}$ tapes can be used and still provide good quality. $60 \mathrm{~min}$ cassettes are preferred, but 120 min tapes also work well.

Take 2 fully-charged heavy duty camcorder batteries to ensure up to $1 \mathrm{hr}$ of taping. These batteries never give as much time as expected (especially with lots of zooming), and older batteries do not hold a charge well.

Use the video head cleaner tape periodically, especially if the recorded image becomes jittery. Plan to clean the head before each series of intertidal video surveys.

Leave the time display on the video for all recording. This provides a fixed visual record on the tape for later reference. This is especially important if tapes are played on a VCR with a different type of counter than that used when the video log was transcribed. It would be preferable to record both date and time, but most camcorders allow only one or the other.

Check the camera housing lens periodically for salt spray outside (especially on windy days) or fogging inside. These conditions will cause blurred images. If necessary, clean the lens with fresh water or lens cleaner, then wipe dry with lens paper. Insert several small desiccant packs inside the splashproof housing to remove moisture.

\section{Video guidelines}

Tape a title sequence (with the site name and date on a piece of paper) at the start of each video survey and at the beginning of each new tape.

Try to videotape at the lowest tide and best light conditions (closest to midday). Unfortunately, many of the good low tides occur in the late afternoon when the sun is low in the sky directly offshore. Best results are obtained under these conditions by keeping the sun behind you as much as possible and by aiming the camera down to reduce the amount of bright sky in view. This helps to minimize under-exposure of shaded reef areas (silhouette effects). 
Hold camera as steady as possible, especially when zoomed in. Remain fixed on still shots for several seconds -- longer than seems sufficient while filming. Pan very slowly. You need to consciously slow down any movements. Slow motion pans work much better than walking while taping. Note that your eye (not looking through the eyepiece) generally can see more detail (bolts, tags, etc.) than shows up on the video, especially when contrast is low. On the other hand, videotapes played back on a color monitor appear much better than what you see through the black and white eyepiece monitor. Sometimes, when looking through the small eyepiece, it is difficult to tell if the camera is aimed correctly at low contrast subjects.

\section{Narration guidelines}

It is not easy to videotape intertidal areas and verbally describe them at the same time. Therefore, it is important to explore the survey site before taping in order to plan what to emphasize and how to describe it.

Set the microphone switch to the wind setting. Talk loudly when it is windy or there is noisy surf.

At the start and end of each site video (and each tape) and periodically throughout the tape, verbally identify the site, date, time, narrator, and any other pertinent information.

Remember to wait several seconds after starting a new tape before talking to be sure what is said will be recorded.

Describe the vantage point at the start of each video sequence. Use standard descriptors for view directions, plot locations, etc. For example, be clear about using "view from" and "view of" when describing a scene. Compass directions may be confusing because local shores can be quite irregular. Instead use "upcoast", "downcoast", "inshore", and "offshore" to describe plot locations and views. Consult the site maps (Figs. 2-5) before starting each video sequence so that correct plot numbers will be included in the commentary.

\subsection{Photoplot surveys}

To survey photoquadrats, first locate them using information from the site map, interplot measurement table, and plot print photographs. Clean the corner markers and note their condition, especially whether repairs are needed. Place a temporary 50 X $75 \mathrm{~cm}$ PVC quadrat frame over each plot to mark it for easy relocation, or tie red flagging on the number bolt. Next, check the camera and strobe (film and batteries loaded?) and assemble the quadrapod apparatus, which holds the camera and strobe directly above each photoplot. Carry the quadrapod to each plot, replace the temporary PVC frame with the quadrapod so that the photo identification tag is in the upper left corner, adjust the three photo identification rings so that each plot number digit appears to the right of each ring, and photograph the plot twice, bracketing for best exposure.

Tide conditions dictate the order in which the quadrats are sampled. If the tide is receding, sample the highest plots, then work down the beach as lower plots are exposed. If the tide is around the low, begin with the downshore plots first. The photographer's assistant must reposition the photo identification tag with the correct plot number each time the frame is placed over a new plot. The assistant also records pertinent information such as photo number, plot number, and exposure on the Photo Log sheet (Form 4). It can be difficult to identify certain species when looking at the slides back in the lab, so it is advisable to jot down (or sketch) a few notes about species composition, cover, unusual or occasional species, etc. while at the plot. After all plot photos are taken, any spare frames left on the roll are used for more general 
overview shots, or of those species that are not directly targeted by photos (e.g., surf grass, boa kelp, owl limpets).

The procedures described here are for a generic $35 \mathrm{~mm}$, single lens reflex camera, with a

$28 \mathrm{~mm}$ lens. Other cameras may be used, but the details of setup and alignment will be slightly different. Use a strobe mounted to the camera to fill in shadows, even in bright sunlight. Read the user manuals for both camera and strobe. Most cameras synchronize focal plane shutters with strobes at a 1/125 second shutter speed. Use that shutter speed with 100 ASA Ektachrome color slide film and aperture settings of $\mathrm{f} 11$ and $\mathrm{f} 16$. This film, at these settings, provides the broad range of image densities required to interpret the photographs in the laboratory. Certainly other films and settings will work, but the recommended settings have proven effective for recording intertidal plots over a wide range of conditions for more than 10 years.

Check all camera gear before leaving for field sampling, while you have no tide-driven time constraints. Use a protective case for the camera, cable shutter release, strobe, film, and spare batteries. Also include lens paper and cleaner, or a chamois skin, a smudge-proof marking pen (sharpie) for marking exposed film rolls, and a lens cap. Bundle the quadrapod components with bungee cords for convenient carrying.

\section{Camera setup}

Load the camera in accordance with the manufacturer's instructions. Check camera and strobe batteries to assure full charges. Having to wait for a slow strobe to recharge, or having to replace a camera battery, during a rapidly rising tide is annoying, and leads to haste-induced errors.

\section{Quadrapod setup}

At the field site, assemble the quadrapod apparatus (Fig. 7). Make sure the PVC rods are securely attached and the frames are parallel by placing the plot frame on a flat surface and pressing firmly on the camera frame fittings. Mount the camera and strobe using a quick release camera mount and the camera's hot shoe. Attach the cable shutter release. Check frame alignment and camera focus by looking through the viewfinder. Adjust the frame as necessary by pressing on the quadrapod fittings. Set the focus at about $0.8 \mathrm{~m}$; you should be able to clearly read the frame number indicator. Set the shutter speed to $1 / 125$ second and the aperture to 11 . Turn on the strobe.

\section{Photographing the plots}

Select the plot to be photographed. Set the plot number indicator rings on the quadrapod plot frame so that the plot numbers are immediately to the right of the rings. Place the quadrapod plot frame over the plot with the plot indicator tag in the upper left corner of the frame. Check frame alignment and focus through the view finder; adjust as necessary. Trip the shutter, check to assure that the strobe discharged, record the plot number and camera settings on the Photo Log (Form 4). If the strobe failed, check the equipment and re-take the picture, recording the failure on the Photo Log. Set the lens aperture at $\mathrm{f} 16$ and repeat the process. Move to the next plot and repeat the process until all plots at the site have been recorded. 


\subsection{Circular Plot Surveys}

Two persons work best for surveying the limpet plots: 1 experienced person to identify and measure the limpets, and an assistant to record the data. First locate the plots, using information from the site maps, the interplot measurement chart, and the plot print photos. Clean the markers and note their condition, particularly whether repairs are needed. This is important since there is only 1 bolt per quadrat. Tie bright surveyor's flagging to each bolt for ease of plot relocation. To survey each plot, attach a $1 \mathrm{~m}$ length of line (or meter tape) to the center bolt and swing around in an arc, carefully searching all cracks and crevices for Lottia. Be aware that the limpets may be covered with barnacles, algae, etc., and can even be confused with chitons. Owl limpets found within that arc (including those touched by the $1 \mathrm{~m}$ mark) are measured with calipers to the nearest millimeter, then marked with a yellow forestry crayon to avoid duplicate scoring. However, limpets $<15 \mathrm{~mm}$ are not scored because it is difficult to distinguish tiny Lottia from other species of limpets. Measurements are recorded on the Owl Limpet Data Sheet by a helper (Form 5). If the limpet cannot be measured in place (due to crevices or other irregularities), estimate its size and note this on the data sheet. Never remove limpets from the rock. Observations including obvious scars from missing limpets and any evidence of predation also should be included on the data sheet.

\subsection{Line Intercept Transect Surveys}

Two persons are most efficient for surveying the point-intercept transects, 1 experienced person to identify the organisms located along the tape edge, and an assistant to record the data. First locate the transects, using information from the site maps, the interplot measurement chart, and the transect print photos. Care must be taken not to disturb the positions of plants along the transect path when searching for bolts. Clean the markers and note their condition, particularly whether repairs are needed. Tie bright surveyor's flagging to each bolt for ease of transect relocation. Once the tide is low enough, run a meter tape (again with care) the length of the transect, starting from the notched bolt. Watch for approaching surges that might disturb the position of the tape or the plants around it. If possible, survey the entire transect during a period when the tape and plants are undisturbed. To score the line-intercept transects, the sampler walks along each transact, calling out whatever taxon falls directly beneath the tape edge. The line cover estimates are rounded off to the nearest centimeter, thus 1000 separate segments are scored for each $10 \mathrm{~m}$ transect. It may appear as if the scoring would be extremely tedious; however, in practice, relatively few taxa make up most of the line-intercept cover. Up to eight taxonomic categories are called out by the scorer and then recorded onto the Line-Transect Data Sheet by an assistant (Form 6). Typical scoring may proceed as follows: "0-46 cm: bare substrate, 46-321 cm: surf grass, 321-378 cm: boa kelp, etc." General observations, such as key species condition (e.g., color and length) and sand cover (if any) are all important to note.

\subsection{Timed searches}

Around the time of low tide, 1 person should spend $30 \mathrm{~min}$ (or 2 persons $15 \mathrm{~min}$ each) searching crevices and pools along the low intertidal zone haphazardly throughout the site for possible occurrences of ochre sea stars (Pisaster ochraceus) or black abalone (Haliotis cracherodii). Plan to get wet at least to thigh level as you kneel to look under boulders and ledges. Use a waterproof flashlight if necessary to see into dark areas. Turn over occasional rocks and look for juveniles. Record the number and size for other sea stars, including bat stars (Asterina miniata), giant-spined stars (Pisaster giganteus), and fragile stars (Astrometis 
sertulifera), as well as any green abalone (Haliotis fulgens). Note other species occurrences for inclusion in the species inventory list.

\subsection{Data management}

After returning from sampling, the data sheets should be organized and checked for completeness and legibility. Field notes should be written up (if not done so already) while thoughts are fresh. It is important to make a list of plot markers that need repairs and to note any ideas for increasing the efficiency of sampling. Data sheets along with field notes are filed into notebooks under each site and sampling period. The film is sent off to be processed. When the slides return, they are marked individually with site name, date, species and plot number. They are then organized by site, target species, and sequential plot number into notebooks filed within plastic slide-holder sleeves to await scoring. For scoring, each slide is projected onto a white board that is marked with a grid of 100 evenly-spaced points. Single taxa ( 9 categories) beneath each of the 100 points are identified and recorded within the proper category on the Photoquadrat Data Sheet (Form 7). Photoplot and all other numerical data are then entered into a computer spreadsheet file and saved for later analysis. 


\section{TABLES}

Table 1. Index Taxa and Monitoring Techniques at Navy North and South Sites. Values in parentheses indicate the number of replicate plots emphasizing those particular species.

Number Total

\begin{tabular}{|c|c|c|c|}
\hline Technique/Taxa & Dimensions & Per Area & Sample \\
\hline Photoplot & $50 \times 75 \mathrm{~cm}$ & 21 & \\
\hline \multicolumn{4}{|l|}{ Acorn Barnacle } \\
\hline \multicolumn{4}{|l|}{ Chthamalus spp. } \\
\hline Pink Thatched Barnacle & & (5) & \\
\hline \multicolumn{4}{|l|}{ Tetraclita rubescens } \\
\hline Rockweed & & (5) & \\
\hline \multicolumn{4}{|l|}{ Pelvetia fastigiata } \\
\hline California Mussel & & (5) & \\
\hline \multicolumn{4}{|l|}{ Mytilus californianus } \\
\hline Goose Barnacle & & (6) & \\
\hline \multicolumn{4}{|l|}{ Pollicipes polymerus } \\
\hline \multicolumn{4}{|l|}{ Other Plants } \\
\hline \multicolumn{4}{|l|}{ Other Animals } \\
\hline \multirow{2}{*}{\multicolumn{4}{|c|}{$\begin{array}{l}\text { Tar } \\
\text { Bare Substrate }\end{array}$}} \\
\hline & & & \\
\hline \multirow{2}{*}{\multicolumn{4}{|c|}{$\begin{array}{l}\text { Circular Plot } \\
\text { Owl Limpet }\end{array}$}} \\
\hline & & & \\
\hline \multicolumn{4}{|l|}{ Lottia gigantea } \\
\hline Line Transect & $10 \mathrm{~m}$ & 6 & 12 \\
\hline \multicolumn{4}{|l|}{ Boa Kelp } \\
\hline \multicolumn{4}{|l|}{ Egregia menziesii } \\
\hline \multicolumn{4}{|l|}{ Sargassum Weed } \\
\hline \multicolumn{4}{|l|}{ Sargassum muticum } \\
\hline Red Algal Turf & & (2) & \\
\hline \multicolumn{4}{|l|}{ Corallina spp. et al. } \\
\hline Surf grass & & (4) & \\
\hline \multicolumn{4}{|l|}{ Phyllospadix spp. } \\
\hline \multicolumn{4}{|c|}{ Aggregating Anemone } \\
\hline \multicolumn{4}{|c|}{ Anthopleura elegantissima } \\
\hline \multicolumn{4}{|c|}{ Other Biota } \\
\hline \multirow{2}{*}{\multicolumn{4}{|c|}{$\begin{array}{l}\text { Tar } \\
\text { Bare Substrate }\end{array}$}} \\
\hline & & & \\
\hline Timed Search & 30 person-minutes & 1 & 2 \\
\hline $\begin{array}{l}\text { Black Abalone } \\
\text { Haliotis cracherodii }\end{array}$ & & & \\
\hline Ochre Sea star & & & \\
\hline Pisaster ochraceus & & & \\
\hline
\end{tabular}


Table 2. Rocky Intertidal Survey Plots and Plot Identification Codes.

\begin{tabular}{|c|c|c|c|}
\hline Plot Type & Key Species & Plot Code & Photo Code \\
\hline \multirow[t]{21}{*}{ Photoplot } & \multirow[t]{5}{*}{ Barnacles } & $\mathrm{B1}$ & 101 \\
\hline & & B2 & 102 \\
\hline & & B3 & 102 \\
\hline & & B4 & 104 \\
\hline & & B5 & 105 \\
\hline & \multirow[t]{5}{*}{ Rockweed } & Pe1 & 001 \\
\hline & & Pe2 & 002 \\
\hline & & $\mathrm{Pe} 3$ & 003 \\
\hline & & Pe4 & 004 \\
\hline & & Pe5 & 005 \\
\hline & \multirow{11}{*}{$\begin{array}{c}\text { Mussel/ } \\
\text { Goose barnacle }\end{array}$} & MO & 200 \\
\hline & & M1 & 201 \\
\hline & & M2 & 202 \\
\hline & & M3 & 203 \\
\hline & & M4 & 204 \\
\hline & & M5 & 205 \\
\hline & & M6 & 206 \\
\hline & & M7 & 207 \\
\hline & & M8 & 208 \\
\hline & & M9 & 209 \\
\hline & & M10 & 210 \\
\hline \multirow[t]{6}{*}{ Circular Plot } & \multirow[t]{6}{*}{ Owl limpet } & L1 & \\
\hline & & L2 & \\
\hline & & L3 & \\
\hline & & L4 & \\
\hline & & L5 & \\
\hline & & L6 & \\
\hline Line Transect & Red algal turf & T1 & \\
\hline & & $\mathrm{T} 2$ & \\
\hline & Surfgrass & G3 & \\
\hline & & G4 & \\
\hline & & $\begin{array}{l}\text { G5 } \\
\text { G6 }\end{array}$ & \\
\hline
\end{tabular}

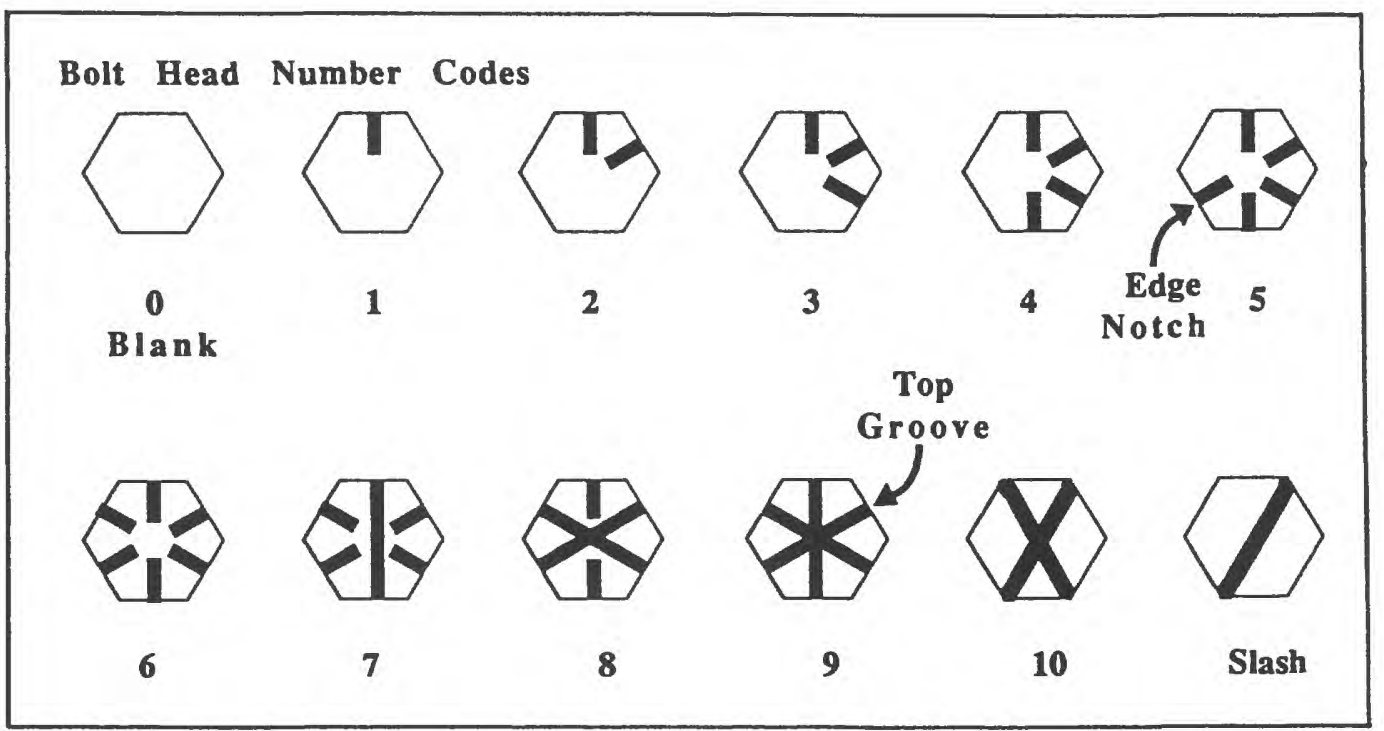


Table 3. Navy North Rocky Intertidal Interplot Measurements.

B $=$ Barnacle $\mathbf{G}=$ Grass $\mathbf{L}=$ Limpet $\mathbf{P o}=$ Pollicepes $\mathbf{M}=$ Mussel $\mathbf{T}=$ Turf $\mathbf{C}=$ Center $\mathbf{N}=$ North $\mathbf{R}=$ Reference $\mathbf{S}=$ Soutu

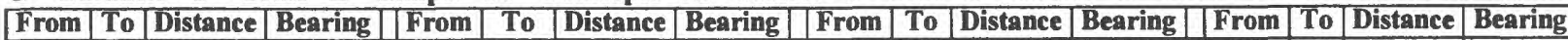

\begin{tabular}{|c|c|c|c|c|c|c|c|c|c|c|c|c|c|c|c|}
\hline & & & & & & & & & & & & & & & \\
\hline $\mathrm{B} 1$ & $\mathrm{~B} 2$ & 3.33 & $160^{\circ}$ & G5S & G5N & 10.01 & $310^{\circ}$ & M6 & M5 & 1.04 & 325 & R2 & $\overline{B 1}$ & 43.95 & 345 \\
\hline B1 & G3 & 13.38 & 220 & G5S & G6N & 36.45 & 110 & M6 & M7 & 1.32 & 85 & $\mathrm{R} 2$ & $\mathrm{~B} 2$ & 40.64 & 345 \\
\hline$\overline{B 1}$ & $\bar{R} 2$ & 43.95 & 165 & G5S & R3 & 31.74 & 45 & M6 & R1 & 3.70 & 55 & $\overline{R 2}$ & $\overline{B 3}$ & 5.16 & 355 \\
\hline$\overline{B 1}$ & T1 & 17.21 & 135 & & & & & & & & & R2 & B4 & 6.27 & 170 \\
\hline & & & & $\bar{G} 6 \mathrm{C}$ & G6N & 5.41 & 320 & M7 & M6 & 1.32 & 265 & R2 & $\overline{\mathrm{B} 5}$ & 8.24 & 165 \\
\hline$\overline{\mathrm{B} 2}$ & $\overline{B 1}$ & 3.33 & 340 & G6C & R3 & 40.29 & 340 & M7 & M8 & 3.00 & 145 & $\mathrm{R} 2$ & G3 & 32.62 & 320 \\
\hline B2 & G3 & 11.75 & 230 & G6C & $\mathrm{T} 2 \mathrm{~S}$ & 29.62 & 5 & M7 & R1 & 2.88 & 60 & $\mathrm{R} 2$ & G3 & 37.53 & 325 \\
\hline $\mathrm{B} 2$ & $\mathrm{G} 3$ & 17.39 & 195 & & & & & & & & & $\mathrm{R} 2$ & G3 & 27.72 & 320 \\
\hline $\mathrm{B} 2$ & $\mathrm{R} 2$ & 40.64 & 165 & G6N & G5S & 36.45 & 290 & M8 & L1 & 4.40 & 165 & $\mathrm{R} 2$ & G4 & 23.00 & 245 \\
\hline $\mathrm{B} 2$ & TI & 14.21 & 130 & G6N & G6C & 5.41 & 140 & M8 & M7 & 3.00 & 325 & $\mathrm{R} 2$ & G4 & 20.77 & 255 \\
\hline & & & & G6N & G6S & 9.97 & 135 & M8 & R1 & 4.07 & 350 & R2 & G4 & 25.82 & 235 \\
\hline $\bar{B} 3$ & $\overline{\mathrm{B} 4}$ & 11.44 & 175 & G6N & $\mathrm{R} 3$ & 35.19 & $\overline{345}$ & & & & & $\mathrm{R} 2$ & L4 & 43.88 & 165 \\
\hline B3 & $\bar{R} 2$ & 5.16 & 175 & G6N & T2S & 26.21 & 15 & M9 & L1 & 5.10 & 5 & $\mathrm{R} 2$ & R1 & 111.94 & 5 \\
\hline B3 & T1 & 18.95 & 360 & & & & & M9 & $\mathbf{L} 2$ & 1.95 & 165 & $\bar{R} 2$ & R3 & 95.95 & $\sim 140$ \\
\hline B3 & T1 & 23.84 & 355 & G6S & G6N & 9.97 & 315 & M9 & $\overline{\text { R1 }}$ & 13.21 & 350 & R2 & T1 & 24.08 & 360 \\
\hline B3 & T1S & 14.15 & 10 & G6S & $\mathrm{R3}$ & 43.86 & 335 & & & & & $\mathrm{R} 2$ & T1 & 28.97 & 355 \\
\hline & & & & G6S & T2S & 31.45 & 360 & M10 & $\mathrm{L3}$ & 1.64 & 360 & R2 & T1S & 19.24 & 5 \\
\hline B4 & B3 & 11.44 & 355 & & & & & M10 & RI & 18.51 & 345 & & & & \\
\hline B4 & B5 & 2.27 & 140 & L1 & M8 & 4.40 & 345 & & & & & $\mathrm{R} 3$ & G5 & 32.33 & 240 \\
\hline B4 & $\mathrm{R} 2$ & 6.27 & 350 & L1 & M9 & 5.10 & 185 & $\mathrm{Pel}$ & $\mathrm{Pe} 2$ & 8.07 & 145 & R3 & G5 & 33.83 & 245 \\
\hline & & & & L1 & RI & 8.23 & 350 & Pel & Pe5 & 15.73 & 165 & $\mathrm{R} 3$ & G5 & 31.74 & 225 \\
\hline B5 & $\bar{B} 4$ & 2.27 & 320 & & & & & Pel & $\mathrm{R} 3$ & 28.27 & 170 & $\mathrm{R3}$ & G6 & 40.29 & 160 \\
\hline B5 & G4 & 23.34 & 265 & $\mathbf{L} 2$ & $\mathrm{L3}$ & 2.11 & 145 & & & & & $\overline{\mathrm{R} 3}$ & G6 & 35.19 & 165 \\
\hline$\overline{B 5}$ & G4 & 22.82 & 280 & $\overline{\mathrm{L} 2}$ & M9 & 1.95 & 345 & $\mathrm{Pe} 2$ & Pel & 8.07 & 325 & R3 & G6 & 43.86 & 155 \\
\hline B5 & G4 & 24.57 & 250 & $\overline{\mathrm{L} 2}$ & R1 & 15.08 & 350 & $\mathrm{Pe} 2$ & $\mathrm{Pe} 3$ & 3.02 & 135 & $\mathrm{R3}$ & L6 & 56.03 & 300 \\
\hline B5 & $\overline{\mathrm{R} 2}$ & 8.24 & 345 & & & & & $\mathrm{Pe} 2$ & $\mathrm{Pe} 4$ & 7.21 & 160 & R3 & Pel & 28.27 & 350 \\
\hline & & & & $\mathrm{L3}$ & $\mathrm{L} 2$ & 2.11 & 325 & $\mathrm{Pe} 2$ & $\overline{\mathrm{Pe} 5}$ & 8.42 & 180 & $\overline{\mathrm{R} 3}$ & $\mathrm{Pe} 2$ & 20.94 & 355 \\
\hline G3C & G3 & 4.94 & 335 & $\mathrm{L3}$ & M10 & 1.64 & 180 & $\mathrm{Pe} 2$ & $\mathrm{R} 3$ & 20.94 & 175 & $\mathrm{R3}$ & $\mathrm{Pe} 3$ & 18.82 & 360 \\
\hline G3C & $\mathrm{R} 2$ & 32.62 & 140 & $\bar{L} 3$ & R1 & 17.04 & 345 & & & & & R3 & $\mathrm{Pe} 4$ & 14.21 & 5 \\
\hline & & & & & & & & $\mathrm{Pe} 3$ & $\mathrm{Pe} 2$ & 3.02 & 315 & R3 & Pe5 & 12.60 & 355 \\
\hline G3N & B1 & 13.38 & 40 & $\overline{\mathrm{I} A}$ & G4S & 42.70 & 315 & $\mathrm{Pe} 3$ & $\mathrm{Pe} 4$ & 4.67 & 175 & R3 & R2 & 95.95 & 180 \\
\hline G3N & B2 & 11.75 & 50 & $\overline{\mathrm{L} 4}$ & L5 & 2.34 & 205 & $\mathrm{Pe} 3$ & $\mathrm{Pe} 5$ & 6.79 & 205 & $\overline{\mathrm{R} 3}$ & $\mathrm{~T} 2$ & 16.39 & 105 \\
\hline G3N & G3 & 4.94 & 155 & $\mathrm{~L} 4$ & L6 & 8.05 & 190 & $\mathrm{Pe} 3$ & $\mathrm{R} 3$ & 18.82 & 180 & R3 & 12 & 13.43 & 90 \\
\hline G3N & G3 & 9.94 & 155 & $\mathrm{L4}$ & $\bar{R} 2$ & 43.88 & 345 & & & & & $\mathrm{R} 3$ & $\mathrm{~T} 2 \mathrm{~S}$ & 20.12 & 120 \\
\hline G3N & R2 & 37.53 & 145 & & & & & Pe4 & $\overline{\mathrm{Pe} 2}$ & 7.21 & 340 & & & & \\
\hline $\mathrm{G} 3 \mathrm{~N}$ & T1 & 19.18 & 100 & L5 & $\mathrm{L} 4$ & 2.34 & 25 & $\mathrm{Pe} 4$ & Pe3 & 4.67 & 355 & TIC & B3 & 18.95 & 180 \\
\hline $\mathrm{G} 3 \mathrm{~N}$ & T1S & 24.67 & 125 & L5 & L6 & 5.92 & 175 & $\mathrm{Pe} 4$ & Pe5 & 3.34 & 235 & TIC & $\mathrm{R} 2$ & 24.08 & 180 \\
\hline & & & & & & & & $\mathrm{Pe} 4$ & R3 & 14.21 & 185 & & & & \\
\hline G3S & B2 & 17.39 & 15 & L6 & G5N & 41.65 & 150 & $\mathrm{Pe} 4$ & T2N & 18.89 & 135 & TIN & B1 & 17.21 & 315 \\
\hline G3S & G3 & 9.94 & 335 & L6 & L4 & 8.05 & 10 & $\mathrm{Pe} 4$ & T2S & 28.71 & 140 & TIN & $\overline{\mathrm{B} 2}$ & 14.21 & 310 \\
\hline G3S & G4 & 27.19 & 190 & L6 & L5 & 5.92 & 355 & & & & & TIN & B33 & 23.84 & 175 \\
\hline G3S & $\mathrm{R} 2$ & 27.72 & 140 & L6 & R3 & 56.03 & 120 & Pe5 & $\mathrm{Pel}$ & 15.73 & 345 & TIN & G3 & 19.18 & 280 \\
\hline G3S & TI & 16.35 & 70 & & & & & Pe5 & $\mathrm{Pe} 2$ & 8.42 & 360 & T1N & G3 & 16.35 & 250 \\
\hline G3S & T1S & 17.66 & 105 & MO & M1 & 1.71 & 195 & Pe5 & $\mathrm{Pe} 3$ & 6.79 & 25 & T1N & $\bar{R} 2$ & 28.97 & 175 \\
\hline & & & & Mo & R1 & 9.29 & 160 & Pe5 & Pe4 & 3.34 & 55 & & & & \\
\hline $\mathrm{G} 4 \bar{C}$ & B5 & 23.34 & 85 & & & & & Pe5 & R3 & 12.60 & 175 & T1S & $\mathrm{B3}$ & 14.15 & 190 \\
\hline G4C & $\mathrm{G} 4$ & 5.00 & 5 & M1 & M0 & 1.71 & 15 & & & & & T1S & G3 & 24.67 & 305 \\
\hline G4C & $\overline{\mathrm{R} 2}$ & 23.00 & 65 & M1 & M2 & 0.96 & 230 & RI & $\mathrm{LI}$ & 8.23 & 170 & TIS & G3 & 17.66 & 285 \\
\hline & & & & M1 & R1 & 7.95 & 155 & R1 & L2 & 15.08 & 170 & & & & \\
\hline G4N & B5 & 22.82 & 100 & & & & & R1 & L3 & 17.04 & 165 & $\mathrm{~T} 2 \mathrm{C}$ & $\mathrm{R}^{3}$ & 16.39 & 285 \\
\hline G4N & G3 & 27.19 & 10 & M2 & M1 & 0.96 & 50 & R1 & M0 & 9.29 & 340 & $\mathrm{~T} 2 \mathrm{C}$ & $\mathrm{T} 2$ & 5.04 & 330 \\
\hline G4N & G4 & 5.00 & 185 & M2 & M3 & 1.75 & 150 & RI & M1 & 7.95 & 335 & & & & \\
\hline G4N & G4 & 9.99 & 185 & M2 & R1 & 7.71 & 150 & RI & M2 & 7.71 & 330 & T2N & $\overline{\mathrm{Pe}} 4$ & 18.89 & 315 \\
\hline G4N & $\mathrm{R} 2$ & 20.77 & 75 & & & & & R1 & M3 & 6.05 & 325 & T2N & R3 & 13.43 & 270 \\
\hline & & & & M3 & M2 & 1.75 & 330 & R1 & M4 & 4.76 & 310 & $\mathrm{~T} 2 \mathrm{~N}$ & $\mathrm{~T} 2$ & 5.04 & 150 \\
\hline $\mathrm{G} 4 \mathrm{~S}$ & B5 & 24.57 & 70 & $\mathrm{M} 3$ & M4 & 2.22 & 190 & R1 & M5 & 3.94 & 260 & $\mathrm{~T} 2 \mathrm{~N}$ & T2S & 10.03 & 150 \\
\hline G4S & G4 & 9.99 & 5 & M3 & R1 & 6.05 & 145 & $\bar{R} 1$ & M6 & 3.70 & 235 & & & & \\
\hline G4S & L4 & 42.70 & 135 & & & & & R1 & M7 & 2.88 & 240 & T2S & G6 & 29.62 & 185 \\
\hline G4S & R2 & 25.82 & 55 & & & & & $\overline{\mathrm{R}} 1$ & M8 & 4.07 & 170 & T2S & G6 & 26.21 & 195 \\
\hline & & & & M4 & M3 & 2.22 & 10 & R1 & M9 & 13.21 & 170 & T2S & G6 & 31.45 & 180 \\
\hline G5C & G5 & 4.97 & 310 & M4 & M5 & 3.51 & 185 & R1 & M10 & 18.51 & 165 & T2S & $\mathrm{Pe} 4$ & 28.71 & 320 \\
\hline G5C & $\mathrm{R3}$ & 32.33 & 60 & M4 & RI & 4.76 & 130 & R1 & R2 & 111.94 & 185 & T2S & R3 & 20.12 & 300 \\
\hline & & & & & & & & & & & & $\mathrm{T} 2 \mathrm{~S}$ & $\mathrm{~T} 2$ & 10.03 & 330 \\
\hline G5N & G5 & 4.97 & 130 & M5 & M4 & 3.51 & 5 & & & & & & & & \\
\hline G5N & G5 & 10.01 & 130 & M5 & M6 & 1.04 & 145 & & & & & & & & \\
\hline G5N & L6 & 41.65 & 330 & M5 & R1 & 3.94 & 80 & & & & & & & & \\
\hline G5N & $\mathrm{R} 3$ & 33.83 & 65 & & & & & & & & & & & & \\
\hline
\end{tabular}


Table 4. Navy South Rocky Intertidal Interplot Measurements.

B = Barnacle $\quad G=$ Grass $L=$ Limpet $P o=$ Pollicepes $M=$ Mussel $T=$ Turf $C=$ Center $N=$ North $R=$ Reference $S=$ South $P e=P$

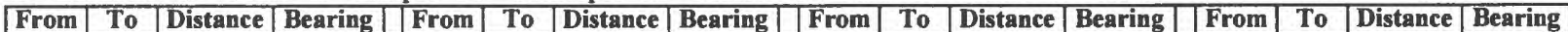

\begin{tabular}{|c|c|c|c|c|c|c|c|c|c|c|c|c|c|c|c|}
\hline & & & & & & & & & & & & & & & \\
\hline B1 & M7 & 27.00 & 330 & G5S & B5 & 9.66 & 25 & M4 & L6 & 1.17 & 285 & $\mathrm{R} 2$ & B2 & 2.64 & 210 \\
\hline B1 & M8 & 2.55 & 110 & G5S & G5N & 9.96 & 335 & M4 & M5 & 0.92 & 55 & R2 & B3 & 2.44 & 165 \\
\hline$\overline{B 1}$ & R1 & 10.26 & 340 & G5S & G6C & 16.17 & 110 & M4 & $\overline{\mathrm{R} 3}$ & 3.38 & 295 & $\bar{R} 2$ & $\mathrm{LI}$ & 3.83 & 245 \\
\hline \multirow[t]{2}{*}{ B1 } & TIS & 18.30 & 315 & G5S & G6N & 13.18 & 90 & & & & & $\mathrm{R} 2$ & $\mathrm{~L} 2$ & 2.08 & 235 \\
\hline & & & & G5S & G6S & 19.97 & 120 & M5 & L6 & 1.85 & 255 & $\overline{\mathrm{R} 2}$ & L3 & 2.05 & 40 \\
\hline B2 & $\bar{B} 3$ & 1.96 & 85 & G5S & $\mathrm{R} 3$ & 18.01 & 355 & M5 & M4 & 0.92 & 235 & R2 & L4 & 31.79 & 180 \\
\hline $\bar{B} 2$ & L2 & 1.16 & 340 & G5S & T2C & 9.48 & 45 & M5 & $\bar{R} 3$ & 3.91 & 280 & R2 & M2 & 2.94 & 40 \\
\hline \multirow[t]{2}{*}{ B2 } & $\mathrm{R} 2$ & 2.64 & 30 & G5S & T2N & 11.88 & 20 & M5 & T2N & 6.38 & 155 & & & & \\
\hline & & & & G5S & T2S & 9.39 & 75 & & & & & R3 & B5 & 11.63 & 145 \\
\hline B3 & B2 & 1.96 & 265 & & & & & M6 & M7 & 1.65 & 180 & R3 & G5C & 13.50 & 180 \\
\hline B3 & M2 & 4.69 & 360 & $\overline{\mathrm{G} 6 \mathrm{C}}$ & G5S & 16.17 & 290 & M6 & Pol & 6.49 & 330 & R3 & G5N & 9.38 & 195 \\
\hline \multirow[t]{2}{*}{ B3 } & R2 & 2.44 & 345 & $\overline{G 6 C}$ & G6N & 4.99 & 340 & M6 & R1 & 18.27 & 160 & R3 & G5S & 18.01 & 175 \\
\hline & & & & G6C & R3 & 29.32 & 325 & & & & & $\bar{R} 3$ & $\bar{G} 6 \mathrm{C}$ & 29.32 & 145 \\
\hline B4 & G5N & 7.31 & 135 & G6C & T2S & 10.34 & 325 & M7 & $\mathrm{B} 1$ & 27.00 & 150 & R3 & G6N & 24.17 & 140 \\
\hline B4 & L4 & 3.94 & 320 & & & & & M7 & M6 & 1.65 & 360 & R3 & G6N & 24.52 & 140 \\
\hline B4 & L5 & 5.45 & 25 & G6N & G5S & 13.18 & 270 & M7 & R1 & 16.79 & 155 & R3 & G6S & 34.20 & 145 \\
\hline $\bar{B} 4$ & L6 & 9.35 & 80 & G6N & G6C & 4.99 & 160 & M7 & T1N & 5.78 & 250 & R3 & L6 & 2.21 & 130 \\
\hline \multirow[t]{2}{*}{ B4 } & $\mathrm{M} 3$ & 2.47 & 330 & $\mathrm{G} 6 \mathrm{~N}$ & G6S & 9.98 & 160 & M7 & TIS & 11.03 & 180 & R3 & M4 & 3.38 & 115 \\
\hline & & & & G6N & R3 & 24.17 & 320 & & & & & R3 & M5 & 3.91 & 100 \\
\hline$\overline{B 5}$ & G5S & 9.66 & 205 & G6N & R3 & 24.52 & 320 & M8 & B1 & 2.55 & 290 & R3 & $\mathrm{T} 2 \mathrm{C}$ & 14.08 & 140 \\
\hline$\overline{B 5}$ & R3 & 11.63 & 325 & G6N & R4 & 81.00 & 110 & M8 & M9 & 1.01 & 145 & R3 & T2N & 9.30 & 135 \\
\hline$\overline{\mathrm{B}} 5$ & $\mathrm{~T} 2 \mathrm{C}$ & 2.54 & 135 & G6N & T2S & 5.59 & 315 & M8 & $\mathrm{R} 1$ & $? 12.23$ & 325 & R3 & T2S & 19.02 & 145 \\
\hline B5 & T2N & 2.77 & 350 & & & & & & & & & & & & \\
\hline \multirow[t]{2}{*}{ B5 } & T2S & 7.44 & 140 & G6S & G5S & 19.97 & 300 & M9 & $\bar{G} 4 \mathrm{C}$ & 12.54 & 235 & R4 & G6N & 81.00 & 290 \\
\hline & & & & G6S & G6N & 9.98 & 340 & M9 & G4N & 13.10 & 260 & R4 & Pel & $? 0.39$ & 80 \\
\hline G3C & G3N & 5.00 & 335 & G6S & R3 & 34.20 & 325 & M9 & G4S & 13.69 & 220 & R4 & $\mathrm{Pe} 2$ & 3.43 & 170 \\
\hline G3C & R1 & 17.29 & 105 & G6S & T2S & 15.25 & 335 & M9 & M10 & 4.03 & 160 & R4 & $\mathrm{Pe} 3$ & 6.78 & 110 \\
\hline G3C & T1N & 8.34 & 20 & & & & & M9 & M8 & 1.01 & 325 & R4 & $\mathrm{Pe} 4$ & 7.67 & 110 \\
\hline $\bar{G} 3 \bar{C}$ & TIS & 7.56 & 100 & $\mathrm{L1}$ & $\mathrm{L} 2$ & 1.96 & 80 & M9 & R1 & 13.23 & 330 & R4 & Pe5 & 7.76 & 110 \\
\hline & & & & $\mathrm{LI}$ & M1 & 13.17 & 290 & & & & & & & & \\
\hline G3N & $\mathrm{G} 3 \mathrm{C}$ & 5.00 & 155 & L1 & R2 & 3.83 & 65 & M10 & G4S & 11.97 & 225 & TIC & R1 & 13.95 & 120 \\
\hline $\mathrm{G} 3 \mathrm{~N}$ & G3S & $10 . \overline{0} 0$ & 155 & & & & & M10 & L4 & 38.45 & 140 & TIC & TIN & 5.00 & 330 \\
\hline G3N & R1 & 21.14 & 115 & L2 & $\overline{\mathrm{B} 2}$ & 1.16 & 160 & M10 & M9 & 4.03 & 340 & & & & \\
\hline G3N & TIN & 6.45 & 60 & $\mathrm{~L} 2$ & $\mathrm{LI}$ & 1.96 & 260 & & & & & T1N & G3C & 8.34 & 200 \\
\hline G3N & TIS & $11 . \overline{35}$ & 120 & $\mathrm{~L} 2$ & R2 & 2.08 & 55 & Pel & $\mathrm{Pe} 2$ & 3.37 & 175 & TIN & G3N & 6.45 & 240 \\
\hline & & & & & & & & Pel & R4 & $? 0.39$ & 260 & TIN & G3S & 12.15 & 180 \\
\hline G3S & G3N & 10.00 & 335 & $\overline{\mathrm{L} 3}$ & $\mathrm{M} 2$ & 1.10 & 40 & & & & & T1N & M0 & 9.79 & 15 \\
\hline G3S & G4N & 16.24 & 160 & $\mathrm{L3}$ & $\overline{R 2}$ & 2.05 & 220 & $\mathrm{Pe} 2$ & Pel & 3.37 & 355 & TIN & M7 & 5.78 & 70 \\
\hline G3S & R1 & 14.19 & 90 & & & & & $\mathrm{Pe} 2$ & $\mathrm{Pe} 3$ & 5.78 & 80 & TIN & R1 & 18.51 & 165 \\
\hline G3S & T1N & 12.15 & 360 & $\bar{L} 4$ & $\mathrm{~B} 4$ & 3.94 & 140 & $\mathrm{Pe} 2$ & R4 & 3.43 & 350 & T1N & TIC & 5.00 & 150 \\
\hline G3S & T1S & 5.95 & 60 & L4 & G4S & 38.71 & 315 & & & & & T1N & T1S & 9.99 & 150 \\
\hline & & & & L4 & M1 & 38.15 & 325 & $\mathrm{Pe} 3$ & $\mathrm{Pe} 2$ & 5.78 & 260 & & & & \\
\hline G4C & $\overline{\mathrm{G}} 4 \mathrm{~N}$ & 5.01 & 330 & L4 & M10 & 38.45 & 320 & $\mathrm{Pe} 3$ & $\mathrm{Pe} 4$ & 1.22 & 65 & TIS & B1 & 18.30 & 135 \\
\hline G4C & M9 & 12.54 & 55 & $\mathrm{~L} 4$ & M3 & 1.52 & 130 & $\mathrm{Pe} 3$ & $\bar{R} 4$ & 6.78 & 290 & T1S & G3C & 7.56 & 280 \\
\hline G4C & R1 & 19.01 & 15 & L4 & $\overline{R 2}$ & 31.79 & 360 & & & & & TIS & $\mathrm{G} 3 \mathrm{~N}$ & 11.35 & 300 \\
\hline & & & & & & & & $\mathrm{Pe} 4$ & $\mathrm{Pe} 3$ & 1.22 & 245 & T1S & G3S & 5.95 & 240 \\
\hline G4N & G3S & 16.24 & 340 & L5 & B4 & 5.45 & 205 & $\mathrm{Pe} 4$ & Pe5 & 1.41 & 200 & TIS & M7 & 11.03 & 360 \\
\hline G4N & G4C & 5.01 & 150 & L5 & G5N & 10.60 & 165 & $\mathrm{Pe} 4$ & R4 & 7.67 & 290 & T1S & R1 & 9.87 & 110 \\
\hline G4N & G4S & 10.08 & 150 & L5 & M3 & 4.46 & 225 & & & & & T1S & TIN & 9.99 & 330 \\
\hline G4N & M9 & 13.10 & 80 & & & & & Pe5 & $\mathrm{Pe} 4$ & 1.41 & 20 & & & & \\
\hline$\overline{G 4 N}$ & R1 & 15.63 & 30 & L6 & $\bar{B} 4$ & 9.35 & 260 & Pe5 & R4 & 7.76 & 290 & $\mathrm{~T} 2 \mathrm{C}$ & B5 & 2.54 & 315 \\
\hline & & & & L6 & G5N & 8.61 & 205 & & & & & $\mathrm{~T} 2 \mathrm{C}$ & G5S & 9.48 & 225 \\
\hline G4S & G4N & 10.08 & 330 & $\overline{\mathrm{L} 6}$ & M4 & 1.17 & 105 & R1 & $\mathrm{B1}$ & 10.26 & 160 & $\mathrm{~T} 2 \mathrm{C}$ & R3 & 14.08 & 320 \\
\hline G4S & $\mathrm{L} 4$ & 38.71 & 135 & L6 & M5 & 1.85 & 75 & R1 & G3C & 17.29 & 285 & T2C & $\mathrm{T} 2 \mathrm{~N}$ & 5.00 & 325 \\
\hline $\mathrm{G} 4 \mathrm{~S}$ & M10 & 11.97 & 45 & L6 & R3 & 2.21 & 310 & $\bar{R} 1$ & $\bar{G} 3 \mathrm{~N}$ & 21.14 & 295 & & & & \\
\hline G4S & M9 & 13.69 & 40 & L6 & $\mathrm{T} 2 \mathrm{~N}$ & 7.28 & 135 & R1 & G3S & 14.19 & 270 & T2N & $\overline{\mathrm{B} 5}$ & 2.77 & 170 \\
\hline G4S & R1 & 22.90 & 10 & & & & & R1 & G4C & 19.01 & 195 & $\mathrm{~T} 2 \mathrm{~N}$ & G5N & 8.79 & 260 \\
\hline & & & & M0 & M6 & 6.49 & 150 & RI & G4N & 15.63 & 210 & T2N & G5S & 11.88 & 200 \\
\hline G5C & G5N & 4.99 & 335 & MO & R1 & 24.69 & 155 & RI & G4S & 22.90 & 190 & $\mathrm{~T} 2 \mathrm{~N}$ & L6 & 7.28 & 315 \\
\hline G5C & R3 & 13.50 & 360 & M0 & T1N & 9.79 & 195 & RI & MO & 24.69 & 335 & $\mathrm{~T} 2 \mathrm{~N}$ & M5 & 6.38 & 335 \\
\hline & & & & & & & & R1 & M6 & 18.27 & 340 & $\mathrm{~T} 2 \mathrm{~N}$ & R3 & 9.30 & 315 \\
\hline G5N & B4 & 7.31 & 315 & M1 & L1 & 13.17 & 110 & R1 & M7 & 16.79 & 335 & $\mathrm{~T} 2 \mathrm{~N}$ & $\mathrm{~T} 2 \mathrm{C}$ & 5.00 & 145 \\
\hline G5N & G5C & 4.99 & 155 & M1 & $\mathrm{L4}$ & 38.15 & 145 & R1 & M8 & $? 12.23$ & 145 & $\mathrm{~T} 2 \mathrm{~N}$ & T2S & 10.00 & 145 \\
\hline G5N & G5S & 9.96 & 155 & & & & & R1 & M9 & 13.23 & 150 & & & & \\
\hline G5N & L5 & 10.60 & 345 & M2 & B3 & 4.69 & 180 & RI & TIC & 13.95 & 300 & T2S & B5 & 7.44 & 320 \\
\hline G5N & L6 & 8.61 & 25 & M2 & L3 & 1.10 & 220 & R1 & T1N & 18.51 & 345 & T2S & G5S & 9.39 & 255 \\
\hline G5N & $\mathrm{R} 3$ & 9.38 & 15 & M2 & R2 & 2.94 & 220 & R1 & T1S & 9.87 & 290 & T2S & G6C & 10.34 & 145 \\
\hline G5N & T2N & 8.79 & 80 & & & & & & & & & T2S & G6N & 5.59 & 135 \\
\hline & & & & M3 & B4 & 2.47 & 150 & & & & & T2S & G6S & 15.25 & 155 \\
\hline & & & & M3 & L4 & 1.52 & 310 & & & & & T2S & R3 & 19.02 & 325 \\
\hline & & & & M3 & L5 & 4.46 & 45 & & & & & T2S & $\mathrm{T} 2 \mathrm{~N}$ & 10.00 & 325 \\
\hline
\end{tabular}




\section{FIGURES}

Fig. 1. Point Loma Rocky Intertidal Monitoring Sites.

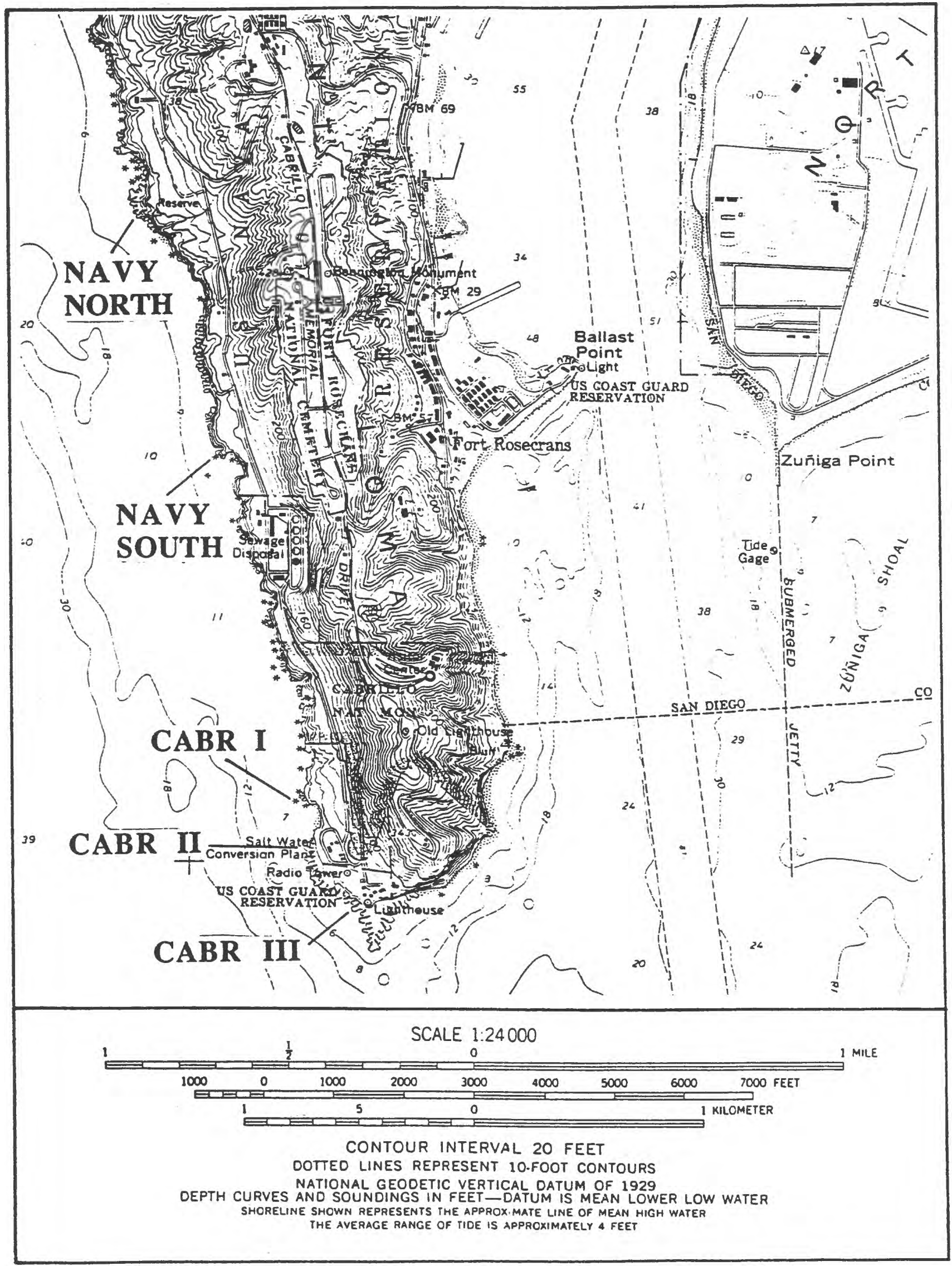




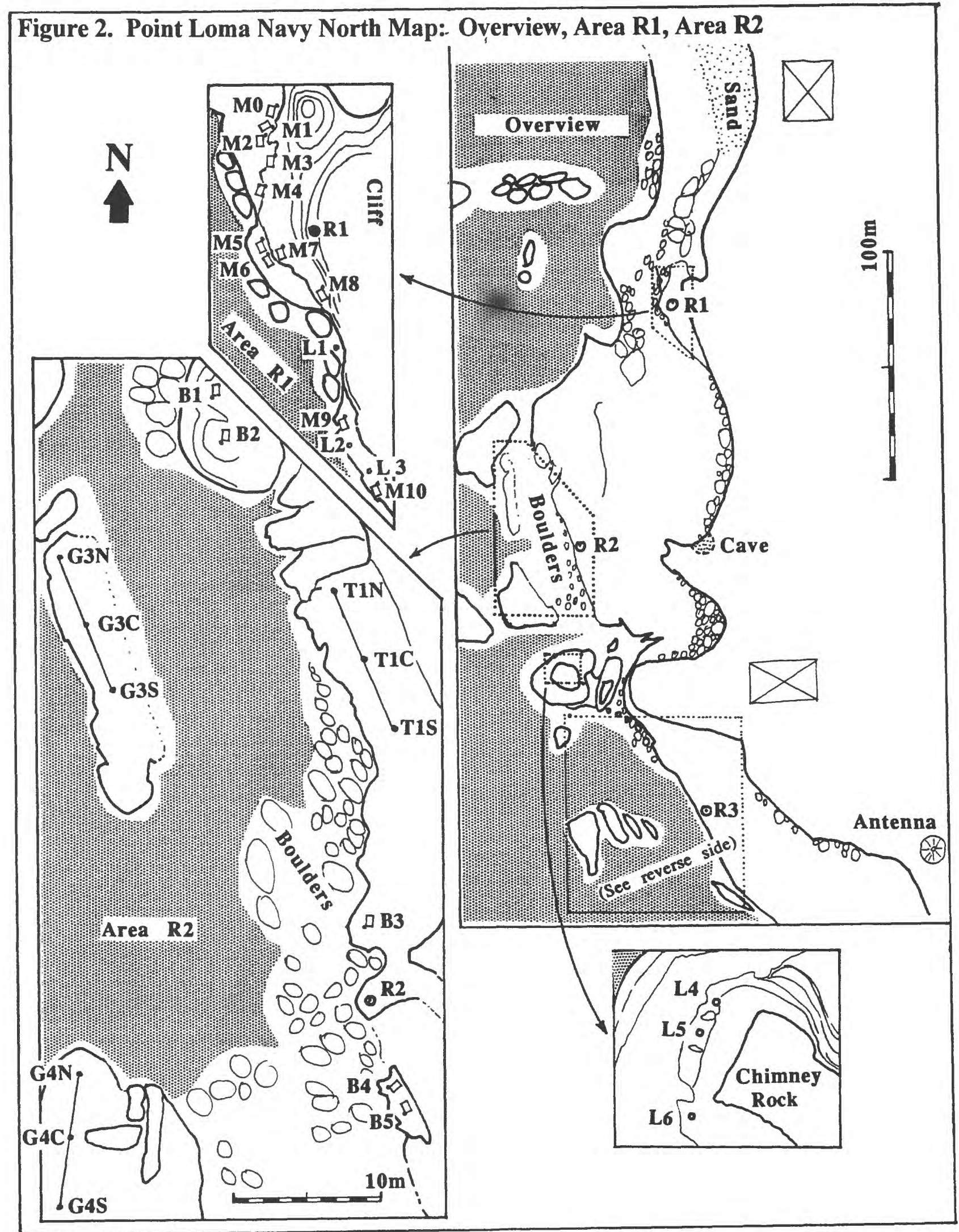




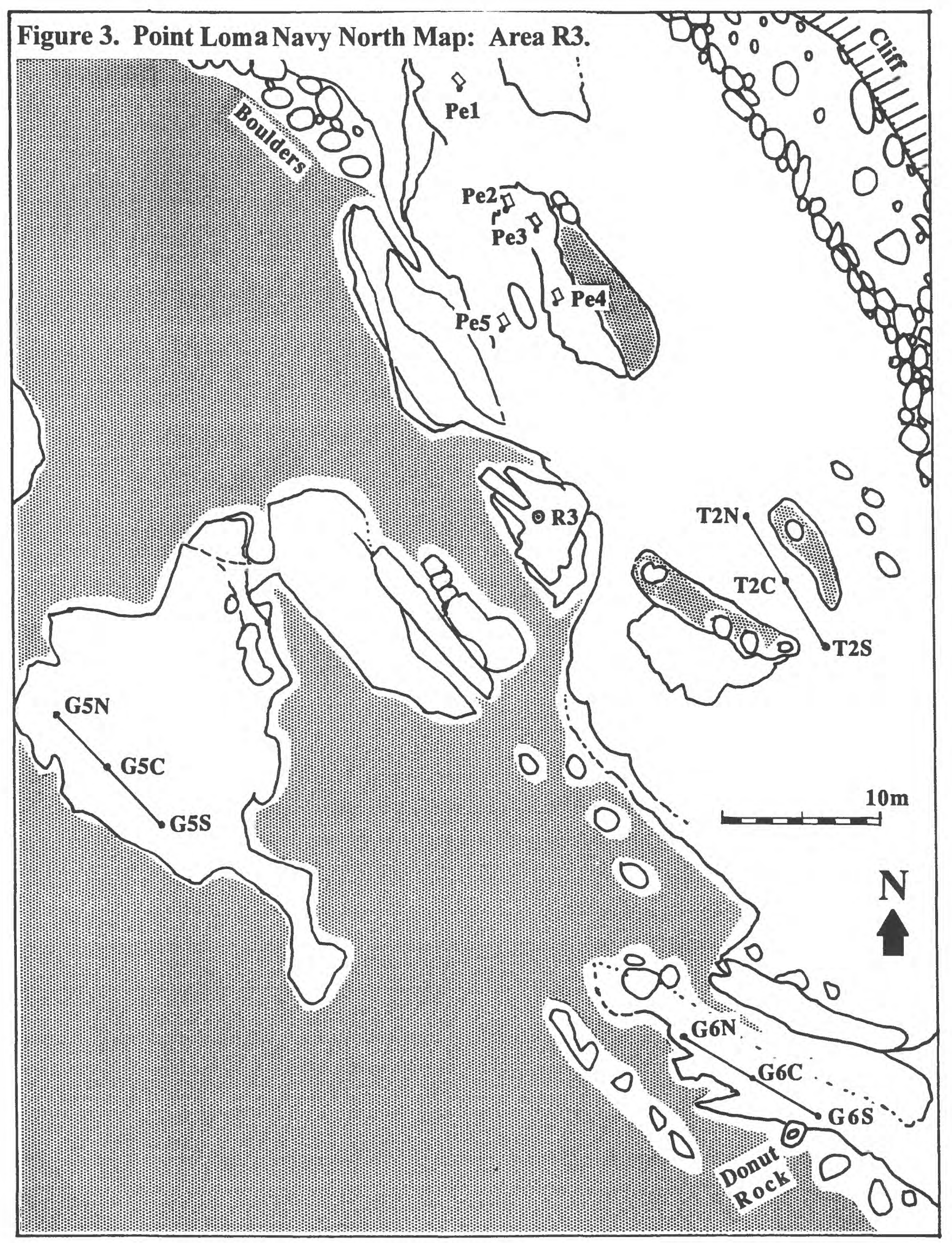


Figure 4. Point Loma Navy South Map: Overview, Area R1, Area R2

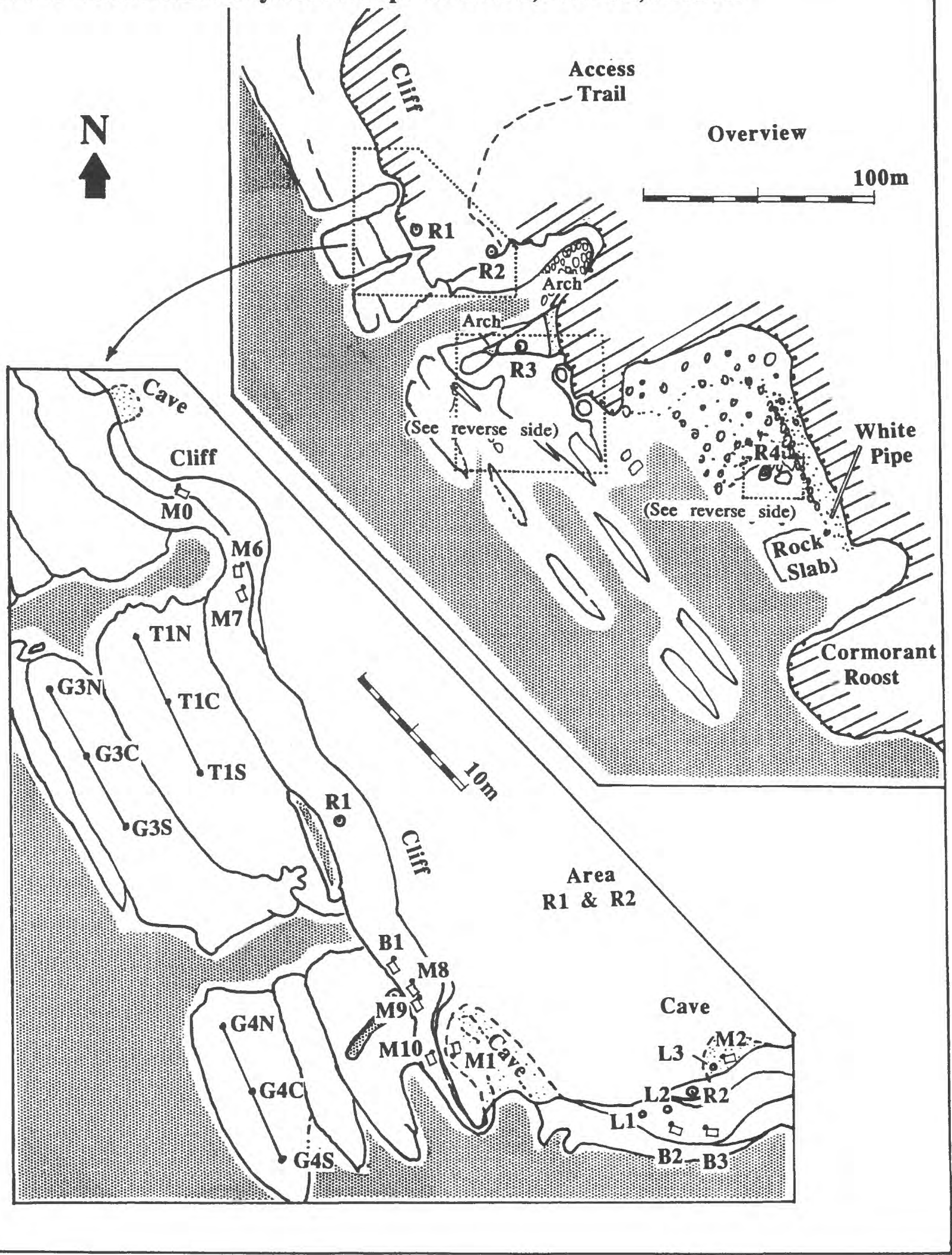


Figure 5. Point Loma Navy South Map: Area R3, Area R4

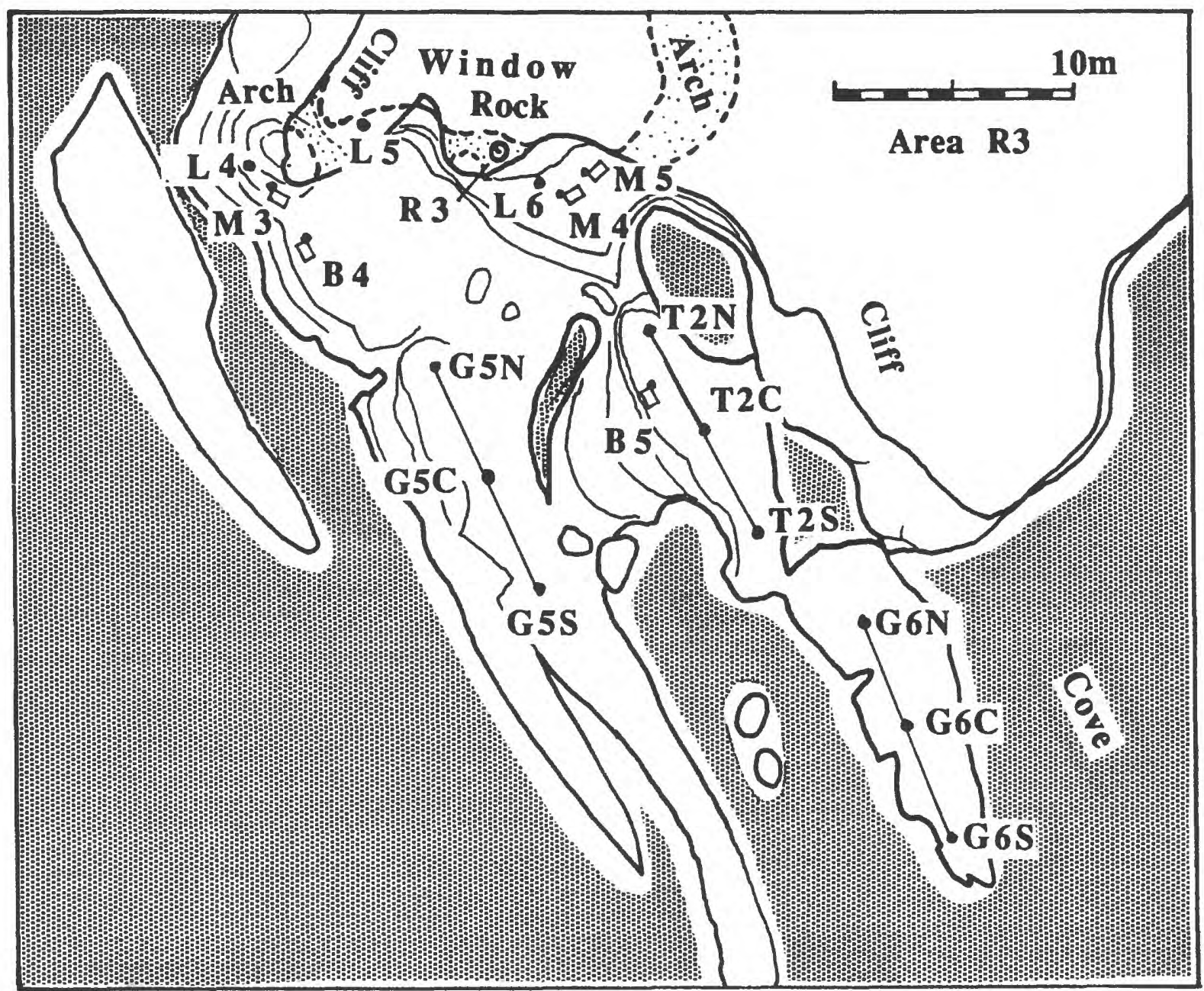

Area $\mathbf{R 4}$

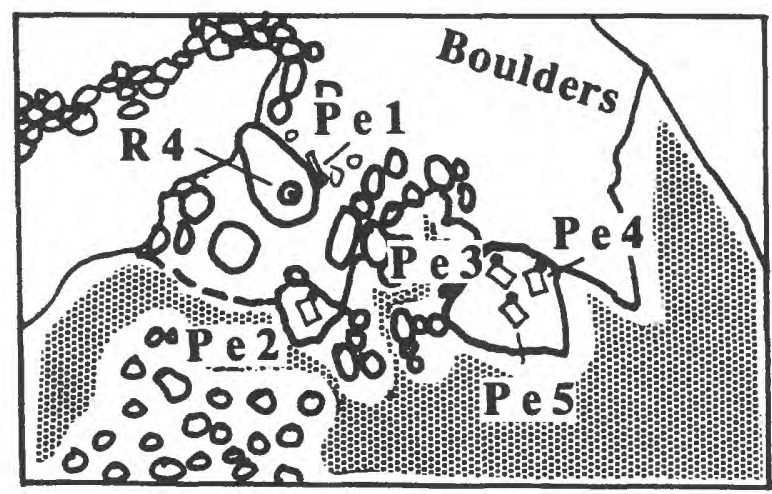

N 


\section{Figure 6. Photoplot Quadropod Apparatus}
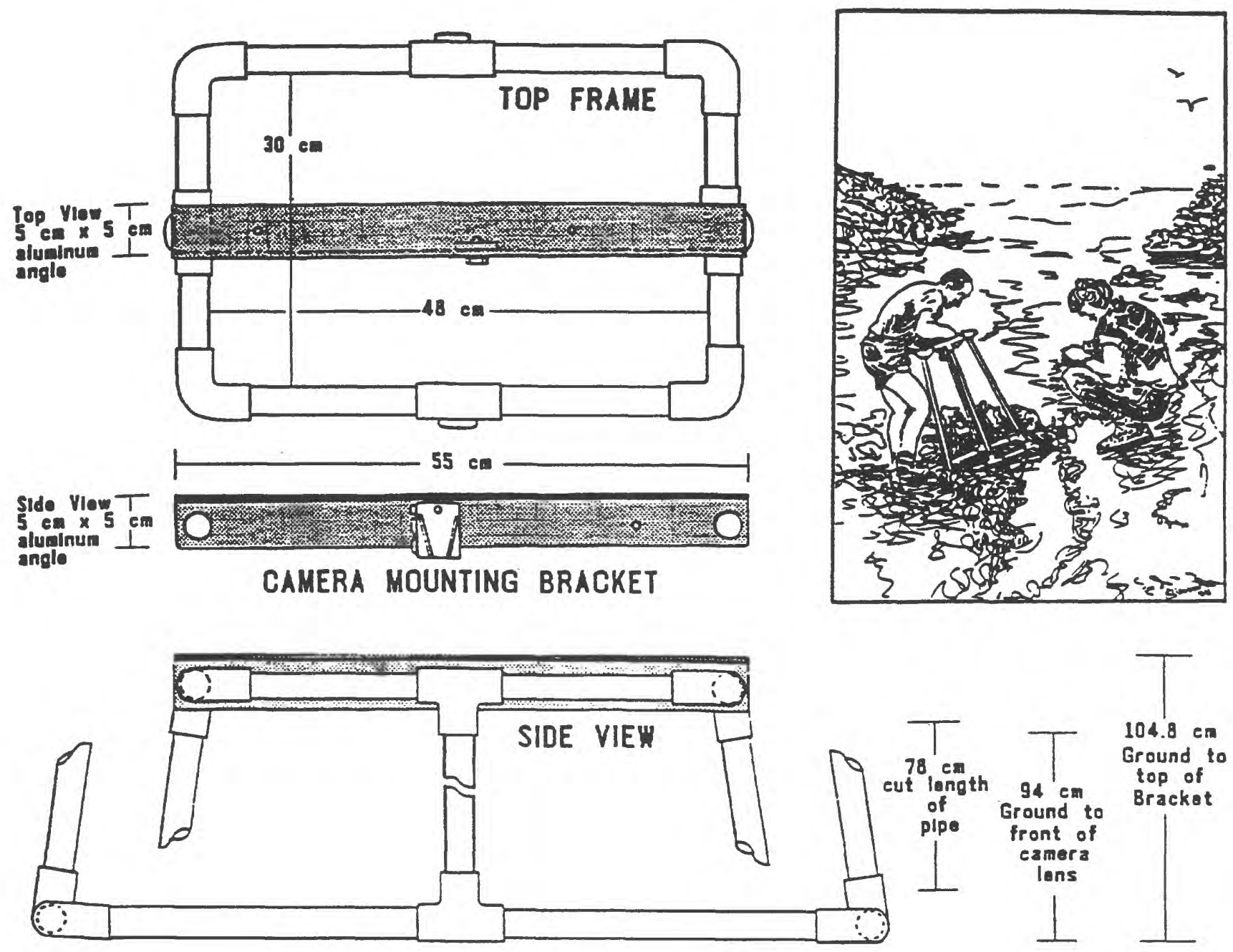

This example reads: \# 473

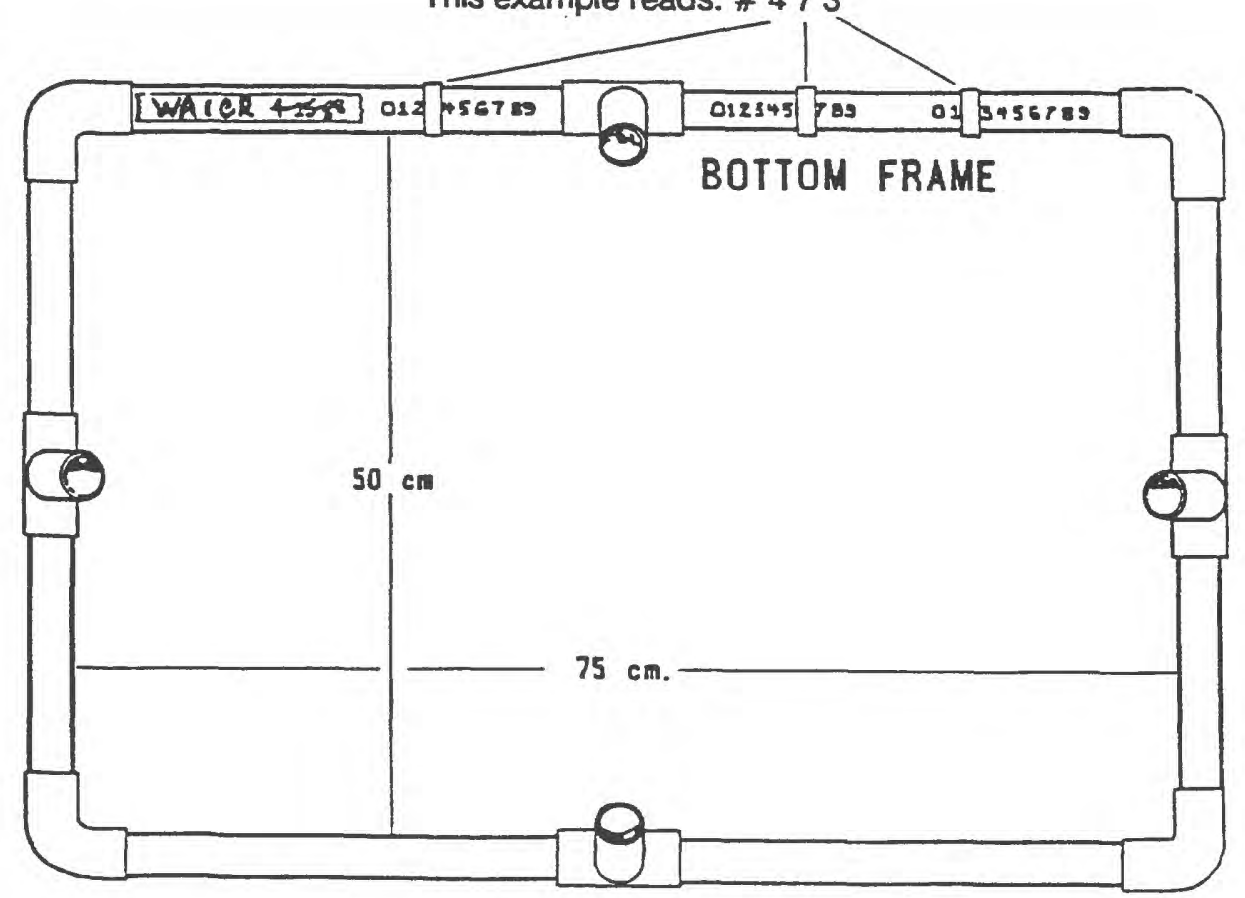

LST OF MATERIALS

1 each, $5 \mathrm{~cm} \times 5 \mathrm{~cm} \times 55 \mathrm{~cm}$ Aluminum $\mathrm{L}^{\mathrm{*}}$ for camera mounting support

1 each, Quick Release Carnera Mount

1" PVC PLASTIC PIPE: For Top Frame 4 each, Elbows 4 each, T's

4 each, $12 \mathrm{~cm}$ pipes

4 each, $20 \mathrm{~cm}$ plpes For Bottom Frame 4 each, Elbows 4 each, Ts

4 each, $23 \mathrm{~cm}$ pipes 4 each, $35 \mathrm{~cm}$ pipes For Legs

4 each, $78 \mathrm{~cm}$ pipes

For slip ring indlcators 1 each, Union cut into $1^{\prime \prime}$ pes and sanded so as to slide on pipe frame. 
Form 1. Rocky Intertidal Interplot Measurements.

\begin{tabular}{|c|c|c|c|c|c|c|c|c|c|c|c|}
\hline From & To & Distance & Bearing & From & To & Distance & Bearing & From & To & Distance & Bearing \\
\hline & & & & & & & & & & & \\
\hline & & & & & & & & & & & \\
\hline & & & & & & & & & & & \\
\hline & & & & & & & & & & & \\
\hline & & & & & & & & & & & \\
\hline & & & & & & & & & & & \\
\hline & & & & & & & & & & & \\
\hline & & & & & & & & & & & \\
\hline & & & & & & & & & & & \\
\hline & & & & & & & & & & & \\
\hline & & & & & & & & & & & \\
\hline & & & & & & & & & & & \\
\hline & & & & & & & & & & & \\
\hline & & & & & & & & & & & \\
\hline & & & & & & & & & & & \\
\hline & & & & & & & & & & & \\
\hline & & & & & & & & & & & \\
\hline & & & & & & & & & & & \\
\hline & & & & & & & & & & & \\
\hline & & & & & & & & & & & \\
\hline & & & & & & & & & & & \\
\hline & & & & & & & & & & & \\
\hline & & & & & & & & & & & \\
\hline & & & & & & & & & & & \\
\hline & & & & & & & & & & & \\
\hline & & & & & & & & & & & \\
\hline & & & & & & & & & & & \\
\hline & & & & & & & & & & & \\
\hline & & & & & & & & & & & \\
\hline & & & & & & & & & & & \\
\hline & & & & & & & & & & & \\
\hline & & & & & & & & & & & \\
\hline & & & & & & & & & & & \\
\hline & & & & & & & & & & & \\
\hline & & & & & & & & & & & \\
\hline & & & & & & & & & & & \\
\hline & & & & & & & & & & & \\
\hline & & & & & & & & & & & \\
\hline & & & & & & & & & & & \\
\hline & & & & & & & & & & & \\
\hline & & & & & & & & & & & \\
\hline & & & & & & & & & & & \\
\hline
\end{tabular}


Form 2. Rocky Intertidal Survey Gear

\section{Documents}

\section{In NOTEBOOK/CLIPBOARDS}

\begin{tabular}{|l|l|}
\hline & Driver's licenses (carry on person) \\
\hline & CFG collecting permit (if collecting) \\
\hline & Intertidal Survey Handbooks (2) \\
\hline & \\
\hline
\end{tabular}

\section{Site Information}

\begin{tabular}{|l|l|}
\hline & Site Maps in plastic sleeves (3 sets) \\
\hline & Interplot Measurements in plastic sleeves (3 sets) \\
\hline & Field Notes from previous surveys (1 copy) \\
\hline & Print Photos of all plots/transects (1 set) \\
\hline & Clear Plastic Sheet Protectors (3 extra) \\
\hline & \\
\hline
\end{tabular}

\section{Data Forms}

\begin{tabular}{|l|l|}
\hline & Field Log Forms (10) \\
\hline & Photo Log Forms (10 dbl sided) \\
\hline & Owl Limpet Forms (10 dbl sided) \\
\hline & Line Transect Forms (15 dbl sided) \\
\hline & Abalone/Sea Star Forms (5) \\
\hline & Bird/People Census Forms (5) \\
\hline
\end{tabular}

\section{Other}

\begin{tabular}{|l|l|}
\hline & $\# 2$ Pencils, sharpened (10) \\
\hline & Grease Pencil for notes on map overlays (1) \\
\hline & Tide Table (1) \\
\hline & Notepaper, (1 spare pad) \\
\hline & Large Rubber Bands for holding notes (5) \\
\hline & \\
\hline
\end{tabular}

\section{In BACKPACK or TOOLBOX}

\begin{tabular}{|l|l|}
\hline & Waterproof Compasses (2) \\
\hline & Bright Flagging Tape (2 rolls) \\
\hline & Small Waterproof Flashlight w/batteries (1) \\
\hline & Duct Tape (1 roll) \\
\hline Cable Ties for repairs (a few in assorted sizes) \\
\hline Waterproof Thermometer (1) \\
\hline Splashzone Epoxy in 2 small tubs (1 set of A\&B) \\
\hline Replacement Bolts, assorted lengths (10) \\
\hline Bungee Cords or Velcro Straps (4) \\
\hline Screwdrivers: normal and phillips (1 each) \\
\hline & Plastic Bags for specimen collection (optional) \\
\hline & Small Plastic Specimen Vials (optional) \\
\hline & Metric Calipers for measuring limpets (3) \\
\hline & Yellow Crayons for marking limpets (5) \\
\hline 1 m Lines or Tapes for limpet plots (3) \\
\hline Wire Brushes/ Knives to clean markers (3 each) \\
\hline
\end{tabular}

OTHER ITEMS

\begin{tabular}{|l|l|}
\hline & PVC Photo Quadrapod Apparatus (1) \\
\hline & PVC Quadrats for marking plots (5-15) \\
\hline & $\begin{array}{c}\text { Meter Tapes: 30 m for marking transects (6) } \\
60 \text { or } 100 \mathrm{~m} \text { for measurements (1) }\end{array}$ \\
\hline & Backpacks/Buckets to hold loose items (several) \\
\hline & Aluminum Clipboards (4) \\
\hline & Foam kneeling pads (3) \\
\hline & First Aid Kit (1) \\
\hline & Portable Drill, Bits, Batteries or Fuel (optional) \\
\hline & Rock Hammer (optional) \\
\hline & Bright Flag Sticks to mark plots (optional) \\
\hline & Orange cones (optional) \\
\hline & Species Identification Books (optional) \\
\hline
\end{tabular}

In CAMERA CASE

\begin{tabular}{|l|l|}
\hline & Camera and Lens (1) (tested) \\
\hline & Strobe (1) (tested) and synch. cord \\
\hline & Batteries for strobe (plus spare) \\
\hline & $\begin{array}{l}\text { Color Slide Film: 36 exposure, 100 ASA, } \\
\text { Ektachrome or equivalent (3??? rolls) }\end{array}$ \\
\hline & Lens Cap, Paper, and Cleaning Fluid (1 each) \\
\hline & Waterproof Marking Pen (1) \\
\hline & Bolt for camera/quadrapod mount (1 spare) \\
\hline & Crescent Wrench for camera mount (1) \\
\hline & Camera and Strobe manuals (1 each) \\
\hline & \\
\hline & \\
\hline
\end{tabular}

\section{In VIDEO CASE (optional)}

\begin{tabular}{|l|l|}
\hline & Video Camcorder in Plastic Housing (1) (tested) \\
\hline & Hi or Reg $8 \mathrm{~mm} 1 \mathrm{hr}$ videotapes (1 plus 1 spare) \\
\hline & Video Battery Packs (2 heavy duty) (charged) \\
\hline & Lens Paper and Cleaning Fluid (1 each) \\
\hline & Desiccant Packs (3 small) \\
\hline & Head-Cleaning Cassette (1) \\
\hline & Small Towel (1) \\
\hline & Video Camcorder Manual (1) \\
\hline & Camcorder Date/Time Disk Battery (1 spare) \\
\hline & Headphone to check sound (1) \\
\hline & \\
\hline
\end{tabular}

\section{PERSONAL GEAR}

\begin{tabular}{|l|l|}
\hline & Intertidal Shoes, Boots, or Booties \\
\hline & Windbreaker and Foul Weather Gear \\
\hline & Spare Dry Clothing \\
\hline & Hat, Sunglasses, and Sunscreen \\
\hline & Snack Food and Drink \\
\hline & Daypack \\
\hline & Wetsuit, Kneepads, Gloves (optional) \\
\hline & \\
\hline & \\
\hline & \\
\hline
\end{tabular}


Form 3: ROCKY INTERTIDAL MONITORING FIELD LOG

Date:

Time:

Page: of

Study Site:

Participants:

Recorder:

Temperature: Air

Wind: Speed (kt) ${ }^{\circ} \mathrm{C}$ Water

${ }^{\circ} \mathrm{C}$ Tide Level (ft)

Wave Height (ft) Direction Cloud Cover $\%$ Surge (light, moderate, heavy)

Field Log (General account of intertidal work, including observations and sketches): 
Form 4: ROCKY INTERTIDAL MONITORING PHOTO LOG

Date:

Page: of

Area: Film Roll \#:

Photographer:

Recorder:

\begin{tabular}{|c|c|c|c|c|c||}
\hline $\begin{array}{c}\text { Photo } \\
\#\end{array}$ & $\begin{array}{c}\text { Study } \\
\text { Site }\end{array}$ & $\begin{array}{c}\text { Quadrat } \\
\#\end{array}$ & $\begin{array}{c}\text { Shutter } \\
\text { Speed }\end{array}$ & F/Stop & \\
\hline 1 & & & & & \\
\hline 2 & & & & & \\
\hline 3 & & & & & \\
\hline 4 & & & & & \\
\hline 5 & & & & & \\
\hline 6 & & & & & \\
\hline 7 & & & & & \\
\hline 8 & & & & & \\
\hline 9 & & & & & \\
\hline 10 & & & & & \\
\hline 11 & & & & & \\
\hline 12 & & & & & \\
\hline 13 & & & & & \\
\hline 14 & & & & & \\
\hline 15 & & & & & \\
\hline 16 & & & & & \\
\hline 17 & & & & & \\
\hline 18 & & & & & \\
\hline 19 & & & & & \\
\hline 20 & & & & & \\
\hline 21 & & & & & \\
\hline 22 & & & & & \\
\hline 23 & & & & & \\
\hline 24 & & & & & \\
\hline 25 & & & & & \\
\hline 26 & & & & & \\
\hline 27 & & & & & \\
\hline 28 & & & & & \\
\hline 29 & & & & & \\
\hline 30 & & & & & \\
\hline 31 & & & & & \\
\hline 32 & & & & & \\
\hline 33 & & & & & \\
\hline 35 & & & & & \\
\hline 36 & & & & & \\
\hline 37 & & & & & \\
\hline 38 & & & & & \\
\hline
\end{tabular}


Form 5: ROCKY INTERTIDAL OWL LIMPET MEASUREMENTS

Date:

Page: of

Study Site:

Recorder:

Measurer

\begin{tabular}{|c|c|c|}
\hline $\begin{array}{c}\text { Plot } \\
\#\end{array}$ & $\begin{array}{l}\text { Length } \\
(\mathrm{mm})\end{array}$ & $\begin{array}{c}\text { Tag } \\
\#\end{array}$ \\
\hline & & \\
\hline & & \\
\hline & & \\
\hline & & \\
\hline & & \\
\hline & & \\
\hline & & \\
\hline & & \\
\hline & & \\
\hline & & \\
\hline & & \\
\hline & & \\
\hline & & \\
\hline & & \\
\hline & & \\
\hline & & \\
\hline & & \\
\hline & & \\
\hline & & \\
\hline & & \\
\hline & & \\
\hline & & \\
\hline & & \\
\hline & & \\
\hline & & \\
\hline & & \\
\hline & & \\
\hline & & \\
\hline & & \\
\hline & & \\
\hline & & \\
\hline & & \\
\hline & & \\
\hline & & \\
\hline
\end{tabular}

\begin{tabular}{||c|c|c|}
\hline $\begin{array}{c}\text { Plot } \\
\#\end{array}$ & $\begin{array}{c}\text { Length } \\
(\mathrm{mm})\end{array}$ & $\begin{array}{c}\text { Tag } \\
\#\end{array}$ \\
\hline & & \\
\hline & & \\
\hline & & \\
\hline & & \\
\hline & & \\
\hline & & \\
\hline & & \\
\hline & & \\
\hline & & \\
\hline & & \\
\hline & & \\
\hline & & \\
\hline & & \\
\hline & & \\
\hline & & \\
\hline & & \\
\hline & & \\
\hline & & \\
\hline & & \\
\hline & & \\
\hline & & \\
\hline & & \\
\hline & & \\
\hline & & \\
\hline & & \\
\hline & & \\
\hline & & \\
\hline & & \\
\hline & & \\
\hline & & \\
\hline & & \\
\hline & & \\
\hline & & \\
\hline & & \\
\hline & & \\
\hline & & \\
\hline & & \\
\hline & & \\
\hline & & \\
\hline & & \\
\hline & & \\
\hline & & \\
\hline & & \\
\hline & & \\
\hline & & \\
\hline & & \\
\hline & & \\
\hline & & \\
\hline & & \\
\hline & & \\
\hline & & \\
\hline & & \\
\hline & & \\
\hline & & \\
\hline & & \\
\hline & & \\
\hline
\end{tabular}

\begin{tabular}{||l|c|c|}
\hline $\begin{array}{c}\text { Plot } \\
\#\end{array}$ & $\begin{array}{c}\text { Length } \\
(\mathbf{m m})\end{array}$ & $\begin{array}{c}\text { Tag } \\
\#\end{array}$ \\
\hline & & \\
\hline & & \\
\hline & & \\
\hline & & \\
\hline & & \\
\hline & & \\
\hline & & \\
\hline & & \\
\hline & & \\
\hline & & \\
\hline & & \\
\hline & & \\
\hline & & \\
\hline & & \\
\hline & & \\
\hline & & \\
\hline & & \\
\hline & & \\
\hline & & \\
\hline & & \\
\hline & & \\
\hline & & \\
\hline & & \\
\hline & & \\
\hline & & \\
\hline & & \\
\hline & & \\
\hline & & \\
\hline & & \\
\hline & & \\
\hline & & \\
\hline & & \\
\hline & & \\
\hline & & \\
\hline & & \\
\hline & & \\
\hline & & \\
\hline & & \\
\hline & & \\
\hline & & \\
\hline & & \\
\hline & & \\
\hline
\end{tabular}


Form 6. ROCKY INTERTIDAL MONITORING LINE-INTERCEPT TRANSECT

Location:

Recorder:

Cover:

Boa Kelp

Egregia sp.

Sargassum Weed

Sargassum

Red Algal Turf

Corallina sp., et al.

Surf Grass

Phyllospadix sp.

Aggregating Anemone

Total:

Anthopleura elegantissima

Other Biota

Tar

Bare Substrate

Total:

Total:

Total:

Total:

Total:

Total:

Total:
Transect \#:

Date:

Reader:

Distance Along Transect (cm):

Comments: 
Form 7. ROCKY INTERTIDAL MONITORING PHOTO POINT INTERCEPT FORM

Site

Survey Date

Scored by

Score Date

\begin{tabular}{|l|l|l|l|l|l|}
\hline BARNACLE PLOT \# & & & & & \\
\hline Total Points & & & & & \\
\hline Acorn Barnacle & & & & & \\
\hline Thatched Barnacle & & & & & \\
\hline Rockweed & & & & & \\
\hline California Mussel & & & & & \\
\hline Goose Barnacle & & & & & \\
\hline Other Plant & & & & & \\
\hline Other Animal & & & & & \\
\hline Bare Substrate & & & & & \\
\hline Tar & & & & & \\
\hline
\end{tabular}

\begin{tabular}{|l|l|l|l|l|l|}
\hline ROCKWEED PLOT \# & & & & & \\
\hline Total Points & & & & & \\
\hline Acorn Barnacle & & & & & \\
\hline Thatched Barnacle & & & & & \\
\hline Rockweed & & & & & \\
\hline California Mussel & & & & & \\
\hline Goose Barnacle & & & & & \\
\hline Other Plant & & & & & \\
\hline Other Animal & & & & & \\
\hline Bare Substrate & & & & & \\
\hline Tar & & & & & \\
\hline
\end{tabular}

\begin{tabular}{|l|l|l|l|l|l|}
\hline MUSSEL PLOT \# & & & & & \\
\hline Total Points & & & & & \\
\hline Acorn Barnacle & & & & & \\
\hline Thatched Barnacle & & & & & \\
\hline Rockweed & & & & & \\
\hline California Mussel & & & & & \\
\hline Goose Barnacle & & & & & \\
\hline Other Plant & & & & & \\
\hline Other Animal & & & & & \\
\hline Bare Substrate & & & & & \\
\hline Tar & & & & & \\
\hline
\end{tabular}

\begin{tabular}{|l|l|l|l|l|l|l|}
\hline POLLICIPES PLOT \# & & & & & & \\
\hline Total Points & & & & & & \\
\hline Acorn Barnacle & & & & & & \\
\hline Thatched Barnacle & & & & & & \\
\hline Rockweed & & & & & & \\
\hline California Mussel & & & & & & \\
\hline Goose Barnacle & & & & & & \\
\hline Other Plant & & & & & & \\
\hline Other Animal & & & & & & \\
\hline Bare Substrate & & & & & & \\
\hline Tar & & & & & & \\
\hline
\end{tabular}

